STATE OF

\title{
MATTO GROSSO
}




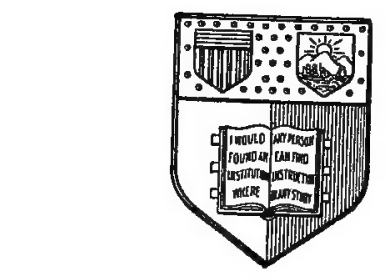

\section{月ew 翼ork \\ State College of Agrículture} At Cormell annibersity

Iitbaca, ‥ 1 .

\section{Iibratp}

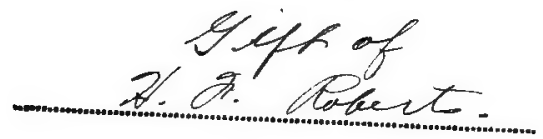




\section{SB 291. Cornell University Library}

Brazil, the land of rubber, at the third

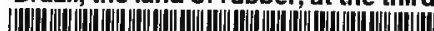

(n)

31924000290167 mann 


\section{Cornell University Library}

The original of this book is in the Cornell University Library.

There are no known copyright restrictions in the United States on the use of the text. 




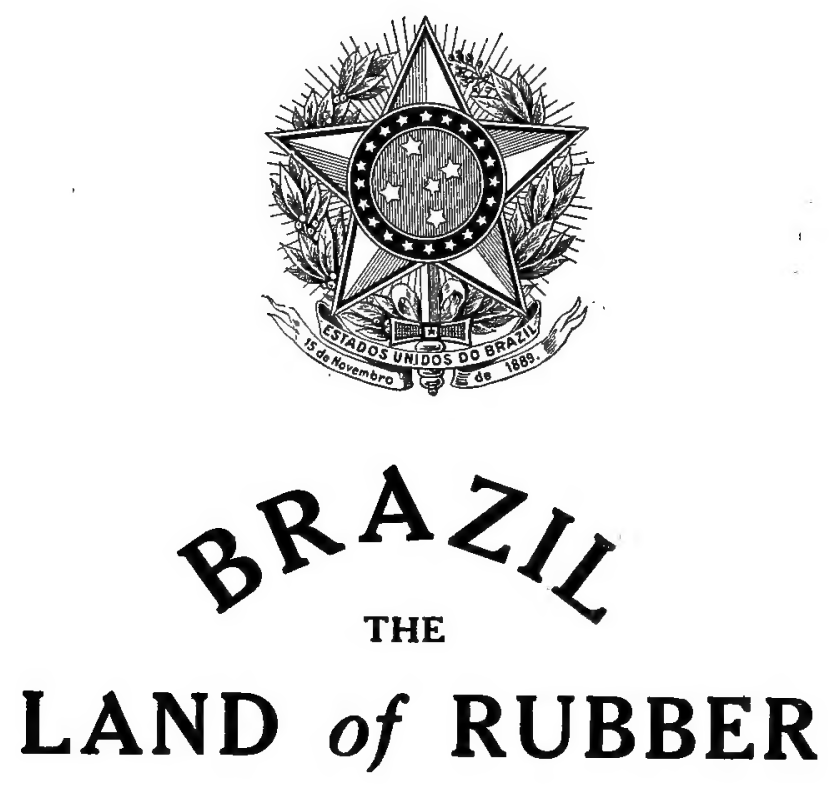

AT THE

\section{THIRDINTERNATIONAL RUBBER AND}

Allied Trades Exhibition

NEW YORK

\section{2}

WITH THE COMPLIMENTS OF

THE BRAZILIAN GOVERNMENT 


\section{BRAZIL COURT}

Brazil occupies no less than ten thousand square feet of space on the Balcony Floor. The Exhibit is specially comprehensive. There is a fine archway to each entrance to the court dominated by the arms of the Federal Government. An Information Bureat is provided, at which all enquiries as to Brazilian rubber will be answered. The walls are hung with statistics and maps of the country. Close by are the offices of the Brazilian Commissioners and a refreshment kiosk, where the Federal Govern. ment dispenses Brazilian coffee to visitors. One of the first things to strike the eye is the huge recumbant figure of the Rubber Colossus, overlooking the mighty Amazon and its innumerable tributaries, all of them highways of the rubber collecting industry. From this point the visitor may, with the assistance of a number of pictures, 22 feet by 12 feet, take a bird's eye view tour up the Amazon. Alongside these pictures is a unique collection from the different States of Brazil of rubber and other products, the preponderance of the rubber industry being illustrated by a fine pyramid of caoutchouc. Dotted here and there are life-sized models of Brazilian workmen in their native costumes. Arriving at the entrance to the Amazonas Section we find Dr. Pinto actually engaged in the coagulation of latex by his new smokeless process, which manufacturers have admitted turns out excellent rubber and which has the great advantage over the native system hitherto in vogue, of saving an enormous amount of both time and labor, whilst giving splendid results. A second series of pictures affords a vivid idea of the salient features of the State of Amazonas. In this section we have a mountain of rubber, and a ball which weighs 1,600 pounds. There is a fine picture of a native tapping a rubber tree and numerous very beautiful photographs. That nothing may be wanting to the completeness of the representation of Brazil's great rubber industry a series of Moving Pictures is shown in the Main Hall of the Exhibition, which visitors will find particularly instructive after they have gone through the Brazilian Section on the Balcony Floor. 


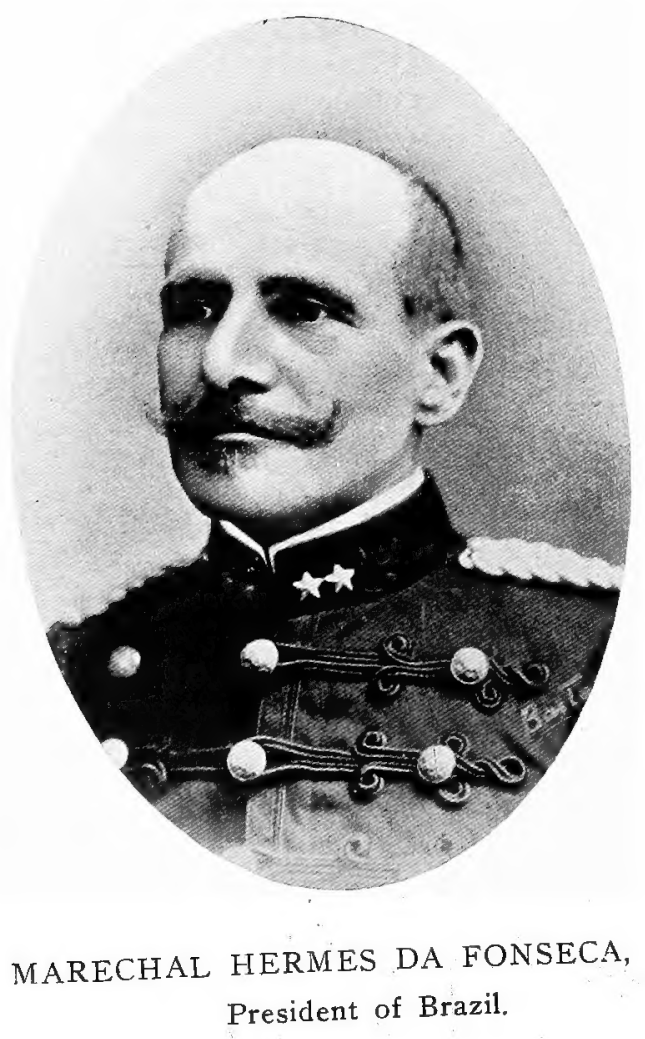




\title{
BRAZILIAN DELEGATION of the INTERNATIONAL RUBBER EXHIBITION, NEW YORK
}

\author{
DISTRIBUTION OF SERVICE
}

\section{FEDERAL GOVERNMENT COMMISSIONERS}

President

DR. CANDIDO MENDES DE ALMEIDA

Assistant

MAIRO BAPTISTA NUNES

Official representation, information and publicity

Vice-President

ADMIRAL JOSE CARLOS DE CARVALHO

Assistants

DR. OSCAR SAYAO DE MORAES

ADALBERTO DE SOUSA ARANHA

Disposition of Exhibits, Decoration, Etc.,

General Secretary.

DR. EUGENIO DAHNE

Assistant Secretary

MR, DILLWYME M. HAZLETT

Accountant

MR. IVO GRACA CAMPOS

Reception of Exhibits, Correspondence, Purchasing, Accounts, Payments, Etc.

\section{STATE COMMISSIONERS}

State of Amazonas

DR. MANOEL LOBATO

Commercial Association of Amazonas

MR. A. W. STEADMAN, New York Commercial Co.

MR. J. LEVY, Manaos

State of Para

Commercial Association of Para

MR. GEORGE E. PELL, General Rubber Co., New York

State of Bahia

J. DO ARGOLLO

State of Minas Geraes.

DR. I. SANTIAGO CARDWELL QUINN

Rubber Demonstration

DR. CARLOS CERQUEIRA PINTO

OFFICE HOURS-9 to $12 \mathrm{~A}$. M. and 2 to $5 \mathrm{P}$. M.

Committee Meeting of Delegation-Daily 3 to 4 P. M. 


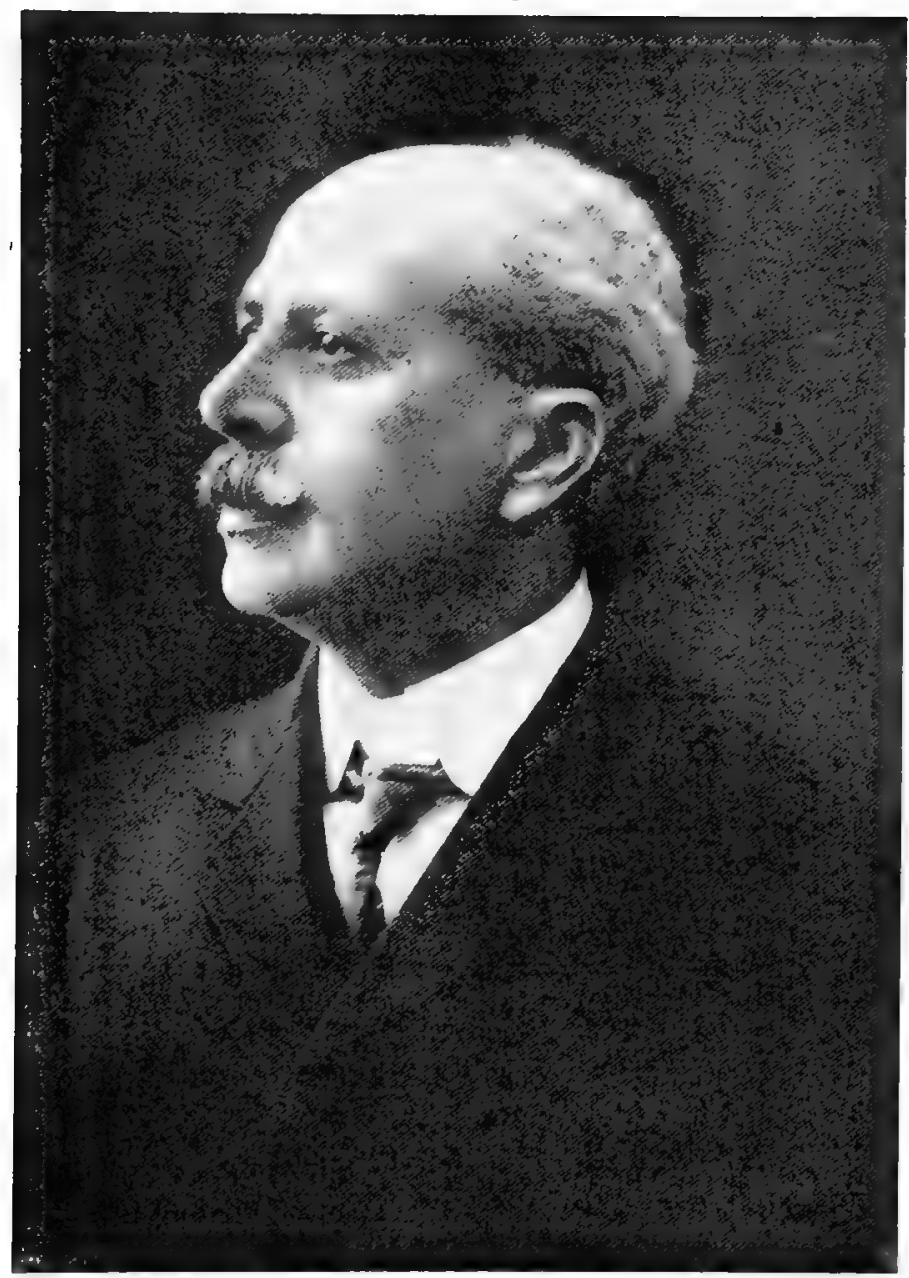

DR. PEDRO DE TOLEDO, Minister of Agriculture of the Government of Brazil 


\section{INTRODUCTION}

Brazil, with its vast and immeasurable virgin forests in the valley of the Amazon, undoubtedly the greatest in the world, traversed by innumerable tributaries, many of which are larger and deeper than many of the rivers in other countries, can be considered the largest storehouse of native rubber of the best quality, all ready to be, extracted, coagulated and applied to all kinds of industries. No other investment of capital can be as remunerative as that invested in the extraction of the native rubber from full grown trees, already existing in large quantities of many millions, and in zones full of natural richness.

For the culture of rubber trees of the various species, the whole northern and central portions of Brazil are well adapted, and will give magnificent results in the near future.

Nature has prodigally provided easy means of communica. tion by waterways broad and deep. The climate is equitable without great variations of temperature, which gives perpetual summer and produces large and nearly uninterrupted harvests of agricultural products.

The difficulties which hinder the rapid development of the extraction of rubber are the obstructions in rivers in certain places, at certain seasons of the year when the water is low, and the fact that the production of rubber is so remunerative that all the vigorous men that are thus engaged do not care to engage in any other industry. Thus it is that living in the rubber regions is very expensive because everything must be brought there, even implements and foodstuffs.

These difficulties, however, have been brought to the attention of the Federal Government of Brazil, and of the States, and in consequence an important Congress was called and presided over by the Minister of Agriculture, Industry and Commerce. The Legislative power also passed special laws providing measures urgently needed to better the existing conditions. These laws also provide for a department under the 
Minister of Agriculture, Industry and Commerce, to be called "The Protection of Rubber," which has already been formed and is at work.

Among the various and important provisions of the law, is the establishment of various experimental stations for advancing the cultivation of the four different kinds of rubber trees found in Brazil, the Hevea braziliensis (seringa), castilloa (caucho), maniçoba, and mangabeira. These trees are all natives of Brazil and can be cultivated from the upper regions of the Amazon to the States of S. Paulo and Parana. That is, from the extreme north to nearly the extreme south, one or other of these species can be cultivated, according to the climate and character of the soil in each region.

Various concessions and money premiums are offered to attract capital and awaken activity in this industry. Certain services, such as the establishment of hospitals, medical attention and hygienic regulations are also provided by the Federal Government.

In the pages of this book will be found, fully treated, the principal points of this important subject. From the statistical tables published and from the exhibits displayed at the International Rubber Exposition in New York, it can readily be seen that the rubber of Brazil is judged the best in the world, and that its production although already enormous is destined to be largely increased.

$$
\begin{gathered}
\text { DR. CANDIDO MENDES DE ALMEIDA, } \\
\text { President Brazilian Commission. }
\end{gathered}
$$




\section{A MONOGRAPH UPON PARÁ RUBBER}

\section{HISTÓRICAL NOTES AḂOUT PARÁ RUBBER}

It is in our diaries of the voyage of the Genovese Columbus, that among the important occurrences of that notable crossing of r the ocean, which gave him immortality, appeared the'first neferences, made by Herrera, to the quality of a certain gum utilized by the aborigines.

In 1536 Gonçalvo Fernandes d'Oviedo in his "Universal History of the Indies," published in Madrid, also mentioned the uses which" the indigenous tribes of North America made of rabber skins in their amusements.

'1:. The, Jesuit Charlevoix also refers to it and more fully, yet does John Torquemada who in his "Indian Monarchy," expresses himself thus: "There is a tree in this country (Mexico) known to the natives as ulequahuitl, to whom it is of the greatest value. "This tree grows in the warm or torrid zone; and presents itself of a medium height with rounded leaves of an ashy color. It furnishes in abundance a species of glutinous white liquid like milk, which makes it of great utility to them.

"The milk of the ulequahuitl is obtained by beating the tree with a sniall hatchet. The liquid is then seen to ooze out from the incision made like blood from a wound. The natives gather it into dry hollow gourds of various sizes. It gradually takes consistency in these receptacles, until it turns into a gummy mass, from which it is easy to adapt it to any form which may be requitred.

"Those who have no gourds, besmear their bodies with the liquid substance, as it flows out from the tree; which in drying forms itself into a species of membrane, which is easily taken off and whose thickness varies according to the coating spread over the skin. Skins very much appreciated for their elasticity are made with this ulli. The ulli solidified serves for shields, which thus are proof against the sharpest-pointed arrows, owing without doubt to the pliability of the material, which does not affect its tenacity.

"Kings and nobles habitually use shoes made of ulli. The Spaniards of Mexico, moreover, impregnate their capes with ulli, so as to make them water-proof, because it is proved that such substance resists water in a marvelous manner, but melts before the action of the sun." 


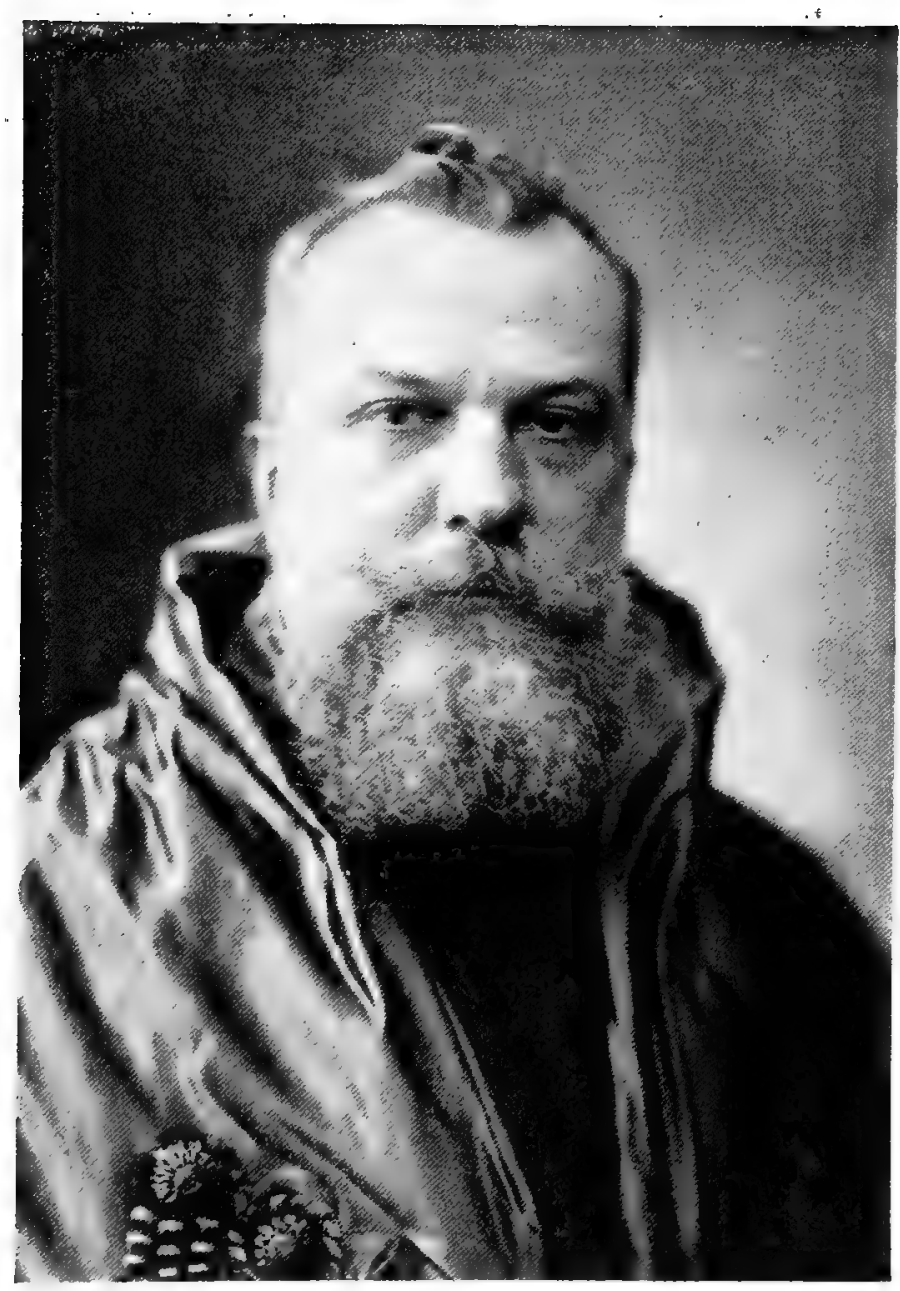

COUNT CANDIDO MENDES DE ALMEIDA,

President of the Federal Government of Brazil Commission. 
In Mexico and Central America, the name of Ule still denotes even to-day one of the rubber trees known as the elastic Castille.

After the Spaniards, the French in 1736 occupied themselves with that substance, whose interesting properties had not up to that date come to deserve the attenion of the Europeans.

De la Condamine sent by the French Government to Perú, in order to measure a degree of the terrestrial meridian, was the first to refer to the Hevéa of the Guyana. In a note that accompanied a small sample of resinous gum of a heavy dark color, almost black, he said to the Academy of Sciences: "There grows in the forests of the province of the Esmeraldas a tree known to the natives by the name of Hevé; a white resinous liquid something like milk runs out from it after making an incision; this substance is collected in a leaf that is laid close to the foot of the tree and afterwards is exposed to the sun, when it gets black at first upon its surface and afterwards by continuous exposure to the sun becomes black in all its mass. Torches, which burn admirably well, are made from it. It is known in Quito, that that tree grows also tupon the banks of the Amazon and that the Mainas call it cautchí. They make earthen moulds in the form of bottles and cover them with that material. Afterwards when the resin gets hard, they break the mould and thereby, obtain unbreakable water-jars much lighter than glass bottles."

Later on he wrote: "many are the uses which the Omaguas make of that resin in the central parts of South America, especially among the Indians of Pará where the Portuguese gave to the tree that produces it, the name of Pauseringa, because from it 'seringas,' much in vogue among the Omaguas, are manufactured; these being little hollow balloons in the shape of a pear, into which a tube is inserted.

"In Para it is moulded in still many different manners, they make borracha, faces of animals, hollow or solid balls and also apply it in the manufacture of boots which become quite waterproof and when smoked acquire the appearance of leather."

Fresneau, a collaborator of de la Condamine, sought to study the vegetable plants which produced that gum, obtaining as a result that Aublet, a French botanist, proceeded to interest himself in the question and completed de la Condamine's studies, and then classifying the hevé under the domination of Hevea Guyanensis.

It was only in 1798 that the Ficus elastica, the first Asiatic plant producer of rubber became known, and up till 1860 South America, English India and Java were the only rubber-producing countries in the world. 


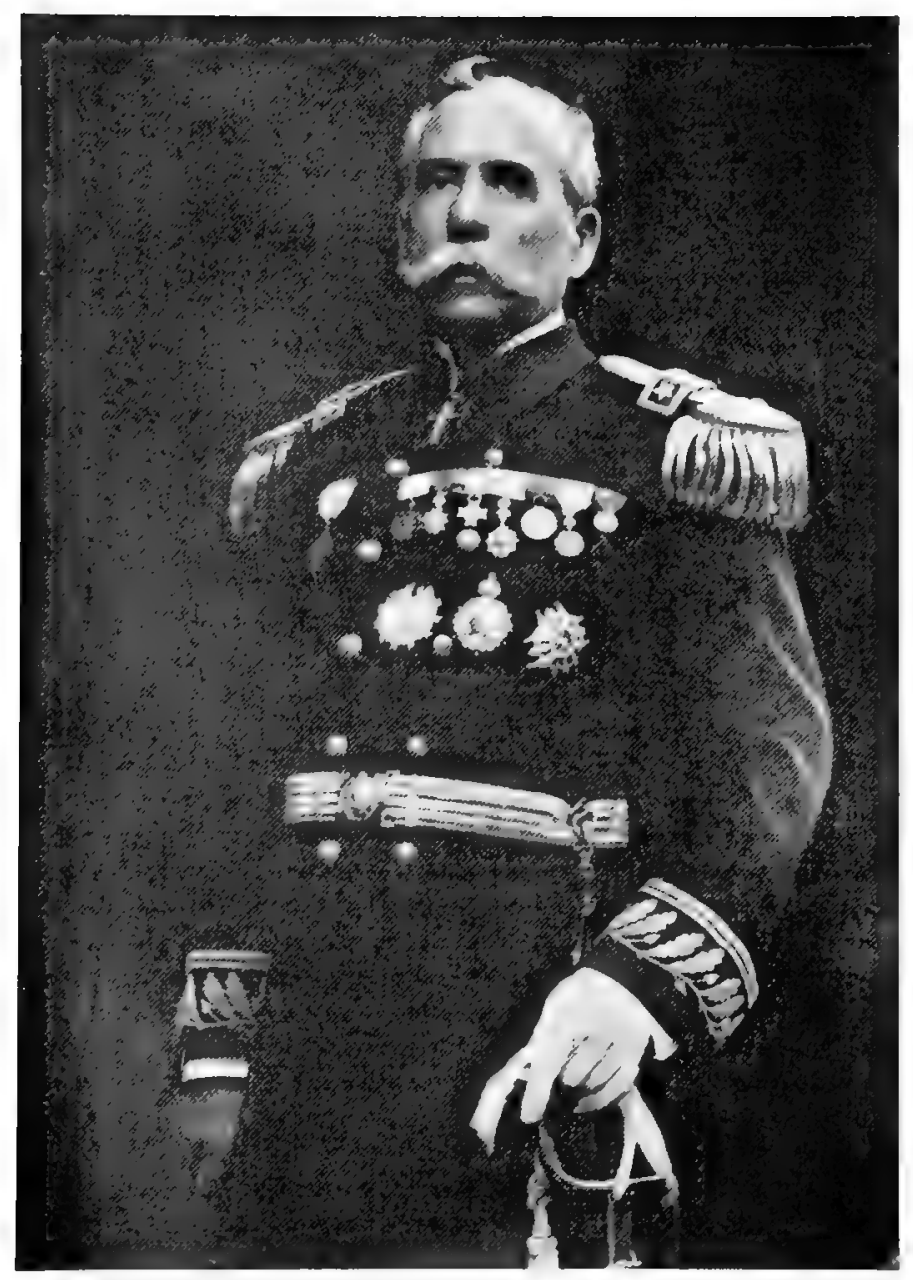

ADMIRAL JOSE CARLOS DE CARVALHO,

Vice-President of the Federal Government of Brazil Commission. 
Much later than this-in 1885, Africa commenced to export this article, an industry which reached its apogée after the creation by Leopold II of the Independent State of the Congo.

In the meantime, in spite of the fact of some of the qualities of rubber and even its applications being known in Europe ever since the Sixteenth Century, it was only during the Nineteenth Century, that this product conquered that position as an article very much in evidence which it now occupies as an indispensable material in modern industry or even still yet for the necessities which civilization created.

Hérissant and Macquer, in 1\%68, discovered the first dissolving processes; in $17 \% 0$, Priestley vulgarized the property of the "borracha" in wiping out lead-pencil tracings from which the English name Rubber is derived; Berniard, Fourcroy, Berthollet, Grossart and others occupied themselves about this commodity, with more or less success. Madier, in 1820, found out a mechanical means of cutting the rubber-blocks in order to obtain elastic threads and three years afterwards, MacIntosh discovered that naptha dissolved rubber and thus made cloth impervious to the action of water.

The adaption of rubber to industrial purposes such as the manufacture of shoes, physical and surgical appliances, elastic cloths, railway-buffers, machine-springs, etc., was fairly in full swing when the discovery of the vulcanizing of rubber by Goodyear sprung up, an occurance which came to revolutionize the insipient industry and enormously enlarge the scope of the commetcial application of that product, which thence forward came to assume exceptional importance. The vulcanizing method consists in the mixing of a certain quantity of rubber with sulphur and in the exposure of that mixture to an elevated temperature and to a high pressure during a certain space of time. The rubber transforms itself considerably; the property of indefinite hardness is lost, but presents greater resistency to the forces of compression and lengthening-out, supports excessively low temperature and becomes less sensible to the action of ordinary dissolving ingredients.

In Brazil already existed up to 1840 , a rudimentary industry of shoe manufacturing and in the water-proofing of various objects. The great demand for rubber caused by the development of the industry in foreign countries and consequently the very high profits that the extraction of rubber in the Brazilian "seringaes" or native rubber-forests presented, destroyed all that initiative and Brazil passed into the position of a mere producer of the raw material. In order to appreciate with what devotion the country lent itself to this occupation, sufficient is it to contrast the 31 tons exported in $182 \%$ with the 36,547 exported in 1911. 


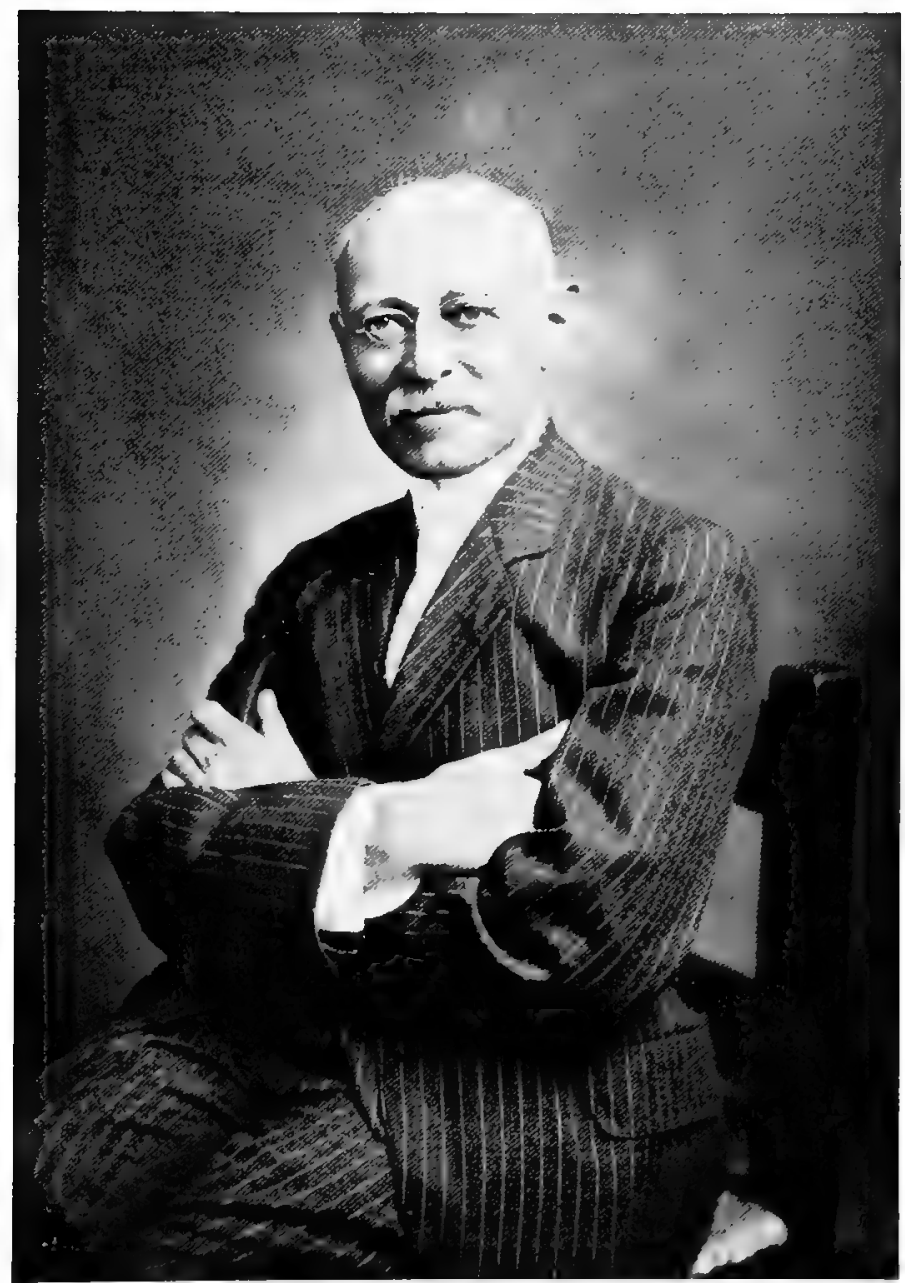

DR. EUGENIO DAHNE,

General Secretary of the Federal Government of Brazil Commission. 


\section{RUBBER-PRODUCING PLANTS - BCTANICAL DESCRIPTION -- PRODUCTIVENESS- REGIONS IN WHICH THEY EXIST}

At the present moment, more than 300 species of rubberproducing plants are known to exist, these being distributed among the tropical regions of the world. Trees of large size, climbing plants and flexible creepers containing the precious latex in their branches, trunk and roots, those vegetable growths from the double point view of quantity and quality of rubber produce have not an equal importance. The species worthy of mention belong to four great families:

1.-Euphorbiacan, Hevea, Micrandra, Manioh. 2.-Ulmacean, Castilloa and Ficus. 3.-Apocynacean, Landolphia, Hancornia, Kickxia Carpodium and Clitandra. 4.-Asclepiadaceas, Callotropia, Cynanchum.

The production of rubber in America is principally furnished by the heveas, micandra, manioh, castilloa and hancornia; that of Asia; by the ficus; and that of Africa by the landolphia, clitandita and kickxia.

In the Amazonian region of Brazil, there exist about 21 species of heveas; of these the principal is the hevea braziliensis, which under the name of "the Pará rubber-tree" deserves to be class'ed in the front rank of all the other lactiferous plants in the world. The hevea braziliensis furnishes the most highly esteemed quality of rubber, and it is the value of that product which determines the prices of all the other species of rubber brought on to the market.

The heveas are powerful trees of from 20 to 30 metres high, the trunk which is cylindric in form and of a light ashy color, generally attains a diameter of from $0^{\mathrm{m}} 80$ to $1 \mathrm{~m} 20$; the branches only commence to grow at about 15 metres from the ground. The leaves fall in June, but are speedily substituted by others; it is during this period that the trees break into flower.

They grow in the valley of the Amazon, which within Brazil embraces the State of the Amazonas, the federal territory of Acre, almost all the State of Pará, the Nort'n of Matto Grosso and of Goyaz and a part of the South of Maranhão, or say about $5,000,000$ of square kilometres.

Their habitat as a general rule is a low and warm region whose temperature varies between $25^{\circ}$ and $30^{\circ}$; without sudden changes during the course of the year and they favor by preference the watery soils, just swampy, damp and even marshy; 
however, at the head-waters of some rivers, they. also live and develop themselves perfectly well in dry and elevated land. In the Amazonic forests, the average proportion is of one heveatree for 80 trees of other species.

The milky latex circulates from the root to the leaves, existing, how'ver, in greater abundancy in the trunk, up to a height of abou: 2 metres from the ground. The heveas in Brazil are generally known by the term "seringueiras" and the forests in which they are found are denominated "seringaes."

The average production of a "seringueira" during the harvest season, which extends over the space of 6 months, is of 5 kilos of fine rubber and 750 grs. of sernamby.

The species most appreciated besides the hevea braziliensis, are the hevea de terra firme, of which Dr. E. Ule treats in his recent studies, and which are found on the frontiers of Matto Grosso, the hevea do Rio Negro, called "seringa. verdadeira" (the real seringa), the hevea benthamiana and the hevea dukei, Hub, from the region of the Japurá, all of them furnishing excellent products.

In the valley of the Amazon exist the micandras, belonging to the same family and producing a rubber of a superior quality, since it is sold under the name of Fine-Pará. The production of these trees goes to the market included in the category of hévea, owing to its similarity to this latter. The micranda syshenoide which is the most known species, is found on the Lower Amazon, in the innumerable islands at the estuary of the great Amazon River: in the valleys of the Madeira, the Solimões, the Japurá and the Purús; the natives give it the names of tapunu, curupita murupita and seringarana.' They are leafy tre whose trunk is of from $0^{\mathrm{m}} 80$ to $1^{\mathrm{m}}$ in diametre and from 20 to 25 metres high. They grow as well in the low lying marshy soil as in the elevated lands, whence comes their denomi nation of tapuru da vargem and tapuru de terra firme. The tapurú is as lactescent or milky as the hévea and the latex which it renders is equally rich, seeing that it gives 50 per cent. of fine rubber.

The trees whose product, the caucho, occupies the second place in the general exportation of rubber from Brazil although as a matter of fact it only commenced to come into the Brazilian markets in the year 1896, belong to the family of the Ulmaceas. These are the Castillas which up till a short time ago have been classed as of the same species as that which grows in Mexico and Central America-the Castilla = elastica, but studies made by professor $O$. Warburg show that they affe distinct species which was thence forward denomisadef Castilla Ulei, Warb. 
The "castillô" is a tree of large "proportions, reaching to a height of from 12 to 18 metres; its trunk with a diametre of from $0^{\mathrm{m}} 60$ to $0^{\mathrm{m}} 90$, is of an ashy gray color, smooth and sparingly branched. The leaves are large, greater, indeed, on the new plants than on the full grown trees and its fruit is of an oily nature.

These trees grow in considerable quantities at the sources or head-waters of the affluents of the Amazon on the latter's right bank, such as the Juruá, the Purús, the Madeira, the Tápajóz and the Xingú, and on its left bank in the valleys of the Japurá, the Iça, the Rio Negro and the Trombetas Rivers. Abundant "cauchiaes" or forests of cautchou trees exist also in the region of the River Tocantins and of the Araguaya.

The "castilloo" is found therefore in the same regions as those in which the "seringueiras" flourish; it exacts a warm climate; a clayey or clayey-silicious soil, but does not thrive in swampy 'ground or such as is easily inundated during the rainy season.

The latex is found as much in the bark as in the alburno and each tree felled produces on an average about 50 litres of latex or say from 18 to 20 kilos of rubber.

"Ceará" is the mundial denomination of another quality of Brazilian rubber, the rubber of the Manicoba tree. The manicoba manihot glaziovii is a handsome tree 10 to 15 metres high, and a native of the Northeastern region of Brazil. A t ts"trunk presents a diametre of from 20 to 50 centimetres and"it possesses few branches; its wood-fibres are weak and light. The cortex, which possesses lactiferous vessels in abundance, is protected by 'a silicose layer, easily removable. 'It is a plant of rapid "gtowth.

According to a classification made by Dr. Ule, there are four species of manioh, the $\mathrm{m}$. glaziovii, the $\mathrm{m}$. piauhyensis, the m. dichotoma and the $m$. heptaphylla, the which exist almost throughout all Central Brazil, being specially abundant in Ceará, Piauhy and Bahia.

Little exigent, it thrives in regions where the temperature oscillates between $22^{\circ}$ and $36^{\circ}$, on low-lyingt ground and it develops itself well in lands of great altitude, in which the thermometric average temperature is about $15^{\circ}$, resisting even the hoar-frost.

It is indifferent to this tree whether the climate be damp or dry as long as the soil is dry.

The species most appreciated are those from Piauhy and the Jequié ("sertão or back-woods of Bahia). Those of Piauhy present two varieties: the white and the black species, the white being the most renowned. They are of small size, with abundant 
foliage and thick bark and darkish stem and give plenty of the milky latex, the average being 1,200 grammes per tree. Those of the Jequié, which grow between the rivers Paraguassú to the north and of the Contas to the south, are a shrub-tree whose trunk does not exceed 30 centimetres in diametre. The bark is fine and of light clear color; it produces about 500 grammes of rubber.

The mangabeira (Hancornia speciosa) is a slender and crooked shrub-tree, 3 to 4 metres high, and abounds on the high-lying table-lands or plateaux in the interior of Brazil. The trunk has a diameter of from $0^{\mathrm{m}} 30$ to $0^{\mathrm{m}} 35$; is scantily leaved; the fruit is eatable, and has a very agreeable taste.

A plant of an extraordinary resisting power, it defies the inclemency of the climate, the absence of rains, the scarcity of humidity and of nourishment from the soil. It predominates in the catingas of the Northern States, in the carrascaes of Goyaz and in the cerrados of S. Paulo, which means to say, that it is found from Maranhão to S. Paulo, now in the Interior, as in the mountain-range of the Mangabeiras between Maranhão and Goyaz, in the central Chapada of Minas, in the Parecis of Matto Grosso and in S. Paulo in the zone comprised between the Paranápanema River and the Rio Grande, tributaries of the Paraná River, and again on the littoral, which is the case from Bahia northwards as far as Ceará.

There are several different varieties of this plant, there being no indications, however, tending to point out any one of these preferable to another with regard to the question of its yield. The latex is of a bluish tint, its richness in rubber varying greatly. Each mangabeira supplies on an average one kilogram of rubber.

Besides the plants mentioned, there are still many others in Brazil which furnish rubber, but which continue to grow without being taken advantage of, on account of the little profit they give.

To speak only of those which exploited on a small scale have yet supplied the Brazilian markets with an appreciable product, we may yet mention the Massaranduba, Mimosups elata, and Frei-Allem, gigantic trees found from the Amazon and Pará to Rio de Janeiro and Minas, abundant in the milky latex, which being coagulated produces a rubber very similar to guttapercha, to which it serves as a substitute in all the latter's most important applications ; and the Sorva, Couma utilis, Muell. Arg., which grow in Pará and in the Amazon valley, the latex: of which, the leite de sorva, enters, with a small coefficient in to the production of rubber in these two States. 


\section{IV-EXTRACTION OF RUBBER, METHODS AND PROCESSES}

The great organic and biologic differences which exist between rubber-trees, exact divers processes of preparation in order to obtain a complete utilization of the productive capacity of each.

It is, however, interesting before entering into a description of the different processes adopted in Brazil, to here state what the chemists think as to what rubber really is.

Rubber is a carburate of hydrogen which in the shape of white globules more or less elongated, are found suspended in the milky latex. The composition of those globules, although even yet, badly defined, is represented by the formula $\left(\mathrm{C}^{10} \mathrm{H}^{16}\right)^{\mathrm{n}}$. Rubber is generally considered as a derivative of the Isoprina, into which it transforms itself when submitted to the action of dry heat, as Bouchardat demonstrated by his experiments in 1879. Treating the isoprina in a strong solution of chloridic acid, an interesting body is obtained, which reminds one of rubber on account of its elastic properties. Wallach; Tilden, Weber, Harries and others gave themselves up to accurate studies upon the composition of rubber; neverthless, up. till to-day, however, no definite result has as yet been arrived at.

The latex, a thick liquid which has the appearance of animal milk, circulates in special vessels, distributed diversely in the organism of certain plants.

The following are the results of the analysis obtained from the latex of the hevea braziliensis by Seelingmann, Scott and Bamber: Seelingmann

Water .55 a $56 \%$ Scott

Rubber $32 \%$

Proteine $22-32 \%$ Bamber

Resin

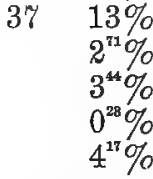

Ash

Sugar

Oily substances.

$9^{7} \%$

traces

$55^{15} \cdot 55^{56} \%$

$41^{20} \quad 32 \%$

$2^{18} \quad 2^{03} \%$ $.2 \%$ to $3 \%$

Specific weight: Seelingmann, 1.019. Bamber: 1.018.

It is advisable to note, that the proportion of water may vary a great deal, influenced sometimes by the season being either wet or dry, and at other times by the weakness or vigor of the tree at the occasion of its being tapped.

The quantities of proteine, resin and ash are dependent on the chemical composition of the soil, those quantities affect the 
quality of the rubber, which is the more elastic, resistent and durable the smaller the proportion of those elements.

* In the coagulation of the latex, the resin incorporates itself in the rubber, it becoming difficult to separate it, which, however, is necessary; the prateine or albuminous matter is the cause of the developing of the bacteria which occasion the putrefaction of the manufactured article.

The method employed in Brazil in the extraction of the latex and in the preparation of rubber from the heveas trees, is the same as that which was taught by the natives and it is a remarkable thing, that due to the excellency of the product resulting therefrom, it is considered even to-day as the best system.

The great production of rubber in Brazil, is due to the exploitation of the natural seringaes. A "seringal" or, better said "seringaes" in the plural sense, are the forests where the hevea trees flourish among other numerous specimens of luxuriant vegetation, and in those regions everybody, i. e., all the ablebodied men, occupy themselves with the extraction of rubber and are known as "seringueiros."

In order to exploit the "seringal," operations are commenced by the construction on the bank of the river, at a place easy of access for navigation, of a large rustic edifice with out-buildings and various sheds. The general edifice serves as a dwellingplace for the owner or his representative and includes a general store or shop with a tavern which does business in selling all the necessary articles required in or connected with the life of exploiting the "seringal," a store-house for depositing the rubber and an office or counting-house. The sheds are the rudimentary habitation-huts of the "seringueiros" and are sometimes constructed in the interior of the forests, so as to facilitate to a greater degree the work which they have in hand.

As soon as the forest is explored and the seringueiras discovered, estrades are opened, these being winding roads cut in the undergrowth and brush-wood with the "facão" (a species of large pruning-knife) and these roads connect a 100 or 150 rubber trees and they lead back to their original starting point. At sunrise; that is to say, at 6 o'clock in the morning, the seringueiro armed with a "terçado" a sort of speer, a fowling-piece or sporting-gun, a small axe or hatchet, a pail and a large number of "tigelinhas," commences his work. The hatchet is the instrument employed for tapping the trees; it takes the form of a common pole-axe, being, however, generally of cast iron and with the edge of the blade blunt rather than sharp, and from 3 to 4 centimetres broad. The tigelinhas are small vessels or cups of tin-plate with a capacity of about one hundred grammes and of a conical shape cut off at the top. 
The seringueiro commences by striking the trees with the hatchet, whose handle is about a metre long, which permits of his making incisions at about from 3 to $3 \frac{1}{2}$ metres from the ground. That operation has for its object to make the latex ascend from the roots; the milk that oozes out is utilized as "sernamby." Two days afterwards, the regular extraction commences, a hatchet with a shorter handle being then used.

To bring this extraction about, "seringueiro" makes the first incision at two metres from the ground, but those incisions must not pierce the cambium and the wood and are as a general rule made at an inclination of $25^{\circ}$. At the lower part of the incisions made by the blows, the "tigelinhas" are fixed, whose sharp and cutting corner penetrates easily into the bark of the tree. The seringuerio operates thus upon all the trees of his road, and this work which occupies him about from 2 to 3 hours being completed, he takes the pail capable of holding 10 litres and recommences his round, gathering into that receptacle the milk contained in the tapping cups, which now empty are boxed one into the other and deposited close to the trunk of each tree.

After that second round and in order that the milk shall not become deteriorated, commences the most delicate operation, that of the smoking process.

For that operation, the seringueiro is supplied with a "boiaao," a kind" of earthen funnel-shaped chimney, a form made like a spatula or putty-knife and a kind of basin "cuia," like a dry gourd, made from the half of the fruit of the cabaceiro (crescencia cuyeté).

The fire made with blocks of urucury (Ataléa speciosa Martius) or with fire-wood of massaranduba, rich in oily substances, being kindled, the seringueiro places the "boião" upon it, the function of this latter being to canalize the smoke so that it escapes at the top, which is open.

Through the loop of a cord hanging near to the "boião" the form is passed and sustained by the "seringueiro" who gives it a gyratory movement; with the "cuya" or gourd, he pours the latex into the part scooped out of the spatula, which he carries off immediately to the smoke. The latex thickens and forming a thin skin upon the which another coating of latex is poured out, which is also passed to the smoke. Those successive and alternate operations form the skins, large balls of rubber, weighing from 20 to 60 kilos, which are the type exported from Brazil. The smoke acting as a solidifyer and at the same time a disinfectant by the presence of creosote; acetic acid, etc., kills all the bacteria that produce putrefaction and hastens by its heat the evaporation of the water:

The rubber thus formed is of a superior quality, but when, 
however, the curds still deposited in the basin, are incorporated with it, the quality becomes damaged, being then quoted as medium fine. The portion of milk which remains adhering to the receptacle or which surrounds the boião and which thickens freely, is reunited into one single skin, and constitutes the "sernamby."

On the following day the work recommences, the seringueiro making new incisions about 7 centimetres below the first, and continuing thus until he reaches the ground.

To that series of blows in the vertical sense, 35 on the average, is given the name arreação. In each seringueira 2 of these arreações can be made per year.

That process which with small variations is employed in all Amazonia, produces, as is known, the best rubber in the world. A seringal may contain in accordance with its size from 40 to 800 roads. Each seringueiro exploits 2 roads; in which he works alternatively. The daily gathering varies between 2 and 8 litres of milk, but an average of 5 litres can be taken for a road which contains 120 seringueiras of 35 centimetres diametre. As each arreação has 35 incisions and the seringueiras supporting 2 "arreações," we have thus for each road 70 days or 140 days for the 2 roads; 700 litres of milk produce 400 kilos or in other words 1.666 grammes per tree.

There are "seringaes," however, in which that average is considerably greater, a medium of 3 kilos per tree not being an exaggeration in some rivers.

Contrary to the almost sedentary life of the seringueiros, the extractors of the caucho (known as caucheiros) are of nomadic habits, and this is so by reason of the barbarous process employed in the exploitation of those trees which is a ruinous one.

The extraction of the latex of the "castillôa" can be done in the same way as that of the latex of the heveas; the caucheiros allege, however, that the cupim introducing itself into the wounds made by the incisions soon causes the death of the plant. Thus they argue that if the tree is condemned, the best way is to cut it down so as to obtain the greatest benefit possible out of it, by the complete utilization of the latex which each tree contains. That reasoning, however, has no foundation in fact

The exploitation of the castillôa is done in the following manner: the "caucheiro" penetrates into the forest and marks each castillôa tree that he finds, with a cut from his knife, which incisions correspond to a sign of possession for extraction later on. Once he has discovered a certain number of these trees, he constructs a temporary wooden hut for himself and then begins 
his work. In the first place he clears the brush-wood around each tree and cleans away the undergrowth from the ground, he then opens small cavities in the lower part of the trunk into which he fixes the "porringers," small vessels made of tin, which are to receive the latex. This done he strikes the tree with oblique "entalhas" of from 1 to $1 \mathrm{r} / 2$ metres in length, canalizing the latex which commences to run from the extensive wounds, by means of mud gutters. At the end of 24 hours the little tin vessels are full and their contents are then all poured into a pail, the "caucheiro" commencing thereafter to cut down the tree, so as to get the full benefit of the latex, existing in the superior part of its trunk. The tree as a general rule is cut at a point above that where the incisions were made, the tree thus remaining suspended above the ground at one end by the lower part of the trunk, where it remains fixed and at the other by its own branches. Along the whole length of the trunk at about a distance of an arm's length from each other, new circular incisions are made and in corresponding cavities on the ground are placed the receiving cups. The latex thus gathered is collected into a pail.

The thickening is done with a solution of common soap about 125 grammes to a pail of water, two pailfulls of that solution being necessary to thicken 30 litres of latex. They also employ the juice of a liane called vetilla which by the description given seems to belong to the convolvulas family-the Ipomea patatas.

The thickening process takes place in rectangular holes of 1 metre long and half a metre broad, whose clayey sides are well paved and into them the latex is poured, care being taken that it is then covered up with palm leaves to prevent the entry of rain water. They thus obtain the caucho planks (rubber in cakes), which arrive in the market full of impurities, that depreciate its value very much and it is not at all a rare thing that water exists in cavities in the interior of it, thereby increasing the weight and making the transport dearer.

The portions of the latex which flow out along the length of the trunk or fall into the cavities after that the cups have been taken away, thicken itself freely and form the "sernamby" of caucho, to-day much appreciated in the rubber markets, because of its being purer and not offering errors in weight.

Each adult tree furnishes on the average from 50 to 56 litres of latex or in other words nearly 30 kilos of rubber. Each cake of the size above mentioned weighs nearly 60 kilos; it is thus necessary to cut down three trees so as to obtain one cake.

The trees cut down sprout and commence to grow again, but 
eight years are necessary to elapse before they can be exploited anew.

No accord has so far been established as to the best methods of extraction to be employed for the different species of manicoba, nor as to the period most appropriate, the duration of the tapping or the yield of the wild trees or planted trees of different ages.

The system adopted for the natural maniçoba, consisting in the tapping of the subterranean organs, has been applied to cultivated maniçoba; the incisions are made in a transversal sense and have the form of a $\mathrm{V}$ with the angle more or less rounded.

The latex is gathered in the ground, at the bottom of a small cavity, opened up on the occasion of the discovery of the parts destined to be tapped; as a rule the worker covers the bottom of the cavity with a coat of clay in powder, in order to prevent the penetration of the latex and its mixing with the sandy soil; the employment of tigelinhas is clesirable or of pots of glazed clay, refractory to rust.

The latex thickens during the day, forming a sort of flat ball or biscuit of rubber, which goes on augmenting as the tapping process is multiplied. At the end of a week the rubber which has been obtained, is gathered together and washed in cold water, with a view of eliminating the remains of the serum and other impurities. This method, although primitive, permits of the production of pure rubber. The trunks and branches of the maniçoba are also cut; however, such system occasions great inconvenience. The extensive flaws heal up with difficulty, as the bark of the tree is relatively thin the lactiferous vessels are located in the deep layers; it is not a rare thing that the death of the tree is caused thereby or that the attack of rodent insects or mushrooms is thereby facilitated. It may be of importance to note, that the incisions made simultaneously on the trunk, the branches and the underground parts, speedily exhaust the maniçobeiras; and so the system of an alternate cutting is preferable.

The tappings are practiced during the first six months of the year and-extend themselves over a period of from 50 to 60 days. Owing to the lack of data, the average yield of production, which varies according to the age of the trees, cannot be determined, however, the average production of the planted maniçobas may under reserve, be calculated to reach during the space of 60 days $120,180,240$, and 300 grammes per tree of $2,3,4$ and 5 years respectively, in accordance with a calculation made by Dr. L. Zehnter.

The actual cost price in the plantations does not exceed $1 \$ 500$ per kilo, and might be reduced through an improvement in the 
systems employed; the cost price of rubber from the native maniçoba is higher, due to the dearness of labor and of freights.

There is so far no process which may be called the best for extracting rubber from the mangabeira; the process in use varies with the region, all of them, however, leading to the complete extinction of the plant.

Under the pretext of the cupim destroying the plant, attacking the incisions that have been made, the latex is usually extracted at a small height from the ground. In the "sertões" or wild woodlands of Bahia, Pernambuco and Parahyba, the extraction is done by making a spiral cutting from the thickest branches to the ground, where the cavity is made for receiving the latex.

Nevertheless, the incisions with the cup attached is now being employed, in the same manner as is customary with the seringueira; for that purpose, the exploiters make horizontal incisions or in shape of a $\mathrm{V}$, with a small instrument called an alegre, penetrating the entire coating of the bark, in the full length of the trunk, from the thickest branches down to the

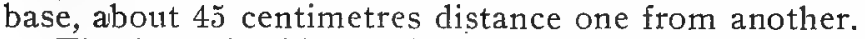

The latex is thickened, sometimes simply with water in the proportion of 3 to 1 , and at other times with chlorate of sodium alone, or with a mixture of alum, as is customary in Bahia and in S. Paulo, or now again by the action of alum-stone, double sulphate of aluminium and of potassium as is done in Pernambuco, Parahyba, and Rio Grande do Norte. All those processes present serious inconveniences, such as the entry of water augmenting the weight, the baneful effects and dampness arising from the use of a large proportion of salt, or the loss of elasticity due to the last mentioned process, which turns the rubber cracky and resinous. The smoking process seems in every way to be advisable whenever the richness of the milky-latex in rubber is perfectly comparable to that of the hevea.

Whilst it is affirmed that the production per tree is from 3 to 5 kilogrammes it is more prudent to calculate the average capacity of each tree as at 1 kilogramme. 


\section{THE ECONOMIC ORGANIZATION OF RUBBER EXPLOITATION}

The economic organization of the exploitation of rubber in the Amazonic valley still remains in its rudimentary condition, continuing almost exactly on the same lines as those adopted when the production of this article--one of the principal sources of the wealth of Brazil-first began to open up.

This unaltered condition of affairs in the modifying of the economical processes, is the consequence of the continuance of certain conditions such as the existence of vast regions still entirely unexplored; the progressive penetration of the seringueiros guided by the course of the rivers into far away regions where rapid mearis of communication are completely lacking, the scarcity of labor, and the necessity of capital being embarked in the extraction of rubber.

The régime of private property is still limited, and does not extend beyond a few kilometres into the Interior, starting from the banks of the rivers, since the greater part of the lands still continue to be the property of the States either of Amazonas or of Pará, and-in the territory of the Aicre-of the Federal Government.

With the object of peopling the rubber-producing regions endeavors are being made to facilitate the acquiring of properties by furnishing their owners with adequate guarantees of protection, special Public Departments having already been created in the State of Amazonas and Para devoted to the fiscalization of the régime of lands; and the rëgime of lands in the Acre Territory is about to be regulated at once by the Federal Government in accordance with the determinations set forth in the new economic measure known as' the Rubber 'Defense Act.

The proprietory question originated itself in the concession of lands granted under certain 'conditions such as that of its effective exploitation and 'cultivation, colonization, etc., and by the legitimation of the possession. : These last were established in the following manner:

The explorer who penetrated into the forest in search of seringaes, examined the banks of the river by which he went up and when he verified the existence of a favorable zone; he landed and after a careful exploration under the direction of specialist-workmen called "matteiros" (forester's) "he 'settled down and gave himself up to the exploitation of the "seringal" "he selected. 
That occupation of virgin ground and its being made use of constituted the act of possession, the first step towards acquiring the property. In order to definitely assure the dominion of the lands selected, it became necessary to obtain a title of ownership from the Government of the State in which these lands were located, this being drawn up only after that the respective marking out and survey by an authorized engineer or surveyor, the depositing of the respective plans, the verification that no anterior rights or claims existed on the part of third parties, as also the payment of the respective taxes being satisfied, which last averaged about $5 \$ 000$ per hectare.

Only after that all these formalities had been complied with, was the concession granted definitely, and the possession considered as complete. The title deeds of the property with the respective specifications is registered in special blocks, which will serve as proof in case of future dispute and will furnish authentic documents in place of the property-titles that may have been mislaid or lost. Once the concession legalized and the possession marked out, the property rights are considered irrefutable.

The dominion of the lands being assured, their usefulness will depend upon the co-existence of two essential factorslabor and capital.

In the regions of the Amazonian valley, sparingly peopled by the want of direct immigration, the work is done by the natives and principally by Cearenses, people from Ceará.

Under the general designation of Cearenses are comprised the populations of the northeast of the country from Bahia to Piauhy, a strong race endowed with rare energy. Having immigrated from their native state fleeing from privations to which the periodical dry seasons reduce them, they arrive completely without the means of subsistence, it being necessary for the owners of the "seringas" who contract their services to take measures for their transport, alimentation and maintenance in the seringaes until with the delivery of the rubber collected, they find themselves in a position to liquidate the debts that they have contracted and the expenses that have been occasioned.

On the other hand in their turn the owners of seringaes not disposing of capital are placed under the necessity of raising loans with which to defray the exploitation of their lands. These resources are furnished them by the traders, part in money and part in merchandise, these traders being known as aviadores whilst the proprietors are called patrons or aviados.

The extensive credits opened by the traders constitute acts of confidence, being guaranteed more by the activity and initiative of the proprietors of the seringaes, than by their respective 
properties; the heavy burdens with which these loanings or advances of money are weighed down, have their origin in the risk which is run by advancing such capital, due to the difficulties of collecting the debts contracted and the far distant nature of the lands given in guarantee. It frequently happens that the traders do not dispose of sufficient means for carrying out all these lending operations in which case they fall back upon the exporting houses, who advance them the necessary money, against a contract to hand over the rubber at a certain late and at prices previously fixed.

\&Thus is established a successive dependency of the seringueiro on the owner of the property, this latter in his turn on the merchant-trader and finally of the merchant-trader upon the exporting house.

Thereafter it is seen how grievously the system of want of capital acts on the whole system on the exportation of rubber and the long series of intermediaries.

Let us see now what is the capital which the owner of the seringal requires to possess for an exploitation of say 200 roads.

A seringal with 200 roads exacts altogether the work of 100 men, whose engagements in the region where they reside and their transport as far as the "seringal" costs on an average $40: 000 \$ 000$ and to each one of them is supplied a sum of $350 \$ 000$ destined to defray the costs of purchase of the indispensable material for making a commencement with the work of exploitation; out of an initial sum estimated at from $\% 5: 000 \$ 000$ to $80: 000 \$ 000$ including casual expenses.

Arrived at their destination, the seringueiros, as they find themselves completely without means, continue to be a burden on the budget of their contractors during the period of the clearing the forests of brush-wood and undergrowth, and the cutting of roads, which are the preliminaries to the gathering in of the rubber. Up till the date of the final delivery, which takes place from 6 to $\%$ months afterwards, the proprietor expends nearly $100: 000 \$ 000$ with the feeding and maintenance of the seringueiros, which is but the preface to a total sum of 180:000\$000 inscribed on the books of the aviador or merchant-trader as being the indebtedness of the owner of the seringal.

This latter in order to meet the charges of the up-keep of the seringueiros, establishes "vendas" or selling-stores, by means of which he supplies not only the goods of first necessity for consumption, but also the tools, utensils and, indeed, everything: that is required for the proper exploitation of the "seringal."

These "vendas" or supply-stores are stocked by the merchant-trader of Belém and Manáos, who send them periodically in steamers or steam launches, the necessary merchandise. Ac- 
cording to the season of the year, the rainy or the dry season, the greater or less the distance to be navigated, in short, in accordance with the condition of navigability of the rivers, the trips are made fortnightly, quarterly or perhaps only twice a year.

The merchandise dispatched is debited to the owner of the "seringal" at the invoice price, augmented by the high expenses for insurance, freight and a commission which varies from 20 to 30 per cent. according to the time-term stipulated for the payment in cash or the delivery of the rubber.

The owner of the "seringal" in his turn re-sells in retail the merchandise received, putting on a high profit to i.ts original price; the seringueiros who already pay interest at the rate of 20 per cent upon the advance of the $350 \$ 000$ which is made to them at the time of their being contracted, are obliged to supply their needs exclusively in the store of the proprietor of the "seringal" and to hand him the rubber which they may have gathered in payment thereof.

The initial supplying of the utensils amounting to $200 \$ 000$ added to the cost of the journey which runs for account of the seringueiro himself, absorb the $350 \$ 000$ of the advance; and his expenses, whilst the extraction of the rubber is proceeding-which lasts for 6 or 7 months-totals up to about $1: 000 \$ 000$, so that when he comes to hand over the rubber, he is already responsible to the proprietor of the "seringal" for an amount of about $350 \$ 000$ including the payment for the renting of the road explored.

His production being on an average of about 400 kilos (in certain regions it is much greater), the worker finishes his enterprise with a very small profit and it is not a rare case that he is not able to satisfy all his indebtedness, a circumstance, this latter, which keeps him continually dependent upon the owner of the "seringal."

On handing over the rubber, the conditions of payment are adjusted and these are generally made in one of the two fallowing ways: either the seringueiro sells the rubber directly to the proprietor of the "seringal" at a reduction of one-third upon the prices ruling in the markets of Belém or Manáos; or he encharges him to sell it in the referred-to market with a discount of 35 kilos of rubber or with a discount of from 10 to 15 per cent. of the net price of such sale, given in payment of the renting of the road exploited.

This defective economic organization of the exploitation of rubber has, as its consequence, the high costs of production which to-day oscillate between $3 \$ 000$ to $3 \$ 500$ per kilo. This 
disadvantageous situation, however, is not a permanent one and may be remedied.

We shall leave for a special chapter the explanation of the means recently adopted for bettering the condition of the seringueiros, augmenting their productive capacity and recompensing them more justly for their.work.

\section{TRANSPORTS AND FREIGHTS}

The problem of transports and freight continues to be one of the most palpitating questions in Brazil, notwithstanding the great progress in this particular made during the last 10 years.

The considerable increase in the mercantile marine and the incessant construction of the numerous railroads of penetration, have not been able to keep pace with the extraordinary development of the country and its notable economic expansion, the national commerce continuing to feel the want of further means of transport and to suffer from the very high rates of freights.

In Amazonia, the difficulty of communication has become still more felt because of the vast region and territories embraced in this great State, sparingly peopled and whose centres of production are located so far distant from the exporting markets of Manáos and Belém de Pará.

.Watered in every direction by innumerable great. rivers, tributaries of the great river-the Amazon-the greatest in the world, the Amazonic region still remains to a very great part unexplored, inestimable riches susceptible of being extracted, lying unutilized, in virtue of the deficiency in navigation; in fact, if the principal rivers are navigated regularly to some extent, even though sparingly, others leading to immensely rich regions are very rarely navigated by either ship or boats, which might assure the transport of the products gathered.

Many and divers are the circumstances which concur towards bringing about this state of affairs, but the most important in resumé is that of the want of capital for the construction of ships and the establishment of regular lines of fluvial navigation as also the obstacles offered either by the irregular courses of some rivers obstructed by waterfalls, shoots and rapids, or simply obstructed by the trunks of trees, and other materials or by the diminutive volume of water during the dry seasons which makes impossible navigation of even ordinary draught.

One of the most interesting phases of the Amazonian problem is, however, in the regulating and increasing of the navigation of the rivers, with the object of assuring ample transport facilities 
and the approximation to the centres of production with the consuming markets. The opening up of the ways of fluvial communication is an essential condition to the progress of the Amazonic region, by the lesser expenditure required by transport upon water in comparison with land transportation which in those regions would be particularly difficult and costly.

The steamers and boats which set out from Manáos or Belém for the Interior, make the passage generally, over-charged with merchandise which by reason of accumulation and its defective packing suffers not rarely serious damages which has the result of bringing about a notable increment in prices. As a general rule the cargo being greater than the space requisite to its accommodation, makes the navigation extremely difficult, the steamers thus not being able to make head-way against the current, which flows at the rate of from 3 to 5 miles an hour, or desiring to diminish the expense in the consumption of coal, seek out the waters the less agitated and approach as much as possible the banks of the river.

The want of minute hydrographic charts and the imprudence of the captains, as also of the masters of steam launches and other floating material, have, as a consequence, the bringing about of frequent strandings, which even though they may not cause damage to the cargo involve interruptions in the trip sufficiently prejudicial.

The unloadings are made frequently on the banks of the rivers under little favorable conditions, by reason of the want of wharves; are very slow and occasion besides lamentable delays, very heavy expenses principally for the packages of great weight.

One of the causes which most determine the dearness of transport in Amazonia, is the supply of combustibles to the steamers, these latter taking in coal only at the port of departure in Belém or Manáos, and this being consumed, purchase wood fuel along the route just as they require it, and for a high price, subjecting themselves thus to the delays incident to loading, at times very great. Coal mines in the basin of the Caquetá have been discovered, but so far it has not been possible to derive any benefit from them, owing to the want of the necessary studies and analysis, which only now the Federal Government is beginning to have made.

For the betterment of this state of things the Federal Government also pretends to contract with a large public company for the establishment of coal depots and combustible oil, at the most appropriate points of the rivers on which the greatest movement takes place in the valley of the Amazon, so that the steamers may be supplied for prices according to a tabular statement previously approved for each year. 
The descent of the floating material by the rivers is much less onerous, as the consumption of combustibles is thereby considerably diminished, thanks to the current which gives an easy impulsion to the floating material; the trips are notwithstanding slow, much time being lost in picking up cargo, almost exclusively rubber, on the banks of the rivers.

The irregularity in the navigation either due to the deficiency of the floating material or by the natural obstacles that the flooding of the rivers bring about, cause extensive prejudice, as it obliges the large cargoes of merchandise upon whose price high interest is collected and occasions them considerable loss of goods deteriorated by their remaining for a long time in sheds and by the damaging effect of heat and dampness.

From thence arises the lamentable dearness of life and the bad alimentation, with their evil results on the health of the inhabitants of those far-away-regions.

The retention in the seringaes of large stocks of rubber deprived of the means of transport must also not be forgotten and its coming simultaneously on to the market at certain times, being taken advantage of by speculators is an important cause of the fall in prices which affects the interests of producres to an appreciable degree.

Regularity and frequency in navigation, permitting successive and regular supplies of rubber would diminish in notable proportions the cost of production, since it would cheapen the cost of labor and avoid the great oscillations usual in the prices.

In order to obtain that desideratum it is not sufficient 'to create new lines of navigation. nor to augment the number of floating material or better their conditions, but it is necessary to adopt certain complementary measures. Thus in the impossibility of preparing from the outset minute hydrographic charts, a measure which would require great expenditure; it were advisable in order to make navigation more secure to indicate by means of small light houses and illuminated buoys of acetyline, the dangerous points which it is desirable to avoid.

In order to obviate the difficulties created by the formation of sand banks, by the accumulation of trunks of trees, and of obstacles of all kinds, it is necessary that attention be, paid constantly to the cleansing of the rivers' and dragging them, in cases where the obstructions cannot be removed by other means and the construction of railways and wagon roads connecting the navigable points.

It would be of the greatest utility to bring about the extension and opening up of telegraphic lines joining the producing centres with the central markets, such measures would have the most beneficient results as much for the owners of seringaes 
as for the shipowners, these latter being once aware of such facilities would cause their ships to be directed to the points where they were required to discharge merchandise or take in rubber or vice-versa and thus avoid all uncertainty upon the advantages to be reaped from those trips, because of the want of knowledge of the cargoes that are being reserved for them, and those who are in contact with them in the markets where the product is sold may be advised as to the quotations and the market prices of the merchandise so that they may take advantage of the most favorable times for effecting their transactions.

The message presented by His Excellency Marchal Hermes da Fonseca, President of the Republic of the United States of Brazil on the third of May of this current year, made special reference to the services of the radio-telegraph in the territory of the Acre, expressing himself in the following terms:

"The three radio-telegraphic stations that have been contracted for in December of 1910, are now in full working order, those of the Rio Branco and Senna Madueira having been inaugurated in September of 1911 and in February of this year. that of Cruzeiro de Sul, which besides speaking with those two and therefore with Manáos, communicates also with Iquitos in the Republic of Perú.

In order to complete this very useful improvement ordered to be done in such a happy hour, there were also contracted for two other stations, one of these being in Xapury and the other in Taruacá, places having a great future before them and already containing an appreciable population as well as a notable material development.

With the installation of those two stations, the territory will be perfectly well equipped in regard to the question of telegraphic communications.

As a consequence of the dearness and the difficulties in the means of transport we get the excessive rises in freight, which at times are equal to and are often greater than the value of the merchandise transported; the truth is that the crisis in rubber made them suffer a certain fall and we no longer see such a thing happen as that the shipowner pays for the price of his steamers in two round trips.

The dominating principle is that of liberty of commerce. In order to assure regular services on the principal rivers, the Federal Government as well as the Governments of the States of Amazonas and Pará subsidize certain companies whose tables of freight charges are approved by the Public Powers. That these are still very high is shown by the fact of competition which in certain lines takes place between the subsidized companies and private shipowners; the latter, however, not being able to go 
beyond the tariff tables of the former, they nevertheless obtain freights and passengers which proportion them high profits, demonstrating thus that the tables of freight tariffs of the subsidized companies are still a long way from the maximum of reduction.

The Commercial, Industrial and Agricultural Congress which took place in Manáos from the 22nd to 27th of February of 1910, considering this position, resolved to recommend to the Public Powers the remodelling of the actual freight tariffs principally in that part of them which relate to alimentary goods, necessary to the sustaining of the extractors of rubber and in the sense of their being substantially cheapened.

Even to-day one of the best businesses in the Amazonic regions consists in chartering steamers for trafficking on the rivers.

If the freight rates on the sections served by the subsidized lines are high, greater still are these on the less favored sections where the rapids of the rivers flowing among the seringaes, make navigation difficult, because in these latter there being no freight tables, they make the price according to their judgment, such prices of transport being contracted directly according to the circumstances of the occasion with the shipper, who has to pay the price as the masters of the steamers are pleased or resolved to charge.

The owners of seringaes subject themselves to the heavy burdens which they are bound to put up with, in the hope of escaping the damage that the retention of their produce for want of transport would cause them .

It is not only the fluvial navigation freights that are much too burdensome, for the freights for ocean navigation are also burdened with this grave defect and thus it is that despite the fact of the distance which separate Brazil from New York and from London, is only half that between the consuming markets and the east, the freights for the latter are incomparably lesss. It behooves the Governments of countries producing rubber in South America to come to an arrangement so as to confer adequate premiums on the navigation companies to Europe and to the United States, who cheapen their freights and cut down in a satisfactory manner the duration of the voyage. 


\section{INTERNAL MARKETS FOR RUBBER-ORGAN- IZATION AND WORKING-TYPES AND QUOTATIONS}

Located in the centre of the most important rubber producing region of the world, Belém and Manáos, the capitals of the two great states of the north, are, in Brazil, the principal markets of that product. Nearly 90 per cent. of the Brazilian exportation proceeds from there, the 16,000 tons of rubber which each of these markets export annually gives place to a considerable mass of business.

If it be true that the commercial transactions gyrate around equal quantities of rubber, Belém has the advantage over Manáos, because it is the seat of a great part of the large exporting houses that operate in the two capitals. Its geographical situation which permits of more rapid communication with the markets of the south, and with foreign ports, contributes also towards its greater commercial importance.

The uses and customs are identical in the two markets. Commerce obeys a rule above all unfavorable to the sellers who cannot put a value on their merchandise but are forced before all things to accept the price imposed by the buyers. That disadvantageous condition of dependency is the natural outcome of the deficient economic organization in the exploitation of the rubber industry in the valley of the Amazon. Reference has already been made in another place to the burdensome commercial relations between the seringueiros and the patrons or proprietors of seringaes and between the same patrons and the commercial traders: The same vices and defects are to be found in the relations between the commercial traders and the great exporting houses. Those latter, possessors of large capital and united together in the common interests, dominate the market, which, weakened by successive crises and always in a precarious state cannot oppose them an efficacious resistence.

That situation can only be modified in the case of the actual economic and commercial methods, which place in the hands of the merchant-trader all the responsibility of the conduction of business in the place, without at the same time arming them with the means of defence against unrestricted speculations.

The merchant-trader's houses are the intermediaries between the seringueiros and the exporting houses. But, their principal function is that of furnishing the seringueiro during the year 
all the goods necessary to sustain him and his employes as well as supplying him with tools, utensils, wearing apparel and in fact, everything that may be necessary to his life in the seringaes.

This supplying is done on credit, that is to say, against the remittance of rubber produced by the borrower and which is sold on its arrival by the merchant-trader to the exporting houses.

The merchant-trader thus requires large capital so as to meet the engagements that he assumes in the market with the great and numerous supplies, which he is obliged to make.

It is incumbent on him also to transport the same for which he nearly always employs steamers of his own, in order to bring the merchandise to its destination in far-away regions, bringing back on the return trip the rubber collected by his aviados, i. e., his borrowers of the seringaes.

The responsibilities assumed become due on the occasion of the arrival of the cargoes of rubber. In fact, it is exactly at this moment that the merchant-trader is most in need of money, because besides the imperious duty of paying the amount of his debts and the immediate necessity which he has of furnishing new supplies to his clients the aviados, he has still yet expenses to disburse with the repair and fitting out of the steamers, which owing to the bad conditions in the navigation of the rivers return nearly always in a damaged condition; balances to pay to the seringueiros whose debts were relatively small or advances to make to those whose production was inferior in value to the supply sent, but who required a new resource under the danger of otherwise not being able ever to liquidate their debt.

Thus it is that the aviador or merchant-trader has no other remedy, but to sell without delay the rubber which has been consigned to him and that is the psychological moment for the decided action of the buyers.

Reduced as to number, well informed about the business and in the possession of daily and direct notices from the consuming markets, perfectly bound up to them by a question of mutual interest, they decide to make the price for the merchandise that is offered to them. It is not always that that price corresponds in reality to those of the foreign market, but the apprehension that seizes the merchant-trader that moved by their interests the buyers may resolve to retire the offer, does not permit him either to hesitate or resist. He hands over the merchandise with a small profit and not uncommonly with a loss.

Treating of an article which up till to-day has been produced in anquantity inferior to the necessity of the industry, whose 
price was kept up high, much above that which might be called a remunerative price, that inversion of the law of economics is a very curious one, because, in this case, it is not the producer who imposes the price, but the buyer who does so.

The difficulties which the merchant-trader had to fight against, have been increased lately with the advent of the "regatôes," a species of barter-commission travelers on the rivers. This trade is exercised by individuals acting for their own account or as agents of the merchants and who go up the rivers with merchandise, doing business at sight in exchange for money or rubber, diverting in this way a large part of the transactions until now exercised through the inter-medium of the merchant-traders.

The principal causes of the precarious position of the "aviadores" or merchant-traders are the lack of adequate capital and the want of banking facilities and other establishments of credit which might come to their aid.

The export houses, however, operate with the greatest firmness. They discount the drafts for the rubber bought, in the agencies of the English banks, and with the product of this operation pay the merchant-traders, and as these drafts are at 90 days sight, it is only after the rubber is sold in New York or in Liverpool that they satisfy their indebtedness, thus trafficking almost covered from any risk whatsoever.

The aviador or merchant-trader receives the rubber by the weight which it shows at the moment of being unloaded; if the trip is a long one the shortage in weight of the rubber may be as much as 15 per cent.; if, on the other hand, there has been no time, owing to the shortness of the trip, for such a thing to happen, it is certain that on its being magazined or stored-up, it will continue to quebrar, i. e., diminish in weight. Thus, therefore, it is to the interest of all parties concerned to sell it and export it as soon after its arrival as possible, which, however, does not mean to say that the question of shortage is not an element which comes into play in making the estimate of its value.

The classifying of the rubber is done upon the occasion of its sale, this being an operation which necessitates a long experience and practice in the knowledge of the article.

Two workmen with iron instruments which they call "gatos," take hold of the skin (smoke-cured roll or ball) by the orifice which is left in its shape on its being made, at the same time that a third workman cuts it down the middle with a sharp instrument called a "traçado." By this means it is easy to ascertain if the manufacture of the internal coatings or layers has'been 
done with the necessary care, and if the weight has been affected by water, or by any other extraneous body.

If the rubber presents itself with an uniform aspect, perfectly smoked and sufficiently elastic, it is classed "fina." If, however, any points present spongy parts proceeding from coagulation of the latex anterior to the smoking process, it is styled "entre-fina." To the agglomeration of residue which congeals freely, the name of "sernamby" is given.

There is still the "borracha fraca" little elastic, whose mercantile value is put in the same category as "sernamby" and which does not come from the latex of the hevea.

This work being finished, the rubber is bought in accordance with the quotations of the day, based upon prices coming from England and from the United States, but as has already been explained, this quotation is not always respected.

There is another anomaly to which it is advisable to refer: whilst the "entre-fina" and the sernamby are quoted abroad at least at 200 réis and $1 \$ 800$ réis less than the "fina" the markets of Belém and Manáos show a difference of 800 réis and $2 \$ 000$.

There are other abuses which also take place in the classifying of the rubber, which gives as a result that the buyers prefer to do business upon inferior qualities, because these offer a larger margin for profits.

The rubber is exported in American pineboxes which can hold nearly 150 Kilos. The dearness of manual labor in the Amazon territory makes it difficult to take advantage of the innumerable species of timber-woods in which the valley of the great river is so abundantly rich.

In the remaining markets of the country where the rubber is negotiated, the price is regulated by the quotations in Pará. These local markets are of little importance and in nothing do they distinguish themselves as to the relative transactions in rubber, from the general mass of business. The class of aviadores or merchant-trader does not exist. Each producer sends his stock to his agent or representative or sells it to the first buyer. The rubber is collected from either maniçoba or mangabeira.

In the commerce of those products, the markets of Bahia and Fortaleza stand out the most prominently, to which places a certain appreciable portion of cultivated plantation rubber converges every year besides a great quantity of native rubber. 


\section{ECONOMIC AND FINANCIAL IMPORTANCE- FEDERAL AND STATE REVENUE- EXPORTATION TAX}

The most superficial examination of the actual economic position of Brazil demonstrates at once and in an incisive manner how important the rubber industry is to the national life of the country.

Posseșsor of the innumerable riches distributed by the three Kingdoms of Nature, it is almost exclusively due to the cultivation of coffee and to the extraction of rubber that Brazil owes its extraordinary commercial development in " these last twenty years.

The great fortunes which the plantations of the famous redbean of the coffee-tree created in the South and the considerable profits which the exploitation of the precious gum have produced in the North, were certainly the causes which most influenced the development of the production to such an extraordinary degree, relegating to a much lower schedule in the general tabular statement of Brazilian exportation, all the products, whose commerce although certainly remunerative, does not show such certain and speedy results.

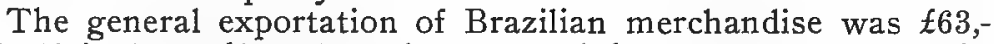
724,440 in $1909, £ 63,091,54 \%$ in 1910 and $t 66,838,982$ in 1911 . To these totals, coffee and rubber contributed during each of the same three years $£ 52,401,276$, $£ 51,342,2^{7 \%}$ and $£ 55,458,221$ respectively-totals these, sufficient by themselves, to guarantee with advantage the Brazilian international commercial equilibrium, when it is seen that in those said same years, the general importation of merchandise amounted to $f 3 \%, 139,354, f 47,871,974$ and $£ 52,798,016$.

Rubber contributed to the general total of exportation with 29.70 per cent in $1909,39.06$ per cent in 1910 and 22.53 per cent in 1911 , or in other words an average of 30.43 per cent per annum. It is worthy of note, that the great difference which took place in the above-mentioned percentages is explained in the fluctutions in the prices of rubber, since the production not only did not decrease, but, as a matter of fact, increased from year to year. Therefore it is seen that nearly one-third of Brazil's export trade is supplied by rubber, and it is nearly twenty millions of pounds sterling that Brazil receives every year, and which goes far to provide for the sustentation, not only of the population of the Brazilian Northwest, comprised in the great 
States of Pará, Amazons and Matto-Grosso and the Federal Territory of the Acre, but for the prosperity of the Northeast States, which get the benefit of a good part of that sum through the intermedium of their sons, who live by the exploitation of the rubber; the Southern States benefit in their turn by the abundance of money in the North, that most secure guarantee of their prosperity, since that being producers of cereals, xarque, coffee, sugar, textile goods, hats and shoes, for a long time already they have constituted themselves the principal furnishers of food-stuffs and wearing apparel to that region. Finally there is still to be considered the benefit to be brought indirectly to the whole country because that sum goes to increase the commerce of importation, thus powerfully augmenting the Federal Customs Revęnue.

The sum obtained by the States of the Amazons and Pará and by the Federal Territory of the Acre, is also considerable every year by the tribute paid on the rubber going out.

This last Territory of the Acre, since its incorporation with Brazil by the Treaty of Petropolis concluded with Bolivia in 1903 , cost the Union (including the expenses incident to the acquisition of the Territory and other resulting compromises of the said treaty, such as the arbitral Tribunal, loans to Bolivia, marking out of the frontier, construction of the Madeira-Marmoré Railroad and expenses for the mobilization of troops, etc.), up till 1909 the sum of Rs. 62,595:562\$038; the revenue brought in during the same period attained the sum of Rs. 58,052:$75 \% \$ 012$, in 1910 moreover the tax upon the rubber produced was Rs. $19,867: 529 \$ 159$ and in 1911 Rs. 9,671: $711 \$ 068$, or in other words Rs. 29,539:240\$227 more, which should be carried to the credit of that very rich region. The rubber of the Acre is exported through the intermedium of the markets of Belém and Manáos, the impost-tax of 20 per cent ad valorem being collected on the occasion of its shipment.

The States of Amazonas and Pará cannot dispense quickly without very serious economic disturbance with the revenue receivable from the tribute paid on the exportation of rubber. As a matter of fact, the State of Amazonas collected the sum of Rs. $16,845: 585 \$ 063$ in 1909 , Rs. $18,069: 162 \$ 372$ in 1910 and Rs. $12,-$ $901: 477 \$ 379$ in 1911; the impost-tax upon rubber brought in those same years respectively Rs. $13,316: 487 \$ 569$, Rs. $14,836: 235 \$ 238$ and Rs. 9,999:031\$526, which can also be reckoned by 79.04 per cent, 82.11 per cent and $7 \% .50$ per cent.

The State of Amazonas taxes rubber produced in the State itself, in 18 per cent ad valorem, and that coming from the Javary, the boundary river with Perú, in 7 per cent. 
In its turn Pará has had in the form of revenue collected in those years, the amounts of Rs. $19,039: \pi 09 \$ 531$, Rs. 20,255:$070 \$ 604$ and Rs. $14,480: 716 \$ 1 \% 6$, the import-tax on rubber rendering Rs. $14,602: 759 \$ 269$, Rs. 14,701:894\$955 and Rr. 9,518:$716 \$ 26 \%$, or 76.69 per cent, 72.58 per cent and 65.73 per cent.

The taxes charged by Pará are 22 per cent ad valorem for Rubber "fina," "entre-fina" and "sernamby," and 15 per cent for whatever other kind. Besides those there is an additional tax of 2.5 per cent in benefit of the Santa Casa de Misericordia charged on the exportation taxes.

These figures seem to show the importance for those States of questions concering the production and consumption of the world's rubber, and with greater reason still for Brazil as a whole. The ruin of one of the most promising regions on the face of the globe, the profound depreciation of Brazilian finances and the dreaded commercial crisis with which the country would have to fight, would be the disastrous effect of the indifference of the Federal and States Governments on such a matter. But that, however, is not the attitude of those Governments; they are decreeing various measures now in course of being carried out and which after minute studies were judged necessary, so that Brazil might continue to maintain her proud position of importance for the precious "black gold" (rubber) in the world's market.

\section{RUBBER-CONSUMING MARKETS - COMPETITION OF OTHER RUBBER-PRODUCING COUNTRIES}

New York, Liverpool, London, Hamburg, Antwerp and Havre are at the present time, by their order of importance, the principal world's markets for rubber.

New York, by virtue of the extraordinary development of North American industries, which in a steadily increasing scale, are consuming constantly greater quantities of raw material, receives almost half of the rubber produced in all the world. Nearly 60 per cent of the rubber negotiated in New York is Brazilian. After this follow Central America and Mexico; but as rubber proceeding from all parts appears in the New York market it is evident that there is no specialty in this business.

Liverpool, perhaps due to the fact of its being the port to which the lines of navigation that run to and from the Amazon are directed, has become the European emporium for Brazilian rubber. In fact, 40 per cent of the Brazilian production is di- 
rected towards that city. Liverpool also receives rubber of various qualities proceeding from the English and other European possessions in equatorial Africa.

The increasing production of the Oriental plantations finds in London one of its principal markets for the precious gum. Although rubber proceeding from different parts appears in the market, it may be affirmed without hesitation, that London is the special centre for cultivated refined rubber (plantation) which is easily explained by the fact that the owners of the extensive plantations in the Malay States are nearly all of them London companies.

Occidental and Oriental Africa, principally German Colonies, send to Hamburg the greater part of the rubber which is negotiated on that market. Brazil enters with about 20 per cent of the total amount of the business.

Antwerp owes its rubber trade to the creation of the Congo Free State, whose production, now in decline, is practically all directed to this city. It also receives rubber from Brazil, and seeing that Belgian capital is employed in the Oriental plantations its future is promising.

Havre, on the other hand, is of greater importance to Brazil; where 75 per cent of the transactions are in Brazilian rubber. It also imports the Congo species, as also those of some of the French Colonies in Africa. However, the great bulk of the production of these latter colonies is directed to Bordeaux.

The methods of sale adopted in these markets, vary very much. From the slow old-fashioned process of sale by private treaty, to sales on time terms, passing through auctions and underwritings, in short all the commonly known modes of negotiating are in use.

The most important market, that of New York, adheres to the old-fashioned method of personal contracts for immediate delivery, which certainly serves better the interests of buyers, than those of sellers; the agitation that was created round this question with a view to reform the market, gave no result whatsoever.

Liverpool presents us the polymorphic type. Private sales, and sales on a fixed day for delivery, or sales by auctions, all take place, consulting thereby the preferences of both sellers and buyers, and establishing the free course of the values. The same happens in London, where, however, the Plantation companies have initiated more advanced transactions, stich as sales of crops in anticipation.

Hamburg and Antwerp also practice sales by auction and on 
delivery. However, in this latter the method of underwriting is that most in vogue and which among all the processes is the one that consults most the interest of the seller. This is carried out in the following manner: $A$ broker advertises a certain quantity of rubber for sale, the particulars of which he supplies (name of seller, weight, quality, estimated price, etc.), about twenty days beforehand. On the day appointed, he receives the offers of purchase closed and sealed; these are then opened in a public place and the prices are inscribed on a schedule divided into columns, each one headed with the name of the house offering. Once this operation has finished, the rubber falls to the highest bidder. The seller has, however, the right to withdraw the goods in case the price that results does not satisfy him.

The Antwerp market adopted this system with the view to competing against cognate markets. As the reducing of the expenses on the product, which corresponded to fcs. 2.60 per 100 Kilos, the same being frs. 4.93 and frs. $\% .30$ in Hamburg and Liverpool respectively, did not suffice, it endeavored to attract the seller by offering the most advantageous prices, and it seems that it has succeeded in its desideratum.

Havre followed its example and it is greatly to be desired that all the rubber markets adopt the same system, not only for the reasons set forth, but also because it is a safe precaution against the manipulations of speculators.

Brazil has always maintained its predominating position in the world's market for rubber, not only as the greatest producer, but also as the producer of the best quality.

In 182\%, the first year about which statistical data exist, Brazil exported 31 tons of rubber; in $183 \%, 289$ tons, or say an increase of 932 per cent; in $184 \%, 624$ tons, or 216 per cent more; in $185 \%, 1,800$ tons, which corresponds to an increase of 290 per cent; in $186 \%, 5,826$ tons, or 322 per cent more; $187 \%, 9,215$ tons, thus augmenting by 158 per cent; in $188 \%, 13,290$ tons, or 144 per cent increase; in $189 \%, 21,256$ tons, representing about 160 per cent more ; and, finally, in 190\%, 36,490 tons, or approximately an increase of 172 per cent.

Within the last decade, that is to say, from 1902 to 1911 (vide statistical statements in fine), the exportation rose gradually to 28,631 tons in 1902 and to 39,026 tons in 1909 , the maximum ever reached so far, to descend immediately to 38,546 tons in 1910 and 36,547 tons in 1911.

Brazil has so far not had any serious competition to fear. It is true that the other producing countries in Central America, South Africa and Asia, send a considerable quantity of rubber on to the market, but this does not affect the Brazilian trade, because, besides being practically all of it of an inferior quality, 
such extra supply is not sufficient to occasion the harmful effects of an overproduction. It is curious to observe, that even within the last decade, the production of those regions which in 1901 was 21,547 tons increased even so far as to surpass the production of Brazil in the year of 1905 , reaching then 35,428 tons; but it diminished as rapidly as it had increased and in 1911 we see it reduced to 23,747 tons. This decrease cannot be attributed to the effects of competition, for instance to the plantations of the Orient, whose production commenced to accentuate itself exactly in the year of 1905 and henceforward. As a matter of fact, competition should bring forth a fall in prices, but however, on the contrary, such did not happen, the quotations reaching in the years of 1909 and 1910 such extremes as had never been seen in the rubber market.. It will be sufficient to point out, that the refined rubber of Pará, which is the Standard regulating type of the market and whose average annual price has been 3,4 and even 5 shillings, went up in those years to $12 \mathrm{~s} / 6$ per pound.

However, a new competitor did appear, which had to be taken into consideration, and which induced the Government of Brazil to adopt some measures tending to protect its great article of export. The considerable and methodical plantations of the hevea brasiliensis made in the peninsula of Malacca in Malasia and on the island of Ceylon, commenced to produce rubber, which it was predicted would within a few years, due to the enormous quantity produced at a low figure, get the mastery of the market.

These plantations, the initial experiments of which date from the year of 1876, with 70,000 seeds sent from the Tapajoz river, an affuent of the Amazon, by Wickham to the Royal Botanical Garden of Kew, have taken an enormous increment since the year 1896, till to-day, due to the results obtained which indicated beyond possible doubt the advantages of the cultivation of hevea, this in view of the constantly increasing price of the product and the new applications which day after day the rubber industry has opened up.

The cultivated-plantation rubber, which appeared on the market with 5 tons in 1901, was represented by 646 tons five years later and at the end of another equal period, by 12,000 tons. It is estimated that if nothing unforeseen happens to the contrary, its production in 1916 will be 70,000 tons, thus reaching the quantity which is at the present moment consumed each year by the necessities of the industry.

It is believed that by that time the inferior qualities furnished by Africa, Central America and even by Brazil, will gradually have disappeared from the market. In order to meet the consumption which, if progression that hitherto has taken place, 
continues, will then be of 98,603 tons, the production of Brazil and of the Orient together will surely render a quantity much superior to that demand.

The average cost per Kilo of fine Pará rubber in the valley of the Amazon is from $3 \$ 000$ to $3 \$ 500$; in India of $2 \$ 650$; however, this difference should disappear under the operation of the Rubber Defence Act, which is inserted further on, and the possible augmentation of the price in the Orient, where manual labor will become dearer later on when all its plantations are in full exploitation, and by the consequent scarcity of labor, against which agriculturists are already commencing to struggle.

The industrial element still continues to give preference to the Brazilian rubber, this being better in quality, nerve and in elasticity-properties these which may probably be attributed to the process of curing, which is not employed in the Orient, or possibly to the meteorologic and climate conditions, the geological composition of the soil, etc. It is true that the quotation for planted rubber has been superior to that of wild rubber, but it is advisable not to forget, that while the former shrinks only 3 per cent, and has a much better appearance, the latter loses 18 per cent of its weight. The price difference is thus amply explained and when accounts are made up it is still the fine quality. from Pará that is the better quoted.

\section{THE INDIA RUBBER PROBLEM-MEANS SUGGESTED AND RESOLVED BY THE STATES}

Threatened with losing the predominant position it has always occupied in the rubber market of the world, Brazil could not, without committing an economical suicide, remain inactive.

The time having come when native rubber would enter into competition with planted rubber, Brazil had to defend its interests by becoming equipped for the struggle, making the cost of its product cheaper in order to ensure its occupying an advantageous position in the market.

Many are the causes which at present contribute to the high cost of Brazilian rubber, but they may be united into three groups, as follows: 1st, expensive labour; and, heavy transport tariffs; and 3rd, excessive export taxes.

The expensive labour is due to the scantiness of population in the Amazon valley, the want of foreign immigration to compensate it, and the high cost of food supplies.

The rubber-producing trees (seringaes) of the Amazon are ex- 
ploited by the natives, whose number is but small, and by the immigrants from the eastern States who, fleeing from the droughts which periodically befall those States and attracted by the liberal profits offered by the extraction of rubber, go there in thousands every year. This current of immigration is, however, insufficient; a proper remedy for. such a state of things would perhaps be foreign labour which still keeps back from the North because it only knows it through garbled information. The bad food and the indifference for all that concerns health conditions, contribute every year to the invaliding of a considerable number of men.

The extraction of India rubber being the occupation which pays best in the Amazon Valley, the pastoral industry, cattlebreeding and farming are altogether despised, so that all the articles of subsistence needed by the population, either come from the South of Brazil, burdened by cost of a long transpert, or from abroad overloaded with high Brazilian Customs duties.

The heavy transport tariffs are due to the numerous difficulties of all sorts that thwart navigation in the affuents and sub-affuents of the Amazon river and to the greediness of ship-owners, encouraged by the absence of competition. On the other hand, the existence of a complete river system has made the Brazilian Governments disregard the necessity of establishing railways which, by shortening distances, might bind the different affluents of the great river to each other.

Finally, the excessive taxation imposed by the States of Amazonas and Pará on its almost only product of exportation is a consequence of the special conditions of life in that Brazilian region, which conditions we have just described. The Governmental and administrative system requires large sums for its maintenance, is unable to avail itself of any other sources of income because they hardly exist. The legislator has had to go on taxing the great product more and more.

In order to cheapen the product, besides removing the causes which have just been shown, two other far-reaching measures have been suggested; the adoption of a process for coagulation of the latex which might decrease the production of inferior rubbers, and planting on a big scale.

At the present moment the exportation of rubber from the Amazon is composed of 50 per cent of rubber "fina," 10 per cent of "entre-fine," 25 per cent of "sernamby," and 15 per cent of "caucho." Now, any process that can do away with or might at least diminish the percentage of entrefina and sernamby would be a means of cheapening the rubber of finer quality (fina). "To apply the same activity to produce 70. or 75 Kilos of "fina" in-" stead of 50 fina, 10 entrefina and 15 sernamby, is the same in 
reality as obtaining the first quality at a very much lower price. Such is the desideratum of the process of Dr. Carlos de Cerqueira Pinto, a Brazilian doctor who has lived for a great number of years among the rubber districts where he has made a most accurate study of the subject. The results hitherto attained are very satisfactory, the Government of Brazil having aided the inventor with a view to spreading his invention once its advantages have been definitely proven.

At the same time, the process of extracting the rubber from trees disseminated in the interior of the forests at a considerable distance one tree from the other, is against all principles of economy. The planting on a large scale, on the margin of the Amazon river, or of its big affluents, but in places of easy access, is an essential measure, especially seeing that the Government aims at maintaining for Brazil in future, the prominent position it now occupies in the trade. Therefore, whilst considering all the complex elements of the question thoroughly, a study had to be made of all the solutions presented. We shall now see what procedure was followed:

In August, 1909, a Congress of seringueiros (rubber gatherers), assembled in Acre with a view to studying and discussing the situation of the rubber trade. In a message addressed to the President of the Republic at the closing of the proceedings. the members of the Congress suggested, as chief measures, easy communications, roads, railway lines, subventioned lines of steamers, colonization promoted by the Government and a. reduction in the export duty.

Laiter on, in the same year, the Pará Government enacted Laws Nos. 1,100 and 1,109 of the 5th and 6th of November, both of which have great bearing on the solution of this most important problem.

The first of said laws gives authority, in article 1st, to the Sitate Government, to enter into agreements with one or more native or foreign companies, in regard to the plantation and exploitation of the seringueira (hevea brasiliensis) against the concession of the following favors:

a. The concession of vacant lands up to twenty thousand hectares with proper demarkations for the Company's plantings.

b. Reduction in the export duty of planted rubber to the extent of 50 per cent in the first 10 years as from the date of the first exportation; of 40 per cent in the second decade; of 30 per cent thenceforward until completion of twenty years.

c. Reduction of 30 per cent in the tariffs of the Bragança railway and in the freights of the line of steamers subventioned by the State, during a term of twenty years, for planted rubber produced by the Company. 
d. Transport free of charge by the Bragança railway and steamers under the States' subsidy of all machinery and plant belonging to the Company and intended for the installation of its establishments; and of whatever colonists the Company may place in its premises as well as of seeds, manure plants and cattle.

e. An advance, by way of guaranteed interest, of 5 per cent per annum on the capital issued by the company holding the concession to the extent of one-half of the paid up capital.

Special paragraph.-This guarantee, whatsoever be the Company's capital, shall not be paid on a sum exceeding $f 400,000$ Sterling over and above $£ 800,000$ Sterling, or its equivalent in paper money.

The advances, by way of guaranteed interest, thus conceded, will be discontinued once the Company's profits attain 6 per cent, and on exceeding 7 per cent the Company will start amortizing the sums loaned by the State to the extent of 5 per cent. on the total sum advanced.

The concession of lands available will be made by way of emphyteusis for 99 years.

The Statutes will have to be approved by the Government, who will name one of the Company's Directors and retain certain rights with a view to the due enforcement of the contract.

Article Second of the Law describes the Company's obligations, which are as follows:

First. To plant at least twenty thousand rubber trees per year.

Second. To carry out instructions from the Agriculture Department of the State in the planting.

Third. To maintain a rural elementary school, with accommodation for the shelter of at least twenty destitute children, and a field of practical tuition of mechanical agriculture, experimental cultivation of tropical plants, experiments in manure, etc.

Fourth. Accessory planting of rice, maize, haricot beans, etc., improving the quality of same by mechanical means.

Fifth. Furnish accurate yearly statistics of the number of plantations made, their state and the general production of rubber and other articles.

Sixth. Use on the bags, boxes and other receptacles containing the goods produced, a trade-mark duly registered at the Board of Trade as prescribed by law.

Seventh: Allow the Government to control all the work carried out by the Company in such manner as the Government may think fit.

Complimentary to the former, the Law of November 6 th concedes prizes and other favors to the agriculturists of the 
State, who, by themselves or associations formed by them, should fulfil the conditions set forth in same.

The prizes are of five hundred mil réis for each plot of five hundred rubber trees properly planted; the favors consist of the distribution free of charge of chemical manure, seeds, plants, instructions and agricultural monographs, gratuitous tuition to all the laborer-planters, transport free by the Bragança Railway and steamers subsidized by the State, reduction of export duties, etc.

Lastly, Law No, 1,115, of the 8th November, 1909, affords protection to the rubber trees that are actually yielding, with a view to improving their production.

Article First authorizes the Government of the State to further the defence of the rubber industry as regards the latex and preparation of rubber, in order to prevent the destruction of the trees existing in the State, punishment being dealt to whomsoever manufactures the product by subversive means.

Article second provides a prize of 50 contos of réis paper money at most, to be awarded at the Government's discretion, to the discoverer or inventor of some process of manufacturing or preparing rubber, which may afford undeniable advantages as regards its manufacture and reduces the inferior classes to a single standard of rubber "fina," ensuring a high price for the article.

The State of Amazonas also, as per Law No. 675 of May 20; 1911, authorizes the Executive Power to concede any advisable favors to individuals or undertakings that may bind themselves to put up in Manáos factories for refinement of rubber by means of new and improved methods; so as to obtain a standard class of rubber for exportation.

The Commercial, Industrial and Agricultural Congress held at Manáos in February', 1910, resolved in its final conclusions to recommend to the Brazilian Government and the immediate neighboring Républics, the reforming of their freights, especially as regards the food supplies; grant favors to navigation; free rivers from obstructions; construct railways; create colonial centres; admit of the pressing and absolute necessity to plant rubber trees in the Amazon valley and open new fields of plantation; suggests the establishment of permanent exhibitions of a highly. educational character; advises the rubber extractors not to give up the process of curing by smoke and condemns entirely the use of acids or alum in the coagulation, and calls attention to the question of the commercial classes of rubber which should be properly defined. Going into details it requests numerous favors for the agriculturists that may go in for planting hevéa rubber trees; cacao and cereals, cotton and other products, and 
that prizes be granted to cattle breeders, experimental fields be opened, as also laboratories of analysis and a service be established for dealing with the yellow fever and paludinous fevers, etc.

Such an important matter could not be solved by halfmeasures; it was necessary and even indispensable to adopt a plan embracing all the solutions suggested and proclaimed as being elements of success, thus obtaining a united plan entailing: some complexity in its execution, it is true, yet clear and simple in its combined purposes.

And this desideratum was achieved by the Feredal Law No. 2,543 A of the fifth of January, 1912.

\section{MEASURES ADOPTED „BY THE FEDERAL GOV- ERNMENT-RIO DE JANEIRO CONGRESS OF RUBBER-REGULATIONS OF THE NEW RUBBER DEFENSE ACT}

For a long time back the attention of the Brizilian Government has been drawn to the necessity of adopting a plan of defence for India rubber, which might solve in a practical and decisive manner the so-long-debated "problem of the North."

In August, 1911, the Minister of Agriculture, after a close study, made with the aid of specialists and persons having full knowledge of that region of the country, drew up a project in the above sense and, recognizing the necessity of still hearing those who are most directly interested in the matter, convened a meeting of representatives of the State Governments, Commercial Associations and other Institutions which might lead to a perfect understanding of what was most advisable to do.

The first meeting was held on August 14, and the Government's plan was hailed with great applause, the same being approved, with slight alterations, in the last session which took place on the twenty-second of the same month.

By Message of September 14, 1911, Marshal Hermes da Fonseca, President of the Republic, sent to the National Congress for approval, the plan duly elaborated; after being carefully studied by Congress it was approved and converted into Law, under No. 2,543 A and was sanctioned on January 5; 1912.

On A.pril 17, 1912, Decree No. 9,521 was enacted with the Regulation for carrying out the measures and services provided for in the law of January.

The measures and services prescribed by Law No. 2,543 A 
of January, 1912, for the economic defence of rubber, regulated by Decree No. 9,521 of April 17, 1912, are as follows:

I. To encourage the rubber extractor and the culivator of the principal rubber-producing trees.

II. To form industries for the refinement and manufacture of rubber articles.

III. To aid immigrants, both from the country and those who have recently arrived from abroad, and the workmen already established in the Amazon valley.

IV. To render transport easy and decrease the cost in the Amazon valley.

$V$. To install productive centres of food supplies in the Amazon valley.

VI. To hold three-yearly exhibitions in Rio de Janeiro, comprehending all that relates to the rubber industry of the country:

The measures contained in the law in regard to making agreements with the States which produce rubber "seringa," with a view to decreasing the export duties and protecting the rubber trade, will be dealt with separately, and with regard to the definition and legalization of freeholds in the Federal Territory in Acre and the revision and consolidation of regulations concerning the coasting service of steamers (included in No. IV) special By-Laws will be drawn up which shall be published in due cotirse.

The measures in reference to the first group and whose object is to encourage the extracting industry and plantation of the principal rubber producing trees are: First; reduction of the cost of tools and materials employed in the rubber trade; second, granting of prizes in money to the planters of the principal rubber trees; third, installation of experimental stations for the cultivation of rubber.

For the reduction in the cost of utensils and materials; free entrance is granted with exemption from any import duties, as well as to everything intended for the cultivation of the seringueira, caucho, maniçoba and mangabeira and the gathering-in and improving of rubber extracted from those trees; whether as regards the extracting industry or the plantation work.

These pecuniary premiums for encouraging the industry, will be conceded to all those who plant entirely anew, or who devote themselves to replanting; in the first case and for every group. of 12 hectares, the premiums will be Rs.2x:500\$000 when the planting is of "seringueira"; Rs. 1:500\$000" when it treats of "caucho" or "maniçoba"; and $900 \$ 000$ when it is thangabeira; in 
the second case and for every group of 25 hectares the premiums will be $2: 000 \$ 000,1: 000 \$ 000$ and 720\$000 respectively. The minimum number of trees for the new plantations will be 250 per hectare for the seringueira and caucho, and 400 for the maniçoba and mangabeira; in the case of re-planting, the distance to keep between the trees should be from 6 metres to $6 \mathrm{~m} 50$ for the first mentioned case and 5 metres for the second. In order to obtain the payment of the premium, it is requisite that the trees be well cared for, and that not more than 15 per cent. are damaged or useless.

The subsidiary cultivation of alimentitious plants or of those useful for industrial purposes, will secure an annual gratuity corresponding to 5 per cent. of the value of the principal premium.

For the cultivation of the seringueira, experimental stations will be localized in the Territory of the Acre, and in the States of Matto Grosso, Amazonas, Pará, Maranhão, Piauhy and Bahia and for the growing of the maniçoba conjointly with that of the mangabeira in the States of Piauhy, Ceará Pernambuco, Bahia, Minas Geraes, S. Paulo, Goyaz, Paraná and Matto Grosso.

Each station will have an area of from 80 to 100 hectares, the land selected having to be suited to the climatic and agrological conditions exacted by the nature or quality of the plant to be cultivated.

Besides the grounds for experimental cultivation, each station will possess laboratories of vegetable physiology for the testing of seeds and phytopathology, of agricultural entomology; of agricultural vegetable chemistry and bromotology and of micropiology and technology; an agricultural and woodlands museum; a gallery of machines and a meteorological post. Thus it will be properly equipped in order to serve those who may consult it upon any matter whatsoever, within the scope of its competency, carry out the analysis of manures and other chemical fertilizers, plants and waters, distribute plants and selected seeds, study the diseases common to growing plants and the means of combatting them, making commonly known by means of the publication of an official bulletin which will be distributed gratuitously to all interested parties, the results obtained relative to the most practical and economical means of carrying out the cultivation of rubber, the best means of bettering its condition, its preservation, the packing of the products, etc.

In order to stimulate the creation in Brazil of the industries for refining and manufacturing all kinds of articles made of rubber, monetary premiums will be instituted as well as exemp- 
tion from taxes, the right of disappropriation for private individuals, that may be necessary for the installation and mounting of factories and the preference of the Government will be granted for such articles, which each factory produces, when supplies are made to the army and to the navy, as well as to other public departments.

The premiums will be as high as 400:000\$000 for the first tactory tur the retning of seringa rubber that may be established in each of the cities of Belém and Manáos; up to 100:000\$000 for the first rubber-refining factory of "maniçoba" and of mangabeira, which may be installed in each one of the States of Piauhy, Ceará, Rio Grande do Norte, Pernambuco, Bahia, Minas Geraes and São Paulo; and finally of 500:000\$000 for the first factory of rubber-made articles, which is inaugurated in Manáos, Belém, Recife, Bahia and Rio de Janeiro.

The exemption from import duties embraces the rights of importation for the materials, machinery, utensils and the necessary tools for the construction and mounting of the factory and the chemical substances, textile articles and divers materials, combustibles and lubricants indispensable for the up-keep and working of the factory during the time-term of 25 years; and immunity from the State and Municipal taxes for the time term of the contract by reason of the factory being considered a Federal Service.

The premium in cash shall only be considered when the capital of the factory is equivalent to 4 times its value. The payment of such premium will be effected immediately after the inauguration of the factory.

The problem of assisting immigrants both national and foreign, who may have just arrived and the laborers established in the valley of the Amazon, is met by the installation of emigrant-hotels in Belém, in Manáos and in the Territory of the Acre, by the construction of hospitals in the Interior and by the creation of agricultural colonies adjacent to such hospitals.

The hotels for the reception of immigrants shall follow the rule and be guided in their installation by that of the Ilha das Flores in Rio de Janeiro, that latter being considered a Model Institution, at the same time the modifications exacted by the conditions of each particular case, that of Belém having sufficient capacity to accommodate 1.500 immigrants; that of Manáos 1,200 and that of Acre 800. Close to each of these immigrantquarters, a store-house will be erected which shall contain all kinds of special tools and utensils employed in the India rubber industry, the which will be sold to the immigrants, who desire to buy them at strictly cost price.

The families of both national and foreign immigrants who do 
not expressly declare that they prefer another destination will be sent to the National Fazendas (ranches) of the Rio Branco, where they will be located and distributed among the different colonial centres in the different colonies.

The hospitals in the Interior are created with a view of providing the inhabitants of the Amazon valley with a centre to which they may have recourse and where they may be treated, acquire medicine and protect themselves against contagious diseases. The points selected for these are Boa Vista of the Rio Branco, S. Gabriel on the Rio Negro, Teffé or Fonte Boa on the river Solimões, São Felippe on the river Juruá, Bocca do Acre on the Rio Purús, at the confluence of the river Arinos with the Juruéna, in the Alto Tapajóz, Conceição of the river Araguaya, and Montenegro on the Amapá.

Each hospital will have accommodation for 100 sick people and will be divided into 5 pavillions, one of these latter being constructed with all the requisites necessary for the isolation of infectious diseases; there will also be a disinfecting house, a laboratory for chemical and microbiologic diagnosis, rooms for surgical operations and for autopsies, consulting rooms and pharmacy.

There will also be a service of propaganda of the habits and hygienic measures necessary for the laborers who work and live in the Amazonian valley.

Adjoining each hospital, agricultural centres will be founded wherein to localize 100 families at the least, these agricultural centres will have for their object the production of the alimenticiary products necessary for the supply of the said hospitals, the cultivation and extensive breeding of the plants and animals consumed as food by the neighboring population located all around, and the constitution of fixed centres of population which shall help towards the increased peopling of the region. The Government will assist the emigrants in the acquiring of lands and shall furnish them with food stuffs at a low price and their maintenance during the initial period.

Amongst the improvements and means tending to facilitate transport and diminish it's cost in the valley of the Amazon, the construction of systems of railways and the betterment of the navigability of the rivers most peopled, is of great importance.

The network of iron roads will be of two different categories: systems of great lines forming an integral part of the general Federal system of railroads and a network of economic narrowgauged railways having the character simply of penetration lines.

Belonging to the first of these categories the following net- 
works will be commenced at once, and constructed within the shortest space of time possible: $1^{\circ}$ starting from Belém de Pará and joining onto the general railway system in Pirapóra, Minas Geraes and in Coroatá, in Maranhão, with the necessary branches to connect the initial or terminal point of navigation on the rivers Araguaya, Tocantins, Parnahyba and S. Francisco; $2^{\circ}$ starting point from the Madeira e Marmoré Railway in the proximity of the mouth of the Abuña, passing by the town of Rio Branco and by the most appropriate point between Senna Madueira and Catay and terminating in the town of Thaumaturgo, with branch line right up to the frontier of Peru, along the valley of the river Purús.

The construction and renting out of these railways will be done in competition by Public Tender.

The concession for the railways of the second category shall only be made to those who undertake to colonize and exploit in proportion as that may be justified, the respective marginal lands; i. e., the land lying along each side of such said lines. The Government will concede a subsidy of 25:000\$000 per kilometre constructed; the technical conditions are: a line of the Decauville portatil, the weight of the rails being $50 \mathrm{kilos}$ per metre, with a gauge of 0.60 between the rails and the minimum radius of the curve 40 meters inclination 0.10 and weight of the locomotives in full working order, 18 to 20 tons.

By way of experiment the Governments will bring about at once, the construction of 2 economic railway systems, $1^{\circ}$ starting from Antiga Sauzel on the left bank of the river Xingti and going up the valley as far as the river Careahy, with a branch leading to the river Tapajoz, whose valley it will follow until the river S. Manoel and with other sub-branches; $2^{\circ}$ starting from the confluent of the Rio Negro with the Rio Branco and following the valleys of Seruiny and the Caratimani passing over the watershed and going on until it terminates in the Alto Uraricoera, with 2 branches, the one for the Alto Paduary and the other for the town of Boa Vista.

The necessary improvements to be made towards effecting the navigability of the rivers at all seasons of the year, by steamers drawing up to 3 feet of water, of the Rio Negro, between S. Isabel and Cucuhy, on the Rio Branco from its mouth as far as S. Joaquim; of the river Purús between Hiutanahã and Senna Madureira, and of the river Acre from its mouth as far as Riosinho de Pedras, will be contracted for by public-tender or by some public company which can prove itself sufficiently capable for the carrying out of the same. The maximum timeterm for the termination of the improvements will be 7 years.

As supplementary measures, the exemption from taxes is 
conceded to the floating material of whatever kind destined to fluvial navigation in the valley of the Amazon and floating depots for the supply of coal and oil-fuel will be established at different points of the river Amazon, its affluents and subaffluents.

The establishment of these depots and the business of supplying the combustibles will be done by signed contract, with the Minister of Agriculture, after the competition by publictender, the concessioner enjoys besides other favors, exemption from import-duties for the floating material and for the combustible material imported as also full exemption from all State and Municipal taxes by reason of the object of his contract being considered a federal public service.

The creation of centres for producing food-stuffs in the valley of the Amazon being held as an element of the greatest urgency towards the successful issue of the plan elaborated, is assured by the following series of administrative measures: $1^{\circ}$, the renting out of the 2 national ranches on the Rio Branco, that of $\mathrm{S}$. Bento and that of S. Marcus, to a public Company or under-taking which agrees to open up, and practice cattle-breeding of different kinds on a large scale and the cultivation of cereals commonly used as aliments, the establishment of a curing establishment for preparing dry meat, known as xharque and a factory of alimenticiary conserved goods, a dairy establishment, a ricemill and 2 mandioca grinding-mills. The company in question will take charge of and localize the emigrants who desire to be placed upon the lands belonging to the said ranches in accordance with the Federal laws regulating such matters.

The favors of exemption from duties for the imported material necessary to the mounting of the fazenda or ranch and the installation of the mills and factories will be conceded, as also for the stud-cattle and seeds imported and for the chemical manures and all materials necessary for the factories and for the cultivation during the whole of the time of the contract. They shall also enjoy the right to disappropriate for public utility and shall have preference for the contract to carry out the necessary works and improvements in the navigation of the Rio Branco.

The colonization of the lands of the "fazenda" of São Marcus situated between the rivers Mahú, Takutú, Surumú and Cotingo on the frontier of British Guyana, will be made directly by the Ministry of Agriculture. $2^{\circ}$ Premiums and favors will be con- 
ceded. to whomsoever may found great ranches for cattle breeding and for great agricultural purposes in territory of the Acre (between Rio Branco and Xapury), in the State of Amazonas (in the region of the Autaz), in the State of Pará (in the Island of Marajó), or in other more convenient point of the lower Amazon.

These premiums are of 30:000\$000 per group of 1,000 hectares of artificial pastures, planted and fenced round, of 100:000\$000 per group of 1,000 hectares of lands effectively cultivated with rice, black haricot beans, Indian-corn and mandioca, and 100 :$000 \$ 000$ per group of 500 tons of manufactured goods, of dairy produce and of preserved meat and xarque, which may have been produced within a time-space of 5 years.

The favors are those of exemption from import duties for everything whatsoever that may be necessary to the proper installation and maintenance of the fazenda or ranch during 5 years. $3^{\circ}$ Concession of favors to a fishing company or undertaking, that shall be established either in Belém or in Manáos, for exercising that industry and all subsidiary industries connected therewith on a large scale on the rivers of Amazonia, The favors consist of the entry free from import duties for all the material belonging to the company as also for all the fittings of steamers and other floating material and factories that may be necessary during the first 15 years, encouragement premiums of $10: 000 \$ 000$ during 5 consecutive years in the event of the production of fish either preserved or salted being maintained at a figure above 100 tons; the right of disappropriation for public utility of the lands or buildings that may be necessary for the undertaking, the exemption from state and municipal taxes.

Recognizing the utility of periodical expositions which are held as centres of special studies, producing practical results by the sum of knowledge which may be derived from them, 3 yearly expositions shall be held in Rio de Janeiro, which shall embrace all and everything which has relation to the rubber-industry. 


\section{THE COMMENCEMENT OF THE WORK-THE EXPOSITION OF RUBBER IN RIO DE JANEIRO IN THE MONTH OF MAY, 1913}

The Superintendence Department of the Rubber-Defence, a provisional Department of the Ministry of Agriculture, Industry and Commerce on which is incumbent the direction and fiscalizing of all the services comprised under the Law No. 2543 of the fifth of January of 1912, has already initiated its works, undertaking the execution of the following measures.

1. Resolution to hold a National Rubber Exhibition in Rio de Janeiro, opening on the thirteenth of May of 1913.

2. Installation of experimental stations, 7 centres for the cultivation of the seringueira (Acre, Amazonas, Pará, Maranhão, Piauhy, Bahia and Matto Grosso), and 6 for the cultivation of maniçoba and mangabeira (Piauhy, Ceará, Pernambuco, Bahia, Minas Geraes and São Paulo).

3. Studies in the valley of the Amazon, in the basins of the rivers Negro, Solimões, Juruá, Purús, Tapajóz and Araguaya, and in the territory of Amapá for the establishment of interior hospitals surrounded by small agricultural colonies.

4. Preliminary services for the construction of 4 of these hospitals situated respectively in Teffé or Fonte Bôa on the river Solimôes in S. Felippe on the river Juruá, in Bocca do Acre and in Montenegro of the Amapá.

5. Drawing up of the plan and inventory of the cattle and buildings in the part to rent out of the National fazendas of the Rio Branco; idem of the part to be colonized by the Government and projects of the colonial centres model farm for cattle-breeding, horse and mule-raising, radiographic stations, etc.

6. Laying of a Decauville line of railway along the rapids of the Rio Branco, in order to secure prompt communication. with the national ranches, which are to be let out.

$\%$. Construction by contract or by administration of 3 . dwelling quarters for immigrants in the Acre, in Manáos and in Belém.

The rubber exposition which is to take place in Rio de Janeiro, 1 every 3 years, will have for its object to show the triennial balance of rubber in its various modalities, comparing it with the situation of the same industry in other countries.

The first exhibition will be inatgurated on the thirteenth of May of the coming year and will be divided into four sections; 
$1^{\circ}$ The cultivation; $2^{\circ}$ extraction $; 3^{\circ}$ improvement; $4^{\circ}$ manufacture of articles.

The sections will be divided into groups and classes comprising the native or cultivated plants, machinery, utensils, processes, commercial types, studies and statistics.

Encouragement premiums will be conferred for the best processes of cultivation, extraction and preparing and for the objects best manufactured, whether of raw material constituting. trade types for exportation or as manufactured articles.

The sale of machinery, utensils and rubber articles and products of all kinds will be provided for against payment of a small percentage, fixed by the organizing commission.

Foreign products may be admitted to the exhibition, but without having the right to a premium. They will enjoy' full custom-house freedom from import-duty, but should they be sold they shall pay the respective import-duty on the occasion of their being handed over to the buyers. The re-exportation of the products not sold will run for account of the exhibitar.

Lectures upon the rubber-industry will be given during the Exhibition-Congress.

The Commission which will carry out the Exposition of the thirteenth of May, is constituted by their. Excellencies Senhores Drs. Pedro de Toledo, Minister of Agriculture, Industry. and Commerce, Raymondo Pereira da Silva, Superintendent of the Rubber-Defence Department, Miguel Calmon du Pin e Almeida, Representative of the National Agricultural Society, Jorge Street, President of the Centro Industrial of Brazil, Julho. Furtado, Inspector of Forests, Gardens, Tree-planting, Hunting and Fishing of the Federal District. Representative of the Municipal Prefecture and Candido Mendes de Almeida, Director of the Commercial Museum of Rio de Janeiro, Secretary General.

The site chosen for the exposition is in the Quinta de Boa Vista, perhaps the most beautiful park of Rio de Janeiro.

The preparatory works, such as the ground-leveling, layingout of gardens, adoption of pavillions already existing, etc., is now already in full course of being carried out.

The opportuneness of this event, the interest evinced in it by the South and North and the United forces of the Institutions that form the organizing commission, will secure a very considerable number of exhibitors.

The month of May, one of the pleasantest months as regards temperature in Rio de Janeiro, is the season chosen by those who desire to visit the beautiful capital and thus the gathering of visitors to the exhibition will certainly be notable.

Thus appears certain the most brilliant success for the Rub-, ber Exhibition of Rio de Janeiro. 


\section{RUBBER EXPORTERS}

\section{ESTADO DO AMAZONAS-MANAOS}

\author{
A. Santos Cardoso \\ Ahlers \& Co. \\ Armazens Andresen \\ Albert H. Alden, Limited \\ Barbosa Tocantins \\ De Lagotellerie \& Co. \\ E. Kingdon \& Co. \\ Gruner \& Co. \\ Gordon \& Co.
}

J. G. Araujo

J. H. Barros

Leite \& Co.

Mesquita \& Co.

R. Suarez \& Co.

Semper \& Co.

Scholtz Hartze \& Co.

Theodor Livy \& Co.

\section{ESTADO DO PARA}

A. Meirelles \& Co.

A. de la Reviere \& Co.

Alves Braga \& Co.

Adelbert H. Alden, Ltd.

A. A. Antunes \& Co.

Barboza \& Tocantins

Braga Sobrinho \& Co.

Coutinho \& Co.

Candido José Rodrigues

De Lagotellerie \& Co.

E. Pinto Alves \& Co.

Gumer \& Co.

Gordon \& Co.

Guilherme Augusto de Mendonça

I. Serfaty \& Co.

Jeronymo C. Botelho

José Furtado de Mendonça

J. Marques Braga

Leite \& Co.

Mello \& Co.

Pereira Bessa \& Co.

Pires Teixeira \& Co.

Pinho \& Costa

Pereira Lemos \& Co.

Raymundo Vieira Lima

Rocha Silva \& Co.

R. Ahlers \& Co.

R. Suarez \& Co.

Santos Amaral \& Co.

Cunock Schrader \& Co.

D. Costa \& Co.

H. A. Astlett \& Co.

J. Marques

Neale \& Staats

Sluglehurst Brocklehurst \& Co.
Boulevard da Republica 34

Boulevard da Republica $3 z$

Rua da Industria 27 e 29

Rua 13 de Maio 21 e 23

Caixa do Correio 353

Rua Senador Manoel Barata Boulevard da Republica 24

Rua da Industria 43

Travessa Campos Salles

Boulevard da Republica 37

Rua 15 de Novembro 30

Travessa Marquez de Pombal 8

Rua 13 de Maio 46

Rua da Industria 59

Boulevard da Republica 36

Boulevard da Republica 25

Praça Visconde Rio Branco 20

Boulevard da Republica 7

Praça Visconde do Rio Branco

Rua da Industria 5 
ESTADO DA BAHIA-S. SALVADOR

Ulmann \& Co.

Rua das Princezas 12

F. Benn \& Co.

F. Steverson \& Co.

Hesse \& Co.

Hirsch, Hes \& Co. Caes do Ouro 27

L. Costa \& Co. Caixa do Correio 133

Ottens \& Co.

Rosbach Brazil Company Rua Corpo Santo

S. S. Schindler

\section{ESTADO DO MARANHAO-S. LUIZ}

Jorge \& Santos

Joaquim Julio Correia \& Co. Rua da Estrella 25

Francisco Freitas \& Co,

Oliveira Neves \& Co.

Currha Santos \& Co. $\quad$ Rua Portugal 28

ESTADO DE MATTO GROSSO-CUYABA

Almeida \& Co.

Alexandre Ador \& Co.

Figueiredo \& Oliveira

Lucas Borges \& Co.

Orlando Irmaos \& Co.

Ponce Azevedo \& Co.

CORUMBA.

Yosetti \& Co.

Pereira Sobrinho \& Co.

Wanderley Bais \& Co.

Pasques Fillio \& Co.

\section{S. LUIZ DE CACERES}

Benedicto R. Villas Boas

Jozo Campos Vidal

José Dulce \& Co.

Manoel Pedroso da Silva Bouden 


\section{MINISTERIUM OF AGRICULTURE, INDUSTRY AND COMMERCE}

\section{BRAZIL}

\section{FEDERAL LAW AND REGULATIONS}

COVERING THE PROTECTION AND DEVELOPMENT OF THE RUBBER I N D US TRY IN B R A Z I L

Decree No. 2,542A of January 5, 1912 and

Decree No. 9,521 of April 17, 1912 


\section{ats

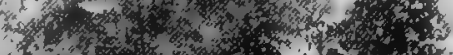 \\ $43^{3} x^{2} x^{2}, 5$

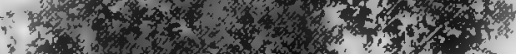

intis

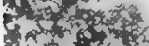
art

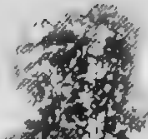

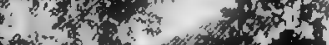

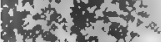

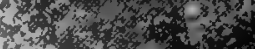
and

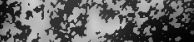

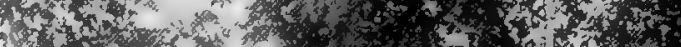
Then

s.t. A.

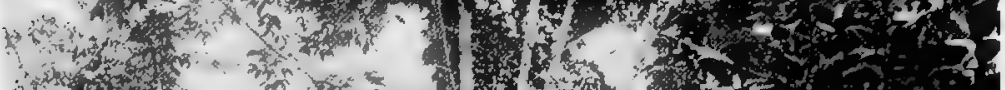

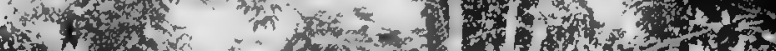

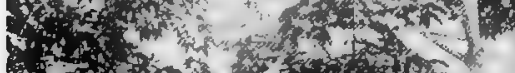

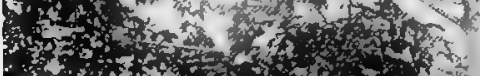

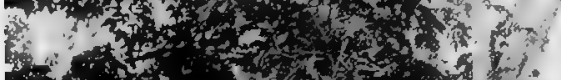

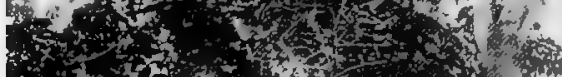

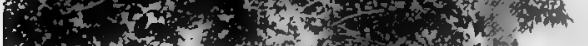
4 r.t. (5)

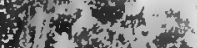

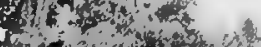

D.

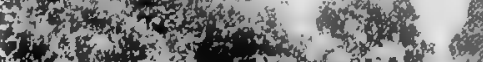

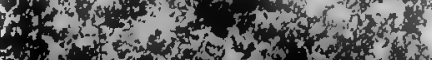

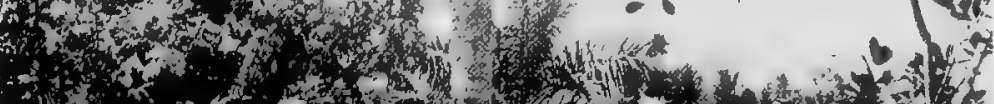

W t)

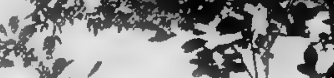

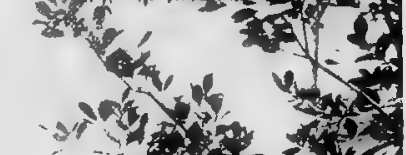

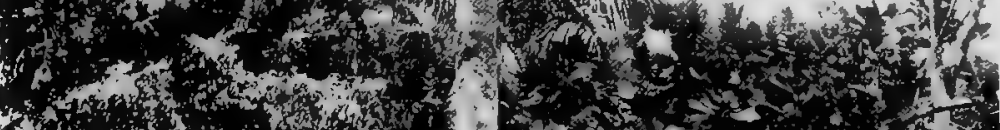

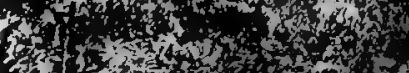

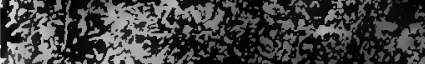

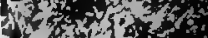

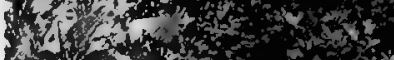

\section{montor}

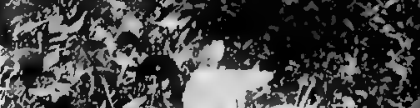

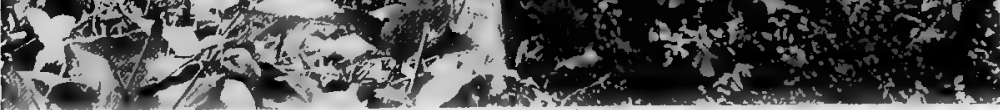

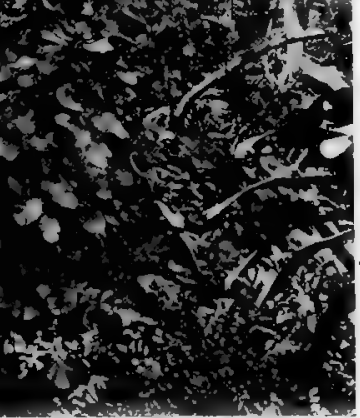




\section{ACT OF CONGRESS}

\section{Decree No. 2542A of January 5, 1912}

Establishing measures destined to facilitate and develop the culture of rubber, Caucho, Maniçoba and Mangabeira, and the gathering and treatment of the rubber extracted from these trees, and authorizing the executive power not only to open the credits necessary to carry out these measures, but also to contract such loans as may be necessary for that purpose.

The President of the Republic of the United States of Brazil:

Hereby makes known that the National Congress decreed and I hereby sanction the following resolution:

Art. 1.-All utensils and materials destined for the culture of rubber (seringueira), Caucho, Maniçoba and Mangebeira and for the collecting or treatment of rubber extracted from these trees, whether for the purpose of extracting or experimenting, shall be admitted free of all custom house duties, including fees.

Only Section.-This exemption will have to be requisitioned of the inspectors at custom houses, who will grant it without delay after verifying the right of those seeking this favor.

Art. 2.-Premiums will be granted to those who start regular and entirely new plantations of Seringueira, Caucho, Maniçoba or Mangabeira, or replant old forests of Seringueira, Caucho, Maniçoba or Mangabeira, as soon as the:plantation has taken place, and will be paid on the following conditions:

(a) For groups of 12 hertares (about 30 acres) of new culture, 2,500 milreis if seringueira; 1,500 milreis if caucho or maniçoba; 900 milreis if mangabeira.

(b) For groups of 25 hectares, the replanting of native seringueira, caucho, maniçoba or mangabeira, 2,000 milreis; for the first, 1,000 milreis; for the second and third; and 720 milreis for the fourth kind.

Section 1. These premiums will be payable one year before the first gathering, when it is shown that the ground is entirely cultivated and the trees well cared for.

Sec. 2. An increase of 5 per cent will be given annually in addition to the premiium offered planters of seringa rubber (to count from the beginning of the planting), who prove that they have cultivated between the rows in all the ground planted, plants of alimentation or of industrial use.

.... Art. 3. The Government will establish, at a selected convenient point, an: experimental station, or field for demonstrating 
the culture of seringueira in the Territory of Acre, in each of the States of Matto Grosso, Amazonas, Pará, Maranhão, Piauhy and Bahia, and for the culture of maniçoba jointly with mangabeira, in each of the States of Piauhy, Ceará, Rio Grande do Norte, or Pernambuco, Bahia, Minas Geraes, São Paulo, Goyaz, Paraná and Matto Grosso.

These stations will furnish gratuitously, selected seed to all those interested, also instructions as to the most practical and economic methods of culture and will supply information concerning general results, which will be verified at the end of each year.

Art. 4.-In addition to the indirect favors which are mentioned in Art. 1 and others which may seem reasonable and necessary, the Government will grant the right of premiums of encouragement, up to the sum of 400,000 milreis to the first plant established for refining the seringa rubber, that reduces the different qualities to a uniform type and superior to that exported and which may be established in each of the cities of Belem (Pará), and Manaos; up to 100,000 milreis to the first refining plant of maniçoba and mangabeira rubber, that accomplishes the same purpose and is established in each of the States of Piauhy; Ceará, Rio Grande do Norte, Pernambuco, Bahia, Minas Geraes and São Paulo; and up to 500,000 milreis to the first factory of rubber articles which shall be established in Manaos, Belem (pará), Recife (Pernambuco), Bahia and Rio de Janeiro,

Only Section.-In order to have the right to the benefit of the above article it is necessary for the factory to have actually employed a capital four times as great as the value of the premium.

Art. 5.-The Government will put up three buildings to house immigrants, to be of sufficient capacity and internally arranged, the same as those on Flores Island. In Belem, Manaos, at an appropriate place in the Territory of Acre; and also at places in the Valley of the Amazon, where they are considered to be the most necessary, hospitals are to be erected, surrounded by small agricultural colonies where the sick can be received for treatment, be vaccinated gratuitously, and where medicines of the first quality are kept-for sale, especially sulphate of quinine. Pamphlets containing suggestions about hygiene, prevention of the diseases of that region and the practical remedies to use in the absence of a physician, will be distributed freely.

The superintendence of these stations will be maintained by the Federal Government, but the hospitals will be entrusted to professionals of recognized ability, under a subvention or other favors, which the Government considers reasonable and rules will be enforced which will secure their proper regulation. 


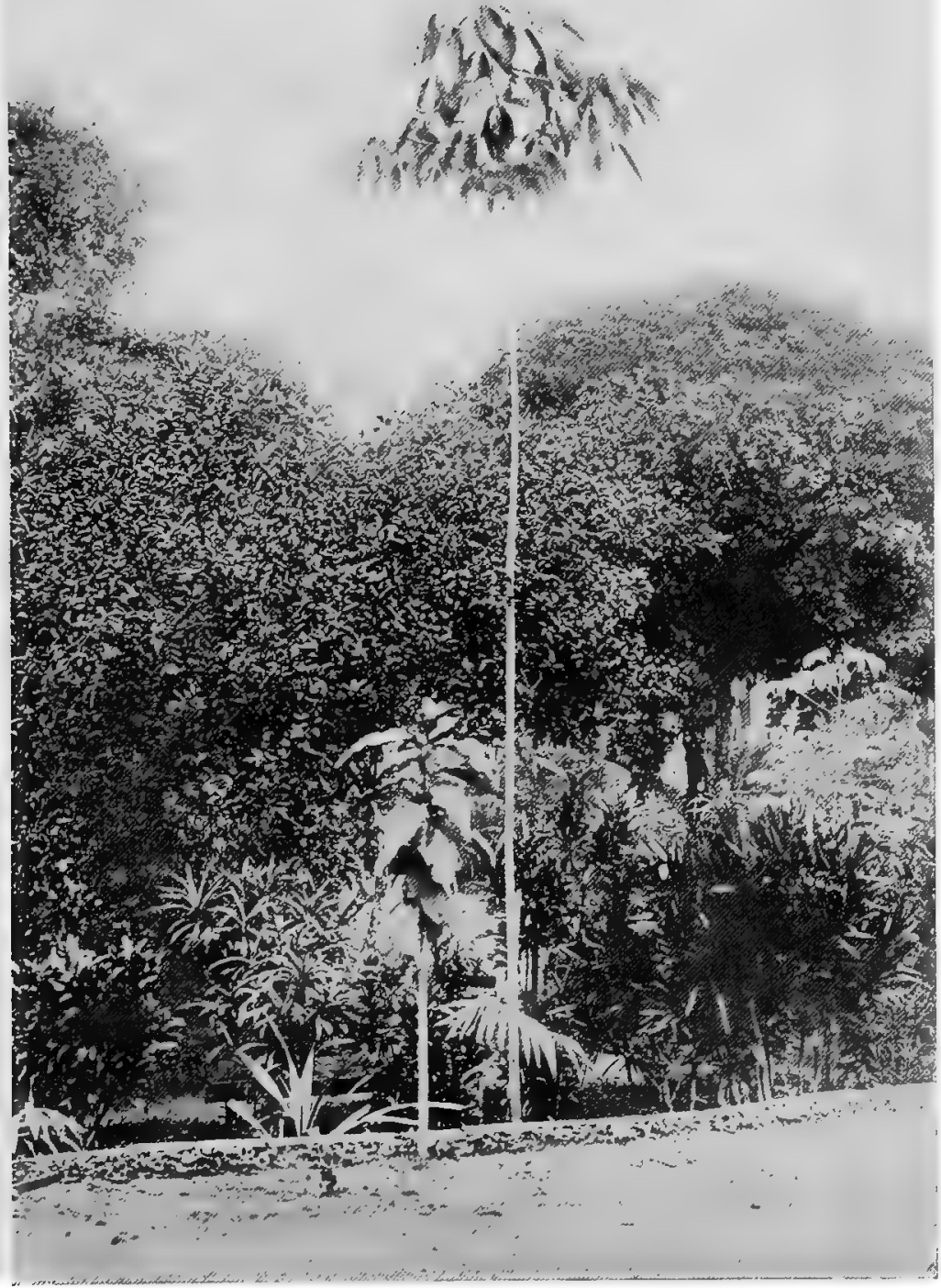

"SERINGUEIRA" HEVEA BRASILIENSIS. MULL, ARG. (11). 
Art. 6.-For the purpose of facilitating transportation and reducing its cost in the valley of the Amazon, the Government will cause to be made, as soon as possible, the following improvements :

1. The construction by the Government of narrow gauge railroads along the Rivers Xingu, Tapajós and others in Pará, Matto Grosso, and of the Rio Negro and Rio Branco and others in Amazonas, through the valleys through which they flow, in accordance with the authorization of Congress, Law No. 1,126, December 13, 1903, at the price fixed per kilometer, according to the difficulties of the region, at the discretion of the Government.

In case the State of Pará and Amazonas should contract for the construction of some of these railroads, the Federal Government for the more rapid completion of the work will concede an increase of 15 contos per kilometer.

2. The construction of a railroad, which, parting at a convenient point of the Madeira-Marmoré Railroad, near the mouth of the River Abuna, passes by the village Rio Branco, and at a point between Senna Madureira and Caty, and terminates in the village Thaumaturgo, with a branch to the frontier of Peru, by the valley of the Purús River.

The construction of this road shall be in accordance with the provisions of Law No. 1,126, of December 13, 1903. As soon as the first section of the trunk line is inaugurated to the village of Rio Branco, the Government will install a custom house at Porto Velho on the Madeira River and announce this port open to commerce with friendly nations.

3. Construction of a railroad starting at the port of Belem of Pará and joining the net work of railroads of Central Brazil at Pirapora, in the State of Minas Geraes, and of Northern Brazil at Coroatá, in the State of Maranhão, with the necessary branch lines to join the initial points or terminals of navigation on the Rivers Araguaya, Tocantins, Parnahyba and S. Francisco. The railroad shall be built according to the provisions of Law No. 1,126 , December 13, 1903, and shall be leased by public competition.

4. The execution of the works necessary for the effective navigation, at any season of the year, of steamers drawing three feet of water; on the Rio Negro, between Santa Isabel and Cucuhy; on the Rio Branco, from its mouth to Fort S. Joaquim; on the River Purús, from Hyutanahan to Senna Madureira; on the River Acre from its mouth to Riosinho das Pedras.

The Government may contract for the execution of these works by public competition, or independent of competition, with one or more individuals or firms offering sufficient guaranty, 
applying the provisions established by the decree, No. 6,368, February $14,190 \%$, or others, which will not impose greater burdens, and which may be more economic.

Art. \%.-For the same purpose as mentioned in the previous article, all vessels of any kind destined for river navigation, are declared exempt from all custom house duties, including fees, revision, rates.

Art. 8.- -The Government will grant the same exemption in addition to the indirect favors found convenient, to the contractor who will bind himself at a public competition, to establish coal depots at points in the valley of the Amazon previously indicated, and to supply steamers and launches with fuel at prices approved by the Government.

Art. 9.-The Government will promote and aid the production of food stuffs in the valley of the Amazon through the following measures, or others which may be found convenient and promise satisfactory results.

1. The leasing of two of the National Reservations on the Rio Branco, at a public auction or private competition to a reliable concern, which binds itself to develop on a large scale, the breeding of cattle of improved types, the production of cereals, and other foodstuffs, to establish packing houses, dairies, rice-shelling mills, flour and mandiok mills, etc.

2. Direct colonization, through the Federal Government, on lands still belonging to the Union, on the S. Marcos Reservation, situated between the Rivers Mahu, Tacutú, Surumú and Cotingo, with native families of farmers and stock-farmers, with a view of developing and increasing the production of foodstuffs, as well as horses and mules.

3. Concession to concerns which propose to establish large plantations or colonies under the above mentioned conditions, one in the Territory of Acre (between the Rio Branco and Xarpury), one in the State of Amazonas (in the region of the Autaz River), and one in the State of Pará (on the island of Marajó or other point more convenient on the lower Amazon), granting them the following favors:

(a) Exemption from all import duties, including fees, for all material imported, necessary for establishing the plantation, including buildings, corrals, pastures, fences, watering places, agricultural implements and machines for the cultivation, harvesting and treatment of cereals, the installation of factories treating dairy produce and packing houses, as well as cattle and seed which may be imported during the first five years after the plantation is started.

(b) Premiums of 30,000 milreis for lots of 1,000 hectares of cultivated pasture, planted and conveniently fenced, and of $100,-$ 
000 milreis for lots of 1,000 hectares of improved land for farming and actually planted with rice, beans, corn or mandioca.

(c) A premium of 100,000 milreis for lots of 500 tons of products made from milk, packed meats and dried beef, which were produced within five years.

4. Exemption from all import duties, including that of fees, for the vessels, instruments, machinery, drugs and ingredients necessary for the installation and working, for a period of 15 years, of a fishing enterprise, including the salting and preserving of fish, that may be established on the Amazon rivers, and the concession of a premium of 10:000\$ for five consecutive years, when the production of salted and preserved fish shall be above 100 tons annually.

Art. 10.- The Government shall proceed to the discrimination, and consequent acknowledgment of the owners of the lands in the Territory of Acre, for the confirmation of their respective property titles.

Section 1.- In the verification the following should be considered as much as possible:

(a) The titles granted by the Governors of the States of the Amazon, of Bolivia and the former independent State of Acre before the treaty of Petropolis.

(b) The mild and pacific possessions acquired by first occupation, or from the first occupant, which shall be found in active exploration, or with its beginnings and habitual residence of the possessor, or his representatives.

Sec. 2.- The maximum area of each lot shall be 10 kilometers square.

Sec. 3.-The Government will review the arrangements of Law, No. 601, September 18, 1850, and Decree No. 1,318, January 30,1854 , expediting a new regulation of lands, with the modifications of the present law and those which appear more convenient to the actual situation of the Federal territories.

Art. II.-Every three years, the Government shall promote the realization, in Rio de Janeiro, of an exposition embracing all that pertains to the national rubber industry, and on these occasions it will grant premiums of encouragement, totaling an amount equal to that which shall be authorized by law of the budget in force, for the best processes of culture and treatment, and to the producers of the best manufactured articles.

Art. 12.-The Executive Power is authorized to enter into an agreement with the States of Pará, Amazonas and Matto Grosso, for the purpose of obtaining an annual reduction of 10 per cent. until the maximum limit of 50 per cent. of the actual value of the export duties placed by the States upon the seringa rubber produced in their territories, and the exemption from any export duty, for the space of 25 years, to begin from the date of this law, 
upon rubber of the same quality and derivation which may be gathered from cultivated seringaes.

At the time the agreement is effected, the executive power shall issue a decree making such reduction which the States may make in the export duty collected on the rubber of the Federal Territory of Acre and conceding an equal exemption upon cultivated rubber.

Art. 13.- In addition the Government is authorized to enter into an agreement with the above mentioned States for the purpose of establishing, in relation to the rubber of the Territory of Acre, the measures of protection and defense, which they have adopted in relation to the production, or other measures which may be thought better, and having the power to issue the decrees necessary for this purpose.

Art. 14.-For the entire execution of this law and the realization of the measures decreed, the executive power, shall issue, as quickly as possible, the necessary regulations; it shall open each year the credits that may be necessary, rendering an account to the Legislative power the year following, of the amounts expended, of the work done, of the results obtained and making the operations of credit which such services and measures demand.

Art. 15.-All laws contrary to this are revoked.

Rio de Janeiro, January 5, 1912, 91st year of Independence and the 24th year of the Republic.

\section{HERMES R. da FONSECA, PEDRO de TOLEDO.}

\section{Order according to Federal Law, number 2,543A, Jan. 5, 1912 Decree number 9,521, April 17, 1912}

Art. 1. The measures and services created by law number $2,543 \mathrm{~A}$, Jan. 5 of the present year, for the economic defense of rubber, has in view:

1. The encouragement of the extractive and cultivating industry of the principal trees producing rubber.

2. The creation of the refining and manufacturing industry of rubber articles.

3. Assistance to immigrants, native and foreign, recently arrived, and to the laborers already established in the valley of the Amazon.

4. To facilitate transportation and decrease its cost in the valley of the Amazon.

5. To create central producers of alimentary foodstuffs in the valley of the Amazon.

6. To discriminate and legalize the possessors of lands in the Federal Territory of Acre.

7. To hold triennial expositions in Rio de Janeiro, embrac- 
ing everything that relates the national rubber industry.

8. To authorize agreements with the States producing seringa rubber, for decreasing the duties of exportation and for the protection and aid of the rubber commerce.

Sole Paragraph. It shall be the object of each of these measures and means referred to in number 8 and of the special rules, that they shall publish at opportune times, as well as those referred to in number 6 and that part of number 4 which speaks of the revision and consolidation of the regulations of the coastwise merchant marine.

\section{TITLE I}

The means of encouragement of the extractive and cultivating industry of the principal rubber producing trees

\section{CHAPTER I}

The reduction of the cost of implements and materials employed in the development of the rubber industry

Art. 2. The implements and regular materials in the list annexed to this regulation, are free of all import duties, including the fees when employed for the cultivation of seringueira, caucho, maniçoba and mangabeira and the improved collection of the extracted rubber, from these trees, whether it treats of the development purely extractive, or of the development of cultivation.

Sole Paragraph. Materials and machinery which shall be discovered or invented during the time this regulation is in force, which have special application to the rubber industry, shall enjoy the same exemption from import duties.

Art. 3. The exemption shall be quickly granted by the custom house inspectors, from whom the claimants should require it, uniting all, or only those necessary as the case may be, the following documents:

1. The last receipt of the duty of declarations of the Municipality or Mayor to whose jurisdiction it pertains, by which is proven that the claimant is developing on his own or rented property, the extractive or cultivating rubber industry, or that he is a merchant established with a house prepared for goods for rubber gatherers, when it treats of regular objects of the first group.

2. Attested by the Municipality or Mayor to whose jurisdiction he belongs, that the claimant possesses proper land and that he is about to effectively undertake the culture of some of the trees above mentioned and treatment of their rubber or an authentic copy of the concession for this purpose, which he may 
- is Mne

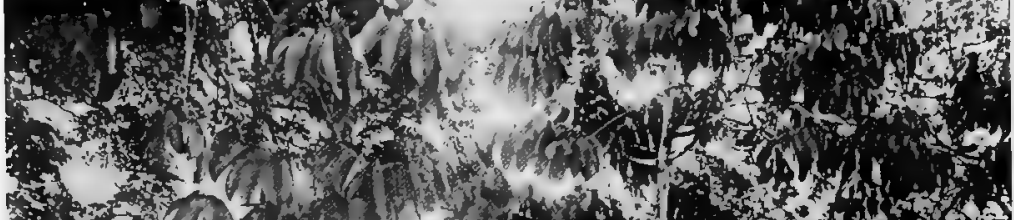

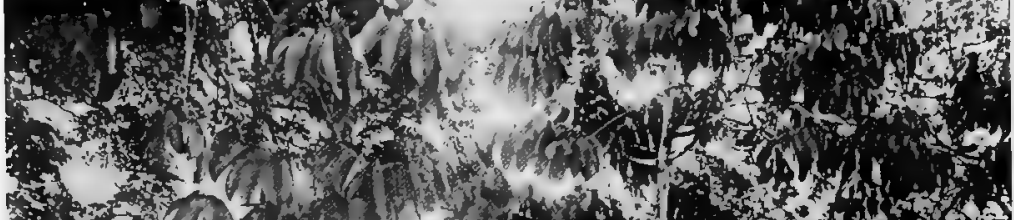

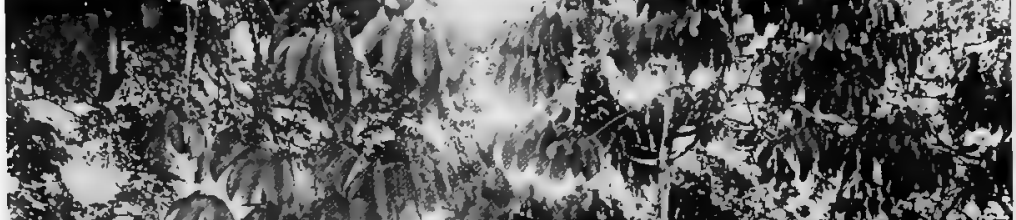
Sint into (3) n n r.

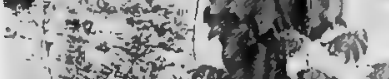
(t)

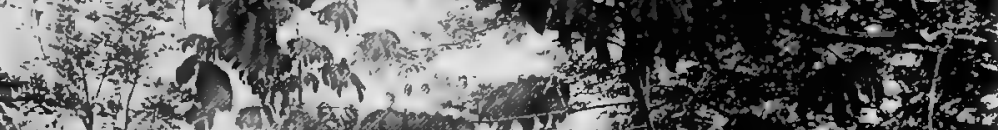
1. 2. 2.

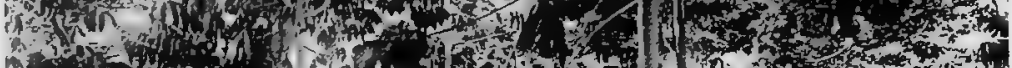

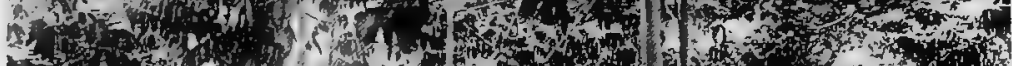

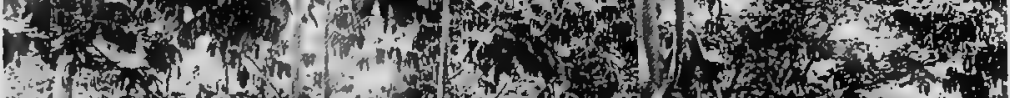
a.

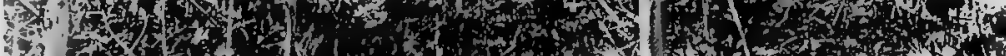

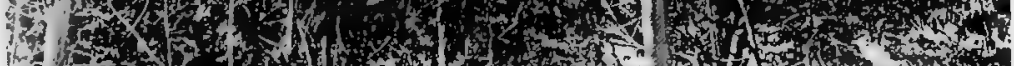

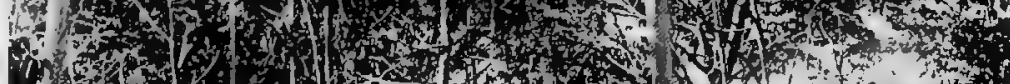
Th

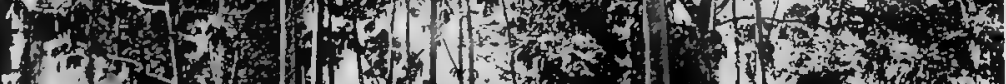

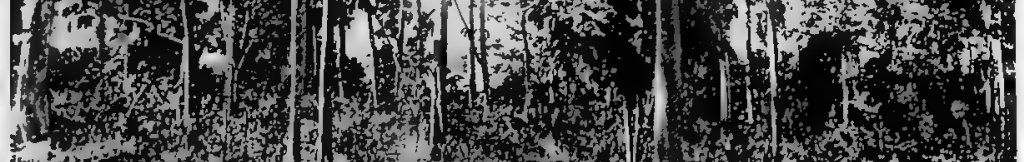
(2)

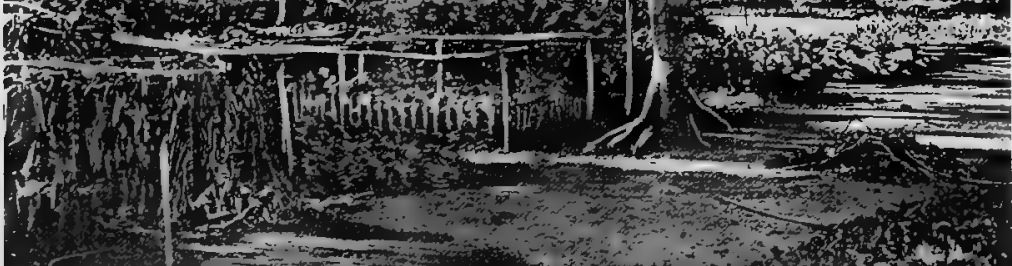

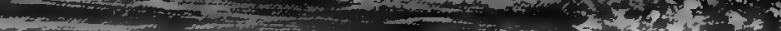


have obtained from the Minister of Agriculture, in case he treats of regular objects of the second, third or fourth group.

3. A detailed statement of the kind and quality of objects or material which it is necessary to import, or has been imported, which it is necessary to despatch.

Sole Paragraph. The importer shall become responsible, during 1 lis period, to the exchequer for any errors that may have ber" made.

Art. 4. The product, drug or object that may be similar to that produced in this country, will not be exempt from import dut $1:$ s, when the cost in this market in which he would have to buy it was equal to that of the imported merchandise, less the value of the import duty which he would have to pay in the custom houses.

\section{CHAPTER II}

The money premiums offered to those who cultivate the principal rubber producing trees

Art. 5. To every one who makes an entirely new culture of Seringueira, caucho, maniçoba or mangabeira, or replants seringaes, maniçobaes, couchaes or native mangabaes, shall be given, in the first case and for groups of 12 hectares, premiums of 2,500 milreis, when it is Seringueira; 1,500 milreis when caucho or maniçoba, and 900 milreis when mangabeira-and in the second case and for groups of 25 hectares, 2,000 milreis when it is seringueiras, 1,000 milreis when couchaes or maniçobas and 720 milreis when mangabaes, when the following conditions are observed:

1. Sending beforehand to the Minister of Agriculture a plan of the property in which he expects to make the culture, indicating the area, water courses navigable for steamers, launches or only canoes, and of the means of access from headquarters to the port (fluvial or maritime) or the nearest station on the railroad, mentioning these respective distances in case the property is situated in the interior. The plan shall be accompanied by a clescriptive memorandum, containing as much detailed description as possible as to the nature of the soil and its adaptation to what shall be principally cultivated, and to those which may advantageously be subsidiary; the production of rubber for the last three years in case it treats of the property in development, and about the conditions of healthfulness.

2. It shall declare whether it is new culture or replanting that is proposed to be done and in the second case the number of trees in development the property has already.

3. When the cultivation is of Seringueiras one must declare 
whether he expects to make parallel cultivations or not, specifying which and whether they occupy the land planted to rubber, or land separate.

4. To communicate to official charged with the fiscalization the beginning and ending of the planting, with the necessary antecedence, the year in which the first harvest will be.gathered, facilitating the examination of the property at any time, and as many times as desired.

Art. 6. The least number of trees per hectare for new culture shall be 250 for seringueira and caucho, and 400 for maniçoba and mangabeira. In the event of replanting, when possible, the distance between the trees should be 6 to 6.50 metres for seringueiras and caucho, and 5 metres for maniçoba and mangabeira.

Art. \%. To those who cultivate with seringueiras plants of alimentation or industrial utility, in all the land improved, or in other land equal to one-third of the dimensions of the first, there will be conferred annually, from the beginning of the cultivation to the year of the first rubber harvest, a supplementary premium corresponding in value to 5 per cent of the principal premium.

Art. 8. Premiums will not be paid for principal or subsidiary cultures which in the final inspections for the first and the annual inspections for the others, the trees show poor treatment or they contain an amount exceeding 15 per cent of flaws.

Art. 9. The premiums shall be paid directly by the Delegacia Fiscal of the State where the property is situated, in the preceding the first harvest of rubber, through the demand of the claimant, with certificate from the Government inspector, declaring that all the conditions required in this regulation were faithfully complied with.

Sole Paragraph. The inspector who makes out the certificate shall immediately notify the Minister and will be held responsible at all times for the value of the premium paid, in case his information should be found false in whole or in part.

Art. 10. At sight of the documents spoken of in Art. 5, and after examining them, the claimant shall be entered ex-efficio in the general register of farmers, existing in the General Directory of Agriculture with the advantages and guarantees it offers him.

\section{CHAPTER III}

\section{The Experimental Stations for the culture of rubber}

Art. 11. The experimental stations for the culture of serinqueira in the Territory of Acre and the States of Matto-Grosso, Amazonas, Pará, Maranhão, Piauhy and Bahia, and for the culture 
of maniçoba jointly with that of mangabeira, in the States of Piauhy, Ceara, Parnambıco, Bahia, Minas Geraes, S. Paulo, Goyaz, Paraná and Matto Grosso, have in view with the experimental study of all the factors relating to the regional culture of each of these trees, for the purpose of furnishing the cultivators with precise data for the adoption of methods and processes, which will make possible the economic and perfect production of their respective rubber.

Art. 12. The experimental stations shall be established on lands that possess the following requisites:

1. Climatic situation and agricultural conditions required by the nature or quality of the plant to be cultivated.

2. The physical constitution and natural chemical composition which will permit conjunctly and parallel the culture of the principal food stuffs or plants of industrial utility.

3. Localization at points easily accessible by good roads so that they can be visited and verified, as well in the fields as in the books of registry of the farmers and agricultural accounts of the practical results and economies of the different services and operations. The existence of permanent water courses, or dams with sufficient capacity to guarantee irrigation when necessary, and also other agricultural services.

Art. 13. The total area of each experimental station shall be from 80 to 100 hectares, so that there can be made at the same time in distinct partial areas the culture of the portions destined for experiments relative to each kind of tree and a demonstration of the normal systematic development of the respective culture, for comparison of the products and their revenue.

Art. 14. In the area reserved for demonstration, there shall be included those which will serve as examples, being the first cultivated between the processes that shall have proven the most advantageous and which are sought to be introduced, and lastly of those generally adopted in that region.

Art. 15. In each station there shall be reserved the land necessary for the establishment of a nursery of fruit trees and the production of selected seeds of alimentary plants or those of industrial utility, whose culture along with the principal plant shall be considered advantageous.

Art. 16. Every experimental station shall have the following installations:

1. A physiological vegetable laboratory, the proving of seeds and phytopathology.

2. Laboratory of agricultural entomology.

3. Laboratory of argicultural, vegetable and bromatological chemistry. 


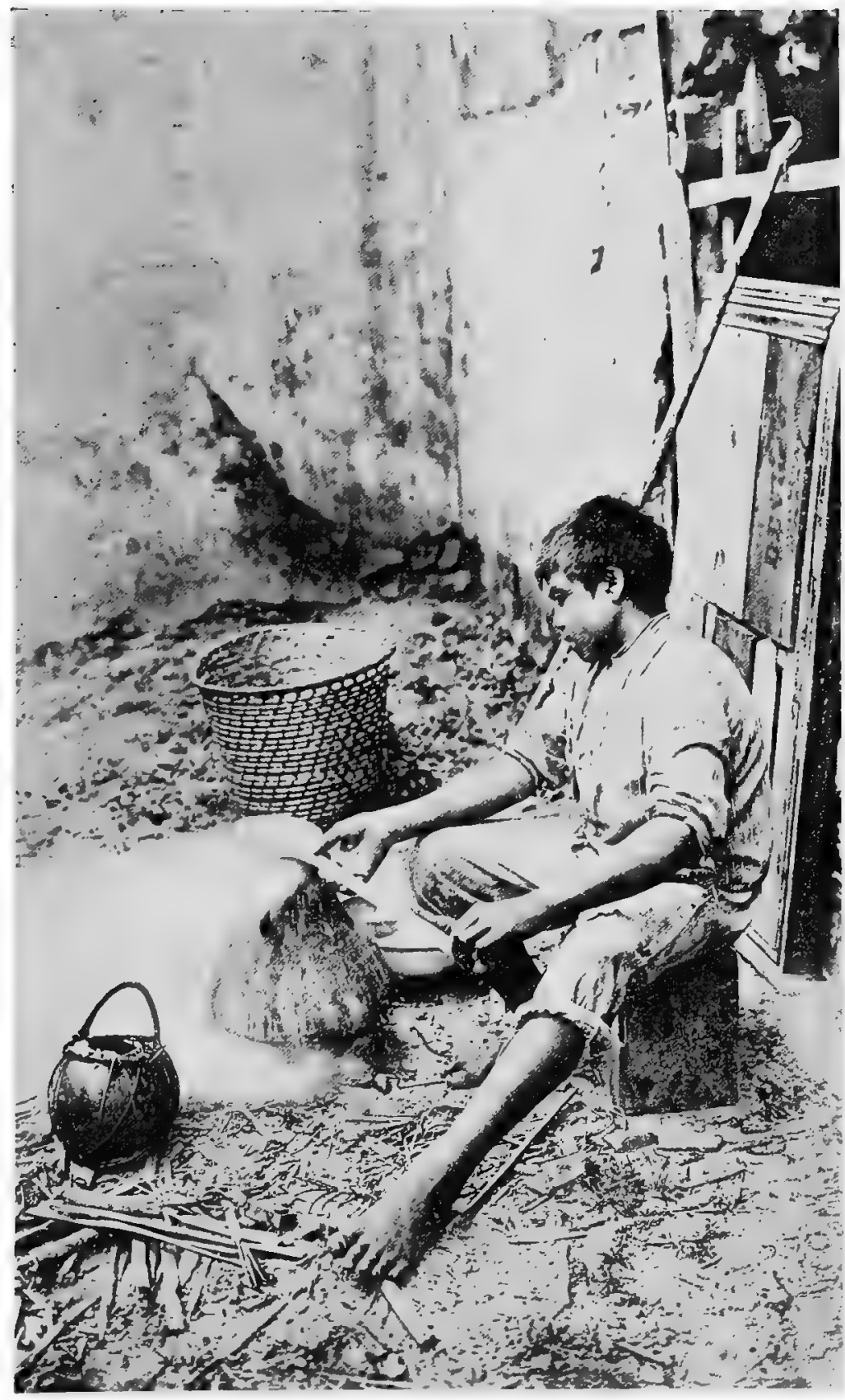

FUMIGATING CAOUTCHOUC. 
4. Laboratory of mircobiological and technical agriculture.

5. An agricultural and floral museum.

6. A corridor for machines.

\%. A meteorological station.

Sole Paragraph. A station that may be established in a region where there already exists a federal institution of similar kind, pertaining to agriculture in general, the installations above mentioned shall be reduced to numbers 5,6 , and $y$ and shall be provided with a small laboratory for the mechanical analysis of the soil, and utensils and instruments necessary for the proving of seeds of useful vegetables, so that a choice or selection may be made and their identity, purity, quality and germanating energy may be verified, including in these experiments those which refer to plants that are injurious.

Art. 17. To accomplish the ends proposed, the experimental stations ought to:

1. Attend the consultations that may be held upon any agricultural question in their line.

2. Execute gratuitously analysis of fertilizers, spices, plants and water, when required by the nearest federal institute, when it does not possess the neccssary laboratories.

3. Distribute selected plants and seeds.

4. Study the diseases common to the plants cultivated and the means of combating them, and explaining these things to those interested.

5. To publish yearly and distribute free of charge a bulletin devoted to the relation of the works done and the useful knowledge acquired relative to agricultural and rural industrial subjects, and especially the results obtained as to the most practical and economic method of cultivating the trees that produce rubber, and the most profitable subsidiary plants, as well as the best methods of the treatment, conservation and packing of the products.

Art. 18. There shall be admitted to the experimental stations, persons who wish to gain a practical knowledge in any of the sections, at the discretion of the Director, who shall fix the number of students in agreement with the chief of the respective section.

Sole Paragraph. On equal terms, apprentices between 15 and 18 years of age, shall be admitted, the numbers to be determined by the respective Director, with the approval of the Minister, who shall have daily tasks corresponding to their capacity and aptitude. The Director in the name of the Minister shall give a certificate, on which shall be indicated the work that has been done, to all those who have completed their apprenticeship. 
Art. 19. The plan of each station shall be organized to meet the peculiar necessities of the zone in which it may be established, conserving, however, the principal fundamentals already set forth.

Art. 20. The position of Director shall be held by a person who is a specialist in any one of the technical sections, and at the same time shall be its chief, an indispensable condition being that in addition to his technical knowledge he shall have had a practical apprenticeship.

Art. 21. The technical positions may be filled, by contract, by native or foreign professors of established ability.

Art. 22. To each of the stations there shall be sent a special regulation determining for them their proportions according to the necessities of the case, fixing the term and salaries of their respective personnel and providing for the special necessities to come.

\section{TITLE II}

\section{The creation of the Refining and Manufacturing Rubber Industries}

\section{ONLY CHAPTER}

Art. 23. The first factory for the refining of seringa rubber that shall be established in each of the cities of Belem (Pará) and Manaos, and of maniçoba and mangabeira rubber which shall be established in the States of Piauhy, Ceará, Rio Grande do Norte, Pernambuco, Bahia, Minas Geraes and S. Paulo, as well as the first factory of rubber articles which shall be established in Manaos, in Belem, in Recife (Pernambuco) in Bahia, and in Rio de Janeiro, there shall be conceded the following premiums and favors:

(a) Up to 400,000 milreis in money to the plants for the refining of seringa rubber;

Up to 100,000 milreis in money to the plants for the refining of maniçoba and mangabeira rubber;

Up to 500,000 milreis in money for plants for manufacturing rubber articles.

(b) Exemption from import duties, including fees in the manner and by the processes described in Articles 3 and 91 combined, as the case may require, for all material, machines, utensils and hardware necessary for the construction and complete equipment of the factory, as well as all chemical substances, cloth and different materials, combustibles and lubricants necessary for the working and maintenance of the factory, during a period of 25 years. 
(c) The right of appropriation for public use, according to the legislation in force, of the lands and improvements belonging to individuals that may be judged appropriate and necessary for the equipment of the factory and its dependencies.

(d) A preference given by the Government for the purchase of the products used in the service of the Army and Navy and the federal public departments, which shall be manufactured by the factories, when they can compete in quality with similar foreign articles-the contract for furnishing the same, adjudicated every 3 years with each factory, for those of their products which were classified in the first place in the expositions mentioned in Article 95.

(e) Exemption from all State and Municipal duties for the same time as in letter $\mathrm{b}$, because the factory is considered to be of service to the Government.

Art. 24. In order to claim these favors any company or organization that expects to erect one or more factories, should conform to the following formalities and conditions:

1. Present to the Minister of Agriculture a previous request accompained by the following documents:

(a) General and detailed plan of the factories;

(b). An estimate of the expenses for the first establishment;

(c) A descriptive memorandum in which the capacity of production of the factory is declared the principal articles intended to be manufactured, the lowest price for which it is proposed to wash and refine rubber, which should be reduced, for each quality, to one type and superior for exportation, in general giving the Government all the information that will help it to form a correct opinion as to the nature and importance of the projected establishment;

(d) Certificates and references which will prove the complete professional and financial ability of the suitor.

2. To obligate himself in the contract made with the Minister of Agriculture, the clause of reversion at the end of the combined term.

3. To allow the official appointed by the Government for the fiscalization, to visit the works during the period of construction, for the purpose of verifying the actual amount of expenses incurred for the first establishment and determining the value of the pecuniary premium, which shall be in any of the three cases, equal to a fourth part of the expense, not exceeding the limits fixed in letter a of Article 23, as well as to visit the establishment when he desires after it begins work, in order that he may be sure, that the materials imported free of duty are effectively and exclusively used in the products of the factory. 
4. To send annually to the Minister, through the said fiscal a prepared statement in which shall be specified:

(a) The amount and quality and the place where produced of the rubber used as raw material;

(b) The kind and quantity and value of the products of the factory used at home and exported;

(c) The number of employes, native and foreign, effectively in service during the year, with specification of their respective classes.

Art. 25. The premium in money shall be paid, as soon as the factory is inaugurated, at the National Treasury or at the Delegacia Fiscal of the State in which it is situated, when authorized by the Minister of Agriculture.

\section{TITLE III}

Assistance to immigrants, native or recently arrived foreigners and laborers already established in the valley of the Amazon.

\section{CHAPTER 1}

The Lodges for immigrants in Belem, Manaos and the Territory of Acre

Art. 26. The lodges for immigrants in Belem, Manaos and the Territory of Acre, shall be establishments installed and maintained at the expense of the Union, intended to entertain immigrants, native and foreign, who arrive at those ports voluntarily or with their passage paid by the Union or by the States.

Art. 2\%. The lodges at Belem shall have the capacity of caring for at least 1,500 , that at Manaos 1,200 and that at Acre 800 immigrants.

Art. 28. The plan of the respective buildings and the different installations of the lodges shall conform rigorously to the conditions required by the climate of that region and fitted for the special necessities of service for which they are intended.

Art. 29. The construction shall be made by a public bidding.

Sole Paragraph. If the first public bidding is not satisfactory, the Government can order the projected lodge ouilt by the Administration.

Art. 30. Annexed to each lodge there shall be an appropriate building, in which there shall be a special receiver of customs for the implements of workmen employed in agricultural and extractive industries, and indispensable for the carrying on 
of their work these implements to be sold strictly at cost price to those immigrants who desire to buy for their personal use.

To those native immigrants who during the times of drought in the States of the northwest and going from there, may arrive at the lodges without resources, shall be furnished free, by authority of the Minister, with the implements indispensable for work.

Art. 31. The families of native and foreign immigrants arriving at the lodges of Belem and Manaos, who do not expressly declare they prefer another destination, shall be transported at the expense of the Union or the lesee to the national plantations of Rio Branco, where according to their aptitude and ability, they shall be settled in colonies, founded by this one or that one.

Art. 32. At the inauguration of each lodge, there shall be applied, with the modifications required by the special conditions of each case, the regulations of the lodge on the island of Flores.

\section{CHAPTER II}

\section{Hospitals in the Interior}

Art. 33. For the purpose of reducing the distances and the time of the journey for the inhabitants of the interior in the valley of the Amazon, who must find a centre of supplies where they can be treated when sick, or provide excellent medicines for their domestic ills; of proportioning to all who may desire means of immuning themselves against contagious diseases, and of creating a propoganda service of the hygienic habits and practices necessary for everyone who must live and work in the Amazon regions, there shall be built a hospital surrounded by a small agricultural colony in Boa Vista do Rio Branco; S. Gabriel do Rio Negro; Teffé or Fonte Boa on the River Solimões; S. Fillippe, on the River Juruá; Bocca do Acre, on the River Purus; at the confluence of the Rivers Arinos and Juruena; on the Alto Tapajóz; Conceição on the River Araguaya and Montenegro on the Ampá.

Art. 34. The hospitals shall be built in places that have the following requisites:

1. To have a plain of low elevation, conveniently ventilated for the construction of the hospital buildings socalled and its dependencies, and houses of residence for the personnel.

2. Existence around or close to the plain of dry lands, provided with good and abundant water, which serve for agriculture and cattle raising and of sufficient area for the founding of an agricultural community of at least 100 families.

3. Facility for the establishment of rapid communication with a fluvial port, or one that must serve them. 
Art. 35. Each hospital shall have a capacity for 100 sick persons.

Art. 36 Each hospital shall possess the following installations :

(a) Five separate pavilions, each for 20 sick, each sick person having 5 cubic metres and an area of 12 square metres.

One of the pavilions should be installed with the necessary requisites for the isolation of infectious diseases; for this purpose it should be divided into rooms for isolation, independent and easily disinfected, with the proper sanitary apparatus.

All the hospital buildings should have the windows protected by wire screening whose openings should never exceed $11 / 2$ millimeter and the doors provided with:

(b) A disinfectory provided with an apparatus to disinfect in boiling lye and a stove for sterilization by the combined action of heat, vacuum and formal. Annexed to the disinfectory shall be the laundry.

(c) A laboratory for the diagnostic clinics and microbiology.

(d) Surgicial operating room.

(e) Clinic consulting room.

(f) Room for autopsies.

(g) Pharmacy.

(h) Sanitary installation, in which should terminate all the drainage pipes of the hospital, destined for the bacteriological treatment of the water used, which not until after this operation must be allowed to flow into the natural river courses.

(i) Dependencies for the administration and quarters of the personnel.

Art. 3\%. In each hospital there shall be made in the respective pharmaceutical laboratory a preliminary study of all the remedies used by the people of that region to determine which are prejudicial and which inoffensive. The respective Director shall show the people in printed circulars, frequently and profusely distributed that their use is improper. Those which are found efficacious and susceptible of improvement, shall be sent for more complete studies in the chemical laboratories and federal pharmacies, letting the people know the results obtained.

Art. 38. When the installation of each hospital is complete, a contract shall be made, by public bidding, or independent of it, as the Government may think best, with some professional of recognized ability, the direction and maintenance of the respective services, the contract including the following obligations:

1. The reservation of one hour daily in the medical consultation room, where the sick known to be without means may freely receive examination and be furnished with the necessary medicines. 
2. The maintenance of a bureau for vaccination against smallpox and other contageous diseases by means considered efficacious, and to attend gratuitously to all who may wish it.

3. To submit for the approval of the Government the regimen internal of the establishment and a table of prices for the treatment of the sick, which should be revised every 3 years.

4. To expose for sale in the pharmacy only medicines of the best quality, especially sulphate of quinine and such other preparations, under penalty of having destroyed all drugs known to be impure in addition to the fine to suit the case that may be fixed in the contract.

5. To give a bond in money, or policies of the public federal debt that will guarantee the good conservation of the establishment during the time of the contract.

6. To distribute abundantly every six months leaflets containing advice about hygiene prevention of the sicknesses of that region, showing in clear language, within the reach of all, those that are improper and the danger in the use of alcoholic drinks, and teaching what measures to take and the common remedies which should be applied in different cases when there is no physician to be had.

7. To be subject to the inspection of the Government which should be very minute and severe as to the condition of cleanliness and conservation of the establishment, the quality of the medicines employed and sold to the public and the care with which the sick are treated.

Art. 39. The hospitals and all their dependencies and sections are not subject to any duties to the state or municipality, being the property of the Union and doing a federal public service.

Art. 40. To each hospital there shall be given an annual pecuniary subvention, proportioned to the services to which it will have to attend, until the income of the establishment and all its dependencies derive a profit of 10 per cent, during 3 consecutive years on the respective capital invested, which amount shall be acknowledged and previously approved by the Government.

\section{CHAPTER III}

\section{The agricultural nucleuses adjacent to the hospitals}

Art. 41. The agricultural nucleuses adjacent to the interior hospital shall be founded by the Union for the following purposes:

1. The production of foodstuffs necessary for the support of the said hospitals. 
2. The intensive culture and breeding of the plants and animals of alimentation generally consumed by the neighboring population.

3. The constituting of fixed centres of population economically equipped, which will serve as a point of parting for colonies of greater importance, capable of gradually attending to the necessities that the growing population of that region may be creating.

Art. 42. The preliminary studies, the plan, the preparatory work and the different installations necessary for the founding of each nucleus as well as the colonization of the lots, and their administration in general, shall be done in accordance with dispositions of decree number 9,081, Nov. 3, and number 9,214, Dec. 15, 1911, observing the following alterations:

1. The selling price of rural and urban lots shall be calculated on the prices established in the land laws of the States of Pará and Amazonas, as a base, applicable to the nucleuses situated respectively in each state:

2. In failure of remunerating work, or when there is insufficient, the judge of the administration, to maintain numerous families, shall furnish them food, charging the same to the heads of the families, calculating this furnishing at the rate of from 2 milreis to 3 milreis daily at the highest, for adults and those over 7 years of age, and one half this for those between the age of 7 to 3 years.

Art. 43. The indians and native workers localized in the agricultural nucleuses shall participate in the advantages and obligations contained in decree number 9,214, Dec. 15, 1911.

Art. 44. Having finished the preparatory work for each nucleus, the lots first colonized shall be those devoted to the production of the foods necessary for the support of the hospital which is in their neighborhood, so that it can count on, from the time of its inauguration, a regular and sufficient supply of these commodities. 


\section{TITLE IV}

Improvements and measures tending to facilitate transportation and decrease its cost in the valley of the Amazon

\section{CHAPTER I}

\section{Lines of railroad transportation}

Art. 45. There shall be constructed in the valley of the Amazon lines of railroad transportation of two classes:

1. Large lines of transportation, making an integral part of the general line of Federal railroads, with identical characteristics and comprising the same principles.

2. Economic lines of transportation, of reduced gauge, provisionally established for easy ways of penetration, whatever may be their development, sufficient to facilitate access to and permit the exploration of the virgen seringas and the good lands for cultivation situated on the upper banks of the Rivers Xingu, Tapajóz, Branco, Negro, and others situated in the States of Pará, Matto-Grosso and Amazonas.

Art. 40. Those lines belonging to the first class shall be immediately begun and constructed as quickly as possible, the following:

1. Parting from the Port of Belem (Pará) and joining the general line of railroad in Pirapora, in the State of. Minas Geraes and in Coroatá, in the State of Maranbão, with the necessary branches to unite the initial points or terminals of navigation on the Rivers Arguaya, Tocantins, Parnaluyba, and S. Francisco.

2. Beginning at a convenient point chosen on the MadeiraMarmoré railroad, near the mouth of the River Abunã, passing by the Villa Rio Branco, and the point most appropriate between Senna Medureira and Catay and terminating in Villa Thaumaturgo, with a branch to the frontier of Peru by the valley of the River Purús.

Art. 4\%. The rules for the construction of these lines is prescribed by law, number 1,126, Dec. 15, 1903, and both shall be let at public bidding.

Art. 48. The Minister of Transportation is to command the studies to be made, to contract for the construction and inspect the traffic of these roads, but he will furnish the Minister of Agriculture a copy of the plans relative to the route and give descriptive memoranda of the project, and when drawing up the papers for the bidding, shall include the clauses which he shall judge necessary and opportune for the colonization of the bordering lands and the development of the industries of the zone 
tributary to the line as well as to attend to the eventual necessities of the commerce.

Art. 49. The construction and the concession for construction of the roads of the second class may be made by the Union or by the States interested.

Art. 50. The Minister of Agriculture is the proper person to construct or permit the construction of those Government resolves to carry into effect at the account of the Union, as well as to authorize the payment of the subvention of 15,000 mibreis per kilometer to those which were contracted for by the States.

Art. 51. The technical conditions of the railroads of which Art. 45. treats in the second part, are the following:

A portable line of the Decauville type.

Weight of the rails, 15 kilos per metre.

Gauge $0,60 \mathrm{~cm}$ between the rails, least radius of curvature 40 M. O.

Greatest incline OmO10.

Weight of locomotives 18 to 20 tons.

Art. 52. The concessions for these roads shall be let at a public bidding according to the rule established in law number 1,126 of 1903 , or independently of bidding with a person or corporation sufficiently able with the help of the payment of the maximum subvention of 25 contos per kilometer, according to the difficulties of the land it passes through, paid by sections of not less than 30 kilometers, completely ready and furnished with the necessary rolling stock, within 90 days of the date of the respective inaugurations.

Art. 53. The concession for these railroads cannot be given to those who agree to build then simply as transportation enterprises, but only to those who wili obligate themselves to colonize and explore, in proportion as they may be justified, the respective marginal lands.

It is an essential condition for the validity of the concession, that the contractor presents to the Minister of Agriculture within the maximum term of one year, proof that he has disposed of the lands for colonization, and a descriptive memorandum of the character and extent of the industries he intends to develop.

Art. 54. Those railroads of this type which in the future may be joined to any general line of transportation, shall be cbliged as soon as its gross earnings amount to 10,000 mibreis per kilometer, to make its gauge conform to the same, and from then for all purposes becoming a part of the general federal transportation system.

Independently of being joined to any railroad in general, these economical railroads shall pass to the jurisdiction of the 
Minister of Transportation and Public Works and shall be obliged to enlarge their gauge to 1 meter, without other favors from the Government, there not being a supplementary term of the contract, if it is wanting for its termination in less than 60 years, when the gross receipts have reached 15,000 mibreis per kilometer during 3 successive years. Before this the railroad may pass to the Minister of Tranportation and the gauge be widened, on his own account, when he shall think it to his interest, or by a new contract, when the Government thinks it necessary to have it done for the necessities of the administration or the defense of the country.

Art. 55. In addition to the subvention per kilometer, there shall be given to these railroads all the indirect favors received by the other railroads of the country.

Art. 56. The maximum term for a concession shall be 90 years, at the end of which the railroad will revert to the control of the Union.

Art. 5\%. Under the right of experiment, the Government shall promote at once the following lines of economical railroads:

1. Parting from "Autiga Souzel," or other point more convenient on the left bank of the Xingu and ascending the left side of the valley to the margin of the River Cariahy, with a branch which parting at a convenient point, shall go to the Tapajóz and ascend the right hand side of the valley until it reaches the $\mathrm{S}$. Manoel which may appear advantageous, ascending the secondary valley and continuing to the dividing of the waters of the two principal rivers.

2. Parting from the confluence of the River Negro with the Branco and by the valley of the River Seruiny, gaining the right side of the valley by the Caratimani river and continuing to the upper Uraricaera, with a branch parting at a convenient point at the request of the upper Paduiry and a branch in the direction of the Villa Boa Vista.

\section{CHAPTER II}

\section{Improvements for the navigation of the Rivers Branco, Negro, Purus and Acre}

Art. 58. The improvements necessary for effective navigation at any season of the year, for steamers drawing 3 feet, on the River Negro, between Santa Izabel and Cucuhy, on the River Branco, from its mouth to São Joaquin, on the River Purús, between Hyutanhã and Senna Madureira, and on the River Acre, from its mouth to Riosinho de Pedros, shall be contracted for by public bidding, or independently of bidding, with 
corporations sufficiently able, under the rule established by decree, number 6,368 , Feb. $14,190 \%$ or others which may not be more onerous and may permit the assurance of the opening of navigation more rapidly on the sections of the rivers to be improved.

Art. 59. In none of the contracts shall a longer term than 7 years be granted the contracting party, to count from the date of its signing, so that safe and free passage is given steamers drawing 3 feet in the entire distance of the contract.

Art. 60. The improvements in the Rio Branco, shall commence with the destruction and regulating of the Cujubim rapid, so that from now on navigation is assured during the Winter to Villa Boa Vista.

Art. 61. The studies, plans, constructions, inspection and direct conservation of these works are under the supervision of the Minister of Transportation; but before the respective contract is signed, copies of the plans and descriptive memorandum referring to the project shall be furnished the Minister of Agriculture, so that he may be heard upon the opportunity and the order in which these works shall be executed, in the interest of the economic development of the region, and that they may be conveniently attended by those casually interested in the colonization and development of the industries along the banks of the rivers, or in commerce in general.

In case it is found that the destruction and regulation of the Culubim rapid cannot be done during one season of low water in the river, the Minister of Agriculture, by agreement with the State of Amazonas, can order to be constructed a Decauville line of the type described in articles 45 , second part and 51 , in the belt line constructed by that State along waterfalls, so that the leasing and colonization of the national plantations of Rio Branco is no longer delayed.

\section{CHAPTER III}

\section{Complementary measures}

Art. 62. All vessels of every kind intended for the fluvial navigation in the valley of the Amazon are free of all import duties, including the fees. This exemption shall be given by the custom houses of Belem (Pará) and Manaos; through a requisition to the Minister of Agriculture, which the importer shall have asked for, declaring in his request the number, class and tonnage, the draft and the cost and the purpose of each vessel.

Art. 63. The vessel imported under this favor, if sold outside the valley of the Amazon, or even within it, to a foreign 
country, shall pay the proper duties according to the law of the budget in force in the year of its importation.

Art. 64. Deposits of coal shall be established for supplying the steamers which navigate the Amazon rivers, and for others who care to use them, in the following places, or in others which be shown to be more convenient: Belem (Pará), Cameta, Breves, Chaves, Mazagão, Gurupá, Souzel, Prainha, Sautarem, Ponta Nova Brasileira, Obidos, Parintius, Itacoatiara, Manáos, Carvoeiro, Moreira, Santa Izabel do Rio Negro, Carmo do Rio Branco, Caracarahy, Boca do Canumã, Baetas, Boca do Rio Machado, Boca do Purús, Campina, Nova Olinda, Canutama, Cachoeira de Hyutanahan, Boca do Pauhiny, Boca do Acre, Rio Branco, Seuna Madureira, Coary, Teffé, Boca do Juruá, Juruapeca, Mearary, Boca do Tarauacá, Cruz iro do Sul, Boca do Jutahy, S. Paulo de Olivença, Benjamin Constant and Santo Antonio de Maripi.

Art. 65. There shall be floating deposits, so that they can be moved from one place to another, as the growth of navigation in this or that place may require; they shall have sufficient capacity for the movement of steamers at the station they are serving and passes modern apparatus for discharging the coal, which will reduce to a minimum the raising of dust, and load the steamers as quickly as possible.

Art. 66. At points where it may be thought necessary, the deposits shall be provided with tanks for fuel oil, which can be placed on the platform with coal, or on separate floating platforms.

Art. $6 \%$ The establishment of the deposits and the business of furnishing fuel to the steamers, shall be by contract after a public bidding and signed by the Minister of Agriculture.

Art. 68. The floating material for the depositories and the fuel imported shall be free of all import duties, including the fees.

The fees in the custom houses shall be ordered through a requisition from the Minister of Agriculture, from whom the contracting party shall ask it, for each shipment, with the necessary data.

Art. 69 . The fuel imported by the corporation can only be sold for river navigation service.

Art. \%0. The maximum prices at which the party can sell fuel to steamers, shall be according to tables approved annually by the Minister. These may be altered during the year, when so necessary in the opinion of the Government.

Art. \%1. The contracting party shall not be subject to payment of any state or municipal duties, because the object is the public federal service. 
Art. 72. In places where the party has and the Government has not deposits of fuel, to him shall be given the preference for furnishing the quantity necessary for the national vessels of war, at the prices received when supplying the vessels of individuals.

Art. 73. In extraordinary circumstances and at the requisition of the Government, the contracting party shall place at its disposition all the deposits of fuel on hand, being afterwards indemnified for a part or all of the fuel delivered, and afterwards another payment of the value of the deposits unused, corresponding to the profits lost during the time of the interruption of his business, calculated on an equal period of the preceding year.

Art. 74. The bidding for the contract shall be upon the terms for the installation of the depositories, their reversion to the Union and the selling price of fuel for the first year.

\section{TITLE V}

The creation of centres producing foodstuffs in the valley of the Amazon

\section{CHAPTER I}

\section{The leasing of the national plantations of Rio Branco}

Art. 75. The Minister of Agriculture can contract for the leasing of the two national plantations S. Bento and S. Marcos, except the part situated between the Rivers Mahú, Takutú, Surumú and Cotingo, by public bidding, or independent of it, with a corporation or party sufficiently able, observing the following dispositions which shall be explained and assured in the clauses of the detailed contracts.

1. The party will be obliged to:

(a) Develop and practice on a large scale, by the best and most modern methods the breeding of cattle of different kinds and the cultivation of the usual alimentary cereals;

(b) Establish a packing house for the preparation of dried beef and a factory for the canning of alimental animal and vegetable products.

(c) Equip a factory for milk products, in which in addition to making cheese and butter, milk shall be prepared by the Pasteur system or some other that may be better, in condition to be supplied to the seringaes and estates of the interior.

(d) Equip a central mill for the treatment of rice and other cereals and two improved factories for mandioca flour, as soon as the number of colonies localized can produce a sufficient supply of raw material for such establishment. 
(e) Receive and localize the immigtants who may desire to settle on the lands of the plantation, in accordance with the dispositions of this regulation and with the decrees number 9,081 , Nov. 3, 1911, referring to the peopling of the soil, and number 9,214 , Dec. 15, 1911, referring to the protection of the Indians and localization of native laborers, in the parts that may be proper.

(f) Present to the Minister for approval the plans and descriptive memorandum, with as much detail as possible, of the agricultural nucleus which he shall be obliged to establish and all the installations referring to the factories and services necessary for the complete equipment of the plantations, within the maximum space of 2 years, to count from the signing of the contract.

(g) Be subject to inspection by the Government for the faithful execution of the contract, on the terms therein established.

Art. 76. To the party or corporation the following favors will be granted:

(a) Exemption from all import duties, including fees, in the form and by the process referred to in article 91 , for all the imported material necessary to complete the equipment of the plantations, including houses, barns, pastures, fences, reservoirs, implements and machines for the culture, harvesting and treating the cereals, installation of mills and factories, improved cattle, seeds of alimentary and industrial plants, as well as for the materials and chemicals necessary to maintain the factories and husbandry, during the time of his contract.

(b) Right of condemnation for public use, of the property or improvements of individuals, which may be necessary, in the opinion of the Government for any of the services of the enterprise.

(c) All the favors specified in articles 131 and 132 of decree number 9,081, Nov. 3, 1911, native and foreign colonies being made equal.

(d) Preference for the contract of the works necessary for the improvement of the navigation of the Rio Branco, if the price is considered acceptable by the Government and the time for the completion of the work not more than 6 years.

Art. $7 \%$. The term of the lease in the contract shall be 60 years, at the end of which all the cattle for breeding and all the improvements then possessed by the lessee shall revert to the dominion of the Union.

Art. 78. Within the term of 1 year, to date from the signing of the contract, the Government will give to lessee a copy of the plans of the plantations, in which shall be marked the water 
courses with a specification of those navigable, the zone of forest and plain and the situations of the occupants who may be found.

Art. 79. The plantations shall be turned over as soon as an inventory of the improvements, and the number of cattle of each kind then on the plantation can be made.

\section{CHAPTER II}

The colonization of the plantation of S. Marcos situated between the Rivers Mahu, Takutu, Surumu and Cotingo

Art. 80. The colonization of the lands of S. Marcos' plantation, situated between the Rivers Mahú, Takutú Surumú and Cotingo, on the frontier of British Guiana shall be done directly by the Minister of Agriculture, who shall order, without delay, to prepare a plan with the necessary details, and afterwards carry them out as they may be necessary:
(a) A town of the aborigines;
(b) An agricultural centre;
(c) A colonial nucleus;
(d) An ambulant course of agriculture;
(e) An agricultural apprenticeship;
(f) A school of practical agriculture;
(g) An experimental station.

Art. 81. The colonization of the lands whether in the agricultural centre, or colonial nucleus, shall be made so that each lot occupied by a foreign colonist corresponds to at least two occupied by families of native colonists, which preferably shall be chosen from those who arrive at the lodges of Belem and Manaos, proceeding from the states of the northwest.

Art. 82. Gradually and opportunely there shall be installed in the colony lands, mills and factories, having in view the improvement and production on a large scale of cereals and other alimentary foods.

Art. 83. In an appropriate locality there shall be established a model plantation for the breeding of cattle, horses and mules, in which there shall be made a comparative study of the native and foreign breeds, which best resist the climate of that region, to verify which may be most advantageously improved by the method of selection, crossing and formation of perfect types.

\section{CHAPTER III}

The premiums and favors to those who intend to found large plantations of agriculture and cattle raising

Art. 84. To large plantations of agriculture and cattle raising that may be founded, one in the Territory of Acre (between 
the Rio Branco and Xapury) one in the State of Amazonas (in the region of the River Autaz), and one in the State of Pará (on the island of Marajó, or other point more convenient on the lower Amazon), the federal Government will grant the following favors:

(a) Exemption from import duties, including the fees, in the form and by the process described, in article 91, for all the imported material necessary to complete the equipment of the plantation, including houses, barns, pastures, fences, reservoirs, implements and machines, for the culture, harvesting and treament of cereals, and installation of factories for milk products, the preservation of meat, as well as for cattle and seed which are imported, within the first 5 years after the installation of the plantation;

(b) Premiums of 30,000 mibreis for groups of a thousand hectores of pastures artificially planted and conveniently fenced and of 100,000 hectores and of 100,000 mibreis for groups of a thousand hectores of land improved for agriculture, and actually cultivated with rice, beans, corn and mandicaco;

(c) Premium of 100,000 milreis paid for groups of 500 tons of foodstuffs manufactured from milk, and canned or packed meat, which may be produced in 5 years.

Art. 85. The claimant of a right to these premiums must make a previous contract with the Minister of Agriculture, in which he obligates himself to:

1. Present within one year a plan of the plantation, in which should be mentioned the river port that would serve him, the courses of the rivers which wash it, with a specification of these navigable for steamers, launches or only for canoes, the zones of forest and plain, accompained by the plan of installation to be made, a descriptive memorandum of the services, and industries that he intends to develop and a detailed relatorio, indicating the quality, the quantity and cost of the materials necessary to import for the first year's work.

2. Allow the plantation and all its dependencies to be visited by the official charged with the inspection, when he is performing his duties, to verify the proper use of the objects and materials imported exempt from duties, the area, the state and kind of culture and the quantity, class and quality of the goods manufactured and destined for foodstuffs.

Art. 86. The premiums shall be paid at the National Treasury or at the Delegacias Fiscaes in Belem and Manaos, by a requisition from the Minister of Agriculture, which the claimant must ask, attaching to his request the certificate of the Government inspector that all the dispositions of this regulation have been faithfully fulfilled, and a statistical table of the work- 
ers employed during the year in each industry and the amount of the annual crop, with the specification of the quantity of each kind.

Art. $8 \%$ The contractor can colonize the lands of the plantation under the order established in Chapter XII of the regulation under the decree, number 9,081, Nov. 3, 1911; the national colonists coming from the states of the northwest are made equal to foreign colonists, for the purpose of the premiums of which articles 132 and 133 treat in the above mentioned regulation.

\section{CHAPTER IV}

\section{Favors to a fishing corporation}

Art. 88. The Minister of Agriculture shall contract with some person, syndicate or company, offering guarantees of sufficient ability, for the establishment of a fishing enterprise, which with headquarters in Belem (Pará) or Manaos, that can be conveniently equipped as quickly as possible, to begin this and its allied industries, on a large scale in the Amazon rivers.

Art. 89. The following favors shall be given the enterprise:

(a) Exemption from all import duties, including fees, for the vessels, instruments and other maritime material; for all the material necessary for the installation, complete equipping and establishment of the enterprise on conditions which would enable it to be a going industry in all its phases, as well as the drugs, ingredients, cans and boxes, or materials to make them, and in general for all that it may be necessary to import from abroad, indispensable to the maintenance of its vessels and factories, during a term of 15 years, to count from the date of its operations;

(b) Premium of animation 111 money to the amount of 10,000 mibreis during 5 consecutive years, when the production of preserved and salted fish shall be annually more than 100 tons;

(c) The right of condemnation for public use, of the lands and improvements belonging to individuals, judged appropriate and indispensable for the installation of any of the establishments that it is necessary to build on land;

(d) Exemption from all state and municipal imports because the object of the contract is for the federal public service.

Art. 90. All the property of the enterprise shall revert to the Union, at the end of the term for which the contract was granted.

Art. 91. The exemptions from duties shall be given by the custom houses in Belem and Manaos, by a requisition from the Minister of Agriculture, from whom it shall be requested, attach- 
ing to the request a memorandum of the objects with specifica tion of the qualities, quantities and ends for which they are needed, and what are imported for the services of the first establishment, and after this what must be imported for its maintenance.

Art. 92. The enterprise shall be subject to inspection by the Government as to the safety of the steamers, and processes employed in fishing, the faithful use of the objects imported, the manufacture of preserving, in which substances hurtful to the public health shall not be employed, nor in the annual production of preserved or salted fish for the purpose of obtaining the premiums in money.

Art. 93. Specimens of fish not well known, the party shall send one properly preserved to the Minister of Agriculture, accompanied by a small relatorio describing the place and conditions under which it was caught and noting anything particular that might be interesting in studying it.

Art. 94: Every commander or master of the vessels of the enterprise, shall make a written communication to the directors for them to bring to the knowledge of the Government, the places where there is the existence of any obstacle to navigation, indicating the position in a good sketch of that stretch of the river, describing its nature and the route to be followed to avoid it. These communications shall be transmitted to the Minister of Transportation in order that he may place a signal on the obstacle, and as soon as possible remove it.

\section{TITLE VI}

The Triennial Expositions Embracing All That Relates to the National Rubber Industry

Art. 95. The Rubber Expositions shall be held in Rio de Janeiro every three years, the first being on May 13, 1913; its object shall be to give the sum of the triennial movement of the national rubber industry in its various modifications, compared with the industry in other countries.

Art. 96. The triennial expositions shall include the rubber industry in all its branches and shall include the following classifications:

1. The Culture.

2. The Extraction.

3. The Improvement.

4. The Manufacture of Articles.

The classes shall be subdivided into groups including native 
and cultivated plants, machinery, utensils, processes, commercial type, studies and statistics.

Art. 9\%. Premiums of encouragement shall be given for the best processes of culture, extraction and treatment, and to the best manufactured products, whether as raw material, constituting commercial types for exportation, or as to manufacture.

Art. 98. The Government shall opportunely request the $\mathrm{Na}$ tional Congress for the necessary enactments to make these premiums effective.

Art. 99. The rubber expositions shall be true expositions held in relation to the machinery and utensils and products of rubber of all kinds, but the sale sought to be registered in a special book, by the payment of a fixed percentage to the organizing commission which shall apply this income to the interests of these same expositions.

Art. 100. Foreign products can be admitted to these rubber expositions, for the purpose of permitting comparison and perfecting the national industry but shall receive no premium.

Section 1. Foreign products destined for the rubber expositions shall be free of all custom house duties, as established in Law No. 2,544, January 4, 1912, Article 89, No. 6, but if they are sold, shall pay their respective import duties when given to the buyers.

Sec. 2. Foreign products not sold shall be re-exported for the account of the respective expositors.

Art. 101. The transportation of the national products destined for the rubber expositions shall be gratuitous.

Art. 102. For these expositions there shall be prepared bound statistics and relatorios especially relative to the former period and as regards the rubber industry in Brazil, compared with the world movement.

Art. 103. During the expositions there shall be held:

1. National congresses specializing upon the rubber industry.

2. Lectures upon subjects previously chosen and illustrated with stereopticon slides.

For the carrying out of what is ordered in this article, the organizing commission shall provide for the respective programs and other measures for its entire success.

Art. 104. From all the principle products exhibited some specimens shall be selected to constitute a permanent exhibit, which shall remain exhibited in the Commercial Museum of Rio de Janeiro, and in whose care shall also remain some reserves to be sent to similar Museums in Brazil and in foreign lands. 


\section{TITLE VII}

\section{The Direction and Inspection of the Service}

Art. 105. The direction and inspection of all the service for the economic defense of rubber, shall be in charge of a provisory department of the Minister of Agriculture, Industry and Commerce, entitled "Superintendency of the Protection of Rubber."

Art. 106. The superintendency is charged with:

1. To receive, to record, to prepare, and to inform the manuscripts which depend upon the despatch of the Minister.

2. To see to the effective and integral execution of measures of an administrative character foreseen in the Regulation.

3. The study, planning, calculating and execution of the work that must be done by the administration.

4. The study, planning, calculating, and execution of the work that must be done by contract.

5. The closing, with the approval of the Minister, of the contracts and the decrees relative to the concurrence of the States and Municipalities for the works and measures which they resolved to aid.

Section 1. Each service that has been definitely installed and is in normal working condition, shall be given over to a section of the Ministry of Agriculture with which it harmonizes and incorporated or subordinated.

Sec. 2. For the measure that is being executed as ordered in Sec. 1, the Government shall provide that the proper lawful budgets shall be apportioned of the means necessary for the maintenance, conservation and development of new settlements.

Art. 10\%. The Superintendency of the "Protection of Rubber" shall be constituted of:

A central section working in the Federal Capital.

A district section with headquarters in the national plantations of Rio Branco.

Partial commissions for services that may be indispensable.

Districts of inspection embracing one or more States, in conformity with the number and importance of the services under way.

Art. 108. The central section shall be composed of a superintendent, a secretary, a constructing engineer, an agricultural engineer, an engineer of the second class, two draughtsmen, two typewriters, a bookkeeper, two clerks, a messenger and two servants.

The district section shall be composed of a chief engineer, an engineer of the first class, engineers of the second class, agricul- 
tural engineers, conductors of the first and second class, a draughtsman, a bookkeeper, a paymaster, a customs officer, technical assistants, journalists and a physician.

The partial commissions shall be composed of a chief engineer, the technical and administrative personal necessary, in conformity with the work to be done, and a physician.

The districts for inspection shall consist of a chief engineer, an engineer of the second class, an agriculturist and assistants to the number necessary and sufficient.

The staff of the employes shall not be fixed, but vary according to the development of the work, and will correspond well with the distribution of the respective work and the special instructions opportunely executed.

Art. 109. The services relative to the triennial rubber expositions, shall be directed by a special commission presided over by the minister and composed of the superintendent, who shall take the place of the minister in his absence, and of the members of the Permanent Commission of Expositions, created by Article 89 of Law No. 2,544, January 4, 1912.

Art. 110. All the personnel of the superintendency shall be considered in commission and dismissed when the work is finished for which it was formed.

Art. 111. There shall be appointed: by decree of the President of the Republic, the superintendent; by preferment of the Minister, the chief engineers, the secretary of the central section, the engineer of the first class and the paymaster of the district section; by the Superintendent, the engineers of the second class, the agriculturists, the physicians, the draughtsmen, the typewriters, the clerks and the customs officials; by the chief engineers, the personnel who work under their direction.

Art. 112. The salaries of the employes shall be those fixed in the annexed table.

For the employes in the services which were incident to the order in the first section of Article 106, the salaries are fixed in accord with tables for similar service already existing in the Minister's department, increased from fifty to eighty per cent for those who shall be situated in the valley of the Amazon, while the high cost of living shall continue in that respective place.

Art. 103. For services which shall be thought advantageous, and when they have good reputations, the Government may employ professional specialists, natives or foreigners, paying them annual salaries not greater than those in the table or a lump sum for the service rendered, as may be advisable in each case.

Art. 114. To provide for the increase in the work of the Director General of Accounts, in consequence of the services men- 
tioned in this regulation, there shall be added to the same Directorship, employees of the Treasury and other departments of recognized ability and the typewriters in commission accepted, under the proposal of the Director General; working overtime, whenever necessary, in accordance with Articles 68 and 71 of the Decree, No. 8,889, of August 11, 1911, the work of counting, examining, inspecting and recording the expenses, distribution of credits, advances, and other things of an urgent nature.

The expenses resulting from the order in this article shall be met by the credits which were opened in accordance with Article 14 of Law No. 2,543A, of January 5, 1912. It pertains to the Minister to fix the gratuities of the typewriters and the employes of the Department of Finance to which this same article refers. 


\section{TABLE OF THE SALARIES OF THE PERSONNEL OF THE SUPERINTENDENCY "PROTECTION OF RUBBER"}

Classes

Monthly Salaries

Superintendent $5,000 \$ 000$ Chief Engineer of the Section Rio Branco... $2,700 \$ 000$ Physician Constructing Engineer

Chief Engineer of the Partial Commission... $2,500 \$ 000$ $1,500 \$ 000$ Chief Engineer of the District of Inspection. $1,250 \$ 000$ Engineer of the first class of the Section Rio Branco. Agricultural Engineer Engineer of the second class $1,250 \$ 000$ $1,250 \$ 000$ $1,000 \$ 000$ $1,000 \$ 000$ Secretary to the Superintendent... $1,000 \$ 000$ Paymaster of the Section Rio Branco... $1,000 \$ 000$ Conductor of the first class. $750 \$ 000$ Customs Official of the Section Rio Branco....... Conductor of the second class................. Draughtsman $750 \$ 000$ $600 \$ 000$ $600 \$ 000$

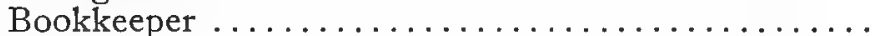
Technical Aid $500 \$ 000$ $450 \$ 000$ Clerk $350 \$ 000$ $350 \$ 000$ Typewriter $200 \$ 000$ Messenger $150 \$ 000$

The personnel in service in the Valley of the Amazon, with perhaps the exception of the Chief Engineer of the Rio Branco section, shall receive an increase over the salaries mentioned in the table, varying from fifty to eighty per cent. according to the judgment of the Superintendent because of the high cost of living in their respective places.

A third part of the annual salary shall be considered the gratuity of the office.

To the technical personnel, to the paymaster, and to the physicians shall be adjudicated by the Superintendent a daily allowance of from $5 \$ 000$ to $30 \$ 000$.

Rio de Janeiro, April 17, 1912.

PEDRO DE TOLEDO.

List of utensils and materials exempt from importation duties, to which Article 2 of Decree No. 9,521 of April 17, 1912, refers: 


\section{FIRST GROUP}

\section{Implements and Utensils for the Rubber Gatherer}

Axes.

Hatchets.

Knives and special apparatus for the incision of trees. Buckets, pails, basins of tin, zinc or other material.
Pitchers for smoking.

Machines destined for the coagulation of the milk.

Cylinders for pressing.

Colanders and their appurtenances.

\section{SECOND GROUP}

\section{Implements and Material for Cultivation}

Electric detoners and their accessories.

Dynamite.

Mining powder and other explosives.

Caps and fuses.

Decauville lines.
Mono rails.

Aerial transporters aut their accessories.

Locomotives and stationary engines.

Chemical drugs, disinfectants and insecticides.

\section{THIRD GROUP}

Materials and Utensils Intended for the Culture of Trees and Treatment of Rubber, including:

Materials for the necessary installations for the mounting of factories, construction of buildings, huts and houses of workmen, box factory and factory for rubber articles.

\section{FOURTH GROUP}

Chemical Substances, Raw Material, Thin Cloth and Othe: Objects Used in the Treatment of and Manufacture of Rubber Articles

a. Coagulants :

Acetic Acid.

Fluoric Acid.

Formic Acid.

Stlphuric Acid.

Hydrochloric Acid.

b. Dissolvents :

Aceton.

Ethylic Alcohol.
Methylic Alcohol (C. I. 4 O). Benzine.

Benzol.

Borax or

Borate of Sodium.

$\left(\mathrm{Na}^{2} \mathrm{~B} .{ }^{4} \mathrm{O}^{7} 10 \mathrm{H}^{2} \mathrm{O}\right)$.

Chloruret of Carbon.

Chloroform.

Ether. 
Essence of Therebentine.

Methylbenzol or Tolnol $\left(\mathrm{C}^{3} \mathrm{H}^{8}\right)$.

Solvent Naphtha.

Oil of Camphor (essence).

Oil of Dippel.

Parafin Oil.

Sulphuret of Carbon.

Tetrachloruret of Carbon.

\section{c. Deodorizers and Disinfec- tants :}

Camphin or Camphene.

Animal Charcoal.

Porcupine Grape Yellow.

Anilines and their derivatives.

Arsenites and their derivatives.

Aureoline.

Cobalt Blue.

Methylen Blue.

Bistre.

Fixed White (Salts of Baryum, etc.).

Creosote.

Cresolin.

Essence of Lavender.

Essence of Lemon.

Essence of Peppermint.

Essence of Menthol ( $\mathrm{C}^{10} \mathrm{H}^{2}$ O).

Essence of Eucalyptus.

Essence of Florence Lily.

Essence of Mustard.

Essence of Moss.

Essence of Rosemary.

Essence of Tomilho.

Essence of Thymol.

Farmol, Formaldehyde or Formalin.

Nitrobenzol.

\section{d. Coloring Materials :}

Cassel's Yellow.

Van Dyck and Bismarck Brown.

Yellow Brilliantine.
Bronze and its derivates.

Orange Bleu.

Brooksite (Mixture of rosin and oils).

Bukaramuguiana.

Pattison White.

Paris White.

Wax for cables (wax, asphalt and rosin).

Cachou.

Rosin Colors.

Massicot.

Minio.

Murexide (purple).

Paris Black.

Lamp Black.

Ivory Black.

Uranitum Black.

Vine Black.

Nigramine.

Ochre of all colors.

Orange Neutral.

Salts of Mercury.

Sulfapone.

Terre d'Ombre.

Falladium Red.

Vermillion (sulphuret of mercury).

e. Hydrocarburets, Heavy Bodies and Oils :

Stearic Acid.

Fish Oil.

Fichetelito $\left(\mathrm{C}^{18} \mathrm{H}^{22}\right)$.

Vegetable Fibre.

Glycerin.

Heptana.

Idrialine $\left(\mathrm{C}^{80} \mathrm{H}^{54} \mathrm{O}^{2}\right)$.

Lanoline.

Linoxine.

Marito Lard.

Naphtaline.

Arachyde Oil (Amendoim).

Cole Seed Oil.

Wood Oil, Chinese and Japanese.

Cotton Seed Oil. 
Layos Oil.

Banba Oil.

Oil of Wool (fat of wool from sheep).

Linseed Oil.

Corn Oil.

Cod Liver Oil.

Nut Oil.

Olive Oil.

Palm Oil (Attalea Excelsis, Bertholetin Excelsis, Maximiliana regia).

Pine Oil.

Ricine Oil.

Soja Oil.

Calves' Foot Oil.

Tung Oil.

Vulcanized Oils.

Nitrated Oils.

Parafin.

Pentan.

Petroleum and all its derivatives.

Stearine.

Vaseline.

f. Resin, Resinous Gums and Lacs:

Yellow Amber.

Ambroid.

Natural Balsam.

Canada Balsam.

Chypre Balsam.

Sulphur Balsam.

Peru Balsam.

Therebentin Balsam.

Talu Balsam.

Benjoim.

Colophane.

Copal.

Banana Gum.

Lac Gum.

Kauri Gum.

Lacs separate.

Enamel Lacs and all their derivatives.
Rhus Lacs.

Mastick.

Rosin Oil.

Ammonia Rosin.

Bourgogue Rosin.

Damar Rosin.

Elemi Rosin.

Hymenea Courbaril.

Rosin (Copal).

Jalap Rosin.

Myrrh Rosin.

Xanthorea Rosin.

Sandarac.

Storax.

Therebentine.

Venice Therebentine and its derivatives.

g. Agents of Vulcanization:

Metallic Antimony and its derivatives.

Bromurets and all their derivatives.

Calcium and its derivatives.

Caustic Lime.

Chlorine (Cl.) and all its derivatives.

Lead and all its derivatives.

Sulphur and all its derivatives.

Iodine and all its derivatives.

Sodium and its derivatives.

Zinc and its derivatives.

h. Fibres and Cloth:

Cotton.

Brass.

Cabo Asbestos.

Maselig Asbestos.

Hemp.

Banana Hemp.

India Hemp.

Sisel Hemp.

Madrasta Hemp.

Manila Hemp.

Fibres of all kinds of vegetable or animal origin.

Vulcanized Fibres. 
Raphia Fabrics.

Lace.

Flax Thread.

Jute.

Wool.

Flax.

Luffa.

Japan Lacs.

Nanking:

Cotton Cloth.

Asbestos Cloth.

Linen Cloth.

Paper Maché.

Parameta.

Rami.

Silk Cloth, animal and vegetable.

Taffetas.

Zaputtine and its derivatives.

\section{i. Isolated Materials :}

Asbestos and all its derivatives. Alexite.

Algina.

Amiante.

Asphalt.

Astrictum.

Russian.

Birch.

Animal and Vegetable Tar of lignite, hulha and all their derivatives.

Bitite.

Bitumen.

Colorifugos and all its derivatives.

Cerasine.

Cork.

Cellulose and all its derivatives.

Esbetine.

Eshalite.

Fermantine.

Fassilite.

Fucasine.

Gasoline.
Gelatine.

Gilsonite.

Hermetine.

Karphite.

Lava.

Ledererite.

Lithine.

Lithocarbon.

Manjak.

Marloid.

Mica.

Mecanite.

Oil of Tar.

Okonite.

Ouralite.

Ozocerite.

Ozotere.

Vegetable.

\section{j. Divers Materials:}

Citric acid $\left(\mathrm{C}^{8} \mathrm{H}^{8} \mathrm{O}^{7}\right)$.

Azotic acid (H. N. $\mathrm{O}^{8}$ ).

Salicylic acid.

Sehacic acid.

Oxalic acid $\left(\mathrm{C}^{2} \mathrm{H}^{2} \mathrm{O}^{4}\right)$.

Oleic acid $\left(\mathrm{C}^{18} \mathrm{H}^{34} \mathrm{O}^{2}\right)$.

Tartaric acid.

Agalmatolite.

Areometers.

Alkalies.

Ammonia.

Salts of Ammonia.

Aluminum and its derivatives.

Alum.

Starch.

Auhydrite.

Autibenzine Pirine.

Astraline.

Atmold.

Whale Oil.

Balenite.

Balons.

Salts of Baryum.

Materials for bleaching.

Bolus.

Camptulikon. 
Afridi Wax.

Japan Wax.

Caruabuba Wax.

Carbarundum.

Materials for

Beech Creosote.

Chlorydrate of Quinine.

Cyanuret of Potassium.

Caseina.

Ceramyl.

Vegetable Coal.

Coal Dust.

Horn.

Mineral and Vegetable Waxs.

Fish Glue.

Coralline.

Caokaline.

Leather.

Copper and its derivatives.

Dextrina $\left(\mathrm{C}^{12} \mathrm{~A}^{20} \mathrm{O}^{10}\right)$.

Dextrose.

Diamond.

Dichlorhydine.

Dielectrics.

Dielectrine.

Eburine.

Sponges.

Tin and its derivatives.

Eternite.

Flour.

Potato Sediment.

Felds Pathe.

Fibroleum.

Metallic Wires.

Sheets of Tin.

Lasts.

Fuller.

Fustian.

Galalithe.

Gas.

Gaze.

Fish Glue.

Glucose.

Glutin.

Graphite.

Mineral Oils.

Gypsum.
Hemalite.

Hatschctine.

Hydrofugine.

Koalin.

Kisselguhr.

Compound Kirrage.

Lactoleum.

Lederine.

Limeite.

Lactoite.

Lactites.

Material for Polishing.

Magnalium.

Magnesium and its compounds.

Magnesia.

Magnesia Calcinated .

Marble Dust.

Morocoline.

Nickel.

Salt of Nipa.

Nitronaphtaline.

Organdim.

Bones.

Pagodite.

Pantasote.

Petrifite.

Earth of Pipe.

Pumice Stone.

Phosphorus.

Plombago.

Pluviosine.

Salts of Potassium

Poudre Rouge.

Anti-ronille.

Sand.

Salitre (Nitrate of Potash K. N. $\left.\mathrm{O}^{3}\right)$.

Soap.

Sawdust.

Silicates of Aluminum.

Bronze Silicium.

Hides.

Luberine.

Luberite.

Metallic Sulphuret.

Isinglass.

Tannico. 
Metallic Cloth.

Turfa.

Tripoli.

Trichopiese.

Hulha Varnish.

Wood Vinegar.

Rio de Janeiro, April 1\%, 1912.

\section{PEDRO DE TOLEDO, \\ Minister of Agriculture.}

Wallasine.

Waterproof Varnish.

Whaleboline.

Xylolithe. 


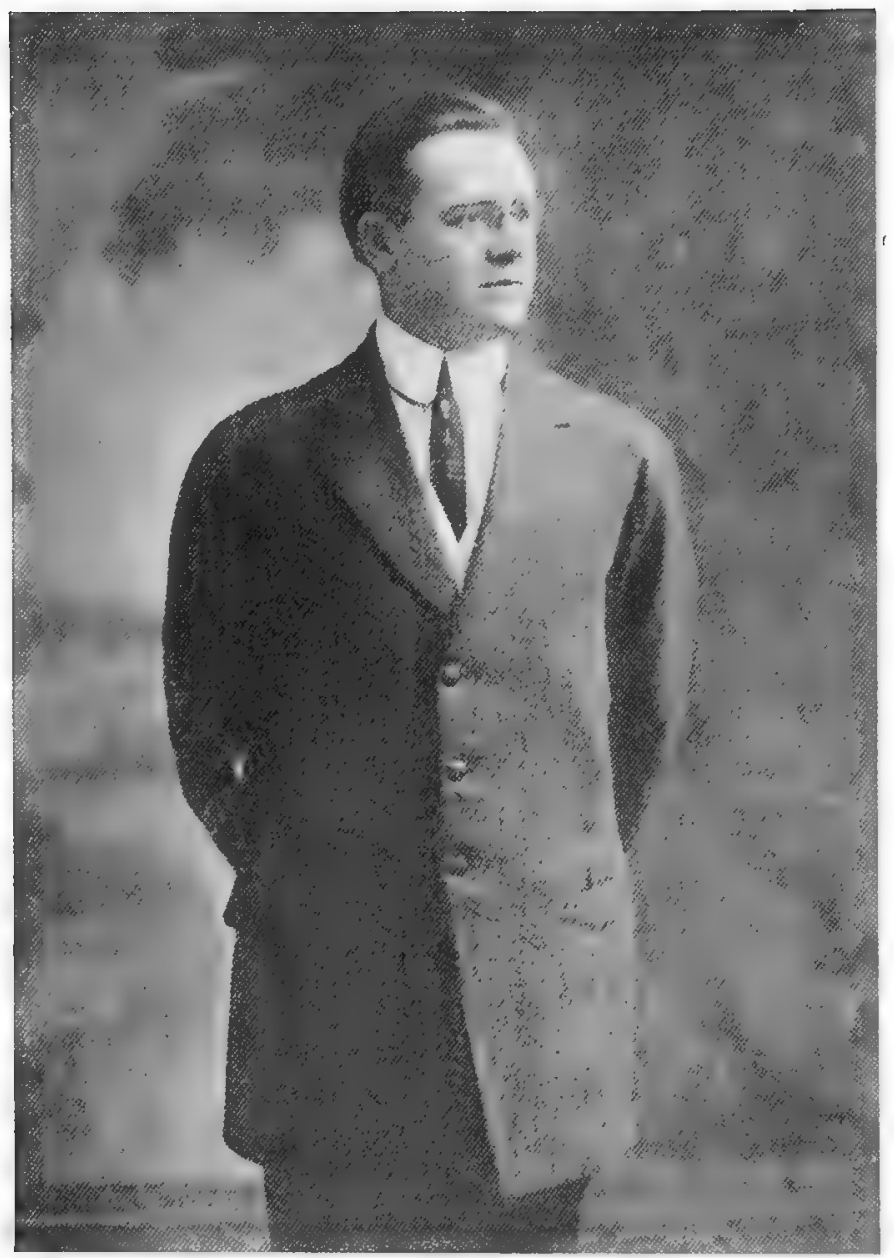

GEORGE E. PELL, ESQ.

Commissioner for the Commercial Association of Para 


\section{PARA}

\section{FURTHER DETAILS RELATING TO PARA HAVE NOT COME TO HAND UP TO THE TIME OF GOING TO PRESS}




\section{COMMERCIAL ASSOCIATION, PARA (BRAZIL)}

\section{DESCRIPTION OF EXHIBITS.}

\begin{abstract}
501 Biscuits
81 Biscuits

111 Biscuits

235. Biscuits

145 Biscuits
\end{abstract}

Quality.

Fine Isiand Rubber,

Fine Island Rubber, Cajary,

Fine Island Rubber, Anapu,

Fine Island Rubber, Cavianna,

Fine Low Xingu,

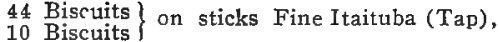

10 Biscuits

Fine High Xingu,

Weight. Procedence. net $1,037 \mathrm{ks}$. From the Islands. net $804 \mathrm{ks}$. From River Cajary, \& partly islands. net $756 \mathrm{ks}$. From River Anapu \& partly islands. net $1,116 \mathrm{ks}$. From Istand of Cavianna.

net $979 \mathrm{ks}$. F r o m Lower reaches of River Xingu (This parcel contains two lots, dry and fresh, should be separated a n d marked "Dry" and "New").

net $937 \mathrm{ks}$. F rom Lower reaches of River

net $696 \mathrm{ks}$. Frapajos. $\mathrm{High \text {i }}$ reaches of River $\mathrm{Xingu}$, above rapids.

$\begin{aligned} 5 & \text { Biscuits } \\ 34 & \text { Biscuits }\end{aligned}$ on sticks Fine Itaituba (Tapajos) Cachoeira

net $1,025 \mathrm{ks}$. From $\mathrm{H}$ ighe I reaches of River Tapajos, above rapids, and state

63 Biscuits

Weak Fine Rubber,

Island Coarse Rubber,

110 Biscuits

20 Balls

2 Bags-1 Bag

I Bag

2 Boxes-4 \& 5

1 Case-No. 3

1 Box

1 Box
Cameta Coarse,

Coarse Itaituba (T'apajos),

Weak Coarse,

Tiras (Strips),

Toc. Caucho Ball,

Tap. Caucho Ball, Cachoeira,

High Xingu Catucho Ball,

Inaja Palm Nuts

Urucuri Palm Nuts

Tin Cups, etc., for collecting Latex

Natural Woods-2 blocks of wood and shavings, used for curing rubber

Machadinhos (Hatchets), collecting and curing utensils

Wooden Stand used for curing large biscuits of rubber. of Matto-Grosso.

net $650 \mathrm{ks}$. F r o m L o we Amazon.

net $1,000 \mathrm{ks}$. From. Islands and affluents of Lower Amazon.

From River Cametá

net $1,515 \mathrm{ks}$. and partly IsIands.

net $302 \mathrm{ks}$. From River Tapa-

net $254 \mathrm{ks}$. F $\mathrm{j}$ rom Lower Amazon.

net 119 ks. From River Tapanet $911 \mathrm{ks}$. From River Tocantins \& Rio Fresco.

net 1,061 ks. From H igher reaches of River Tapajos, above rapids, and State of Matto-Grosso.

net $1,044 \mathrm{ks}$. From H i g he I reaches of River Xingu.

\section{Used for curing Fine Rubber. Used for curing Fine Rubber.}


The AMAZONAS

Section 


\section{AMAZON STATE IS THE LARGEST ONE IN BRAZIL}

Area in square kilometers, 1,894, 724 .

Population, 600,000 inhabitants. level.

Capital, Manaos ; 60,000 inhabitants, $32^{\mathrm{m}}, 40^{\mathrm{m}}$ height from sea-

It exports rubber and woods for construction and for other works, Pará nuts, Guaraná and some other products.

Beans, corn, rice and almost every kind of cereals grow there beautifully.

It is put in communication with Europe by one English and two German Steamship Companies, and by cable and wireless telegraphy. These companies have improved their steamers, which go to Europe. To the United States it is served only by the English company, every ten days. They are cargo boats.

Principal cities: Stacoatiara, Manicoré, Humaythé, Teffé, Parintins and Labrea.

Medium temperature, $27^{\circ} 2^{\prime}$ centigrade.

Rains-Evaporation in mm., 1592,0. Height, 1525,3 (in 202 days).

Wind-Velocity in one second, $1^{\mathrm{m}}, 60$. Direction, east.

\section{EXPORTS OF RUBBER FROM STATE OF AMAZONAS SINCE 1827 UP TO 1907}

Years.

Kilograms.

$183 \%$ 802,410

1847

$4,286,570$

$185 \%$

$7,134,195$

$186 \%$

$2,969,070$

$187 \%$

$17,403,574$

$188 \%$

$43,454,671$

1897

$106,424,423$

$190 \%$

$120,434,947$

From 1827 to 1852 the exports belong to Pará and Amazonas together. 


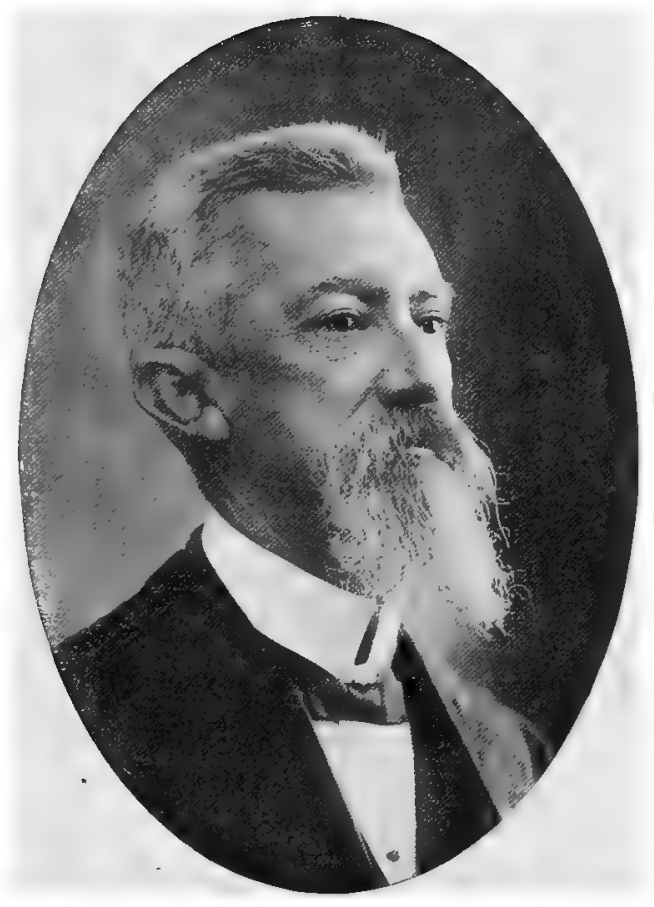

\section{COLONEL ANTONIO CLEMENTE} RIBEIRO BITTENCOURT

Governor of the State of the Amazonas, Brazil 

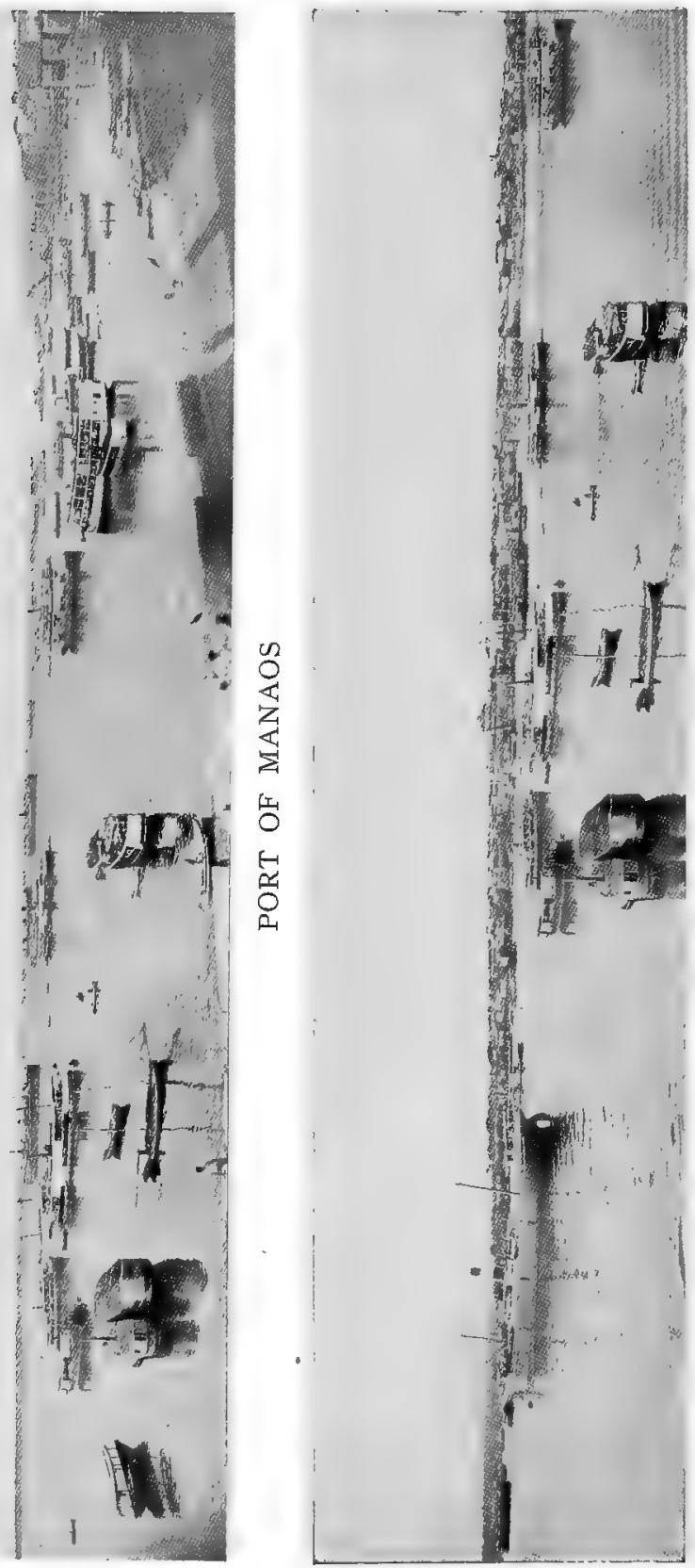

告

兵

愛

1

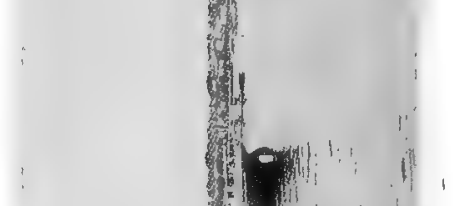




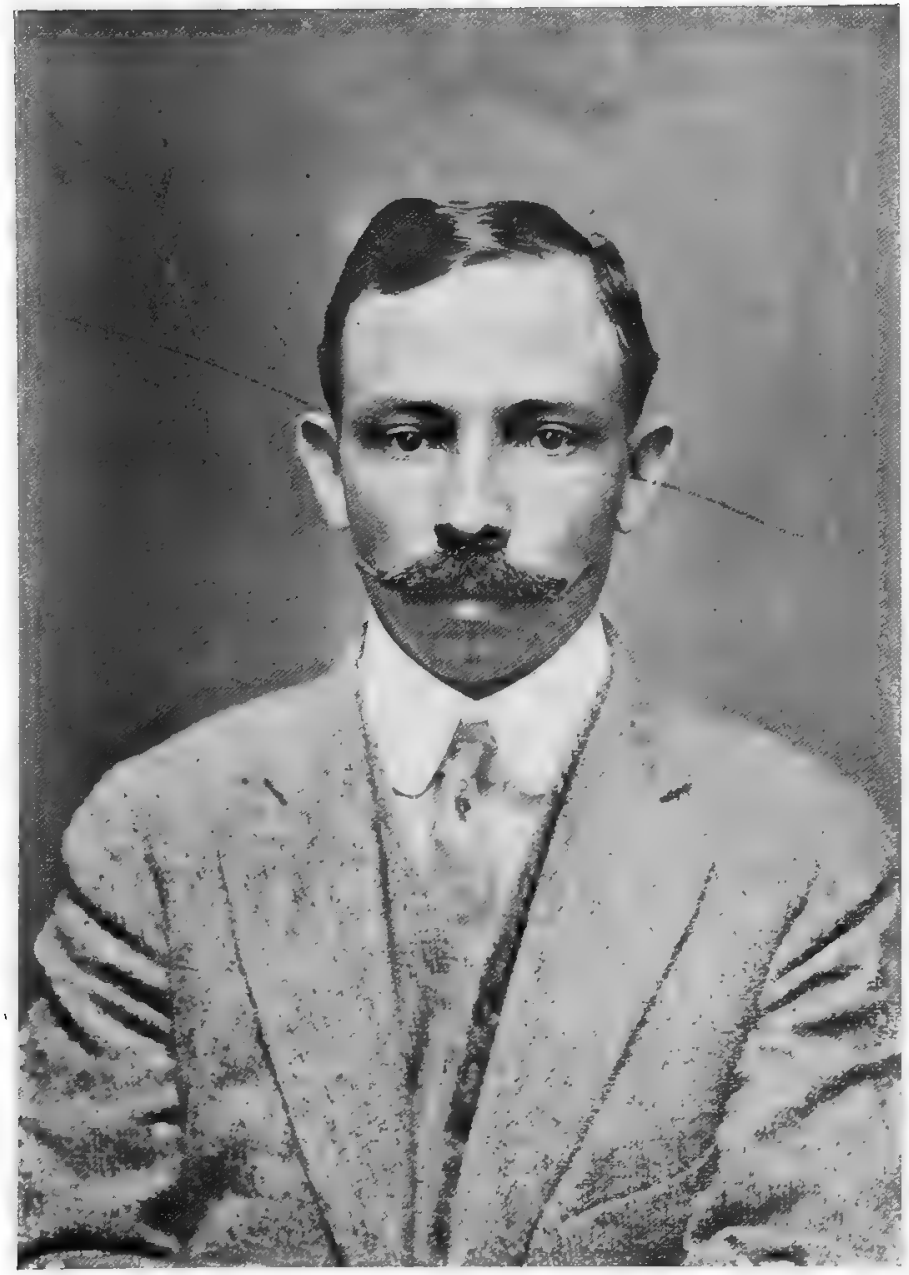

DR. MANOEL LOBATO

Commissioner for the State of the Amazonas, Brazil, also of Matto Grosso and the Federal Territory of Acre 


\section{RUBBER IN THE STATE OF AMAZONAS}

General Ideas about the State. Progress in the Means of Transportation. Climatological Conditions.

The State of the Amazonas is the largest one in the Brazilian Republic. Notwithstanding its well-known natural resources that are not limited, according to many persons, to the precious milk of the rubber tree- that wonderful tree of fortune-which is disputed by various producing centers, its vast territory is yet far from being completely and properly populated.

The emigration currents towards that section have started lately, so that the population of hardly over two hundred thousand souls a few years ago, to-day is over six hundred thousand inhabitants, without any exaggeration.

As such changes are taking place the conditions of life are being altered every day. It is true that there still prevails in the books of gay tourists who consider humbug as a condition of inexhaustible success, the impression that the native indians travel about half nude and armed with arches and arrows, chasing the lost Europeans through such outlandish regions of the world.

The remark, however, is not based on real facts. The native Indians are not now to be found in very accessible places. The foreigner who lands in the Amazonas capital, for instance, may be sure that his habits and his civilization will not cause any fright.

It is difficult to find among the natives who possess some education and means one who has not been through several European countries, especially France; so that as soon as the visitor lands he notices an atmosphere of modern improvements and all the novelty and gay spirit of Parisian life; the latest fashions are found at once in Manaos.

The progress of that beautiful princess of the Rio Negro (Black River) is most remarkable, because it is at the most only twenty years. Until the proclamation of the Republic in Brazil, Manaos amounted to almost nothing. From 1889 to this date began its stupendous development, counting already over 60,000 inhabitants.

To-day it has comfortable homes, good and solid buildings of artistic architecture. Its port is perfectly fitted to receive the visits of the large transatlantic steamers, which places it 


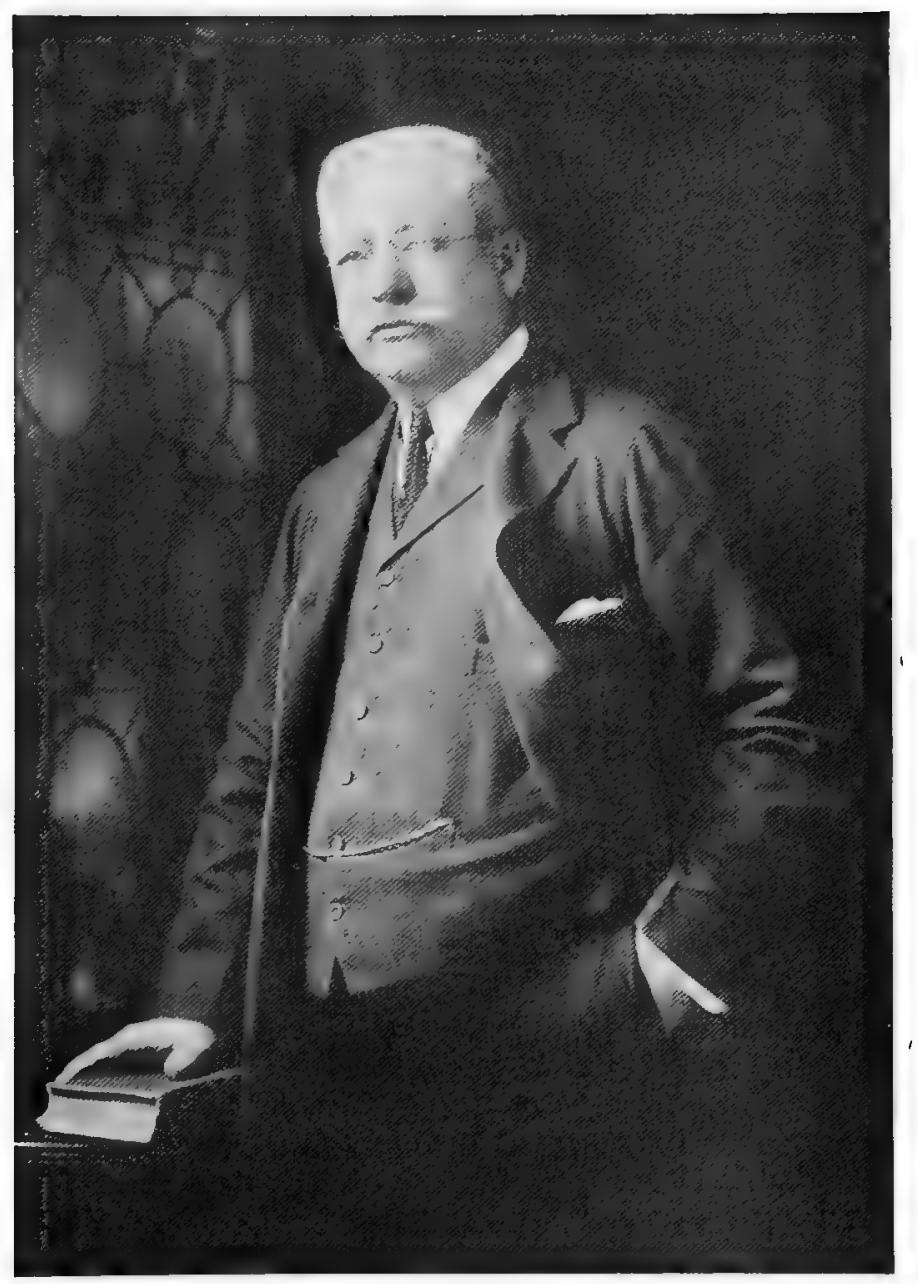

A. W. STEDMAN, ESQ.

Commissioner for the Commercial Association of the State of Mañaos, Matto Grosso, and the Federal Territory of Acre, Brazil 
in communication with the leading European ports. The navigation line for the United States, served by an English company, is not yet of the required progress to insure all the necessary comfort to the passengers who venture to undertake the long trip. Furthermore, it is served by steamers that do not possess the modern requirements of speed, which at present is of first interest not only for the passengers who look for a pleasure resort as well as for the intercourse of commercial relations with the world's markets. That is the reason why the interchange between Amazonas and New York has been rather slow, which interchange could be of greater magnitude than it is to-day if there was a more intimate knowledge between the parties.

I would not want to end this information about the capital of the State of Amazonas without quoting some paragraphs from the excellent work, "The Rubber Country of the Amazon," written by Mr. Henry C. Pearson, Editor of the "India Rubbeı World":

"When one considers that this city is a thousand miles from the seacoast, in the heart of a vast tropical jungle, with wild Indians within a hundred miles of it, its presence seems incredible. In a way, it is as modern as New York or Chicago. The latest Parisian fashions are there, and almost anything that civilized man desires is obtainable. Prices are high, to be sure, because both luxuries and necessities are imported and subject to a duty of 100 per cent. But when something besides rubber is produced by the magnificently fertile lands that surround it, Manaos will be one of the great and beautiful cities of the world and living as reasonable as anywhere."

That progress, although it has been made principally in Manaos, in some form is also affecting the interior of the State. The river navigation is made quicker than before and on elegant and up-to-date steamers, which navigate throughout all the tributaries of the Amazon River.

Furthermore, the Madeira-Mamoré railroad has produced a great improvement in the transportation facilities adopted in the State for the quick delivery of merchandise in the interior.

The most distant points of the territory are now connected by wireless telegraphy: The news of the world can be transmitted daily to the capital of the State by means of double river cable and by wireless telegraphy of the Marconi system.

The climatic conditions are not so terrible as pictured in the minds of the outside people, who do not know the real facts and the true geographic situation of the State.

Mr. A. R. Wallace, in his "Narrative of Travels on the Ama- 


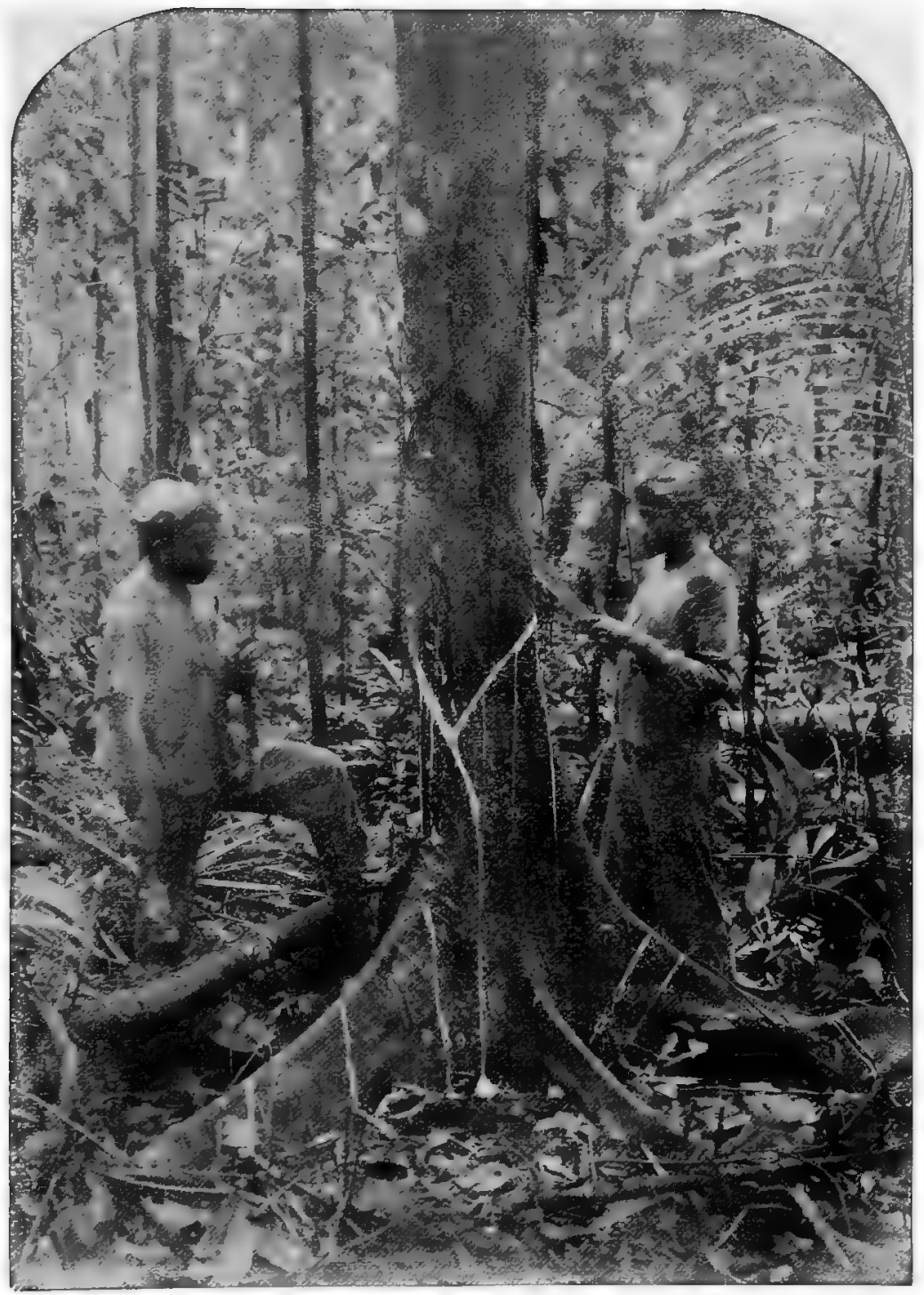

CAOUTCHOUC PROCESS No. 1. The Men Set to Work Bleeding the Base of the Castilloa. 
zon and Rio Negro," and Captain Maury, in his book "The Amazon and the Atlantic Coast of South America," show themselves so enthusiastic over the climate of Amazonas and recommend it "as one of the healthiest and mildest in the world." That easy enthusiasm is not so good for us as the competent French engineer, Mr. Paul Le Cointe's opinion, after many years in the northern part of Brazil. Thus he expresses himself:

"The Amazonia, an immense tableland slightly concave, situated entirely in the tropics, crossed by rivers of colossal dimensions, with lakes and swamps, the remains of the original water basin, badly separated by modern alluvium land, covered with impenetrable forests from which emerge here and there some plains, ought to, have a specially hot, damp and unhealthy climate.

"That is the reputation which it has enjoyed for a long time and which has frightened away the European immigration; but it is not deserved in such an absolute manner; as a hot country is perhaps on the contrary the less deadly for the settler as well as for the traveler."

\section{THE AMAZON AS RUBBER PRODUCER}

It is indeed very difficult if not absolutely impossible to limit the rubber producing region of Amazonas. In almost the whole of the vast territory of that State there are found rubber trees and where they do not grow, they certainly can be successfully planted. Over large tracts of lands on the banks of rivers not navigable, there are extensive rubber forests not explored on account of lack of population.

That exuberance of the Amazonian flora, that arrangement of nature to furnish resources to the rubber extractor for many years, kept him away from any other occupation except that of raising the arm and wounding the tree of fortune in order to obtain prosperity. There was no necessity of planting that which the open road of the forest presents at each step; also why worry with a view to obtaining any other process of securing the "hevea brasiliensis" when its milk in the primitive state is obtained at the lowest price of exploitation and cultivation, preserving all the excellent qualities of the rubber?

The presence of competitors in the world's market, more than the damage caused to the health by the smoking process of coagulation, is the reason to establish new exploitation. The rubber plantation is now being conducted perhaps without obeying the scientific criterion, but more in the shape of facilitating the gathering of the latex. 


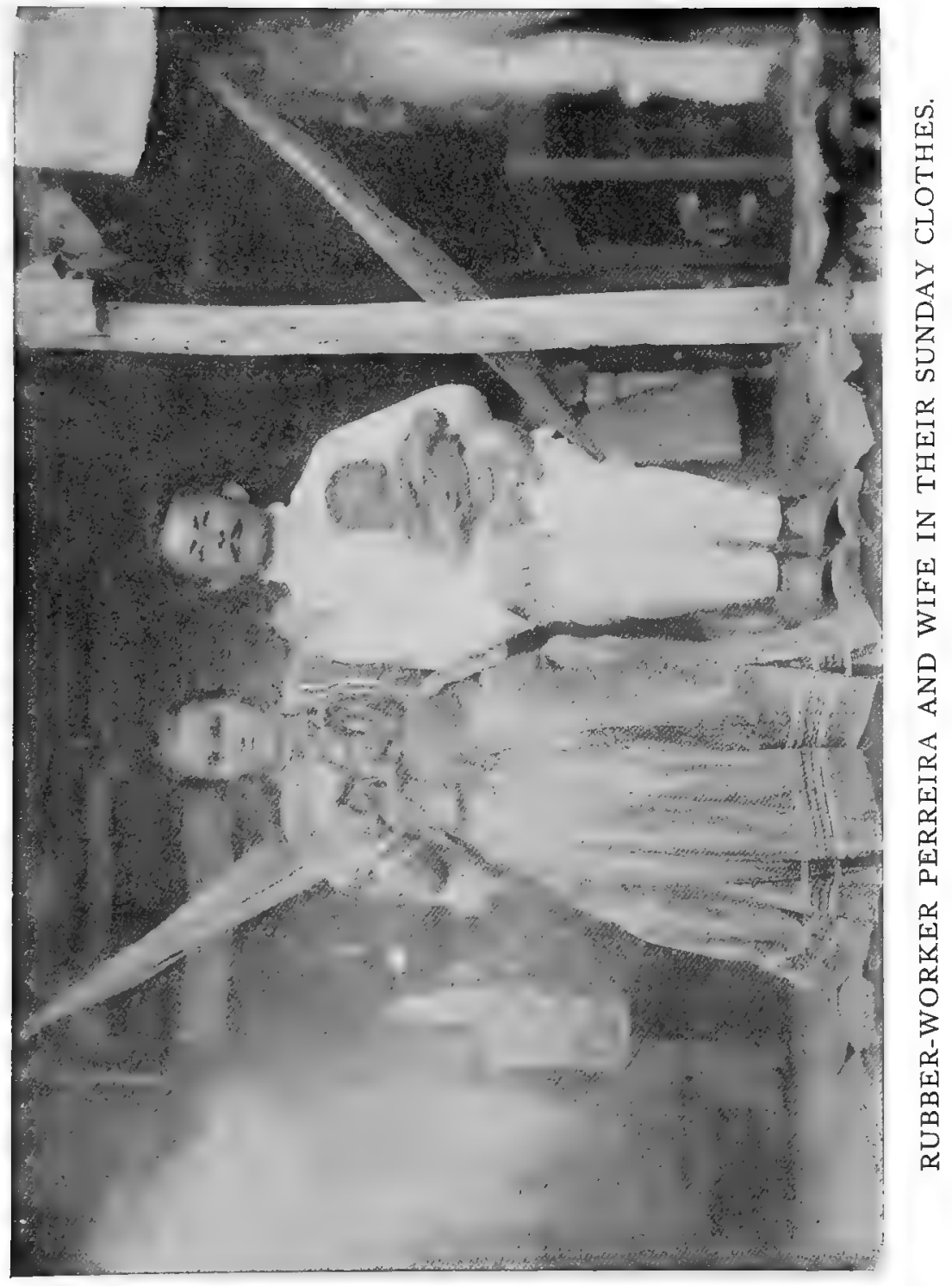


One hears a good deal about high prices in the Amazonas, and careless observers state in opposition to that the cheapness of life in the Asiatic Islands and other points of the world. I do not think that a thoughtful person without any interest in connection with enterprises and plantations elsewhere in the world, would be able to use such an assertion, which is so unjust.

The French engineer, Mr. Paul Le Cointe, who-is an expert in the matter, writes the following:

"For the work to be executed, the number of workmen required is much less where the production of those men is high, hence to calculate the price of hand work, the individual production is the factor that may become more important than the pay to the men who work by the day.

"In the Far East, the workmen are paid from Fr. 75 to Fr. 1.25 , equal to 14 cents to 23 cents, approximately, including feeding. In the Amazonas, the pay per day amounts to Frs. 4.75, or that is, almost 91 cents for all the work, which is three to four times more."

Let us examine the cost in Asia and in the Amazonas for the different work required by the cultivation of the rubber trees.

According to Mr. Stanley Arden, it is about 38 cents for each kilogram of rubber in the plantation (the data that I am presenting in connection with this matter is from the book of Mr. Le Cointe, entitled "Le Caoutchouc Amazonien et son Concurrent Asiatique").

Mr. Lamy Torrilhon speaks about the Kuala Lampur Rubber Company (Malay), which had in 1909, 404,012 rubber trees from one to six years old. Calculating the price of cultivation of that rubber at Fr. 4 per kilogram or approximately 76 cents, Mr. Stanley Arden also calculated that the cost of a hectar of plantation before reaching the period of exploitation (the sixth year, according to him) was only Fr. 816 , or more or less $\$ 15 \%$, including the salaries and establishment of European employees, and Mr. M. G. Vernet, of the Pasteur Institute of Nha-Trang, calculated Fr. 3,000, about $\$ 580$.

Mr. Le Cointe further states that Mr. Stanley Arden in his calculations of expense seems to presume the plantation in lands not thickly wooded, because he counts for the burning and clearing of the land, hardly one-third the cost of felling the trees, when in the forest it is about the same. Of course, lands not properly protected and in the virgin state in the tropical countries, are less fertile than those covered with thick forests, fur- 


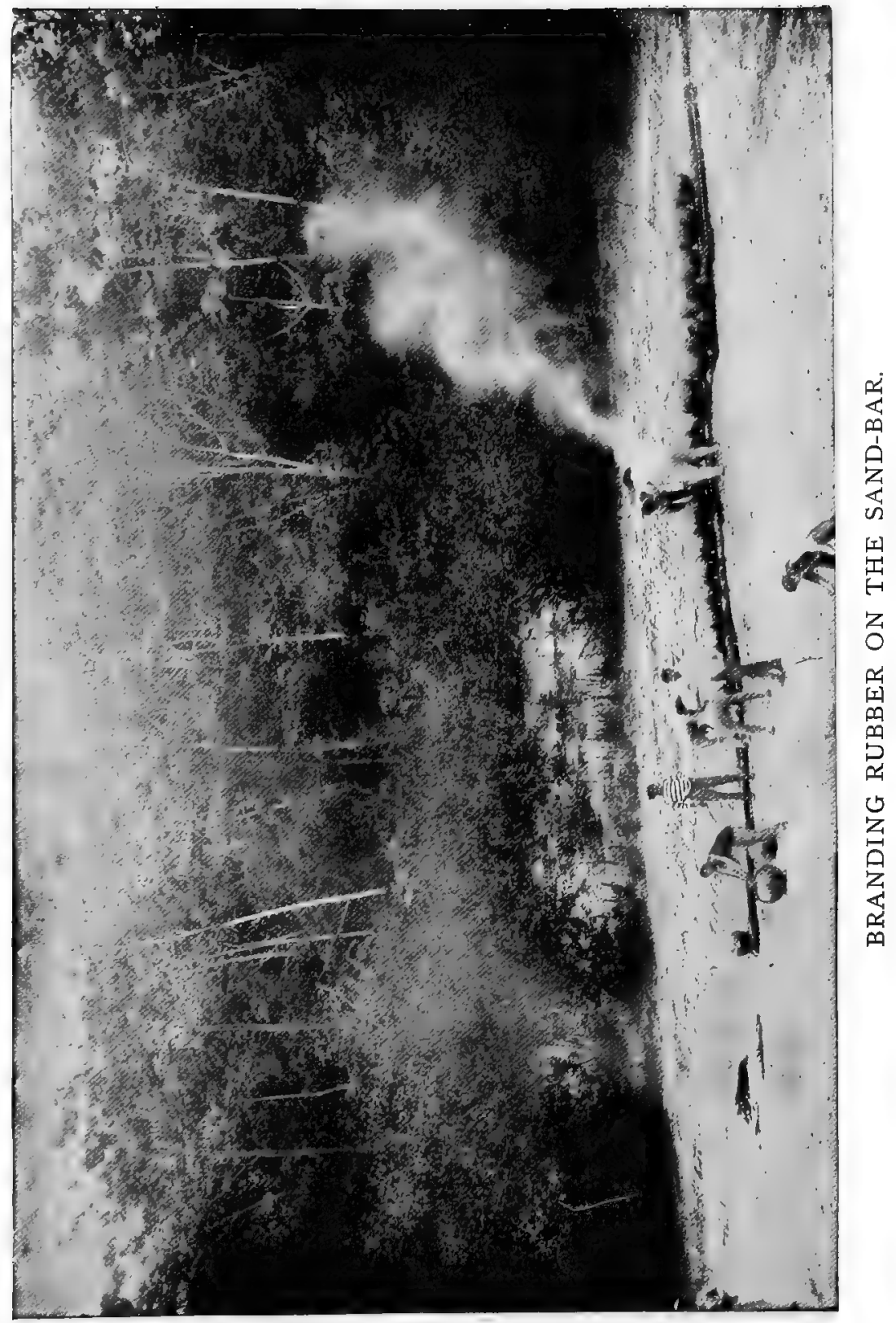


thermore the lands that have been devoted to a prolonged cultivation of plants, like coffee, tea, etc., are to a large extent exhausted, and if rubber trees were attempted to be planted there, the result would be that it would largely lose the advantages by having to fell new trees.

Mr. Le Cointe also speaks of about 225 trees per kilogram, when practically that number can be doubled; besides this the calculation made by the same author of about $\$ 18$ for the clearing of the hectar, at the rate of $\$ 14$ per day for each workman shows that the price for that work in almost clean land will take sixty-two days, whereas in the Amazonas we only count on twenty-six days for each clearing of a hectar in a virgin forest.

This argument, it seems to me, shows that there is a purpose to bring up a cheapness which is more apparent than real, with the determination of recommending the Asiatic plantations to the detriment of the Amazonas rubber plantations.

This plan of attack is not the most correct one. We have the advantage of having workmen who easily adapt themselves to the producing land, and with the measures of protection that the Government is going to guarantee to the rubber planters, the life of the contractor is going to become easier.

The tree which is planted in its own region, is less subject to ravages, being less persecuted by the destroying parasites, is not violently fell by hard winds.

As every day increases the number of industries which requires rubber as a raw material, it is therefore necessary to exploit it in different centers, counting even with possible disaster, but nowhere in the world, in accordance with the most reliable statistics, is there more favorable land for the planting of rubber trees than in the various territories of the Amazonas. That territory has been placed by nature to be the emporium of that industry, and counts with all the means to preserve that privilege, and for the guarantee of the planter as soon as the rubber tree develops itself, it has other resinous trees stuitable for construction, and excellent fibres which can be sold at a profit. The Brazilian walnut is so abundant there that it is a second source of income in the State of Amazonas.

\section{THE PRODUCTION OF RUBBER}

Only during the first six months of this year, notwithstanding that the time for the full crop was not as yet due, from Manaos there were exported to the United States 2,328,389 kilograms of fine rubber, 602,180 medium quality, sernamby 991,088 , caucho 


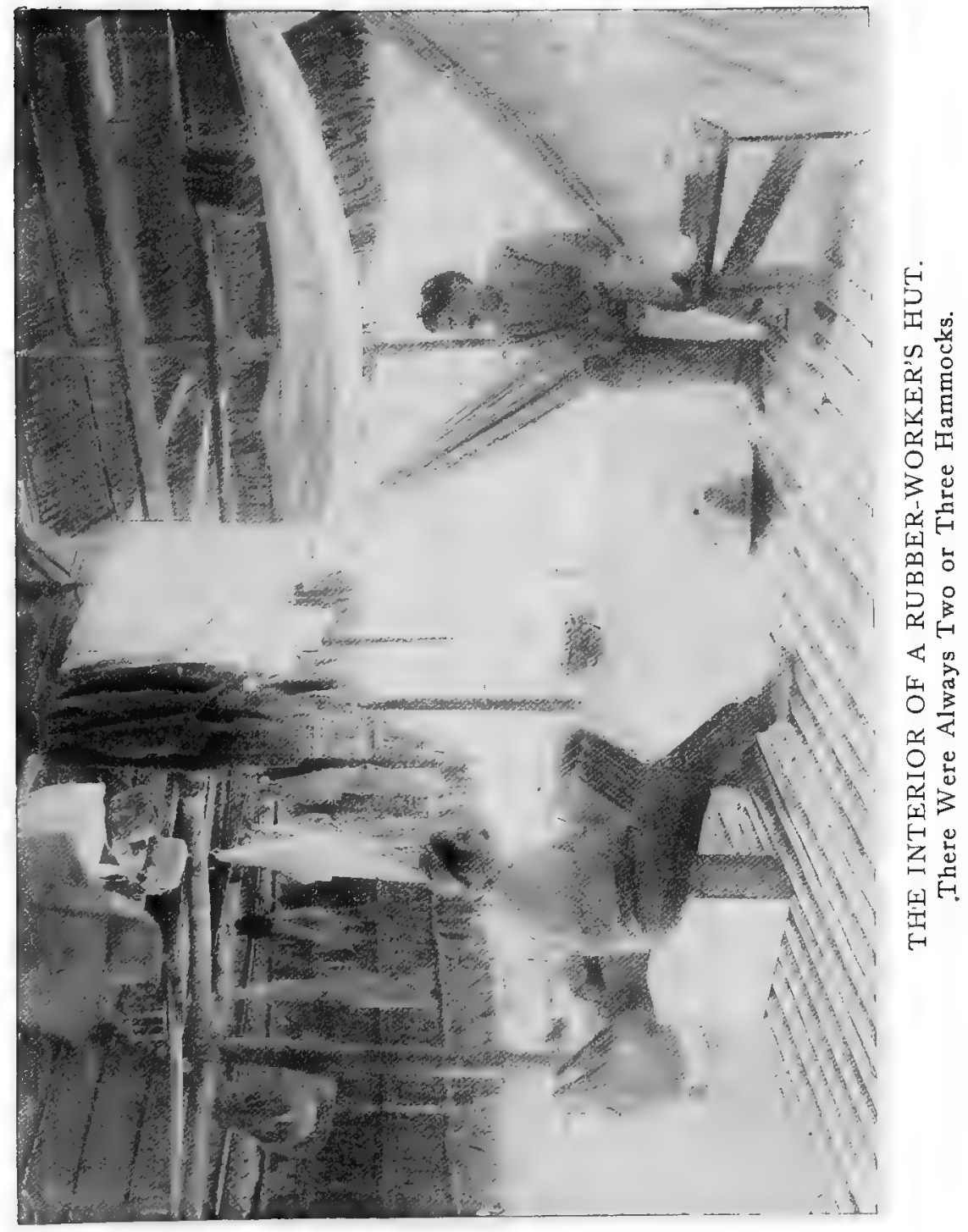


798,024 ; to Europe, first quality $2,449,776$, medium quality $40 \%$,278 , sernamby $50 \%, 860$, caucho $1,368,489$; from Itacoatiara, first quality 37,240 , medium 3,858 , sernamby 26,237 , caucho 11,405 , that is for the Amazonas a total of 9,531,824 kilograms, almosi half of the export of 22,902,401 kilograms made in that period for that State, besides that of Para and Iquitos. The production of Amazonas in 1910 was 10,466,231 kilograms; in 1911, 10,122,242 ; this year, it is expected that there will be an increase of more than 15 per cent of the production of last year.

This is due only to the active work of a few thousand workmen. What would be the colossal production of that territory, when the work of the men will be facilitated by a rational distribution of rubber trees!

Reflecting. upon that. I am reminded of the words of Dr. T. Huber:

"A regular planting industry will have a marked and salutary influence upon the extraction of wild rubber and the management of wild rubber forests."

Furthermore, I have the full conviction that the future of that industry competently managed will offer in Amazonas, and in order to be more exact, in Brazil, more guarantees of success than in any other region in the world.

M. LOBATO. 


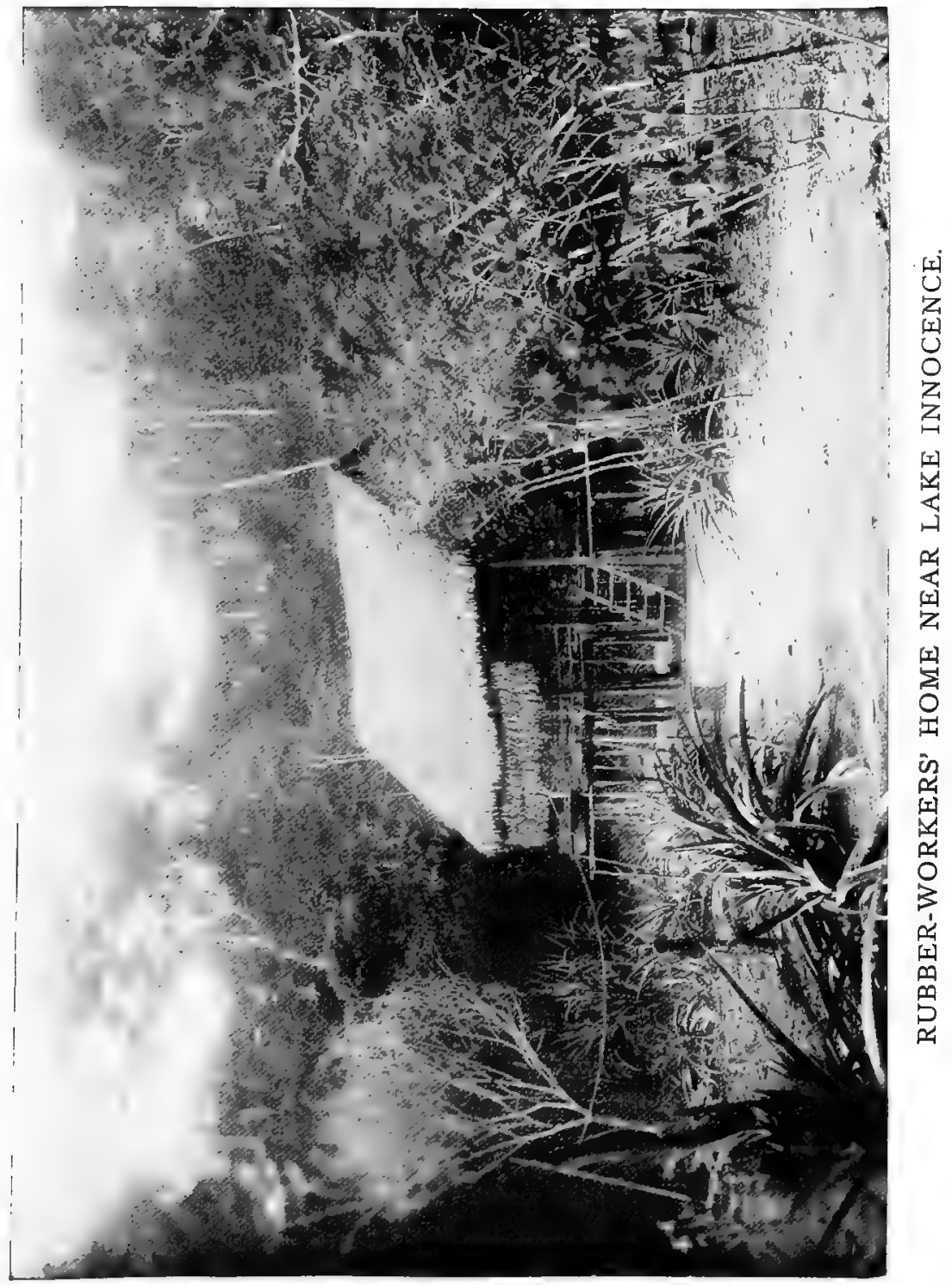




\section{BRAZIL}

\section{The States of Amazonas and Matto-Grosso, and the Acre Territory}

The Commercial Association of Amazonas exhibits samples of rubber from the States of Amazonas and Matto-Grosso, and from the Acre Territory, having been authorized by the respective Governments for this purpose.

\section{STATE OF AMAZONAS}

The main stream of the River Amazon flows through the entire territory of this State, and within its boundaries is joined by many tributaries.

The boundary with the State of Pará is formed by the same river, and that with Matto-Grosso and the Republic of Bolivia by the Upper Madeira River. The River Javary, a tributary of the Solimoes (or Upper Amazon), forms the boundary with Peru, as does the Upper Rio Negro (the waters of which connect with the Orinoco through the Cassiquari Canal), with Venezuela. Before the formation of the Federal Acre Territory, the upper reaches of the Rivers Acre, Purus, and Jurua also constituted the frontiers of the State of Amazonas with Peru and Bolivia.

The capital of the State, Manaos, is situated in the bay of the Rio Negro, three days distant by steamer from the capital of the adjoining State, Pará. The nearest European port, Lisbon, can be reached in thirteen days, and New York in eighteen days.

Manaos is the turning-point for ocean going steamers from the United States of America, and Europe, as well as from the South of Brazil.

The companies engaged in the transatlantic service are:

The Booth Steamship Co., Ltd. (British), with four sailings each way to and from Liverpool per month, calling at Itacoatiara, Pará, Madeira, Lisbon, Leixoes (Oporto), Vigo and Cherbourg, and three sailings to and from New York per month, calling at Pará and Barbadoes.

The Hamburg-Amerika Line and Hamburg-Sudamerikanische Dampfschiffahrts-Gesellschaft (German), with two sailings per month to and from Hamburg, calling at Pará, Madeira, Lisbon, Leixoes (Oporto), Havre and Antwerp. The Booth Steamship Co., Ltd., also runs two lines, one from Liverpool and the other from New York, as far as Iquitos, the capital and principal port of the Loreto province of Peru. Maritime communication with Southern Brazil is maintained by the "Lloyd Brazileiro" and the 


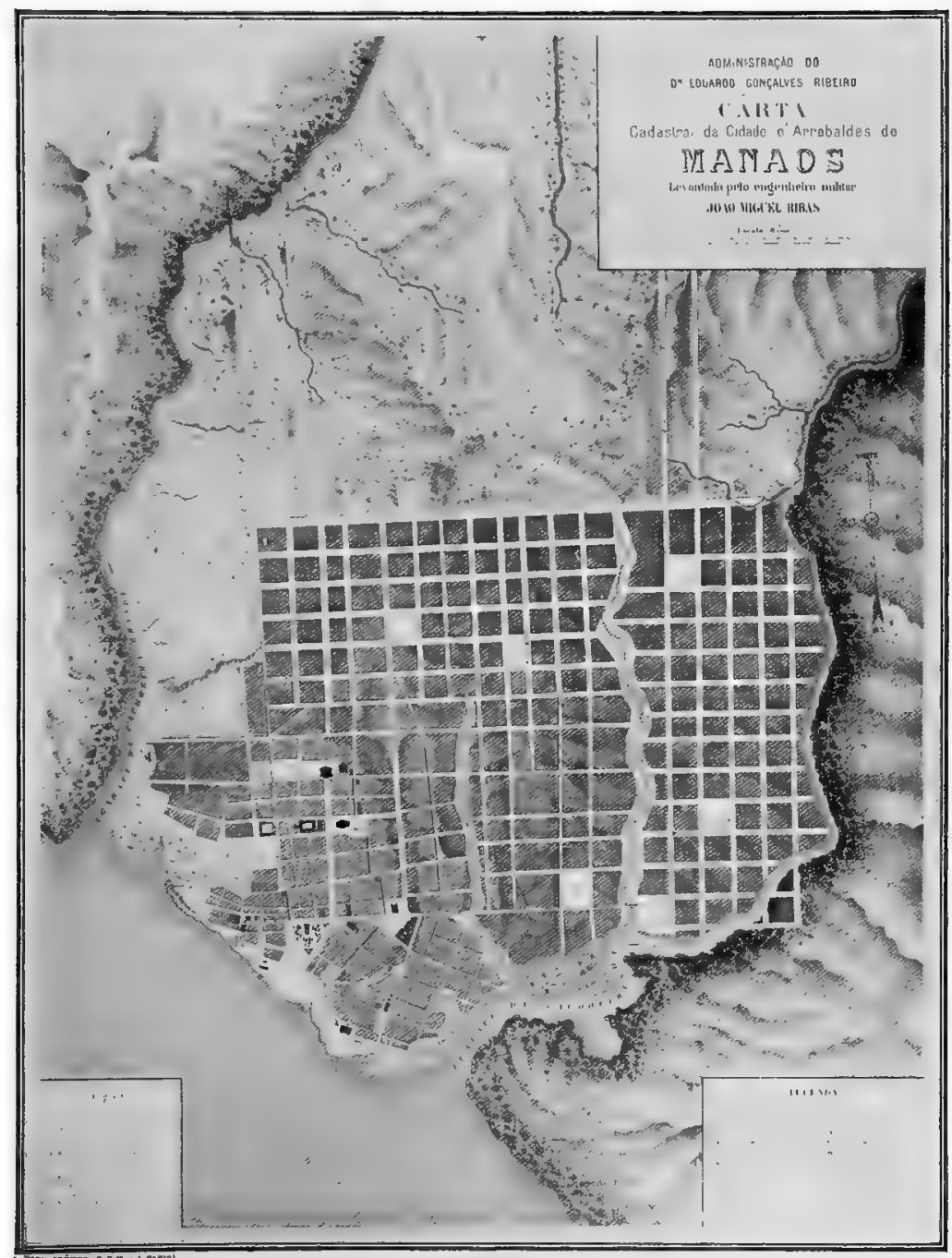

MAP OF MANAOS 
"Cia. de Commercio e Navegacao," the former having six steamers per month, and the latter three. The voyage from Manaos to Rio de Janeiro occupies from 14 to 16 days.

The river navigation is controlled by the Amazon River Navigation Co. (1911), Ltd., and numerous private steamers, which form a flotilla only to be compared with that of the River Mississippi. A new company "A Companhia Navegacao do Amazonas" is about to commence operations. All these steamers call at Manaos, or have their headquarters there.

Telegraphic communication is as follows: By means of the Amazon Telegraph Co., Ltd., in combination with the Western Telegraph Co. to and from all parts of the world.

Wireless Telegraphy (Marconi and Telefunken systems), is already making considerable headway. The Marcòni station at Manaos, in the hands of the Madeira Mamore Railway Co., receives and transmits messages to and from Porto Velho, on the Madeira River, the starting point and headquarters of the railroad, as well as to and from the Telefunken stations at Senna Madureira, Empreza and Cruzeiro do Sul (the capital towns of the three divisions of the Acre Territory).

These last stations are not yet.open for use by the public, and other intermediate stations are still in course of construction.

Manaos has also' a station of the Amazon Wireless Telegraph \& Telephone Co., Ltd., which transmits messages to Pará, and has lately been in regular communication with the station in Iquitos belonging to the Peruvian Government. By this route it is possible to send messages to Lima, the capital of Peru, on the Pacific Coast. However, the Company mentioned has so far not succeeded in obtaining the official permission of the Brazilian Government to operate in Brazil.

Manaos has a permanent population of upwards of 70,000 inhabitants. Its houses and public buildings conform to modern architectural ideas, and some of its buildings, such as the State Theatre, the Public Library, the Palace of Justice and the "Benjamin Constant" Orphan Asylum are magnificent.

The streets, squares and avenues are well lighted by electricity and the town possesses an excellent electric tramway system. The drainage scheme is almost completed, and the water supply is very satisfactory. The port works are in the hands of the Manaos Harbor, Ltd. There are some excellent hotels, and a splendid telephone service.

The following banks carry on operations in Manaos:

The London \& Brazilian Bank, Ltd., and The London \& River Plate Bank, Ltd. (British), agencies.

Banco do Brazil (Brazilian), agency.

Banco Amazonense (Brazilian), Head Office. 


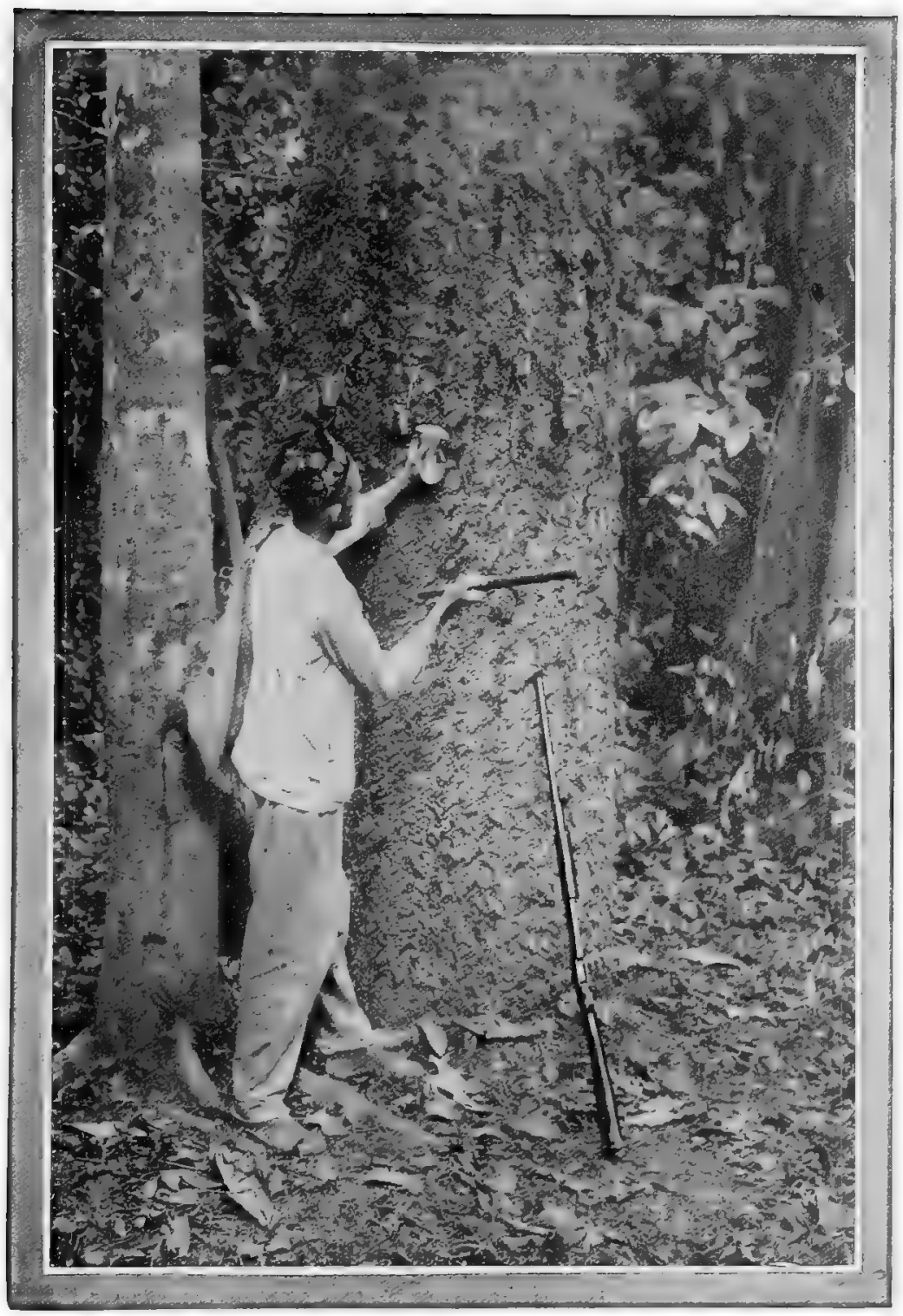

A “SERINGUEIRO” TAPPING A RUBBER TREE. 
Banking Firms: Zarges Ohliger \& Co. (German).

Life, Fire \& Marine Insurance Companies:

Northern Insurance Co. (British), agency.

Royal Insurance Co. (British), agency.

"Mannheim" Insurance Co. (German), agency.

Lloyd Amazonense (Brazilian), head office.

And agencies of the following Brazilian companies: Garantia da Amazonia, Seguradora Paraense, Allianca da Bahia, Commercial Paraense, Lloyd Paraense, Allianca, Paraense.

Rubber is the chief industry of the State, being its principal product and source of income. The predominance of this industry dates from 1863, and within a few years it superseded entirely the planting of rice, coffee, cocoa, sugar cane, beans and maize.

Up to $18 \% 0$ rubber was generally exported in the form of roughly made shoes, hats and caps, as well as in sacks and in bulk, the greater part of it going to New York, via Pará. Later, the present system of biscuits or balls, cut and packed in cases, came into use.

Considerable business has always been done in Amazon with the United States of America, although formerly the proportion shipped to America was greater than at present, as it was only in later years that the heavy competition by London and Liverpool came into being.

The production of the various rivers during 1911 was:

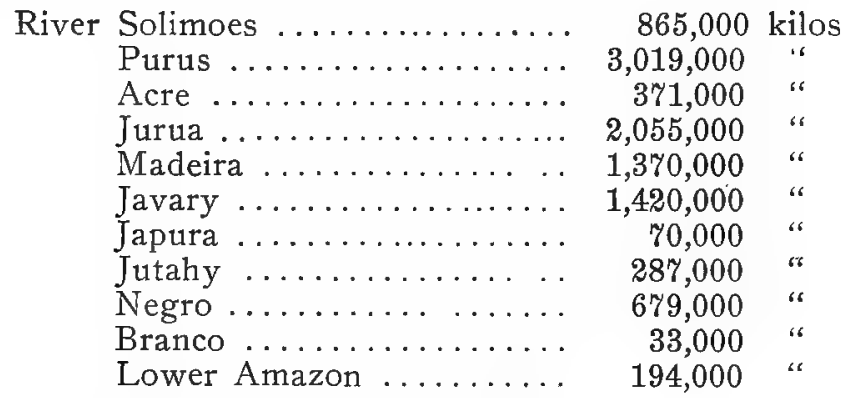

The rubber exporting houses are:

Zarges Ohliger \& Co. (German).

Adelbert H. Alden, Ltd. (American).

Ahlers \& Co. (German).

General Rubber Co. of Brazil (American).

De Lagotellerie \& Co. (French). 


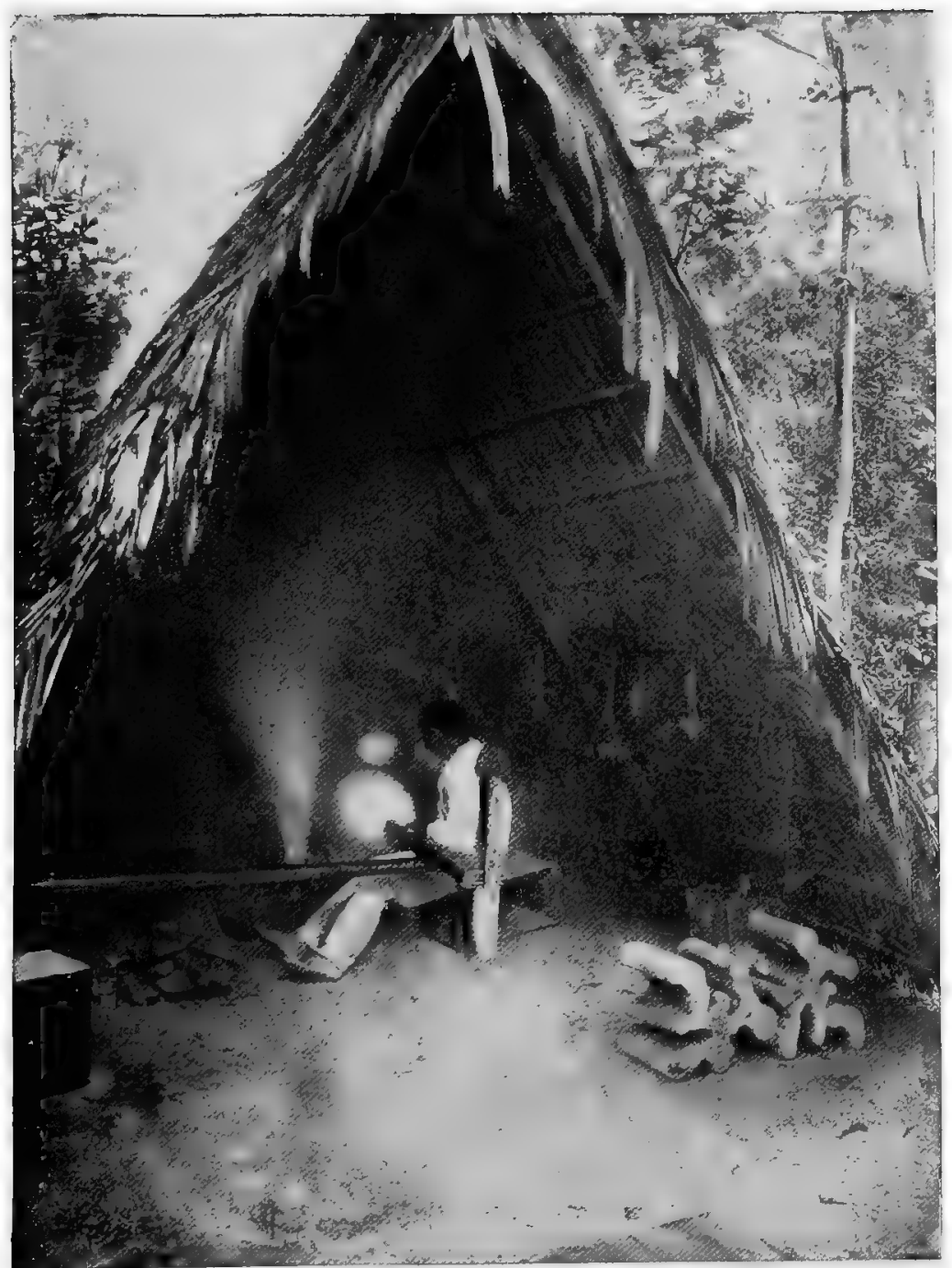

"DEFUMADOR," OR SMOKING-HUT. 


\section{STATE OF AMAZON EXHIBIT INCLUDES:}

Pyramid of 50 tons rubber.

Models of River Steamers.

Rubber Milk.

Photographs and Maps:

Rubber Toys, etc., made by natives.

Basins, Pails, etc.

Large Rubber Tree Stump and several Young Rubber Trees,

Exhibited by Messrs. Asenei \& Co., River Madeira.

Rubber Milk.

Nuts and Appliances for Smoking Rubber.

Exhibited by Sno. Raymundo Monteiro da Costa

\section{COMPARATIVE RUBBER STATISTICS}

\begin{tabular}{|c|c|c|c|c|c|c|c|c|}
\hline \multirow[b]{3}{*}{$1894 \ldots \ldots \ldots \ldots \ldots$} & & \multicolumn{7}{|c|}{ Comparative Rates of Fine Pará } \\
\hline & s. & d. & & s. & d. & & & \\
\hline & 2 & 9 & to & 3 & 1 & $\$ 0.64 \mathrm{r} / 2$ & to $\$$ & $\$ 0.73$ \\
\hline $1895 \ldots \ldots \ldots \ldots \ldots \ldots$ & 3 & $0^{1 / 4}$ & to & 3 & $4 \mathrm{I} / 4$ & .70 & to & $.81 \frac{1}{2}$ \\
\hline $1896 \ldots \ldots \ldots \ldots \ldots$ & 3 & $0 \%$ & to & 3 & 83,4 & .71 & to & .85 \\
\hline $1897 \ldots \ldots \ldots \ldots \ldots \ldots$ & 3 & 5 & to & 3 & 9 & $.79 \mathrm{I} / 2$ & to & .89 \\
\hline $1898 \ldots \ldots \ldots \ldots \ldots \ldots$ & 3 & $71 / 2$ & to & 4 & 5 & .82 & to & 1.06 \\
\hline $1899 \ldots \ldots \ldots \ldots \ldots \ldots$ & 3 & 10 & to & 4 & $7 / / 4$ & .91 & to & 1.10 \\
\hline $1900 \ldots \ldots \ldots \ldots \ldots \ldots$ & 3 & $8 \pi / 2$ & to & 4 & 9 & .83 & to & $1.11 / 2$ \\
\hline $1901 \ldots \ldots \ldots \ldots \ldots$ & 3 & 4 & to & 3 & $11 \mathrm{I} / 2$ & .76 & to & .95 \\
\hline $1902 \ldots \ldots \ldots \ldots \ldots$ & 2 & 10 & to & 3 & $9 \mathrm{I} / 2$ & .66 & to & .92 \\
\hline $1903 \ldots \ldots \ldots \ldots \ldots \ldots$ & 3 & $6 \mathrm{I} / 4$ & to & 4 & 8 & .78 & to & 1.13 \\
\hline $1904 \ldots \ldots \ldots \ldots \ldots$ & 3 & $103 / 4$ & to & 5 & 6 & .89 & to & 1.32 \\
\hline $1905 \ldots \ldots \ldots \ldots \ldots$ & 4 & $10 \mathrm{~T} / 4$ & to & 5 & $83 / 4$ & 1.13 & to & 1.35 \\
\hline $1906 \ldots \ldots \ldots \ldots \ldots \ldots$ & 4 & $11 \mathrm{I} / 2$ & to & 5 & $51 / 2$ & 1.16 & to & 1.28 \\
\hline $1907 \ldots \ldots \ldots \ldots \ldots$ & 2 & $113 / 4$ & to & 5 & 3 & .69 & to & 1.24 \\
\hline $1908 \ldots \ldots \ldots \ldots \ldots \ldots$ & 2 & $9 I / 4$ & to & 5 & 5 & .65 & to & 1.30 \\
\hline $1909 \ldots \ldots \ldots \ldots \ldots$ & 4 & 10 & to & 9 & 2 & 1.13 & to & 2.15 \\
\hline $1910 \ldots \ldots \ldots, \quad \ldots \ldots$ & 4 & 10 & to & 12 & $4 / 2$ & 1.16 & to & 2.90 \\
\hline $1911 \ldots \ldots \ldots \ldots \ldots \ldots$ & 3 & 10 & to & 7 & 1 & .90 & to & $1.67^{\prime \prime}$ \\
\hline
\end{tabular}


FEDERAL TERRITORY OF ACRE 


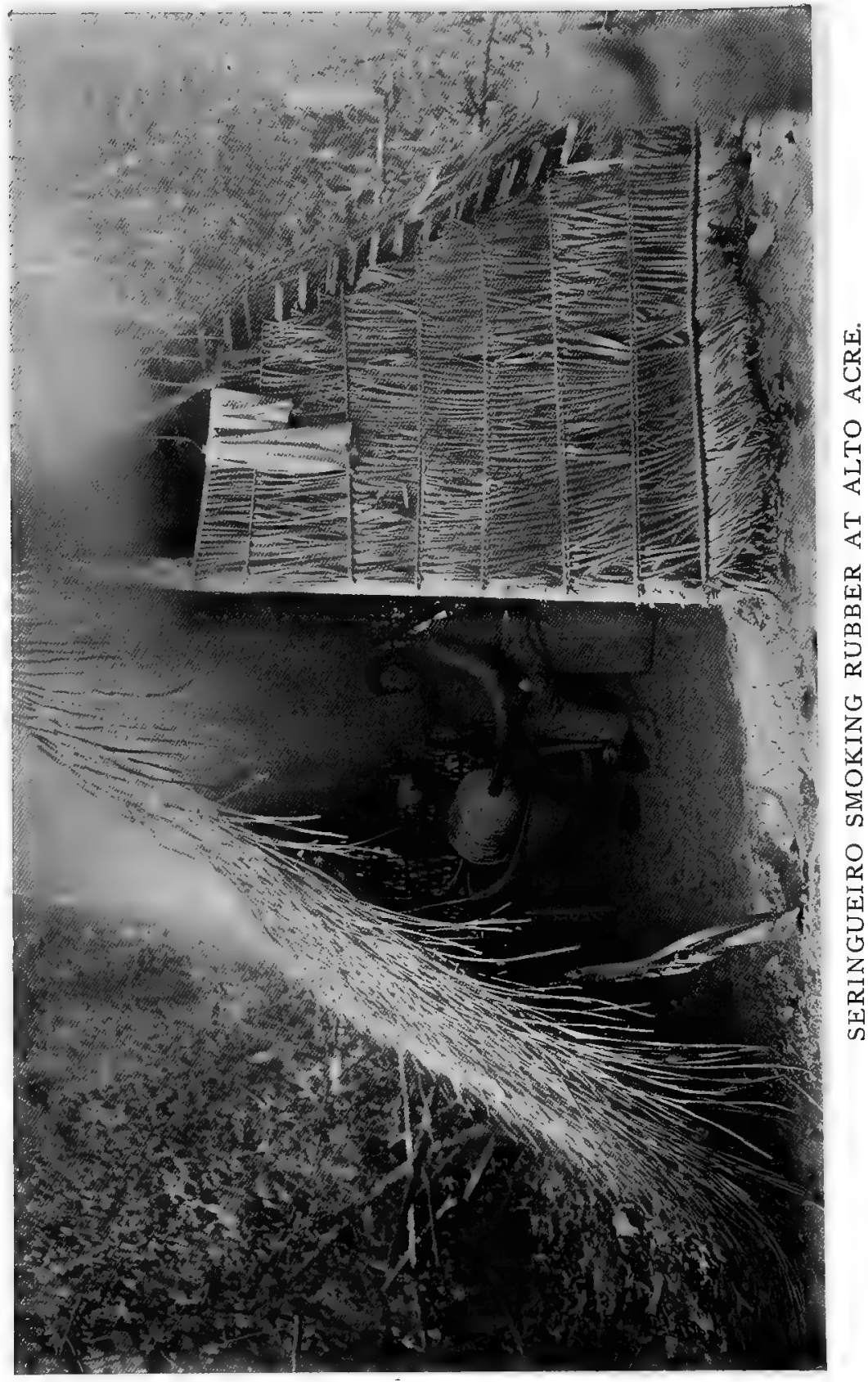




\section{THE ACRE}

\section{THE FLUVIAL REGION THAT IS RICHEST IN RUBBER}

As far as the wealth of rubber obtained from natural sources is concerned, Brazil ranks first among all the world's rubber producing countries. While the East Indian section, with its plantation grown product, has already outstripped her in the quantity of its annual plantation output, the superior excellence of genuine Para rubber has not been attained. The "fine rubber" that comes from the inundated region of the lower river country is best known. In the upper districts of various southern affluents, fine rubber trees grow, but no longer in the lowlands that have long been subject to inundation, they occur rather in forests that are overflowed seldom, if at all, that even extend over the hilly districts. The method of collection and the entire operation of rubber production varies in many respects from the more familiar methods of the inundated districts. This applies particularly to Acre, with its characteristic and peculiar river section:

To explore this section, from economic and scientific points of view, I undertook a journey last year, 1911, at the instance of the Associacão Commercial.

The results of this journey will be embodied in a detail report, it is at present proposed to make only a brief summary to supplement the pictures shown in the exhibition.

Our better knowledge of Acre dates back barely a quarter of a century. At that period uncertainty prevailed as to which of the countries adjoining Acre, Brazil, Bolivia and Peru, were the owners of the territory. In more recent times these conditions have been adjusted, the greater part having been awarded to Brazil, while Bolivia received a portion of the left bank of the upper Acre. The boundary between Bolivia and Peru is as yet undecided. The latter country includes the uppermost left bank of the source section which contains but few fine rubber trees.

The Acre is a right affluent of the larger tributaries of the Purús, entering above the mouth of the Rio Negro and coming from the Southwest, and flows, like these, through the boundless forest tracts of the Amazon River country. It rises in elevated ground, East of the Andes, in a still partly explored 


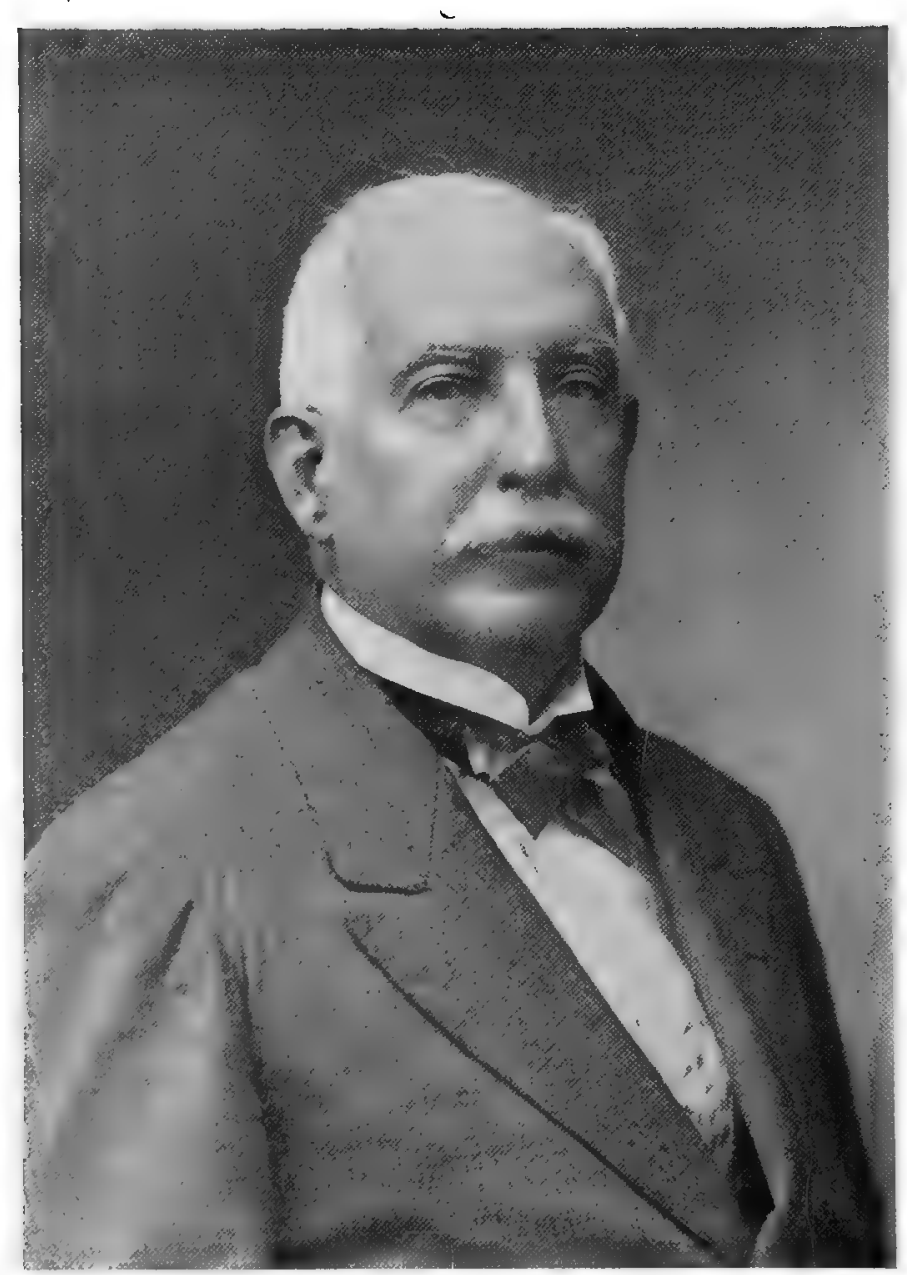

DR. CARLOS DE CERQUEIRA PINTO, Inventor of a Smokeless Process for Curing Rubber. 


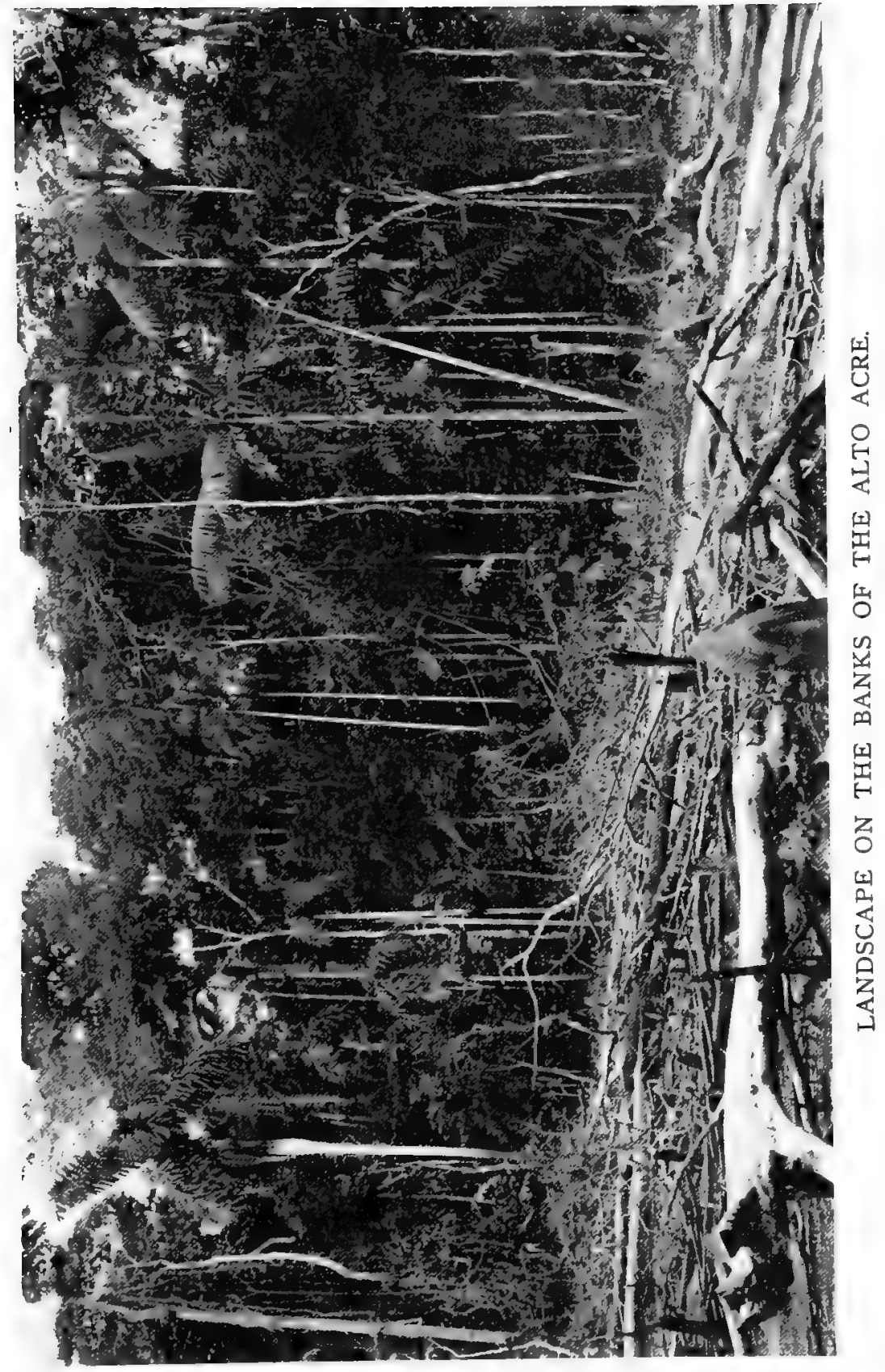


territory, very difficult of access, at about the eleventh degree of southern latitude and $70 \mathrm{r} / 2$ longitude and flows at first eastward, to the Bolivian boundary at $69^{\circ}$. From this point, the Acre flows first Northeast, with a constantly increasing northerly inclination, until it enters the Central Purús at $82-3$ South latitude and $67 \mathrm{r} / 2$ longitude. The small steamers run from this point to the junction with the Amazon and on to Manáos in six to eight days.

In November more than 40 large and small steamers are despatched from Pará and Manáos. They carry supplies for the rubber district and load, for the return trip, fine rubber and other caoutchouc varieties. Such steamers have, as a rule, a cargo capacity of 100 to 300 tons. The largest, taking as much as 500 tons, are at most 50 to 60 meters in length.

The journey from Manáos to the Purús, is usually accomplished in one day. The Purús is a stately river, which, in its lower reaches often attains a breadth of 1,000 meters and although it gradually narrows, it always retains, until its confluence with the Acre, a breadth of several hundred meters.

The trip to that point takes, as a rule, 12 to 16 days and except for the last stretch of about three days, is open all the year. Here is the place called Cochoeiras, where there are rapids, which during the dry season of about four months, obstruct steam navigation on the Purús. The Acre, on the other hand, has a narrow but deep bed, is rarely over 100 meters wide and often contracts to 50 to 60 meters. In the dense forests, there may be seen, from time to time, clearings on the banks with the Baracaos that are the stations for the fine rubber business. Also occasional larger places of residence, villages and little towns, where longer stops are often made, are encountered.

We first pass Antimary, at the mouth of a river similarly named. Then we soon reach Porto de Acre, a large residential place, where the steamers must have their papers passed and pay duties.

This is the beginning of the Federal territory, which is separate from the State of Amazonas and is subject to the central government in Rio de Janeiro. Hardly a day's journey up stream lies the little town of Empreza, with its picturesque houses embowered in foliage. It is the most important place on the lower Acre and the second largest residential town in Acre Territory.

About three days' journey up the river the town of Hapury is reached, which contains several thousand inhabitants and enjoys a considerable trade. It is the largest and most important town in the entire Acre territory.

When at times in the river's narrow water course there are a dozen large steamers lying and a lively business intercourse 


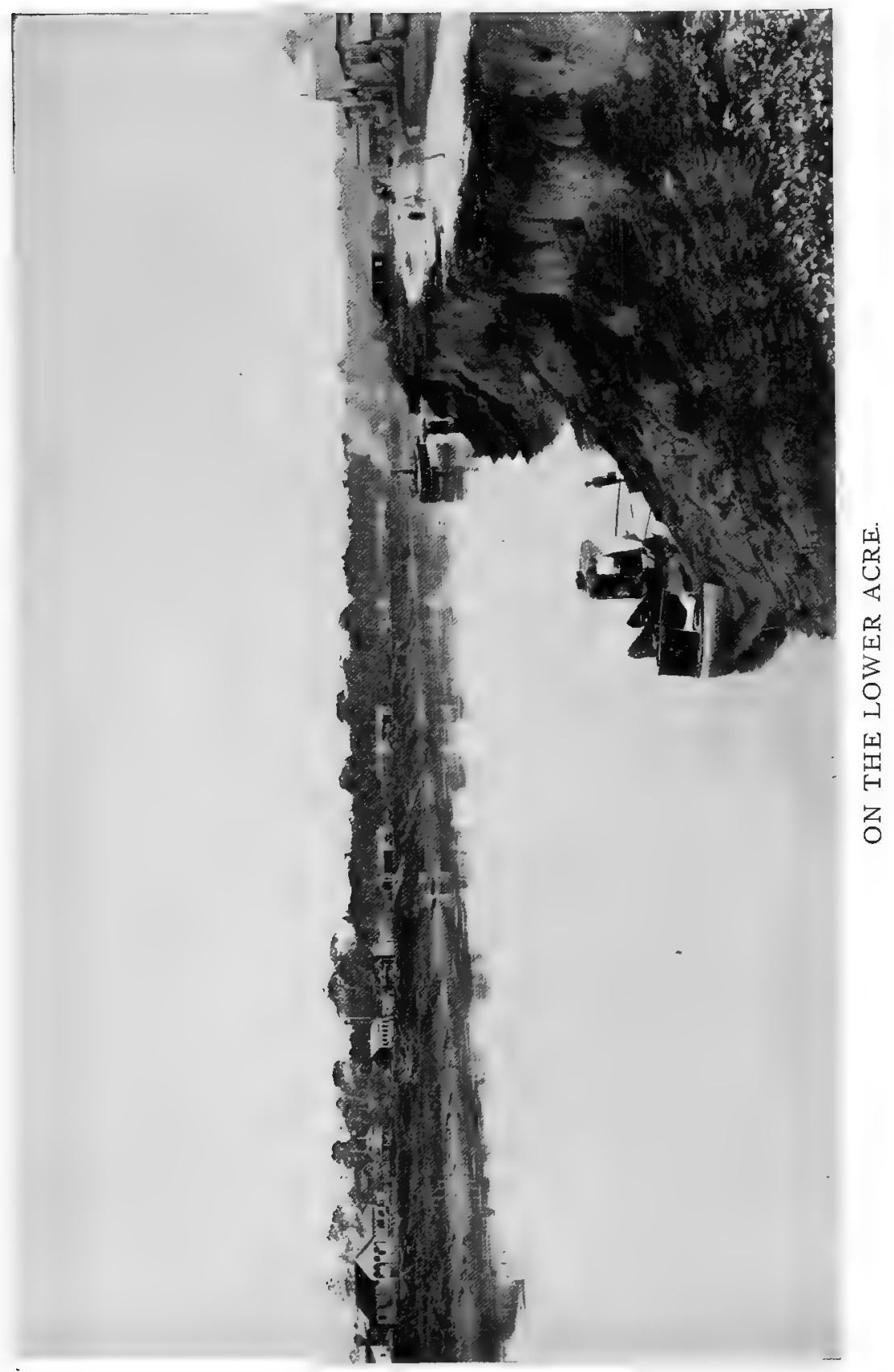


is everywhere in progress, the scene, in the depth of the primeval forest, creates quite an imposing impression. Hapury is considered already in the district of Alta Acre and from this point, the difficulty of navigation increases, the breadth and volume of water of the river alike decreasing. Very rapidly during long, rainless periods, the river water level lowers and the further progress of the steamers becomes impossible. They must anchor at a convenient place and wait until the river rises again. In lower Acre, where water is more plentiful, such interruptions are less frequent, but in upper Acre they are the rule. The farther the river is ascended the more frequent are these compulsory stoppages, often lasting eight to fourteen days. Highwater in the river often lasts but a few days, so that the steamers must stop again. Then too, the many windings of the river make navigation exceedingly difficult. On the upper Acre travel is by day only, boats laying to at night.

Following the course of the river, 85 kilometers above $\mathrm{Ha}$ pury, Igarapé de Bahia is reached, on the Bolivian border and then the little town of Cobija. It is situated on the right bank and belongs to Bolivia, whereas on the left bank, Brazilian territory continues. The steamers here are subject to the Bolivian customs regulations and must pay duty on all goods destined for Bolivia.

A large number of the steamers that start from Manáos, go only as far as this or as Hapury, only a few venture to penetrate further and are not deterred by the great loss of time.

Above Cobija are some of the most productive rubber sections where there are goods to discharge and rubber to be loaded. A few steamers follow the Bolivian border up to the terminal station. Tacna. Here, as a small affluent from the right, the Taverija flows into the Acre, forming at the same time the boundary between Bolivia and Peru.

Bolivia maintains here a small military post, whereas there is only a commissioner for Peru. If the steamer has met with favorable conditions, the trip from Manáos may have been made in a month; ordinarily, however, it takes two or three months. The return trip is made much faster, some steamers, that do not stop, make Manáos from upper Acre in fourteen days.

Above Tacna there are but two rubber forest districts or seringaes as they are termed, the Seringal Auristella on the Peruvian side and the Seringal St. Francisco on the Brazilian side. The latter is a very productive and still young rubber forest, farther up the river the fine rubber trees suddenly cease and their output is no longer remunerative.

The climate, like that of the Amazon country, is humid and hot, with a rainy and a dry season. The southerly situation, 


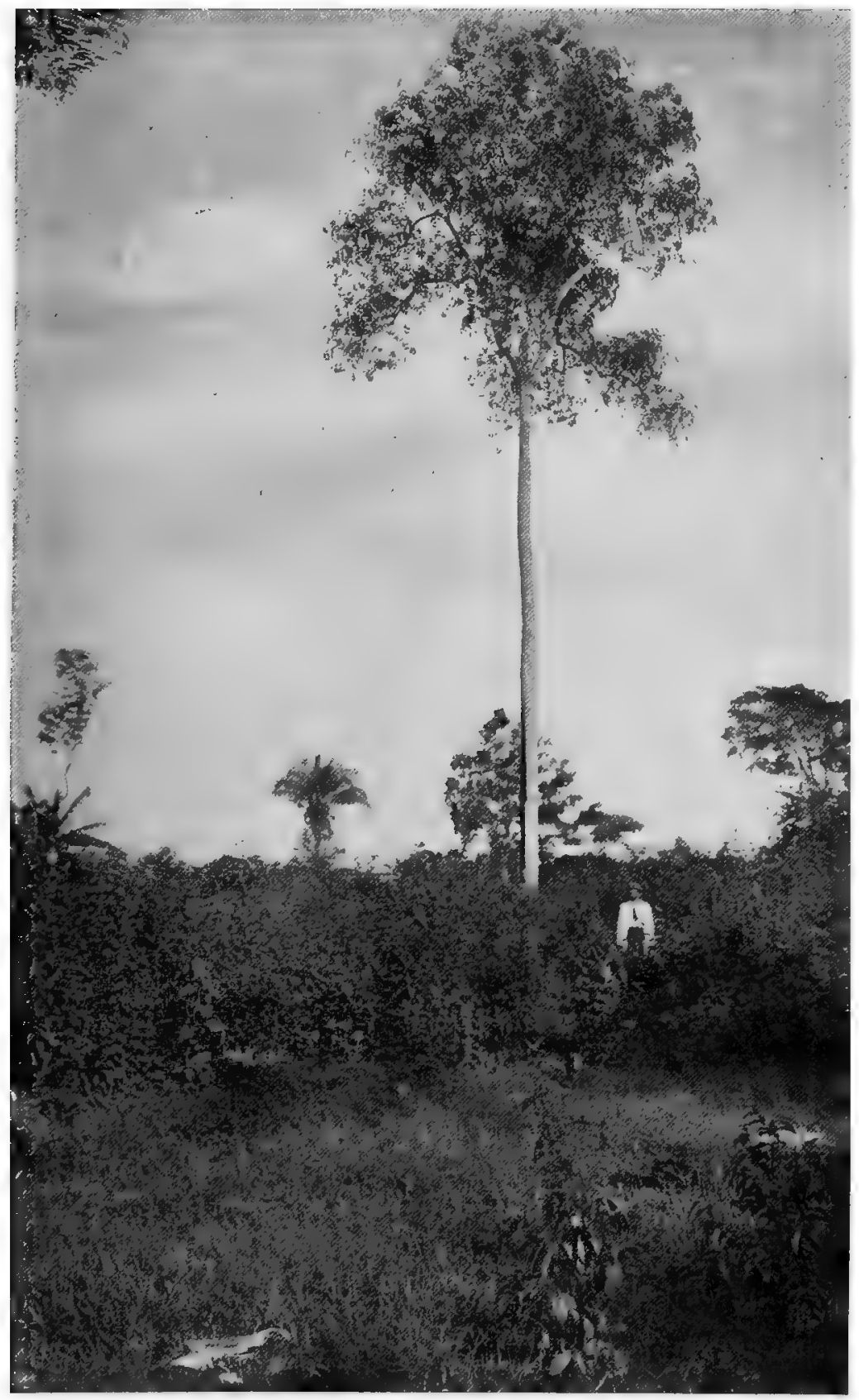

RUBBER TREE AT HAPURY. 
however, causes a somewhat more marked difference between the two seasons. In April, the rains become less frequent and then, until October, there are no or but very few heavy precipilations; some times the fallen leaves on the ground in the woods are dried out and even the dew is absent. There then occur, however, especially in the months of June, July and August, steady cold spells, when the thermometer, in the morning, sinks to $8^{\circ} \mathrm{C}$. and often does not go above $12^{\circ} \mathrm{C}$. during the day. These so-called Friazens last several days and are recurrent, but cease in September. Thunder storms and violent rain storms begin in October, so that in November the rivers are usually navigable again. In December the first steamships arrive. In January and February a rainless period is frequent, which is followed, in March and April again, by a rainy spell. Many steamers undertake, usually at this time, their second voyage and if they have good fortune they make three trips to upper Acre.

The copious precipitation, the heat and the fertile soil have produced in Acre a luxuriant primeval forest, which is higher and more densely overgrown than that of the lower river courses of the Amazon country. Trees of 40 to 50 meters in height are not infrequent, they form a forest of varied composition. There may be found here representatives of the most diverse plant families; some of which, in the cool season, lose their foliage. The forest is densely overgrown with plants, shoots and shrubs. Where a thorny growth, Tapoea and other underbrush gets the upper hand, a macheté or axe is necessary in forcing a path through the virgin forest.

Various kinds of trees are used by the natives for building houses, fashioning canoes and other purposes. For export, however, neither these useful woods nor many other products of the forest, have attained any importance. The fruit of the cacao tree and Pará nuts, rot on the ground, transportation to Manáos being too costly. The caoutchouc products are, however, present in such abundance and possess such great value, that their acquisition and transportation recompenses every effort and have been the cause of the development in these distant primeval forests of a busy life.

The water in the deeply hollowed bed of the Acre, swells in flood time and submerges the land on the adjacent shores and some sand banks, but for the most part does not penetrate into the forest or only for a short period. The flooded forests of the lower water courses, often miles in extent, are lacking and the fine rubber trees grown on land free from inundation, often reaches up into the hills in the hilly or mountainous district.

The fine rubber tree belongs to the Hevea brasiliensis, Múll. 


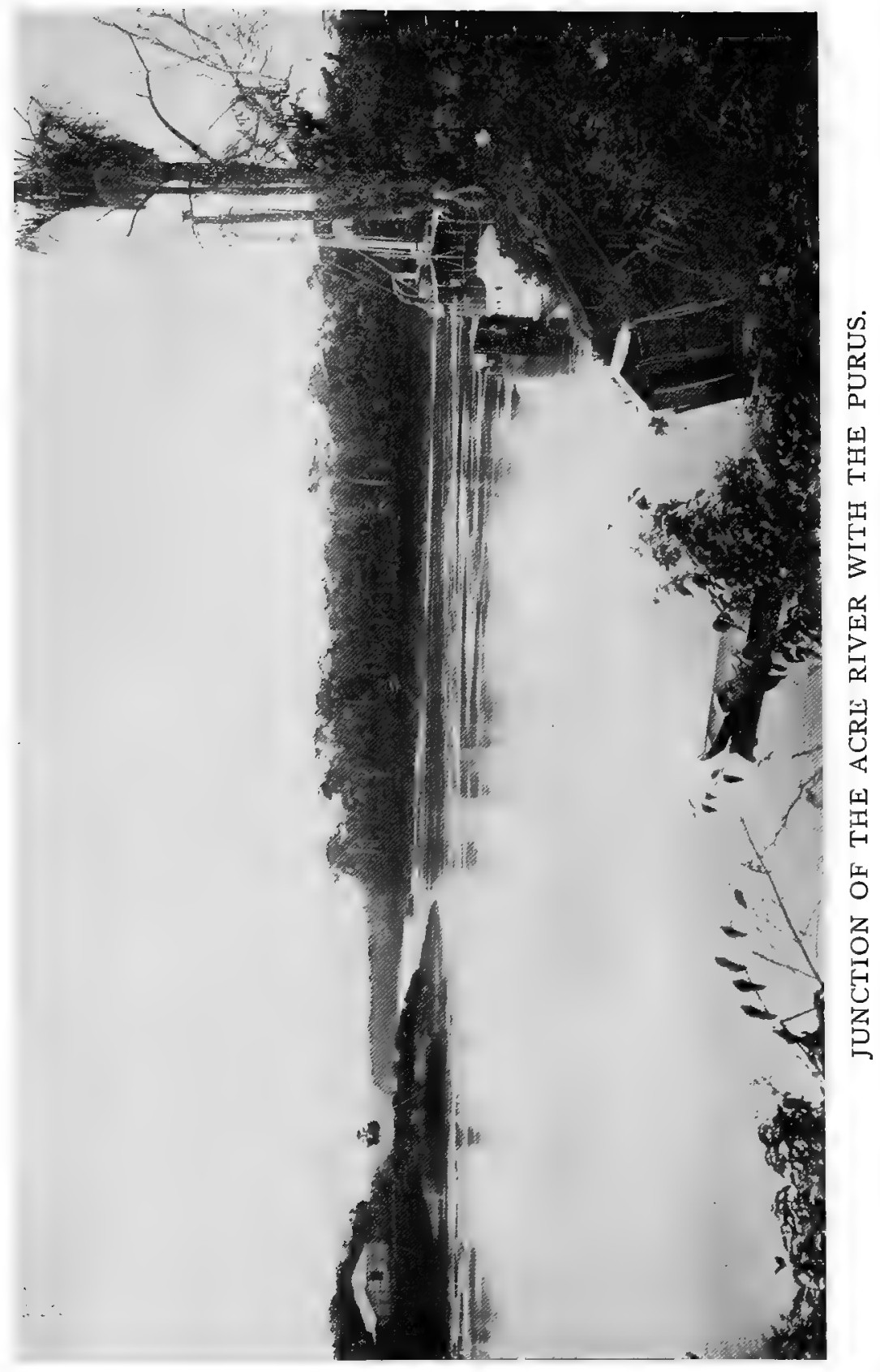


Arg. or to their near families. It is higher and more vigorous than the trees in the inundated districts and has somewhat larger and longer seeds. Trees of more than 40 meters in height and up to five meters in circumference, are not rare. Whether the Acre fine rubber tree is a special species or a variety of Hevea Braziliensis, can be determined only by a very painstaking investigation. In yield of rubber and quality of product, the Acre tree surpasses that of the inundated districts.

Of other Hevea varieties Hevea cuneata Hub. the Seringa vermelha, occurs but rarely, also sapium tapuru, Ule, is found but rarely. Castilloa Ulei, Warb., the "caucho" of the Peruvians, is quite plentiful and is generally utilized, its exploitation being regarded sometimes as more profitable than the fine rubber. Just as in the Amazon country, under the title "caoutchouc," the product of castilloa is mainly understood, so, in Acre, for the yield of the Hevea, the name "fine rubber" is used.

At present, there are on the Acre no unowned, unused lands, but some of the seringaes in operation are capable of further development. In lower Acre there are many seringaes that are badly exhausted and furnish but a small yield. The rubber collectors too, who, as is well-known, cut down the Castilloa trees, are compelled to go further into upper Acre all the time to find profitable work.

Acre territory is regarded as the most productive fine rubber section, especially on its borders; on the little river Hapury and towards the Taurumano, which belongs to the water-shed of the Madeira, the output is said to be exceedingly rich. In proportion to their longitudinal extent, the extent of the woods belonging to Acre, in breadth, is comparatively small, for in a one or two days' journey, it is possible to reach the district of another river. The rubber forest properties are consequently all measured from the river and include usually, a territory of several hundred square kilometers, often in fact, equal to small principalities. Many owners have also several seringaes, often in Bolivia and Brazil simultaneously.

In such a seringal on the river bank, the dwelling with warehouse accommodations and sales-place, is erected, known as the Baracâo in contradistinction to the small Baraken of the work people.

About the Baracâo the forest is usually cleared to afford land for planting and pasture for the cattle.

The management of the seringal and its. entire business, proceeds from the Baracâo. According to the extent of the seringal, from twenty to several hundred work people are employed on it. Through the entire forest, paths, known as estradas, are laid out, from which all obstructive brush and hanging creepers, are cut 


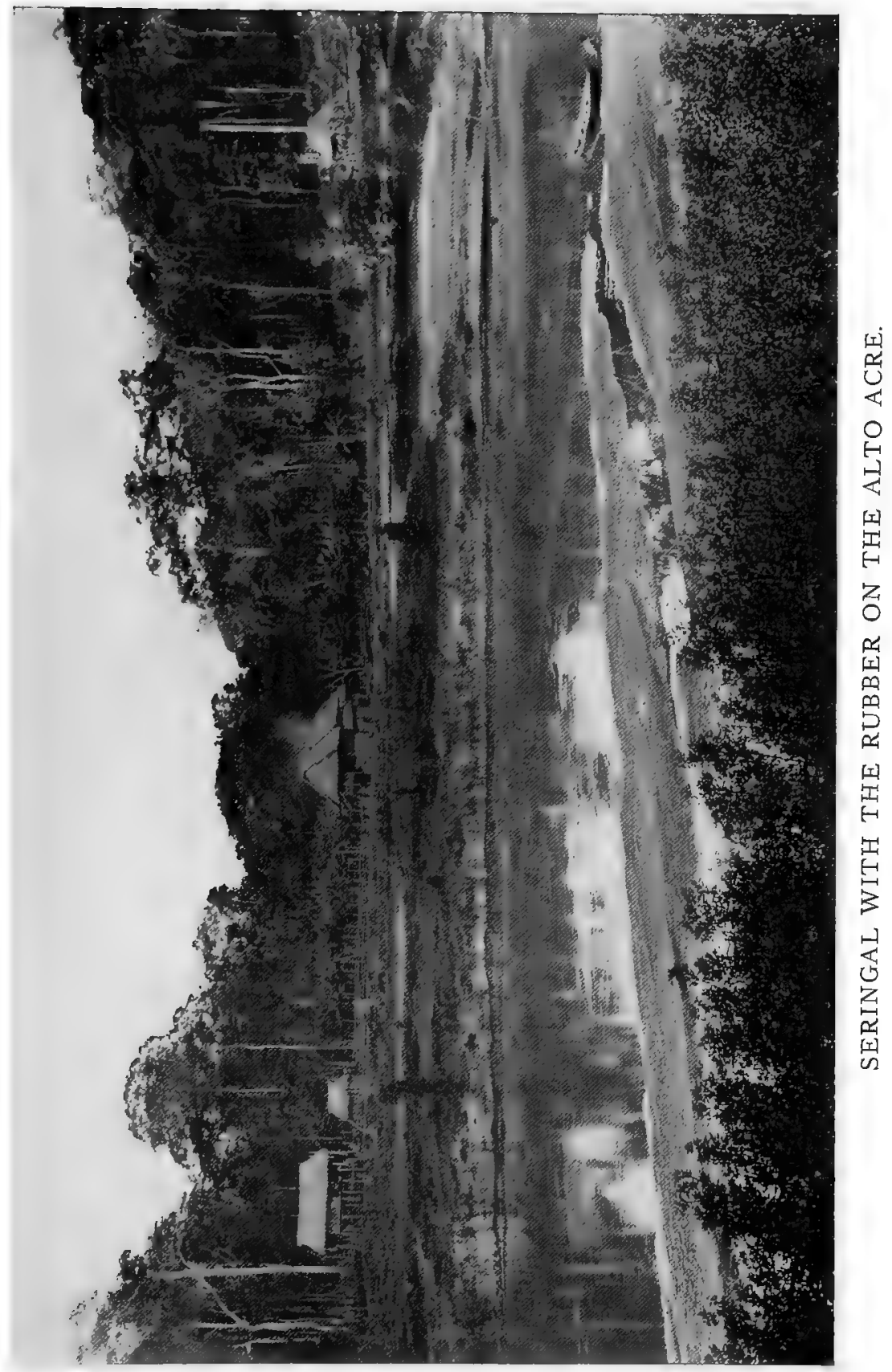


away with the macheté. These estradas, where possible, are laid out in loops, so that they lead back to the starting point and are so planned as to include from 100 to 150 fine rubber trees.

Every seringueiro is alloted two or three estradas to work. These seringuciros live in the interior of the forest in special baraken, either with their families, or usually several together. The different baraken are connected by broader roads that can be traversed by mules.

In May or June, after the estradas have previously been put in order, the gathering of fine rubber commences. The seringueiro proceeds in the early morning into the forest, taps the trees in the customary manner with the little axe Maschadi, attaches the tin cups and afterwards collects the accumulated milk. It is afternoon when he reaches home with the milk he has collected in a rubber bag or in tin cans, to be smoked. In a little hut, roofed with palm-straw, the smoking is proceeded with. Pieces of wood that give a copious smoke are burned and over the fire is placed a tin cylinder, known as a Boiao. The seringueiro first collects, in the middle of a round, strong stick, some coagulated rubber milk and pours the still fluid milk, which he has in a large tin dish, over this place, turning the stick so that the smoke can impregnate the coagulating caoutchouc. He continues this operation until the milk in the tin pan is all used up.

By this means, a rubber ball is produced which is enlarged in the succeeding days until it weighs about 50 kilos. The stick is then withdrawn and the ball, stored with others, until the mule train comes for it. A mule can carry on each side of him 50 kilos without over-exerting himself.

If, however, the weight of the ball exceeds sixty.kilos, the mules are overloaded and the seringueiro who made the balls pays a fine. Where the dwelling place of the seringueiro is near a river and the fine rubber can be transported by canoe, larger balls, that often weigh more than 100 kilos are made.

This gathering and preparation of the fine rubber differs materially from that practiced on the lower water courses where the milk is smoked with much greater care, on the shovel shaped mould and the balls, as a rule, weigh but 10 to 30 kilos. On the Acre, the seringueiro will gather in a day 15 to 25 liters of milk, which will yield 7 to 12 kilos of dry rubber, whereas in the inundated section he will be able to gather but one-half or onethird as much. Of course the seringueiro can smoke the milk much more carefully and take certain precautions, as for instance, that the rubber-milk is never heated. On the Acre on the other hand, the milk is warmed as a rule, because otherwise the large mass is difficult to manage. There is no question but that in this manner the quality of the rubber, which is prepared 


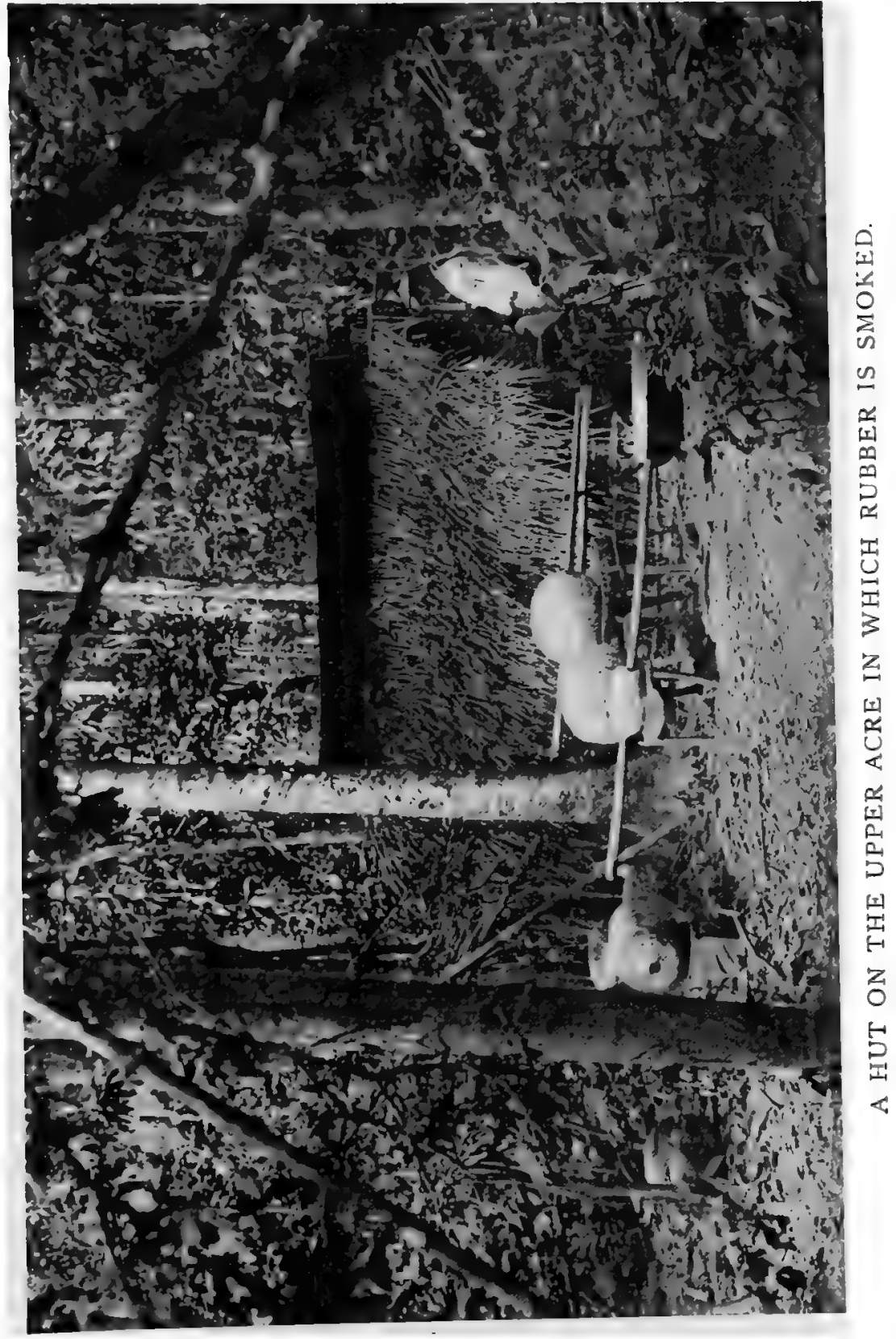


from the best material and certainly would yield the best product, suffers. Nevertheless the rubber balls from Acre, prepared in the primitive manner, furnish a good and much sought for rubber. The tapping of the trees also is often effected with less care, small steel axes being used that make wounds that are too deep and as a result, the seringaes in the Acre are exhausted more quickly than those in the inundated district.

From the baracaos the stations on the banks of the river, small mule trains proceed to the interior to bring in the rubber balls, which are laid in rows, usually in the open air, so that they will be thoroughly dried before loading them on the steamer. By the same mules, food and supplies are sent to the seringueiros in the forest. When the rubber gathering ceases in December or January, the seringueiro has other important work to do. Roads must be opened and repaired, clearings made in the forest, huts erected, wood cut and finally the paths set in order for the approaching harvest. During the rainy season, the steamer brings new supplies and food, which the seringueiro must buy at the Baracao.

Concerning the duties the seringueiro has to perform, there are special regulations, which prevail in most seringae and of which written or printed copies are often furnished.

To each seringueiro is allotted two or three estradas, each with 120 to 200 trees. For this he pays 15 per cent of his gathering of fine rubber to the owner of the forest and an additional 10 per cent if he uses the mules for transportation. The remaining rubber belongs to the seringueiro in so far as he does not have to pay it for goods purchased. As a rule, the owner purchases a portion of the product on the spot at a price that is, of course, somewhat lower than is paid in Manáos, the remaining portion is shipped, for account of the seringueiro, to Pará and Manáos, and he receives the full market price for it, of course, after deducting freight and duties. The balance is placed to the credit of the seringueiro and paid to the firm representing the owner in Manáos or Pará. Certain items, for instance, the price of Sernamby, consisting of residual scraps of rubber, the seringueiro also receives in Acre. In some cases payments are made in rubber products, a form of payment quite common in other transactions.

On the upper Acre, a seringueiro will usually collect in a day as much milk as will yield from 6 to 15 kilos of fine rubber. Two liters of this milk yield a kilo of dry rubber, whereas with Manihot Glaziovi, 3 liters are required for this. Exceptional cases occur where the seringueiro furnishes milk for 20 to 25 kilos of fine rubber in one day. Daily collections of more than 40 liters, however, a single worker can hardly control and he 


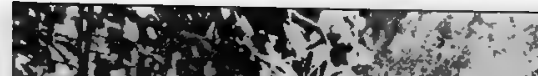

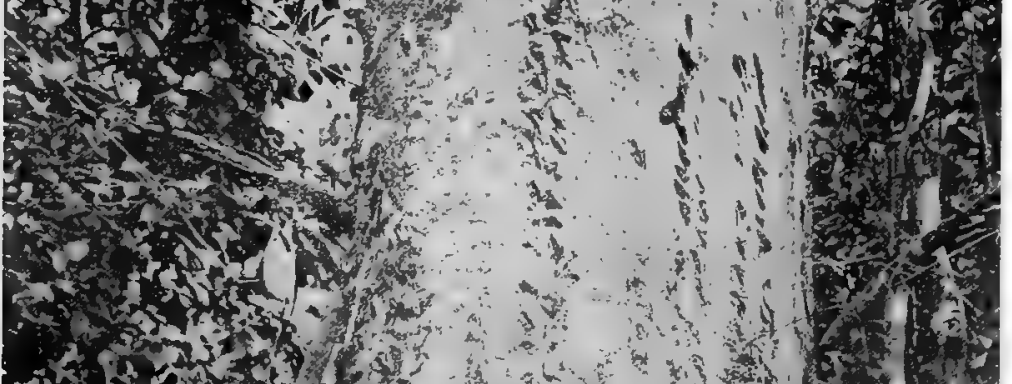

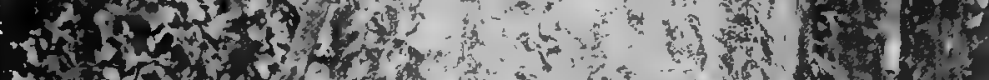

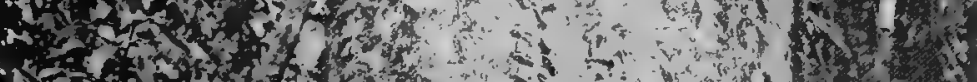

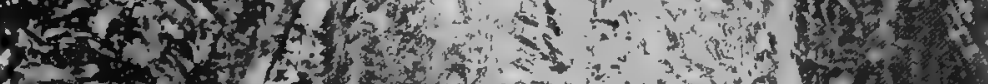

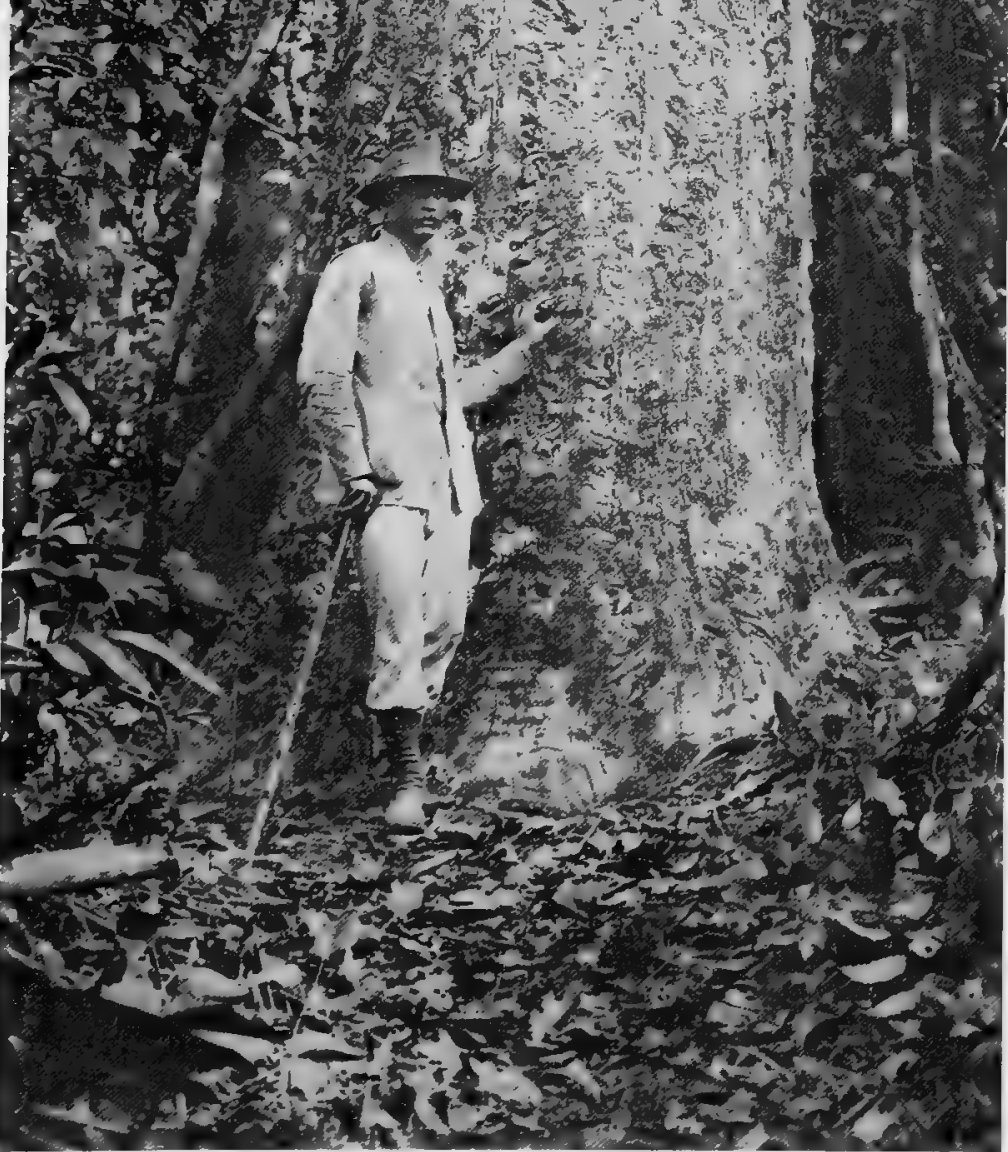

RUBBER TREE OF NEARLY FIVE METERS IN CIRCUMFERENCE. 
must then have an assistant for carrying and smoking. The yearly production of a seringueiro amounts, in the better rubber forest properties, to upwards of 1,000 kilos of dry rubber.

Some owners offer a reward, such as for instance, a gold watch, for the most industrious and luckiest seringueiro. On the Seringal S. Francisco, for the crop year 1911-1912, a seringueiro won the gold watch who had collected 2,500 kilos. The annual highest yield of caoutchouc from the Castilloa was only $1, \% 00$ kilos, for the forest there in regard to Castilloa is already very much exhausted. Otherwise the yields of this rubber are more variable and higher than those of fine rubber.

If the price of rubber rules high, a seringueiro has quite a considerable income and with a little frugality can acquire a property.

If, on the other hand, the price of rubber drops below five milreis, the seringueiro has trouble to make both ends meet with his income and easily gets into debt. The supplies that he must purchase from the proprietor or his representative (lessee) are very expensive. The customs duties, the long haul and consequently high freight, the risk, the different losses, which the proprietor suffers through debtor workmen, and the occasional high price of fine rubber, which forces all prices upward, makes everything in upper Acre very dear.

The prices of some of the most necessary supplies and goods are about as follows.

1 kilo mandioka flour, $2 \frac{x}{2}$ milreis.

1 kilo coffee, 4 milreis.

1 kilo sugar, 3 milreis.

1 kilo beans, 3 milreis.

1 kilo rice, $2 \mathrm{~T} / 2$ milreis.

1 kilo dried meat, 5 milreis.

1 kilo fresh meat, 4 milreis.

1 chicken, 30 milreis.

1 dozen eggs, 10 milreis.

1 bottle brandy, 8 milreis.

1 meter goods, 3 to 6 milreis.

1 woolen quilt, 120 to 140 milrcis.

1 pair boots, 40 to 60 milreis.

1 cake washing soap, $31 / 2$ milrcis.

1 piece fine soap, 5 milreis.

1 macheté, 14 to 22 milreis.

1 package matches, 3 milreis.

1 carbine, 200 milreis.

1 kilo powder, 28 milreis.

1 kilo shot, 4 milreis. 


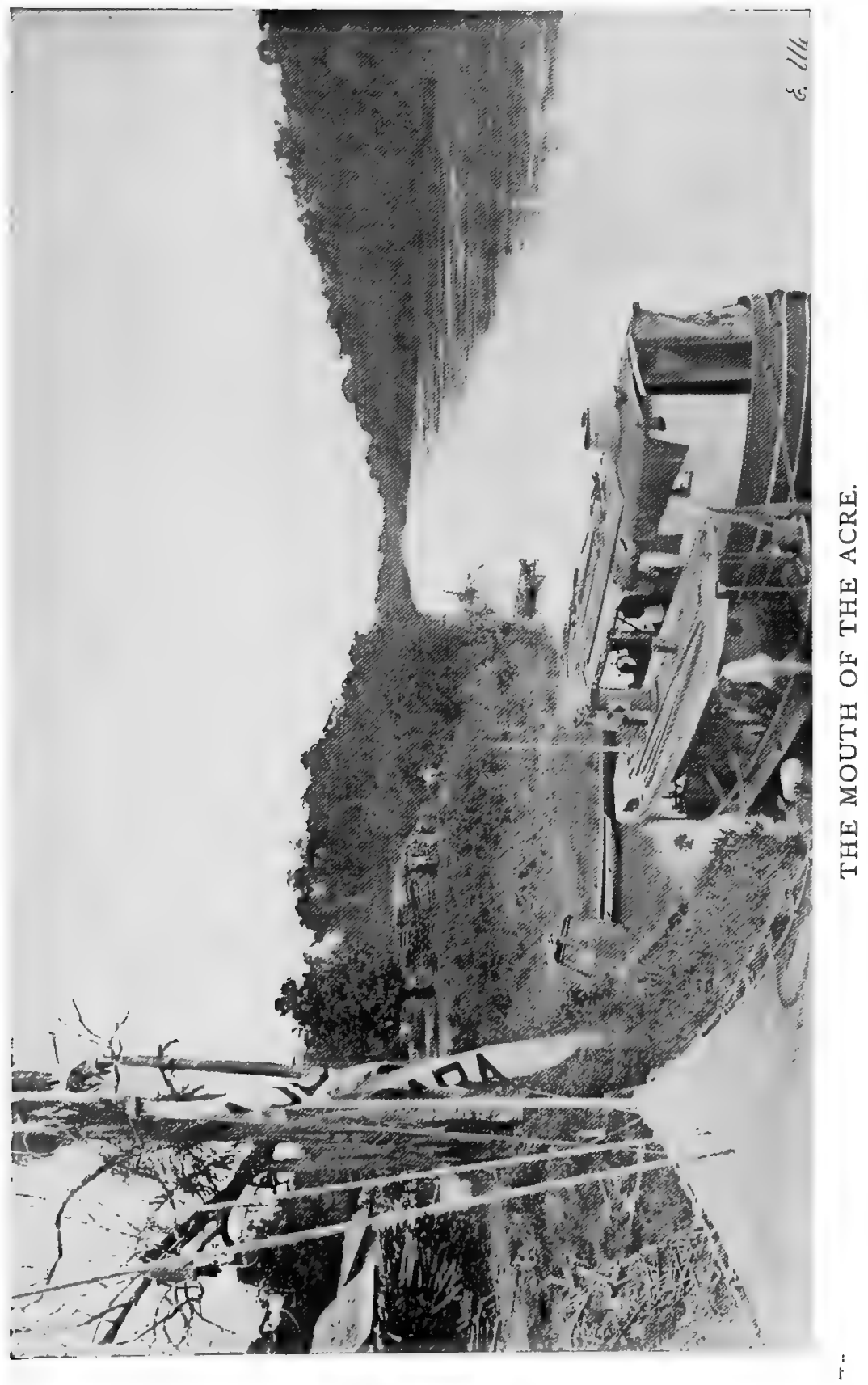


1 pound sterling is now worth about 15 milreis, so that four shillings (about one dollar U. S.) $=3$ milreis.

On the lower Acre, goods are much cheaper and they fall still lower down to Manáos, where many articles only cost onethird or one-fourth as much, or even less, but Manáos is nevertheless an expensive city.

The large profits which fine rubber often yields, make all labor very dear. For this reason agriculture has developed but slowly and most food supplies must therefore be imported. Nevertheless cattle raising is constantly growing, stock being brought in from Bolivia. Bananas, the tubers of the sweet mandiola, beans and some vegetables are extensively grown, especially by Peruvians and Bolivians. Often the seringueiro will plant some bananas and cultivate a small patch of cleared land, but this is not favorably regarded by the proprietor. In some seringaes, even the marriage of the seringueiros is opposed; everything is directed towards obtaining the largest possible quantity of fine rubber.

Although the Acre is not very full of fish, fishing, in the dry season, is attended with some success, which particularly benefits dwellers on the banks of the river. Hunting also, in some sections, furnishes residents with fresh meat. As animals of the chase may be enumerated, monkeys, Taca, Aguti, wild swine, small varieties of deer, sloths, tapirs, various wood fowl and ducks.

Very different from the arrangements customary, as a rule, in the Acre, are the conditions in the Bolivian rubber districts, which for the most part are owned by a single proprietor, N. Suarez y Hermanos. He is said to produce 1,500 tons of fine rubber per year, and could produce more than four times the quantity if the entire forest concession, which is probably as large as South Germany was all put in operation. One portion of this rubber forest is situated on the Acre, but the greater part includes the Southwestern tributaries of the Rio Madeira. In the properties on the Acre, the working methods are adapted to Brazilian customs, especially where Brazilian seringueiros are employed.

While in the Seringaes, trade is conducted mostly through the Baracões, there are in some places, notably in Cobija, Hapury and Empreza, various business houses, through which the owners of seringaes, captains of ships and other persons, can supply their wants, for before the steamer returns, there is often a scarcity in some products.

The retail trade is mainly in the hands of so-called Turks, various Orientals, from Syria, Arabia, Tunis and Morocco. They have large boats, propelled by poles and oars and which contain 


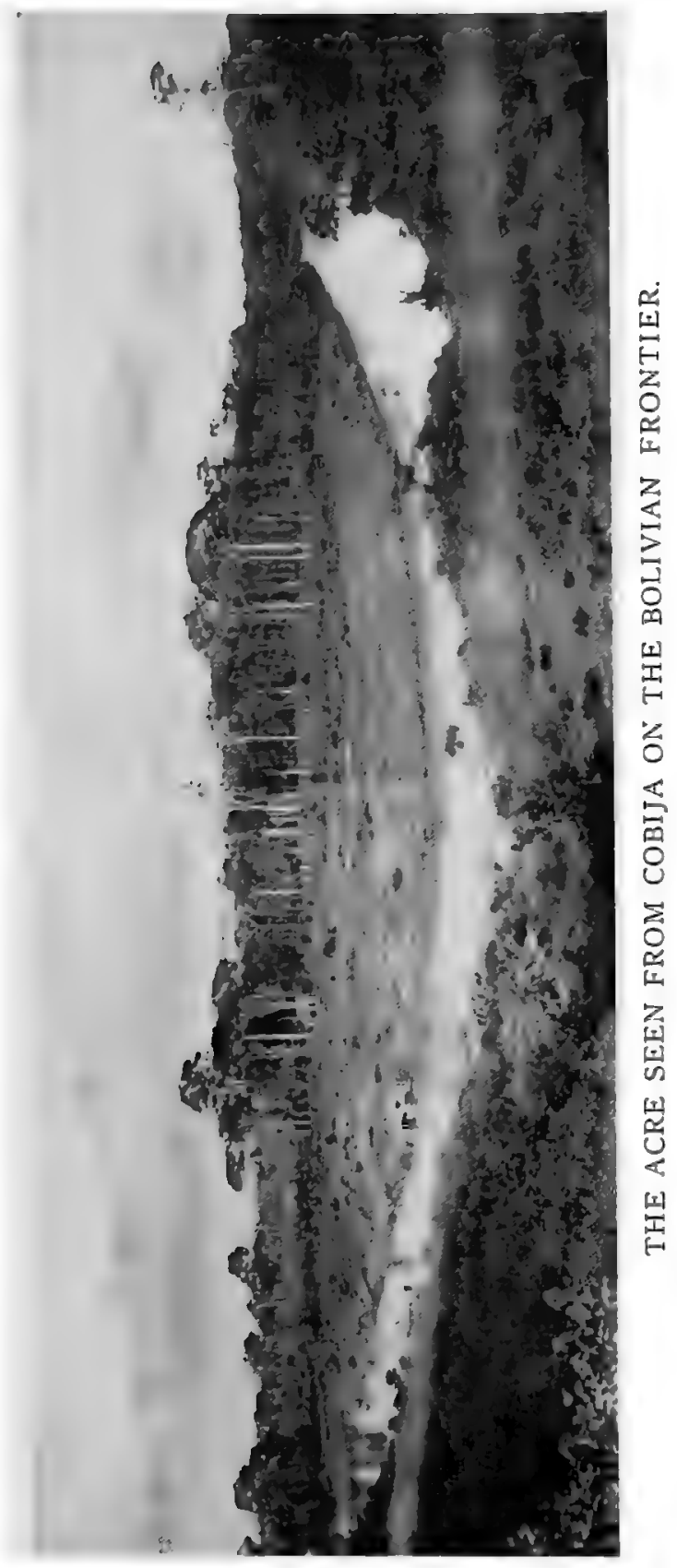


the goods in a covered space. These Turks travel as pedlars for years about on the rivers, selling their goods for money or rubber. This commerce is designated Regatao and is not favored by proprietors, who sometimes forbid stopping in their territory. The seringueiro can not only buy cheaper of them, but can dispose of caoutchouc surreptitiously.

Those who encounter favorable conditions on the Acre, who are diligent and economical, can, by working in the rubber industry, or in any other field of activity, soon acquire a property. The majority, however, squander their earnings on trips to Manáos, Pará or Ceara, or suffer from sickness.

Although hygienic conditions on the Acre have improved with the times and there are numerous healthy localities, malaria still prevails there a greät deal, and other diseases, notably beriberi, are often fatally prevalent. Many privations, caused by the difficulties of travel, and a certain amount of luxury, made possible by the large earnings, often contrast with one another.

From Acre, during the year, about 5,000 tons of fine rubber, inclusive of other rubber products, are exported, of which certainly a portion comes from the adjacent territory.

This quantity, according to the price of rubber, will represent a value of 20,000 to 75,000 contos of reis, about $\$ 5,000,000$ to $\$ 15,000,000$. These are figures that play a part in the total output of rubber, the importance of which is increased by its quality.

\section{THE ACRE TERRITORY.}

Previous to the Treaty of Petropolis, in 1903, between Brazil and Bolivia, the Acre Territory formed part of the State of Amazonas, one portion being, in fact, still in dispute. By virtue of this treaty the Acre Territory became Brazilian, Brazil in exchange paying $£ 2,000,000$ to Bolivia, an indemnity to an American syndicate, and undertaking to construct the Madeira Mamore Railway.

The Congress then empowered the Federal authorities to administer the Territory until the question should be finally settled.

The administration is much the same as that of the other States. Recent laws have tended to decentralize the administration, the latest being one giving municipal independence. The three provinces of the Territory are:

Upper Purus (capital Senna Madureira).

Upper Jurua (capital Cruzeiro do Sul), and

Upper Acre (capital Empreza). 


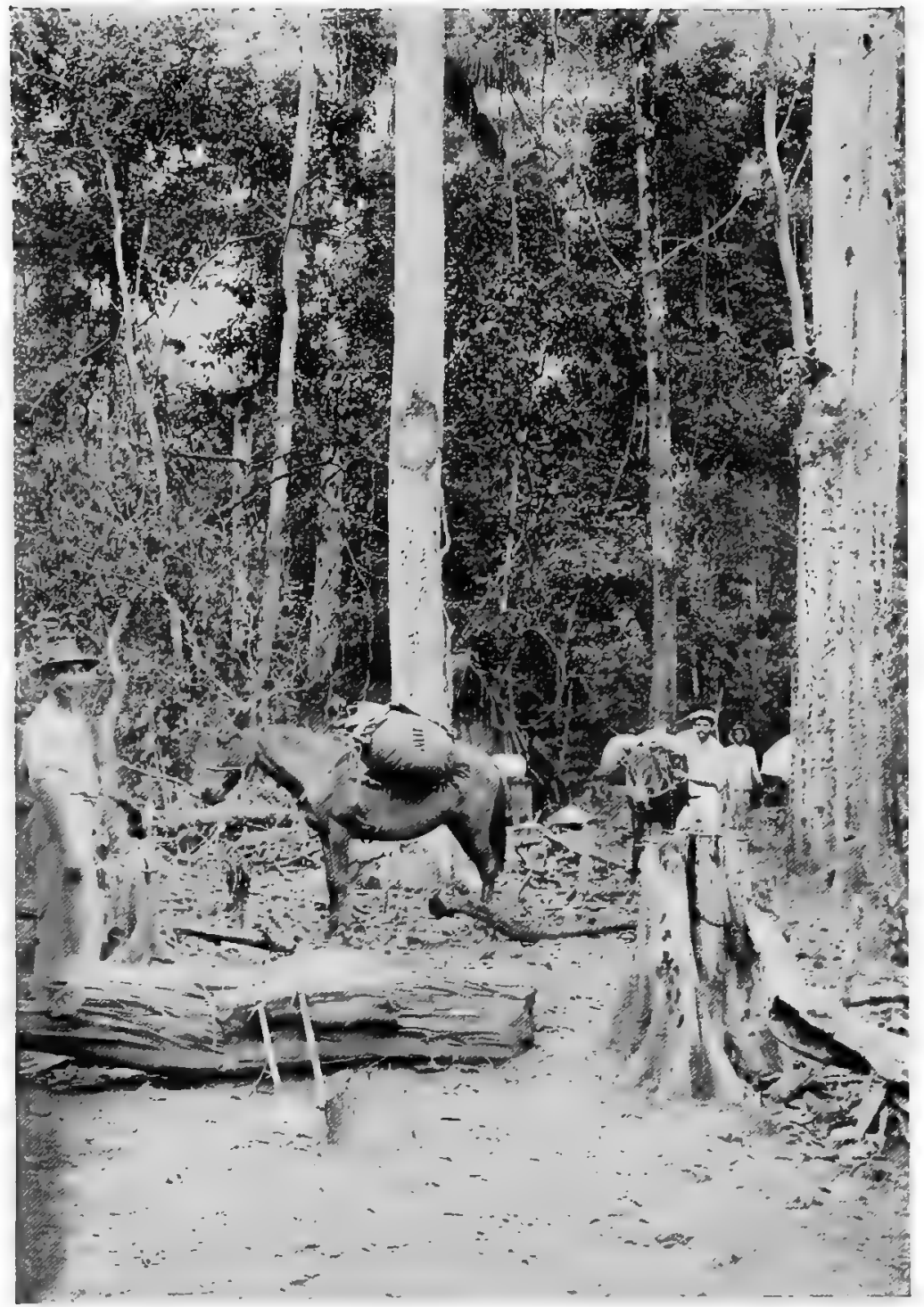

TRANSPORT OF RUBBER BISCUITS. 
The only product and export is rubber, the proportions during 1911 being:

$$
\begin{aligned}
& \text { Upper Purus ...... 4,042,000 kilos } \\
& \text { Upper Jurua ....... } 3,008,000 \text { kilos } \\
& \text { Upper Acre ....... 3,526,000 kilos }
\end{aligned}
$$

One of the most serious questions has been that relating to the ownership of land. The Federal Congress is prepared to solve this problem satisfactorily, by recognizing bona-fide holdings dating from before the Treaty of Petropolis, giving preference to property deeds granted by the State of Amazonas, next to those given by the Republic of Bolivia during its brief occupation, and then to any possession obtained in good faith during the whole interregnum, up to the date of the last law passed.

\section{GENERAL OBSERVATIONS.}

For the protection of Brazilian rubber, and in order to facilitate and develop its culture, as well as its final handling, a Federal law was passed on January 5th of the current year. (No. 2513 A.)

Its principal measures are especially concerned with Amazon rubber and the country in which it is produced, viz.: the States of Amazonas and Matto-Grosso and the Acre Territory. The scheme embraces the construction of railways and roads, the clearing of rivers, reduction of import duties and of dues on river navigation, the establishing of coal depots, living accommodation for laborers, centres for the production of foodstuff, model cattle farms, prizes to rubber planters and exemption from import duties on all material for rubber working.

Besides the Madeira Mamore Railway, which benefits principally the Madeira River district of Matto-Grosso, and a further branch of the same railway, now in course of construction, and which is intended to open up the Bolivian district of the Beni River, the Brazilian Government will construct another railroad (in the route of which the Commercial Association has suggested some alterations) to commence from Manaos and to work through the region of the Rio Branco, to link up with the English railroad already constructed in British Guiana up to the Brazilian boundary. This railway will open up to the State of Amazonas a huge tract of country admirably suited to agriculture of all kinds, and to colonization by Europeans.

The Association Commercial will also propose the construction of a further railroad to communicate by means of branch lines with the various provinces of the Acre Territory, in order to bring the product of that region to the lower Purtis River, at a point which will admit of free access to steamers of deep draft to and from Manaos. 


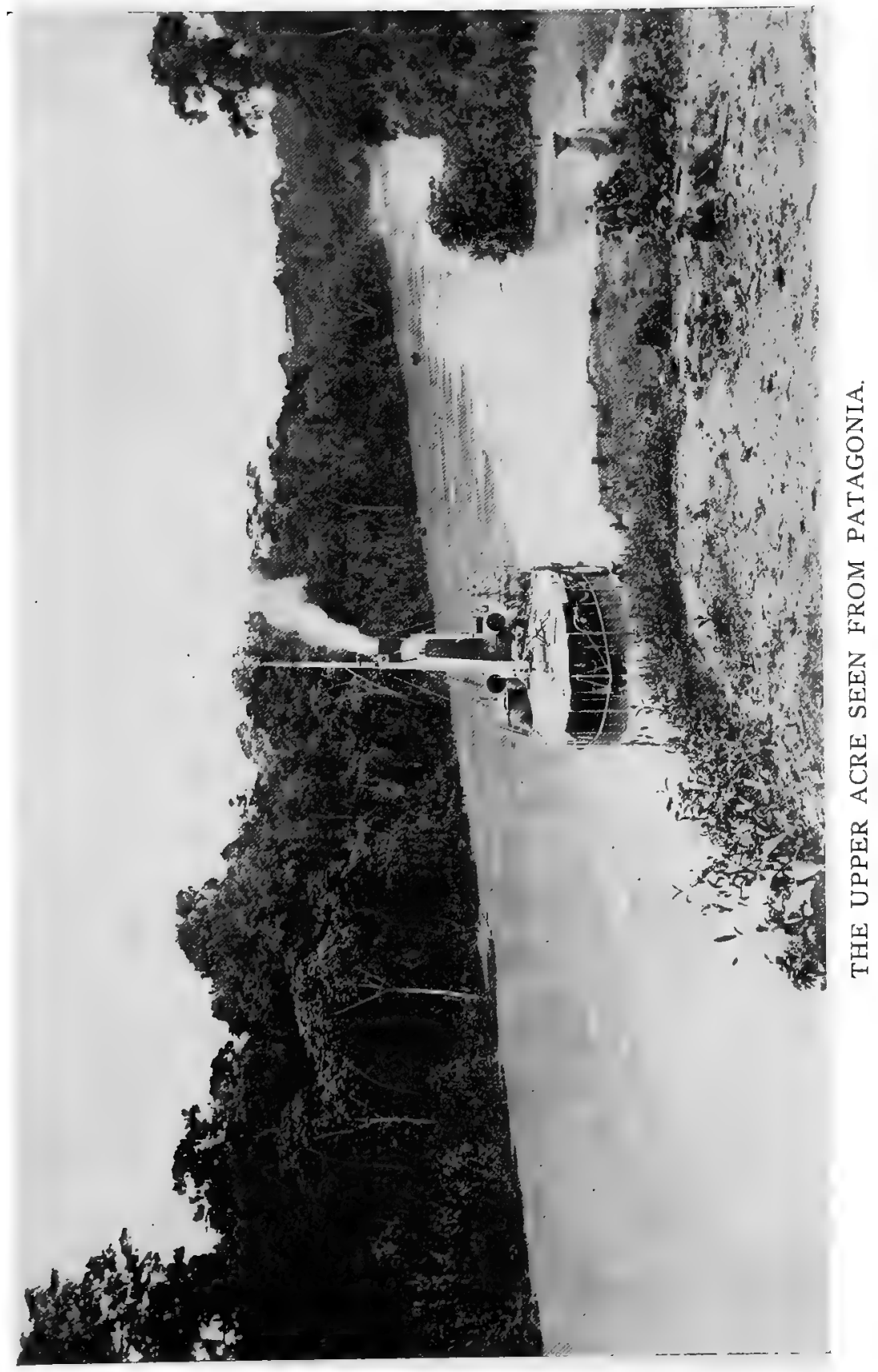




\section{DR. CERQUEIRA PINTO'S PROCESS}

\section{EXTRA FINE PARA}

This rubber was cured for export in the rubber estate "IRACEMA," in the Federal Acre, Amazonia, Brazil; by Dr. Cerqueira Pinto's process of smokeless coagulation. (See The India Rubber World, August 1, 1909, page 396, and copy of the same journal of 1st September, the same year, page 435.)

The enclosed sample contains 68 kilos and belongs to the lot of 5.000 kilos (11.025 lbs.) that Dr. Cerqueira Pinto holds to be sold in New York.

Dr. Cerqueira Pinto's process is one of coagulation of the latex of the "Hevea Brasiliensis" by an ingredient patented by the Brazilian Government_- "LACTINA"--absolutely free of any acid.

The latex after the coagulation is pressed through a cylinder in order to dry out.

This rubber was tested and classified as of STANDARD type by the Government of the United States of America.

It offers the resistance of 2,010 pounds per square inch according to the experiments made by The Manhattan Rubber Company in July, 1909. This rubber means a saving to the manufacturer of at least 20 per cent, in the opinion of the Favorite Rubber Mfg. Co. of New Jersey and of 25 per cent, as per the analysis made in London.

The author of this process calls the Jury's attention to his rubbers and is willing to furnish with the sufficient quantity in order to prove to the entire satisfaction of his assertions. It vulcanizes as well by acid as by vapor. Dr. Cerqueira Pinto will prepare, during the Exposition, in September, before the public and the manufacturers, his rubbers with both Hevea and Castilloa latexes, yield of the trees in October, 1911, in the Federal Acre, Brazil. He shall present as well a large quantity of similar rubbers cured by the author on different occasions. They are true rubbers of commerce cured for export. They are clothed by a vegetal varpish, soluble in water, which is also a discovery of Dr. Cerqueira Pinto, to prevent the mould.

CASTILLOA OR CAUCHO.

Prepared by the process of Dr. Carlos de Cerqueira Pinto. (See the India Rubber World of September 1st, 1909, page 435).

The included sample weighs 68 kilos. The author holds 1,400 pounds of this quality to be sold in New York market.

The article was cured by rubber laborers of the estate "Iracema" in the Federal Acre, Amazonia, Brazil, during the months of July to December, 1911. They are rubbers of commerce and cured for export. 


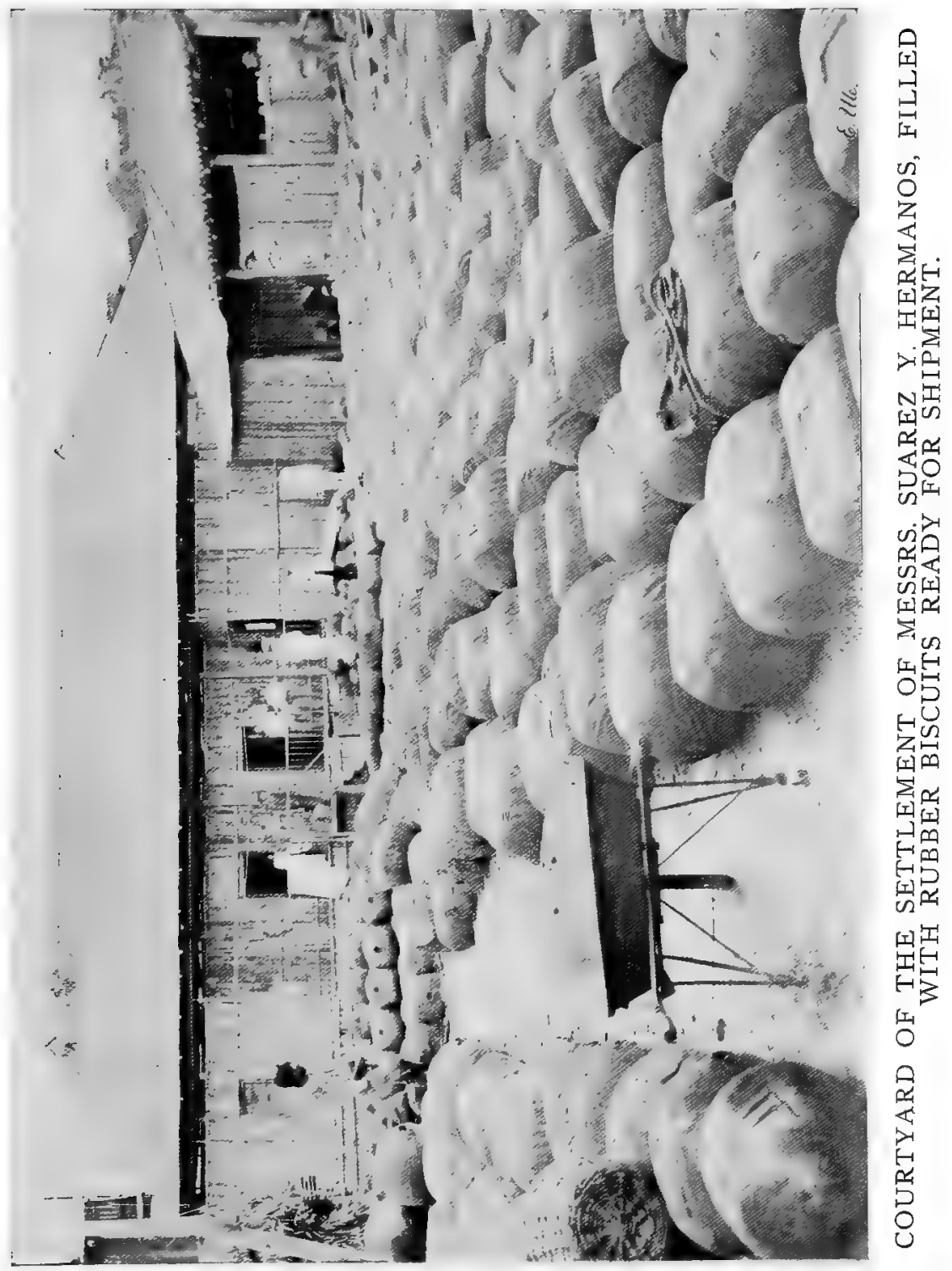




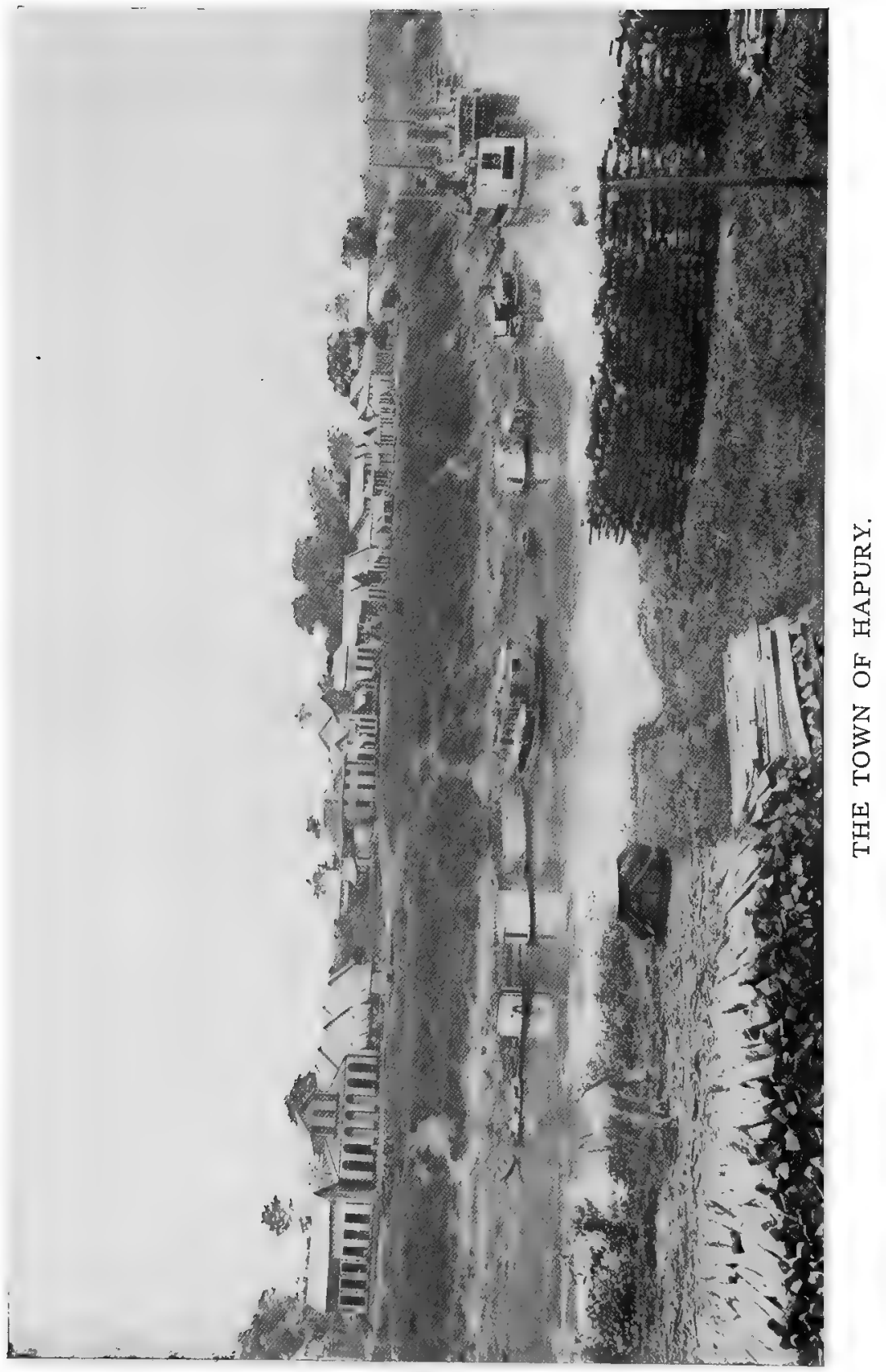




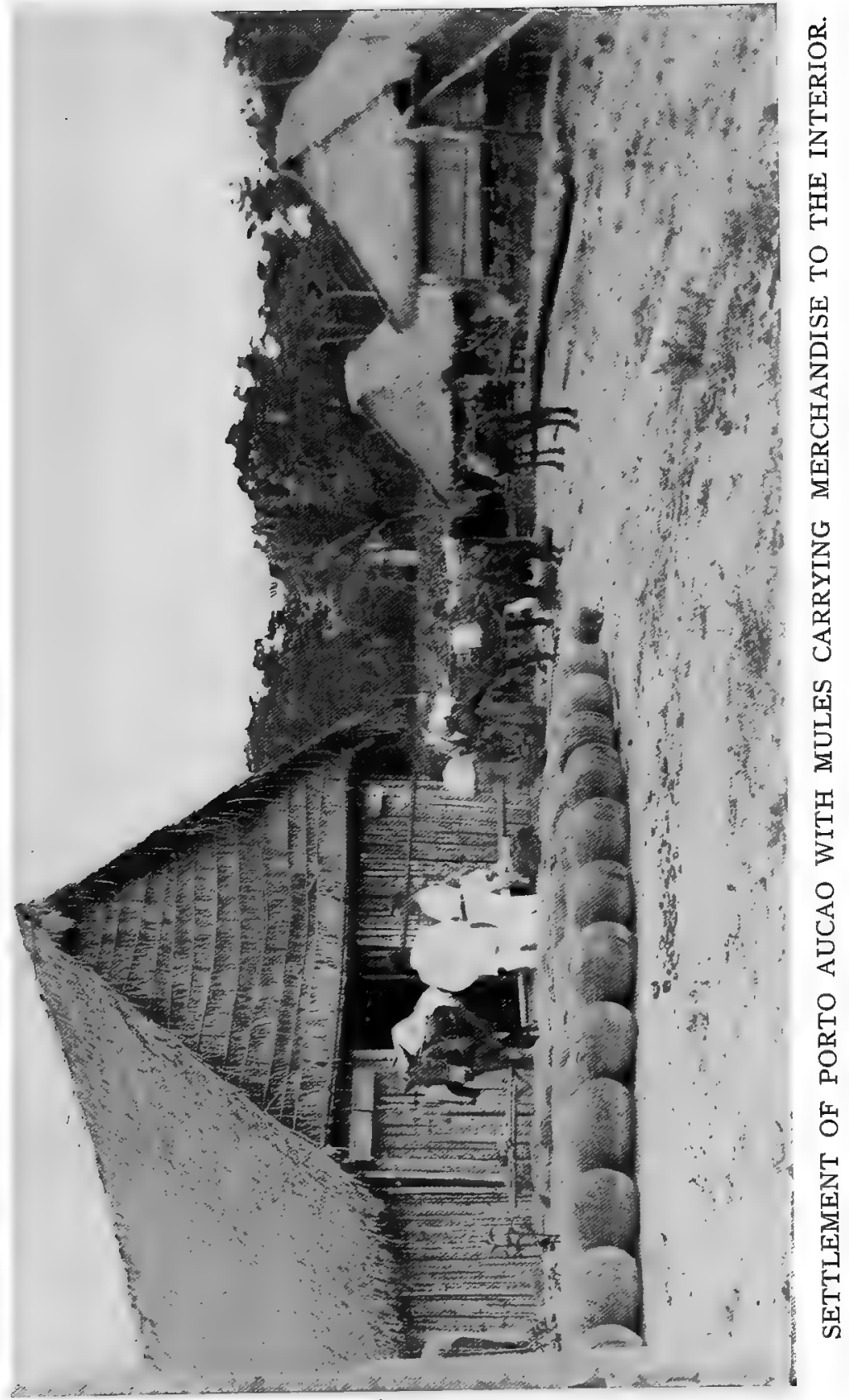




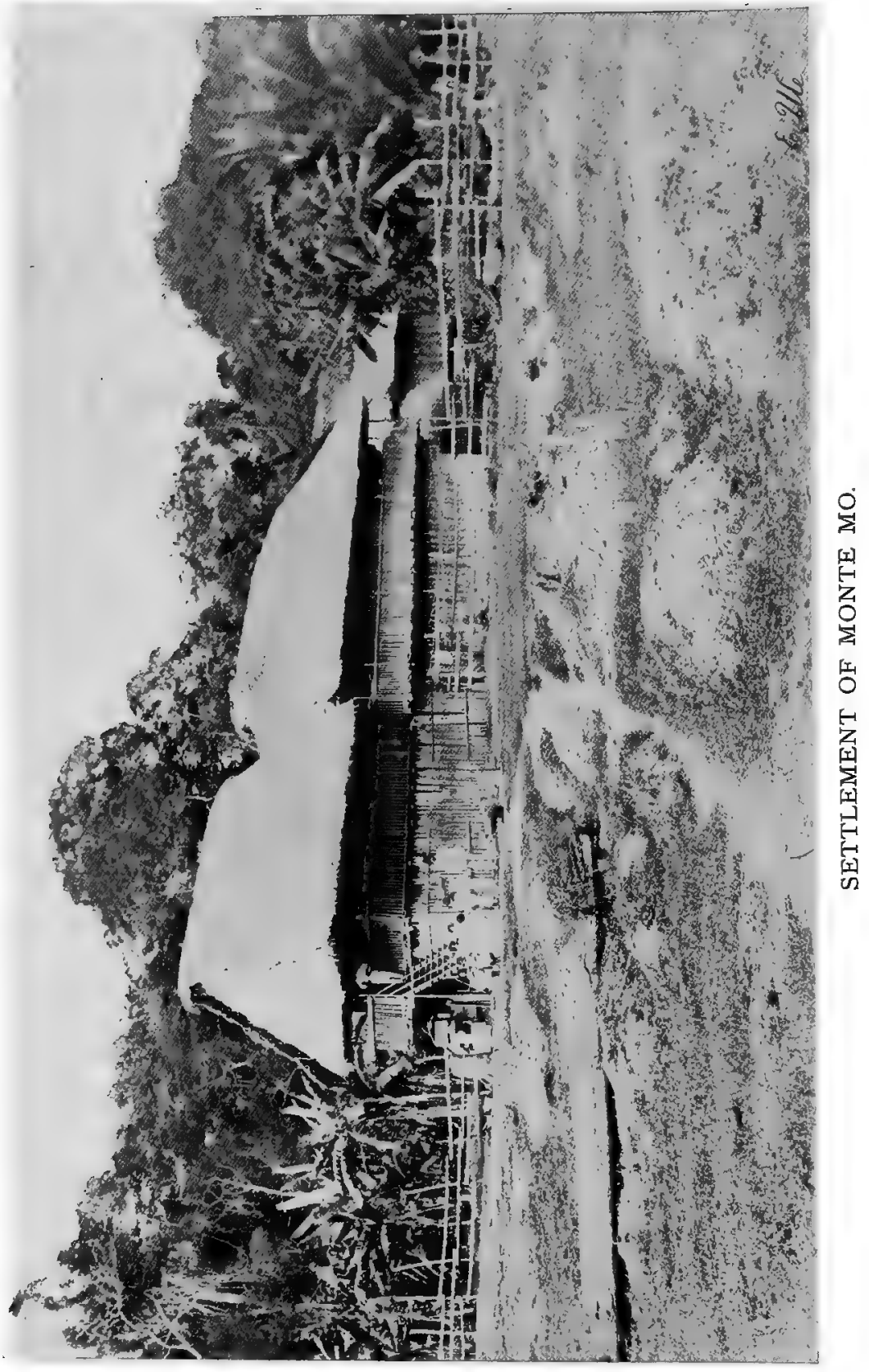




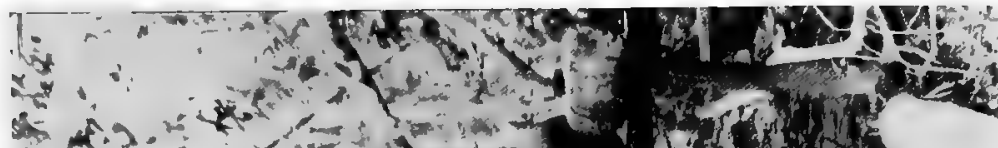
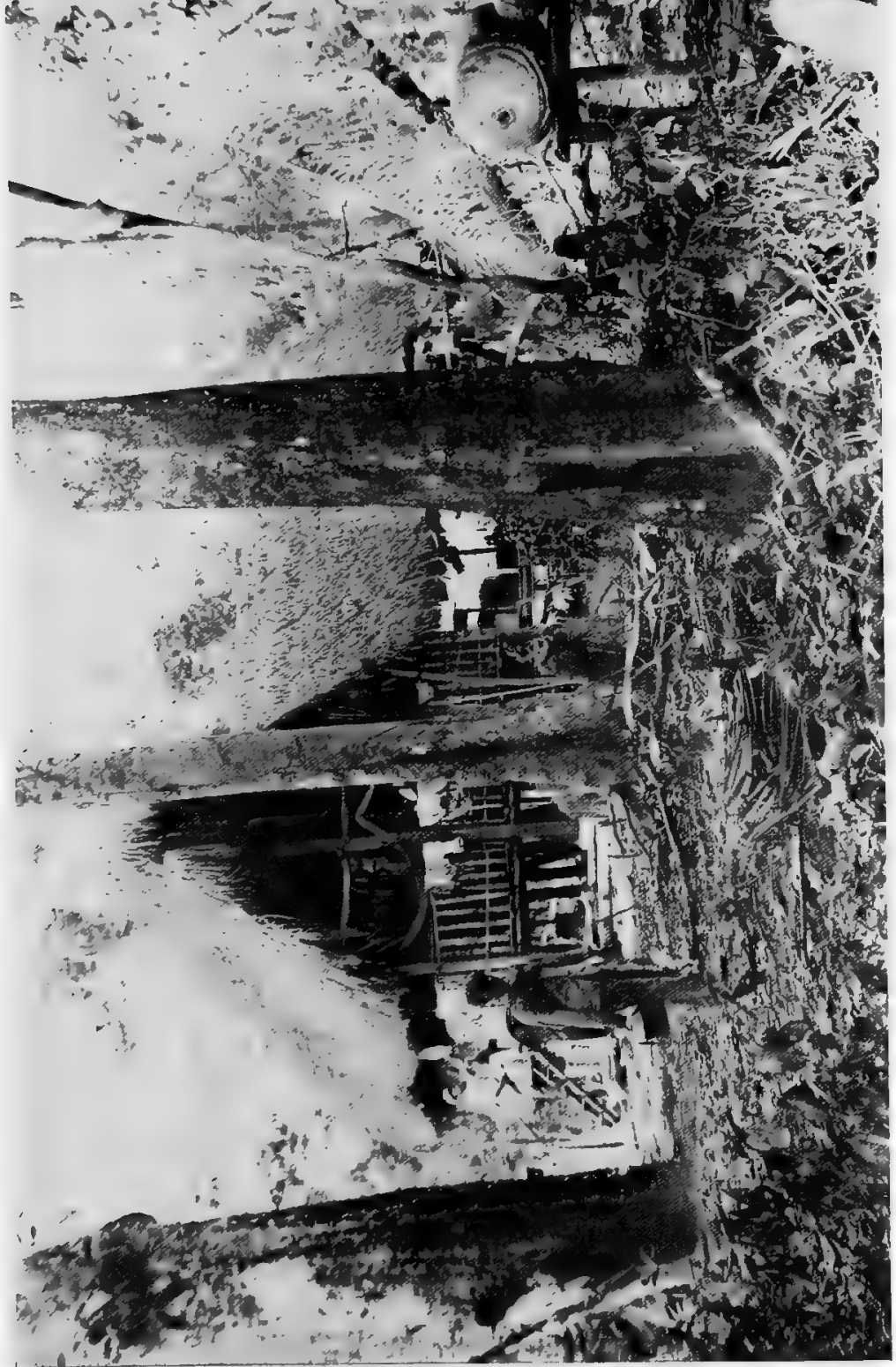



\section{THE STATE \\ OF \\ MATTO GROSSO}




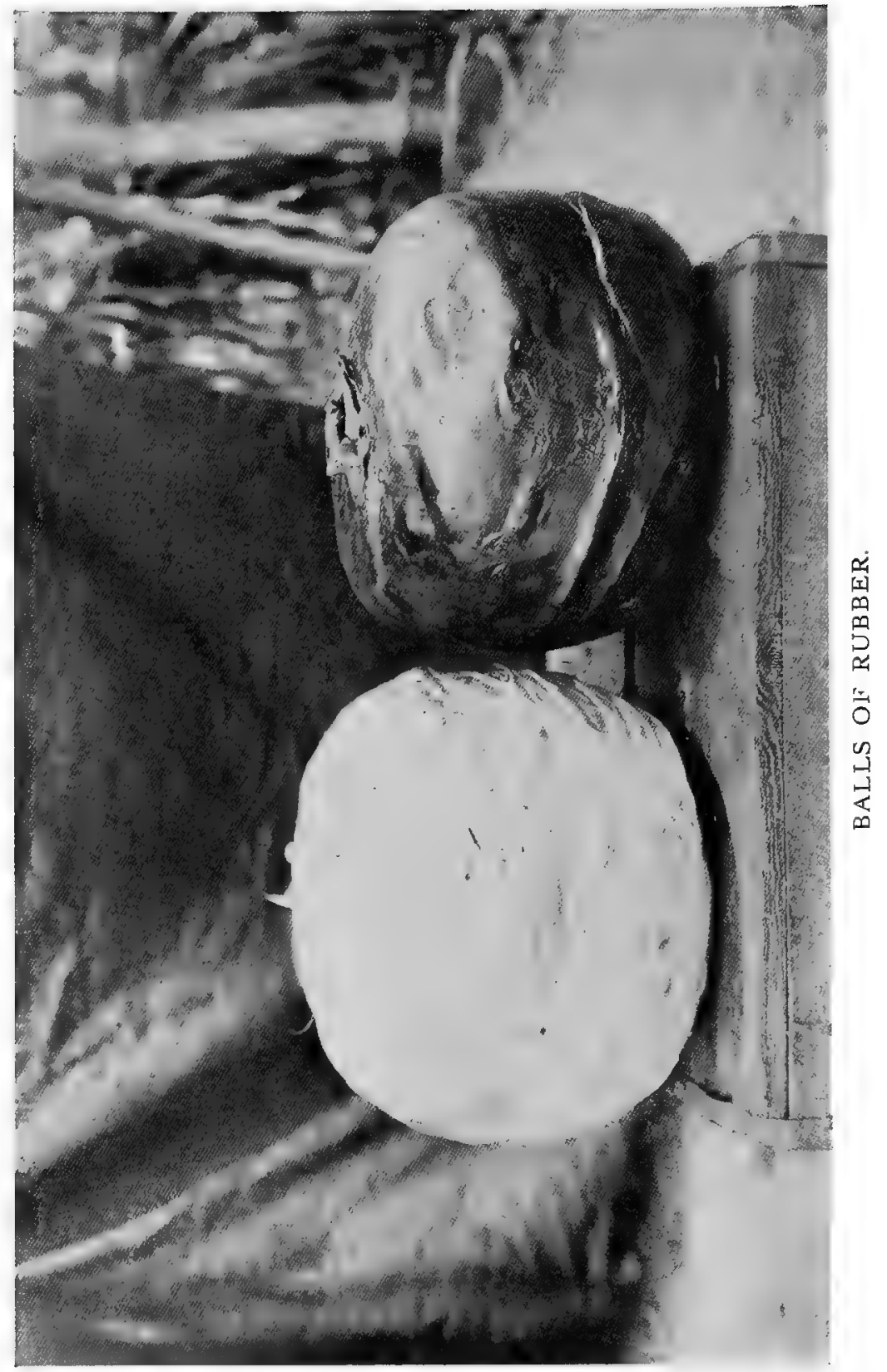




\section{THE STATE OF MATTO GROSSO IN THE THIRD INTERNATIONAL RUBBER EXPOSITION IN NEW YORK, 1912}

\section{BY \\ LEOPOLDO DE MATTOS}

Dr. Joaquim Augusto da Costa Marques, President of the State of Matto Grosso, 1911-1915

\section{The State of Matto Grosso, Brazil, at the Third International' Rubber Exposition in New York, 1912}

Of the twenty states composing the Republic of the United States of Brazil, Matto Grosso is second to the largest in its territorial extension. It is situated south of the States Amazon and Pará, having on the East the States of Goyaz, S. Paulo and Parana, on the South the Republic of Paraguay, and on the West Bolivia.

It embraces on the map that portion of the earth's surface which extends, approximately from the fourth degree South of the Equator to the Tropic of Capricorn. Its immense area is about 50,175 square leagues, or according to Mr. Candido Mendes it has an area of $1,379,651$ square meters. Its population is actually about 350,000 , not including a considerable number of uncivilized Indians, whose improvement is carried steadily forward by the united efforts of the State and Federal Governments.

Without mentioning its capital, the principal cities of the State are Corumbá, S. Luiz de Caceres, Miranda, Nioae, Focoué, Santa Aunade Paranabyba, Diamantina, Rosario, Livramento, and the new and recently incorporated municipality, S. Antonio de Rio Madeira. Its capital, Cuyabá, is situated on the left bank of the river of the same name, 288 meters above sea level, and owes its origin to the Paulistas, who formed colonies in the western part of Brazil during the first part of the Eighteenth Century.

In 1719 Paschoal Moreira Cabral ascending the River Coxipé Mirim, founded on the left bank of this stream a village which 
was called Forquilha, but to-day is the city of Cuyabá, where in those early days a rich gold mine was discovered. In those days, according to Elysés Reclus, the vast region of Matto Grosso, was hardly anything except a narrow, ordinary zone, nothing more than an immense solitude of undefined limits and unknown, but given over to Indians and wild beasts. It was joined to the rest of Brazil by the lonely paths of hunters, and by channels of the rivers that had their origin there. Really in those days communication with the remainder of Brazil was as difficult as with Matto Grosso. It is within the memory of many and known to those who read the history of Brazil, that it was impossible for the troops who were enrolled and equipped in the coast provinces, to go directly to the aid of their compatriots in Matto Grosso, when the Brazilian people had to respond to the declaration of war by Paraguay.

With the thousands of obstructions in their path, a portion of the army composed of 3,000 men, which left Rio de Janeiro in April, 1865, and which could only be organized in Uberaba, in the upper basin of Paraná, was reduced to about $\% 00$, when it arrived at that safe and impregnable place.

The war with Paraguay being ended, there is no doubt that the victory gained by Brazil opened wide the ports of Matto Grosso, for the natural declivity of the soil, the course of the streams, with the free river navigation, guaranteed by her triumph, established a regular line of packets between Rio de Janeiro, Corumbá and Cuyabá, by way of the River La Plata, passing by Montevideo, Buenos Ayres and Assumption.

The fluvial ways of the Guaporé, Madeira and Amazon were constantly used in the Eighteenth Century, after the exploration made by Manoel de Lima in 174\%. Navigation by the Guaporé river to the Madeira, in short to S. Antonio, which is the initial point of navigation on this last mentioned river, is long and full of difficulties. Withal, Matto Grosso is gradually approaching the coasts of Brazil by means of railroads, such as the Northwestern Road, which will shortly unite it with Rio de Janeiro, and the railroad, already projected, which, parting from S. Luiz de Caceres, will reach the old city of Matto Grosso, where the Gauporé begins to be navigable, to Guajará-Mirim, the terminal point of the great Madeira-Marmoré Railway.

In a short time, as can readily be seen, these roads will be a reality, the navigable rivers being united by the stretches of railroads between them. The Paranapanema and the Ivahy in the States of Paraná and S. Paulo, continue on the one side of the Paraná River, ascending the Ivanhema, and the Brilhante, as far as the neighboring mountains of Miranda, in the meridional part of Matto Grosso. 


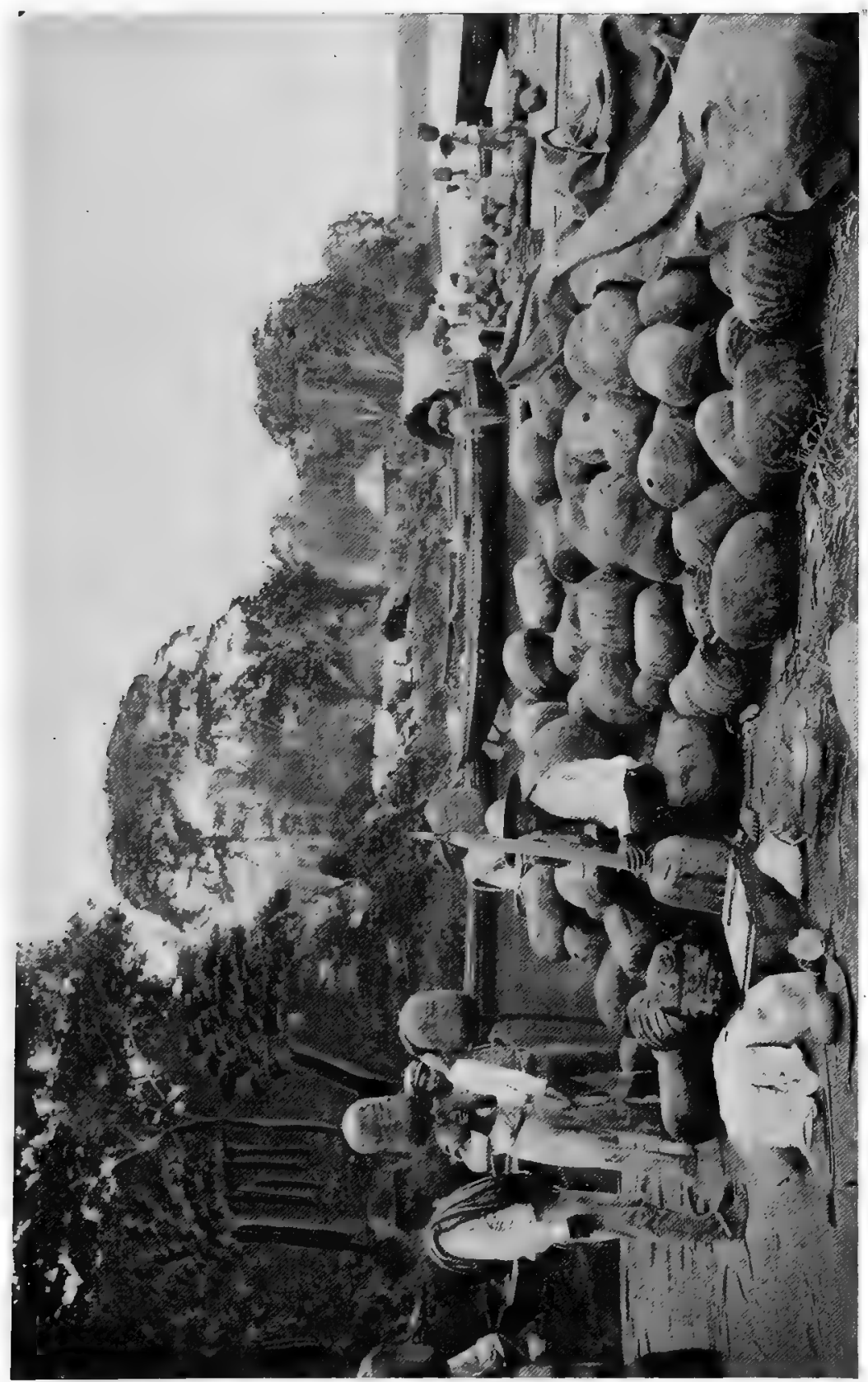

PI 9

学岁

되 디

की

$\circ$ 응

$H$

난

죽

된

舟叟

ㅁㄷㅚ

8 용 $\infty$

$\varangle$ 되 $\varangle$ 甹 ต

㽞

을

I

项娄 药 
The magnificent regions of Matto Grosso promise in the near future, to be great centers of population and consequently a future focus of civilization by probable fusion of the different elements of immigration, which will certainly come together there in the flight of time, and the increased facilities in the way of transportation. Somewhere it has been said, that colonization without doubt will come from the South, from Paraguay and Argentina; but at the present time, with the completion of the Madeira-Marmoré Railway, undoubtedly colonization will also come from the North, communication being facilitated by the Amazon River, the Madeira being one of its tributaries, on the right bank of which is situated Porto Velho, the initial point of the Madeira-Marmoré Railway. These effects are already commencing to produce results as may be seen from founding of a new municipality and district of Matto Grosso, called the municipality of St. Antonio of the River Madeira, reached by the abovementioned railway and to which region we will devote a special chapter later on.

Already one sees the farthest northern side of Matto Grosso filling with people, while the southern side really contains the greater number of inhabitants.

Matto Grosso is one of the regions of least roughness on the continent of South America. There are no elevations of the land which constitute real mountains.

The elevated lands have their points of culmination in the western bases of the Mantiqueira, the Aymores, and the Espinhaço; and continue, gradually lowering from this side to the West of Goyaz, and on the other side are the elevated lands at the base of the Andes, which incline to the East with its supports. Elysée Reclus says that an intermediary plain, separating the two geographical districts, goes winding in the form of a valley, that in other ages certainly was a maritime strait separating the two islands-Western Brazil and the Andes.

To-day rivers run in the depression where formerly there was a sea and the plain is actually full of alluvial soil. The true center of South America is between the two cities of Cuyabá and Corumbá.

To those who do not know the region, the slopes of the hills are mistaken for mountains and geographical maps show a chain of mountains more or less continuous, between the basins of the Tapajóz and the Madeira, between the head waters of the same Tapajóz and Paraguay and finally between the Tapajóz and the Araguaya. Nevertheless this semi-circular plain exists only in fragments, because the elevations which are found in the plains of the upper Paraguay and its tributaries are only a high, level ground of horizontal sections or slight elevations and worn away by the rivers which flow into the great Amazon. 


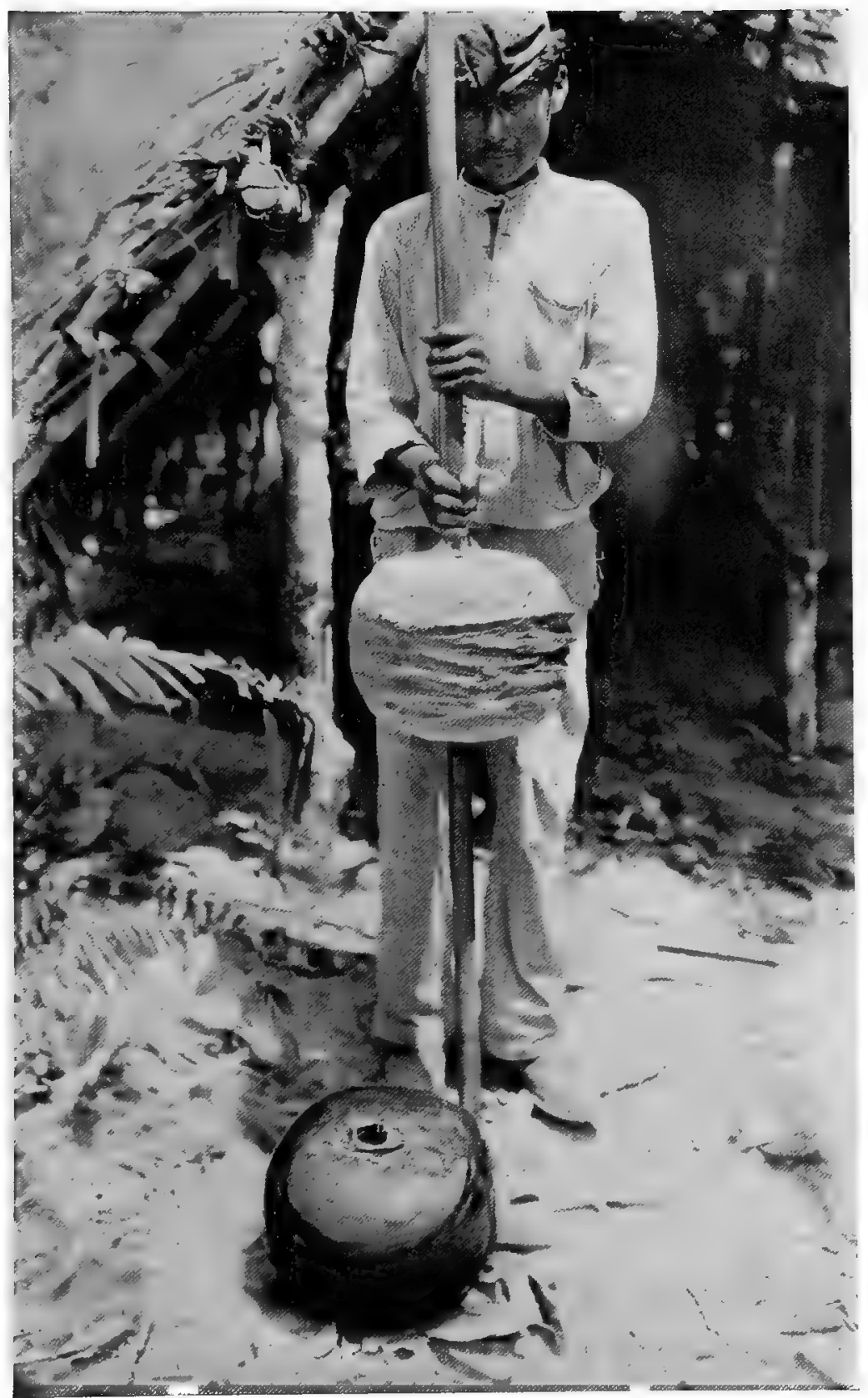

REMOVING THE BALL OF RUBBER AFTER IT HAS BEEN SMOKED. 
They are rather tablelands than mountains, for they do not reach an elevation, except in some parts of the tableland, of more than 100 meters, while the mean elevation of a range of mountains is 500 meters.

This geographic district in the State of Matto Grosso is indifferently called the cordillara of Parecys, but does not present a mountainous aspect except on the South side. On this scarred side, the rock is cut into peaks, or cut away into obelisks. On the other side towards the Tapajóz and Xingú, a long range extends and gradually declines into the plains of the State of Amazonas. D'Orbiguy found in the high northern part of Matto Grosso, the existence of beds pertaining to the carboniferous age and corresponding to rocks of the same nature which on the opposite side of that region are found in the Bolivian bases of the Sierra of Santa Cruz. After this Hart and Derby verified the fact that the southern parts of the Araxá, which are the elevated borders of the tableland, date probably from paleozoic epochs, and there are found the carboniferous, devonian and silurian beds. Fossil beds found by the Geologist Smith below the hillocks of the plains, 50 kilometers east of Cuyabá, place these facts beyond doubt. More to the North is the zone of the rocky places, which in links cut the Madeira, Tapajóz, Xingú, Tocatius and their tributaries, the walls denuded by erosion, are all of the crystalline formation, granite, gueis, porphory and quartzite. The elevations that unroll in the direction of the South, between the sources of the Paraguay and Araguaya, following between the Paraguay and the Paraná, do not present the same characteristics as the tablelands of the North. The high parts of Western Matto Grosso were separated from the East and West sides and devastated by lateral excavations, take in certain places the aspects of true mountain chains, and for this reason they are named, from the North to the South, the Sierras of S. Jeronimo, Maracajú and Anhauhaly.

Eruptive rocks, called basaltic in this country, probably porphyritic rend the beds of sandstone, of which the mountains are composed and appear to form by their disintegration "red lands," similar to those which give the farmers of S. Paulo their abundant harvests of coffee.

In a sort of circle limited by a semicircle of elevations isolated masses have been lifted up, rocks whose outlines, seen from a distance, have a perfect regularity. The hills proper, for the greater part, have geometrical forms, which it should be said, great forces have crumbled, leaving smooth walls like the sides of pyramids. The tops of the tablelands, as well as summits, have been maimed by a force certainly corresponding to the other summits, which now may be seen as part of the same 


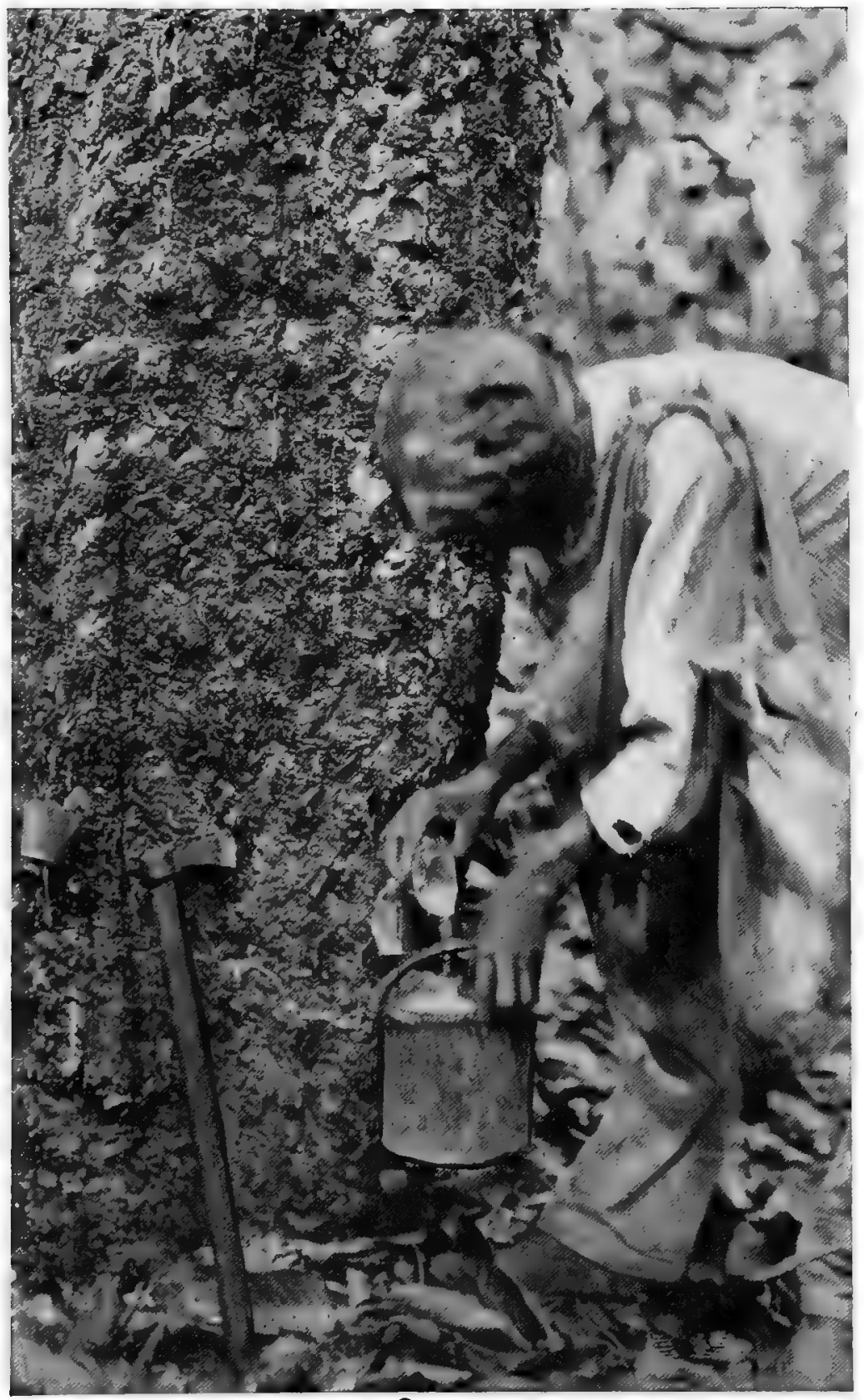

COLLECTING THE LATEX. 
prairie. According to Taunay, who traveled over the country, these masses of sandstone in horizontal beds regularly placed one above another, are formed of marshy sediment deposited by the sea of fresh water, which in former times covered this region.

The ruins of these hills and slopes contributed also to change the physiognomy of the landscape. These excoriations were picked up and dragged by the rivers, to form new beds and soil, and much rock disappeared below the continued crumbling of the mountains. Others show nothing except their summits above the land of recent formation. Masses that held them to the tablelands and the chains of the interior are separated from them, because their bases are buried and they emerge abruptly from the soil. These distinctive peaks to which the name of itambea has been given, raise their heads above a sea of trees, like some great buildings erected by the hand of man. To the East, the southern part of Matto Grosso, they range themselves in files and group themselves in archipelagoes, each time becoming higher and more numerous. The part that goes towards the West are solitary peaks on the circle of the horizon and may be seen along the banks of the River Paraguay, and even on the other side of the same.

The Upper Guarporé, Itenez of the Bolivians, although situated in the immense basin of the Amazon as a tributary to the Madeira River by the Marmoré, belongs to the State of Matto Grosso, for the city of this name was founded on its banks and nearly the whole population of the state accumulated in this depression, through whose western half the river finds its way. Its principal source is very obscure. It rises in a grotto along the the border of the Araxá, and takes first a southerly course, parallel to other rivers which descend towards Paraguay. On leaving the last hills it curves to the West, and afterwards to the Northwest, where already enlarged by numerous tributaries it crosses the plain, where there is found the city named at its founding Villa Bella and to-day called Matto Grosso.

The Paraguay is one of the most known rivers of South America, as a way of navigation, as Elysée Reclus affirms. Few rivers have such a slight declination in proportion to their length. Castelnaw says that it rises at an altitude of 305 meters, in places where tranquil waters glide slowly to the sea, the altitude of the land being scarcely 200 meters. At a point 4,000 kilometers from the sea, the declination is scarcely 5 centimeters. Therefore, steamers of light draft can freelv ascend to the confines of Brazil, far to the North of the two Republics of Argentine and Paraguay and arrive at the base of the tableland by the principal river and its tributaries, Jaurú, Sepotuba, Cuyabá, 


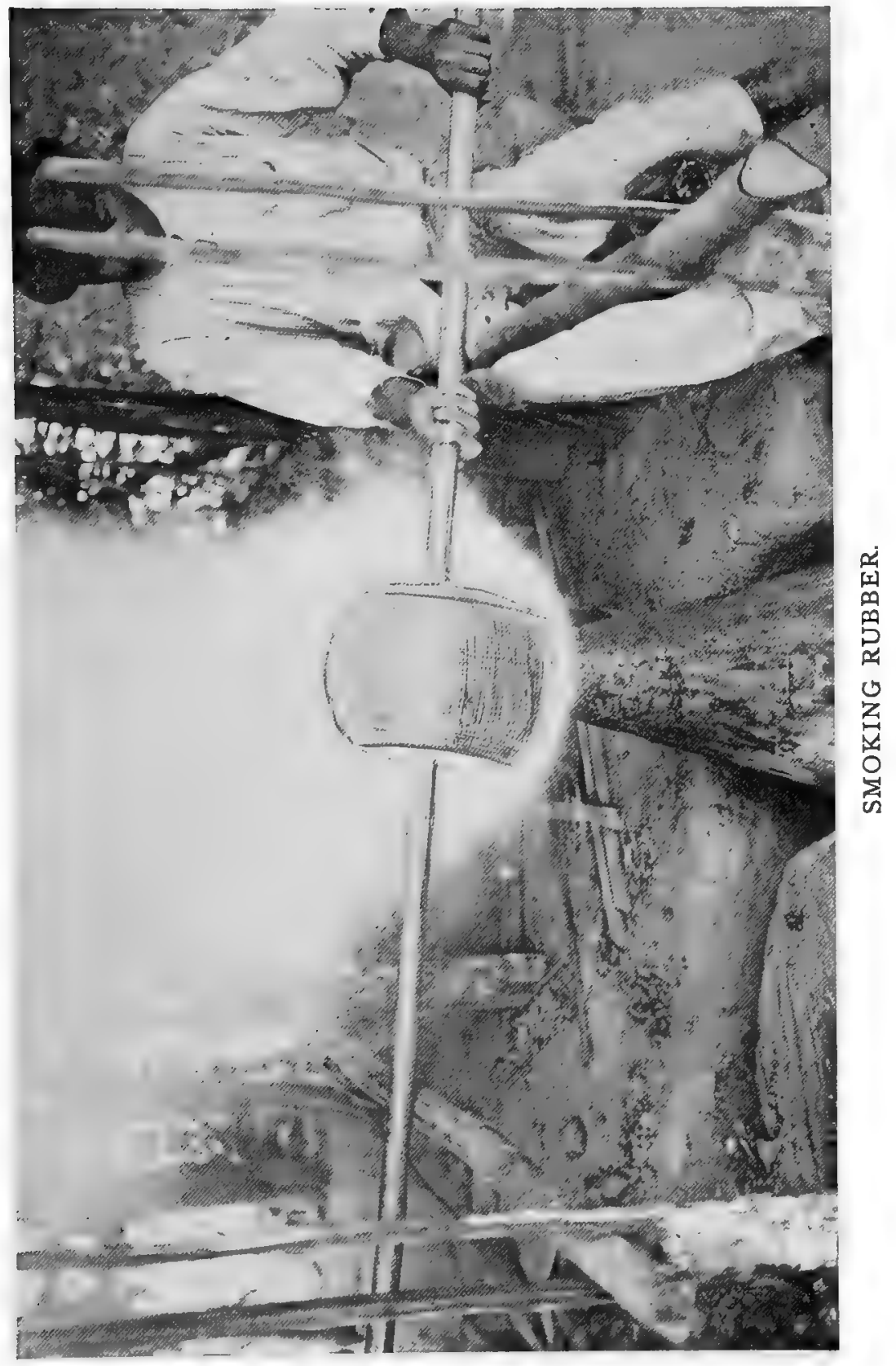


S. Lourenço and Taquary. The Paraguay presents another notable phenomenon, which is the crossing its sources with those of the tributaries of the Amazon.

The River Jaurú approaches the Guaporé so closely that it would be easy to make a canal from the waters of this western river to a tributary of the Jaurú. Another tributary of the Paraguay, the Aguapehy, is only separated from the Alegre River, which flows by the old city of Villa Bella, to-day called Matto Grosso, by a low and narrow isthmus, which according to Leverger measures 5,280 meters. Duning 17\%2, and even later, it was proposed to cut a canal at different places in this isthmus, but the work was never done because of the little commerce of that locality. Certainly, railroads, in the near future, will supply the absence of a canal and will join Montevideo to Pará, passing through the larger part of the State of Matto Grosso, and by a continental navigable water way of 8,300 kilometers, as Bartholomo Bossi says.

The Paraguay River has as its principal tributaries the S. Lourenço, enlarged by the waters of the Cuyabá, the Taquary, the Mondego, and the Apa, the last marking the boundary between Brazil and the Republic of Paraguay. At the time of the floods, its level, and that of its tributaries, rises 10 to 11 meters and overflows to the right and the left, forming a temporary sea, which extends to great distances, being lost to sight and continuing in lakes. The first Spanish explorers gave it the name of Lake Xarayes, in its lower section, where it receives the nearly dormant waters of its principal tributaries. This lake is about 600 kilometers in length from North to South, between the mouths of Jauru and the hills of "Fecho-dos-Morros," and in certain places reaches a width of 250 kilometers.

It is not permanent, as you already know, but at certain seasons of the year there are overflows, which the Indians called bays and rightly, for here there were bays of an ancient sea, which to-day are nearly dry, and most of these lakes are in constant communication with the Paraguay River, either by underground openings, or by long canals. These latter are called the lakes of Uberaba, Gaiaba, Mandioré, Caceres, etc. Some of these lakes contain only fresh water from the overflowing rivers, while others being ancient cavities are now filled with salt water, and have in their depths beds of salt, which give to the liquid a soapy characteristic. It is singular that this contrast by nature of fresh and salt water is also found in the lands of the vast plains, and thus it is, that these extensive fields, covered by a rich alluvial soil, bear heavy forests. Here the agriculturist can certainly obtain marvelous harvests. It is certainly true that these fields of Matto Grosso will serve for agriculture as well as pastoral industry. 
The height of the lands, formed in the center of this vast valley, hinders the tributary from remaining in a regular channel, and the waters escaping from both sides ramify in a labyrinth of rivers and false rivers. The lateral branches follow in the zones of the lakes, to the confluence of the Taquary and Miranda Rivers, which descend from the mountains on the East. These receive in the upper region, a tributary called the Coxim, which travelers consider one of the most picturesque rivers of Brazil. It is curious to see, in some places, the waters of the Coxim crowded between perpendicular walls 50 meters in height and the small vessels floating on their bosom at the bottom of an opening not more than 10 or 12 meters in width.

\section{THE CLIMATE}

The climate of Matto Grosso is relatively warm in the lower parts and those overflowed by the high waters of the Paraguay and other rivers. In the region of the tablelands the climate is cool and healthy. The movement of the air columns is determined by the open passage way between the Andes mountains and the highlands of Brazil, as well as in the center of the South American continent, and are held by it. The warm winds, coming from the region of the Amazon, are succeeded in the Winter time by the winds which blow from the cool pampas. In the high parts of the circle of hills and mountains which surround the tablelands of Matto Grosso, the cold goes below the freezing point. The copious rains brought by the cooling winds refresh the central tablelands of Brazil and then dash themselves against the sides of the Andes. They fall with great regularity in the Summer and are frequently accompanied by thunderstorms. According to observations taken by some, the annual fall of water is 3 meters, and in Cuyabá about 135 days of the ordinary year'are rainy ones.

\section{ITS SITUATION}

The State of Matto Grosso, from its geographical situation in the Continent of South America, placed at the point of separation of the two great basins of Brazil, contains at the same time the flowers and faunae of the Amazon and Plata regions. Nevertheless, the tropical flora predominates with its infinite variety of vegetable forms in all the forest regions, that is to say, along the banks of the rivers, and among the famous species found along the shores of the River-Sea, there are few which are not found in the region of the Upper Cuaporé, and specimens of which may not be seen. 
In no other parts, like here, will the development of Cipo's palm be found. In $18 \% 5$, a boundary commission discovered one of these palms Urumbamba (Calamus procumbeus) or Des Moncus rudentum de Martins, of more than 20 meters in length, with hardly the thickness of a centimeter. The cotton tree, tobacco, ipecac, there called "poya," grow spontaneously on the plains and in the forests. The last grows abundantly in the forests of the Upper Jaurú and the neighboring rivers. Maté, the most notable product of the tablelands of the South, and which has made some regions rich, as the State of Paraná, grows here spontaneously between the Rivers Miranda and Apá, without speaking of the seringa, which is found in immense and thick forests in a district that extends from Cuyabá to Madeira and which will be the special subject of this leaflet.

The woods for building are very abundant and of a great variety, such as Brazil wood, Jacarandá, Peroba, Canella, Cedro, Jequitibá, Massaran-duba, Arco, Ferro, Setim and Vinhatico.

Among the animals are found deer, tapir, panther, and also a large number of small animals usually found in tropical regions. The fowls and birds along the streams and the songsters in the forests are, because of their variety, almost innumerable. The ostrich is found in the region of the pampas and on the margins of the upper Paraguay. There are many varieties of fish in the large and small rivers.

In the mineral kingdom, the State of Matto Grosso has numerous mines of gold, silver, platinum, copper, tin, mercury, coal, iron, precious stones, diamonds, etc. There are already four English companies developing gold mines. There is also granite, crystal, malacacheta, limestone, sal-geunna, etc. Finally, in the region of the Araxa, there are sulphur mineral springs.

In Matto Grosso are found the largest cattle ranches, not only as to their territorial extent, but also as to the number of horses and cattle, some of them numbering 100,000 head. The number of cattle is calculated to be 2,000,500,000 head. Although the transportation of cattle from Matto Grosso to Rio de Janeiro is difficult, it is generally done by a road running West to Uberaba, where they pass the Winter season of two or three months and being recuperated are sent by railroad to Rio de Janeiro. Hence it is easy to see that with the completion of the Northwestern Railway of Brazil, the problem of transportation to the coast will be solved. Also with the completion of the Madeira-Marmoré Railway the navigable rivers of 'Matto Grosso, will in short time, be linked with the port of Pará. Before long another railway will extend from S. Luiz de Caceres, the ancient city of Matto Grosso, where the River Guaporé commences to be navigable to Guajara-Mirim, the terminal point of the Ma- 


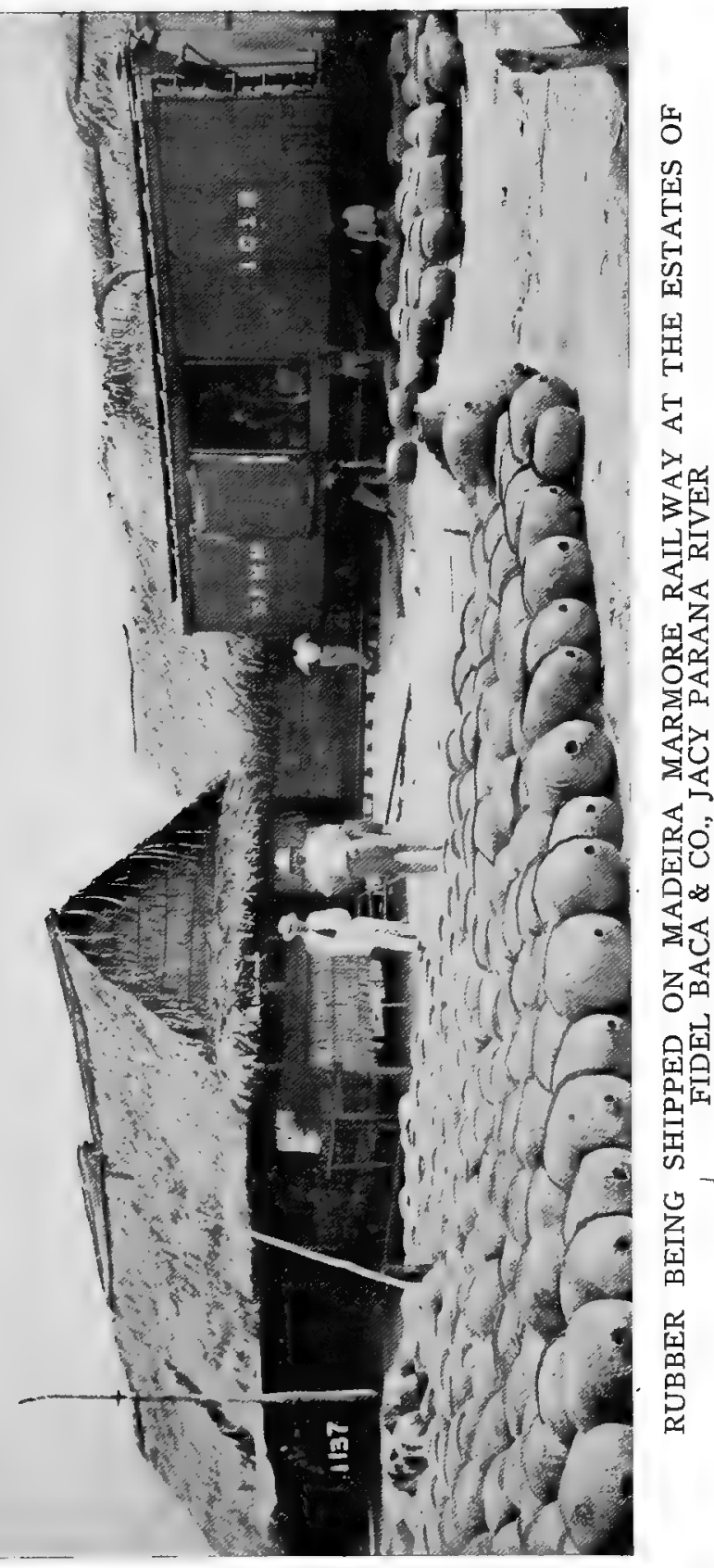


deira-Marmoré Railway. This will solve the problem of the transportation of cattle to the States of Amazonas, Pará, etc.

From this brief exposition one concludes that the State of Matto Grosso is very rich in cattle and gold, diamonds and coffee, tobacco and mate, rubber and ipecac, and all other products of the tropical and temperate zone. Without doubt it will come to be one of the largest and richest empires of the world.

Endowed with a warm climate in the North, it has in other regions a temperate and even cold climate. The tablelands contain a rare accumulation of wealth, yet little explored. Naturally people, in their activities and progressive conflict for a livelihood, will come here from all parts of the world. By their intelligence and endeavors they will make that part of Brazil an industrial, commercial and maritime mart. Here from the fusion of the different races, a great civilization will arise, and mankind will progress onward and upward to the final conquest of the land.

\section{RUBBER}

The rubber sent to this Exposition, comes from the vast regions served by the Rivers Machados, or Dgy-Paraná, Jamary, Jacy-Paraná, Mutum-Paraná, Paca-Nova and Guaporé and their tributaries, which in turn are tributaries of the great Madeira River, on whose right bank is situated the new municipality St. Antonio do Rio Madeira, installed July 2, 1912.

The new municipality has the following limits: Starting at the falls of St. Antonio do Rio Madeira, on parallel $8^{\circ} 48^{\prime}$, the River Madeira above; the River Madeira above to the mouth of the Guaropé on parallel of $12^{\circ}$, and on this parallel to its intersection with the River Camararé ; on this river below to its confluence with the Juruema; on this river below to the point where it unites with the Arinos; on the parallel at this point which passes to its intersection with S. Manuel River; it follows this river down to its confluence with the Tapajóz; and from this point back to St. Antonio Falls, along the line that divides Matto Grosso from the Amazonas. All this immense territory of the new municipality is traversed on the North by the Madeira-Marmoré Railway, which was completed and opened for traffic, September 7, 1912. It starts at Porto Velho and terminates at Guarajá-Mirim, a distance of 390 kilometers.

The Madeira-Marmoré Railroad, in addition to the stations already opened in Porto Velho, Candelaria, St. Antonio, JacyParaná, Abunã, Villa Murtinho, and Guarjará-Mirim has 46 places of stopping, which corresponds to the number of camps.

Among the ways of communication that St. Antonio do Rio 
Madeira, the new municipality, has with the neighboring States of Amazonas and Pará, as well as with the capital and other cities of Matto Grosso, we would mention the telegraph line which the Federal Government is constructing along with its public road ways. There are two gangs of engineers and workmen engaged in the construction of the telegraph line. One started at St. Antonio in the North, and the other at Diamantina in the South. Leaving St. Antonio the telegraph line follows parallel $8^{\circ} 48^{\prime}$ until it comes to the River Jamary, a distance of about 60 kilometers. Arriving there its course is changed to the headwaters of the Dgy-Paraná River, to a place called Urupá. Here it will meet and be joined to the line coming from the South. On June 3, 1912, at the very headwaters of the DgyParaná River, the telegraph station of José Bonifacio was opened, by the gang from the South, while those from the North had, previous to this, opened the stations of St. Antoino do Rio Madeira and Jamary. This notable undertaking is under the efficient and extraordinary devotion of the Colonel of Engineers of the Brazilian army, Candido Roudon, who has a record for the construction of telegraph lines in Brazil and South America.

Within a year, more or less, the telegraph line will follow along a roadway 40 meters wide, and about 200 leagues in length, extending from Cuyabá to St. Antonio on the Madeira River. This immense roadway of communication cutting all this vast interior, rich in rubber and gold, will have a telegraph station every 10 leagues. In Porto Velho, the initial point of the Madeira-Marmoré Railway, there is already working a wireless telegraph station of the Marconi system. There is daily communication with Manaos. Also with Iquitos and with the Federal department at Acre, Purus and Juruá.

Transportation from Manaos to St. Antonio on the Madeira River is made in good condition and comfortable vessels. During the time of low water, that is during the dry season of the great Amazon and its tributaries, only vessels of 500 tons can ascend to those places from Manaos. In the time of high waters, when the valley of the entire Amazon is overflowed, the transAtlantic steamers of 7,000 to 9,000 tons, ascend in four days from Manaos. This has been done in the transportation of materials for the construction of the Madeira-Marmore Railway. The vessels easily approached and made fast to the two wharves made of wood, one of which is in front of the offices at Porto Velho and the other at Candelaria. The Government of the Republic, however, has determined to build of stone and lime the wharves between Porto Velho and St. Antonio on the River Madeira.

The small steamers which navigate during the dry season, 


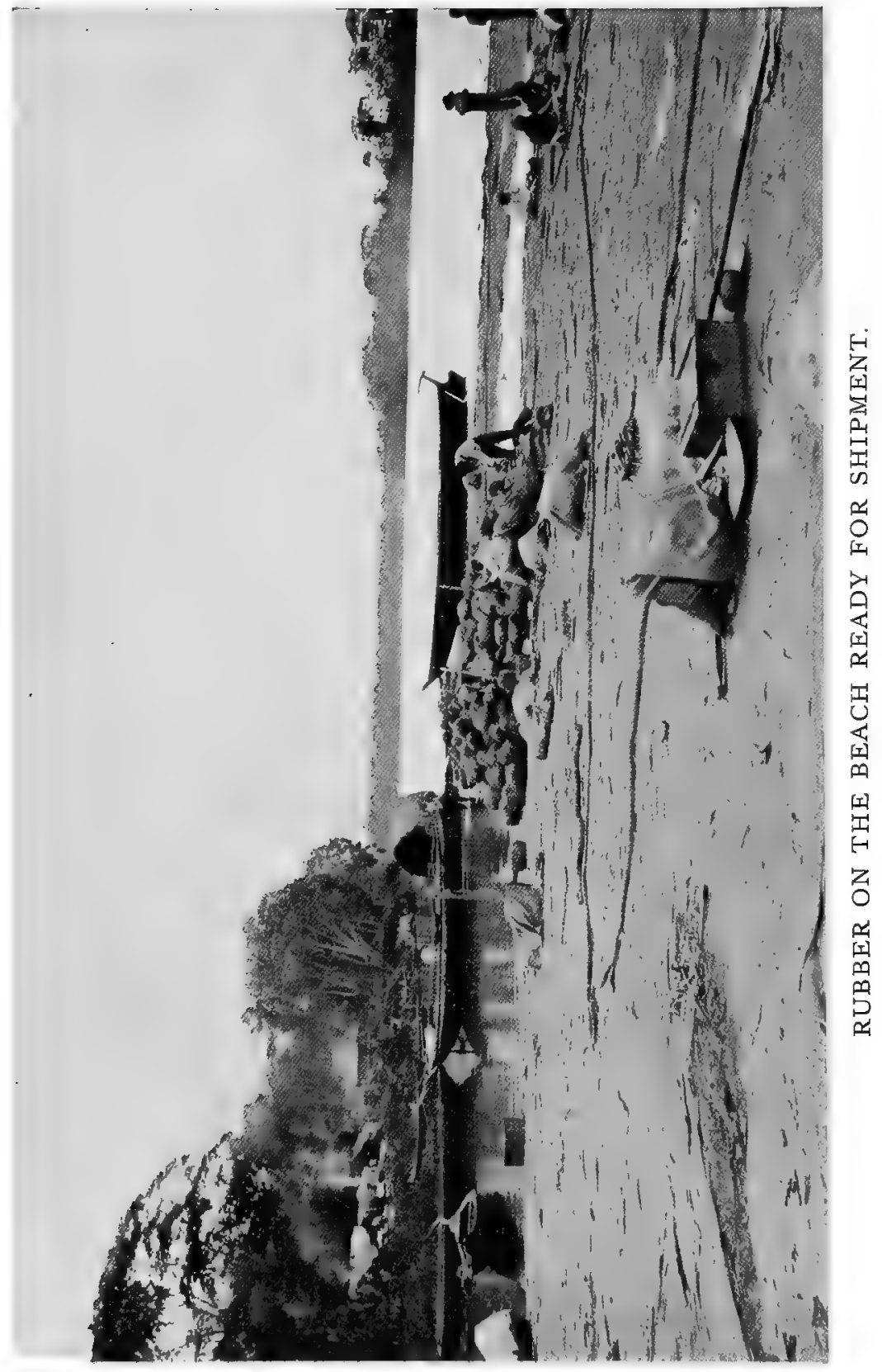


have accommodations for first and third class passengers, are lighted by electricity, have an artificial ice plant and make the voyage from Manaos to Porto Velho and St. Antonio in about five days, at the average speed of ten miles an hour, calling at the small Amazonian ports and cities situated on the banks of the Madeira River. In descending the river both the large and small steamers make the voyage in from three to four days.

The rubber from St. Antonio on the Madeira River is of the same physical and chemical constituents as all the rubber of the Amazon Valley. This is worth remembering, when we think of this new municipality in the State of Matto Grosso, being the frontier of the States of Amazonas and Pará.

In the Manaos market, where the rubber comes by way of the Madeira River, and in that of Pará, which it reaches by way of River Tapajóz, it is always quoted at the same price and under the same conditions as those produced in the regions of the Amazon proper.

The production has been increasing annually since 1906 and is actually about $2,000,000$ of kilos annually. This will certainly increase to an amount that cannot be foretold, with the completion of the Madeira-Marmore Railway, the wagon road and telegraph line and the constant improvements in navigation.

During the first six months of the current year, the production of rubber was greater than for the same length of time in any year since $190 \%$, as can be verified from the report annexed.

In those regions, between Cuyabá and the new municipality, there exist rubber (seringa) forests capable of producing in one year, more than $40,000,000$ of kilos of rubber.

To attain this ideal, it is only necessary that the captains of industry should join in the development of extraction. This fountain shoots forth from the earth spontaneously without the necessity of cultivation. To encourage and stimulate those who wish to employ there, their endeavors and capital, the law of the State of Matto Grosso offers special favors. These are offered to those who wish to develop the vast forests of rubber existing, as well as to those who wish to plant and cultivate the Syphonia elastica.

Speaking of the Rubber Exposition soon to be held in New York, it is proper to call attention to the well-known fact that already the capitalists of North America have begun the development of that region.

The large capitalist, Percival Farquhar, of North America, has already incorporated two rubber companies, the Muller and Guaporé, under the social terms of July, for the purpose not only of developing the extraction industry of the hevea braziliensis, but also for the different branches of agriculture necessary for the making of sugar, cotton cloth, etc. 
Actually the extraction of rubber in the vast seringaes of the municipality of St. Antonio of the River Madeira employ about 5,000 workmen. This number will constantly increase, as the said municipality becomes the center of the currents of commerce, industry and agriculture, from Matto Grosso and the Republic of Bolivia.

This is easy to imagine, when we see that the Madeira-Marmoré Railway will place it in communication to the South with S. Luiz de Caceres, by means of the River Guaporé, and by the railway, which, from $S$. Luiz de Caceres will extend to the ancient city of Matto Grosso, thus joining the basin of the Plata-by means of the Paraguay River, to the basin of the River Amazon. And to the West the same Madeira-Marmoré Railway, reaching to Ribeira-Alta, will bind the vast and rich regions of the Bolivian Republic to the basin of the Amazon, by means of the Madeira River. Presently the chief engineer and director of the Madeira-Marmoré Railway, Mr. H. Dose, will leave for that region, to begin the construction of the branch Guajara MirimMatto Grosso, to Ribeira Alta, Bolivia, which will be finished within a year and a half, and be about 100 meters long.

In addition to this with the prompt construction within a year of the wagon-telegraphic line-roadway from Cuyabá to St. Antonio on the Madeira River, we can easily conclude, that the municipality of St. Antonio on the Madeira River, will indeed become the converging point of these great and strong currents of development of progress and of civilization.

In conclusion it should not be forgotten that this territory herein described serves not only for the production of rubber, which there, as in the whole valley of the Amazon, is native and grows according to the laws of nature. It also should be mentioned that cacao and cotton are native, while there can be planted and cultivated, sugar cane, coffee, vanilla, corn, beans, rice, tobacco, potatoes, brazil nut, etc. The Madeira-Marmoré Railway Company has the concession of a vast amount of land along its line, which it proposes to plant in cacao, sugar cane, etc.; thus improving these lands.

From this description, in which we have endeavored to set forth only the truth, giving the facts concerning the region in question, it can be concluded that the new municipality of St. Antonio on the River Madeira, which actually exports to the markets of the world, via Pará and Manaos, about 2,000,000 kilos of rubber, will in a few years, with immigration and from other causes, export from 10 to $15,000,000$ kilos.

The author of this article asks indulgence for any shortcomings it may contain, as it was written in the spare moments he could find, while laboriously collecting the samples of rubber 


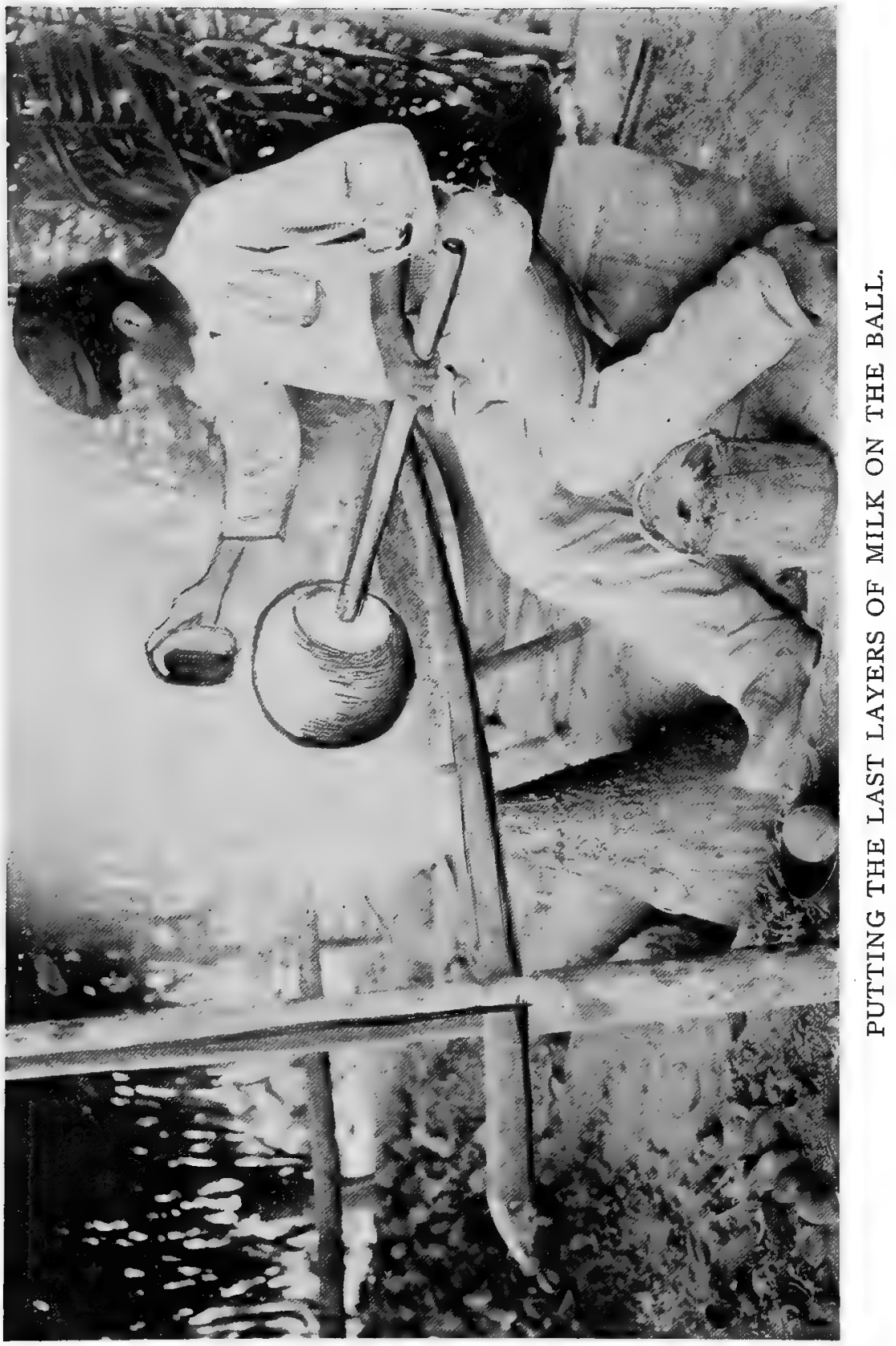


and putting them on board the steamer at Manaos for New York. The samples of rubber from the State of Matto Grosso, which are seen in this International Rubber Exposition; have been exhibited by order of the Government and at the expense of the Commercial Association of the Amazonas.

\section{STATE OF MATTO GROSSO}

\section{Inspection Department of the North}

Table showing the production of rubber in the valleys of the Madeira and upper Tapajóz, for the years 190\%-1912, in comparison with the first six months of 1912 :

\begin{tabular}{|c|c|c|c|c|c|c|}
\hline Origin & 1907 & 1908 & 1909 & 1910 & 1911 & 1912 \\
\hline Machado and Jamary.. & $1,092,454$ & $1,252,194$ & 910,982 & $1,295,605$ & $1,317,917$ & $1,315,995$ \\
\hline $\begin{array}{l}\text { Jacy-Paraná, Upper Ma- } \\
\text { deira and Moré..... }\end{array}$ & 98,464 & 152,713 & 150,759 & 142,458 & 201,562 & 259,612 \\
\hline Upper Tapajóz ....... & $\ldots \ldots$ & 156,034 & 167,841 & 107,458 & 73,688 & 113.453 \\
\hline & $1,190,918$ & $1,560,941$ & $1,229,582$ & $1,645,521$ & $1,593,167$ & $1,689,060$ \\
\hline
\end{tabular}




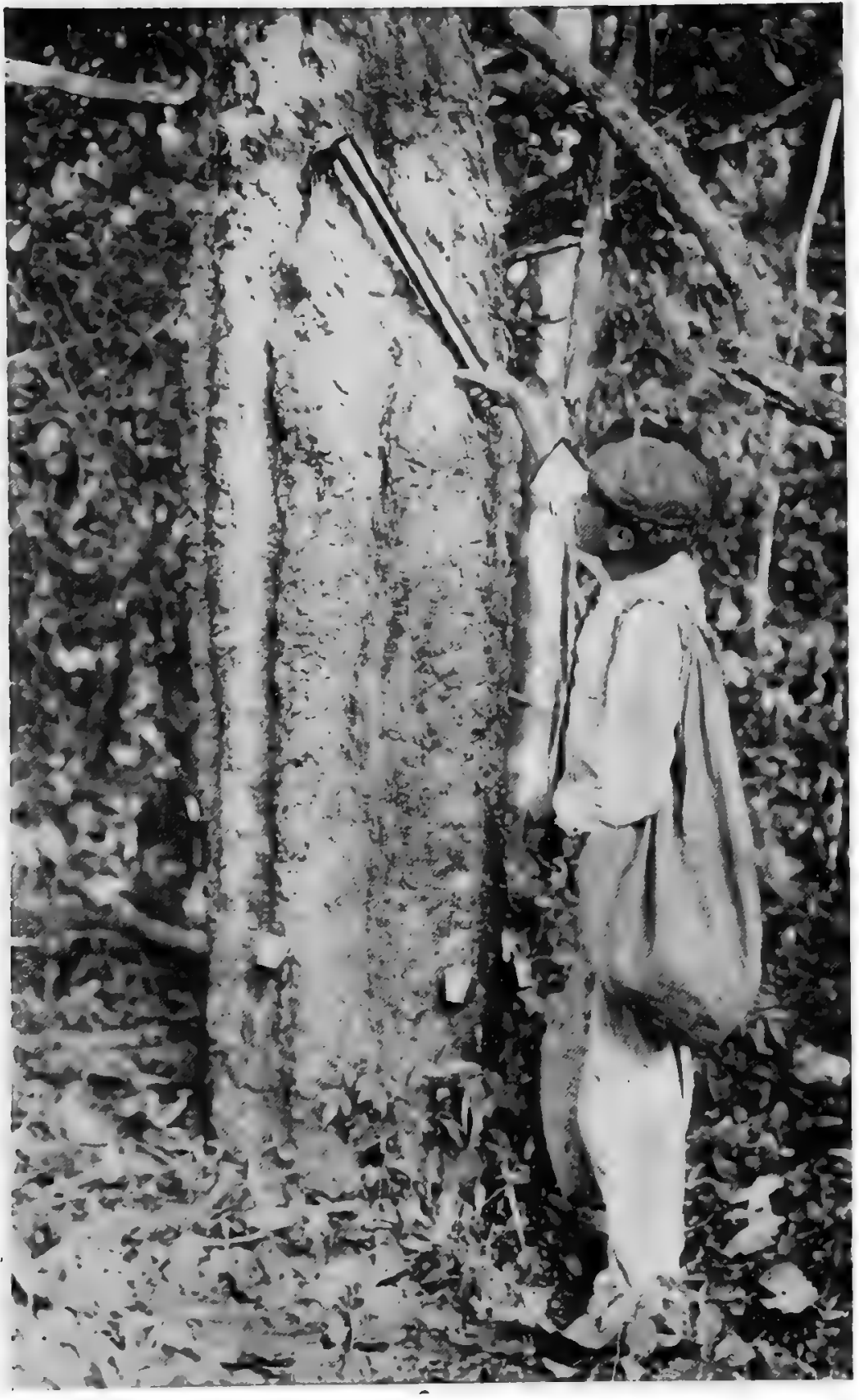

TAPPING THE RUBBER TREE. 


\section{STATE OF MATTO-GROSSO}

The capital, Cuyaba, and the principal port, Curumba, belong to the hydrographical system of the Paraguay River.

The boundaries of this State, formed by the Amazon River, embrace the upper basin of the Madeira River, which as the result of an agreement with the State of Amazonas appertains to MattoGrosso, whereas it previously belonged to the former State.

This territory constitutes the judicial and administrative province of Santo Antonio do Madeira.

The executive and fiscal administration is entrusted to a Fiscal Delegate in Manaos. The collection of duties is attended to by the State Customs of Amazonas.

The rubber producing rivers, with total production of MattoGrosso, are:

$$
\begin{array}{rrrr}
1908 & 1909 & 1910 & 1911 \\
\text { Kilos } & \text { Kilos } & \text { Kilos } & \text { Kilos }
\end{array}
$$

Machado and Jamary. 1,253,000 911,000 $\quad 1,296,000 \quad 1,318,000$ Jacy Parana, Upper Ma-

$\begin{array}{lllll}\text { deira \& Mamore... } & 153,000 & 150,000 & 143,000 & 202,000\end{array}$

During the first half of the current year the production has shown a considerable increase, this being largely due to the opening and developing of the Madeira Mamore Railway, which passes through the whole region of these rivers. 


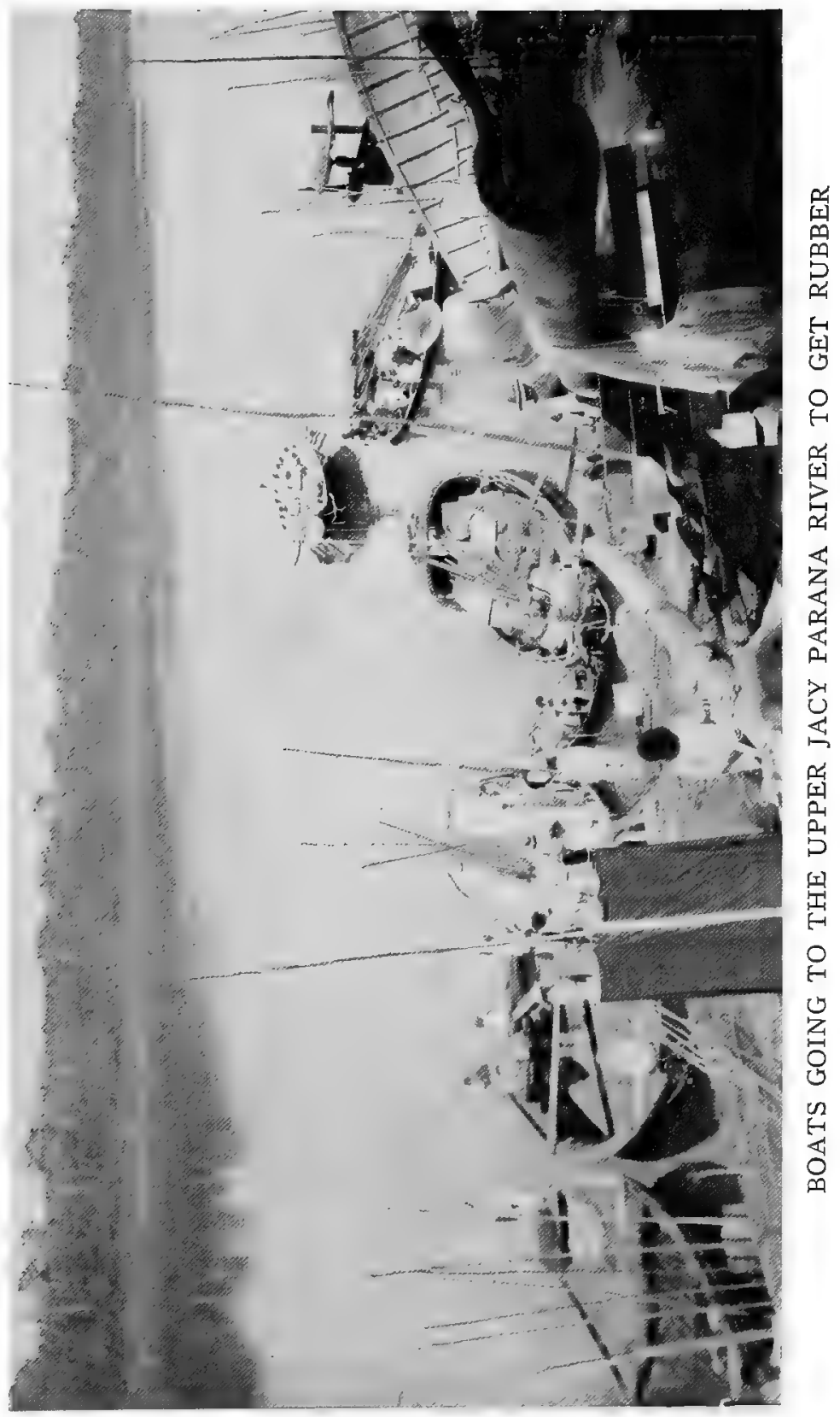




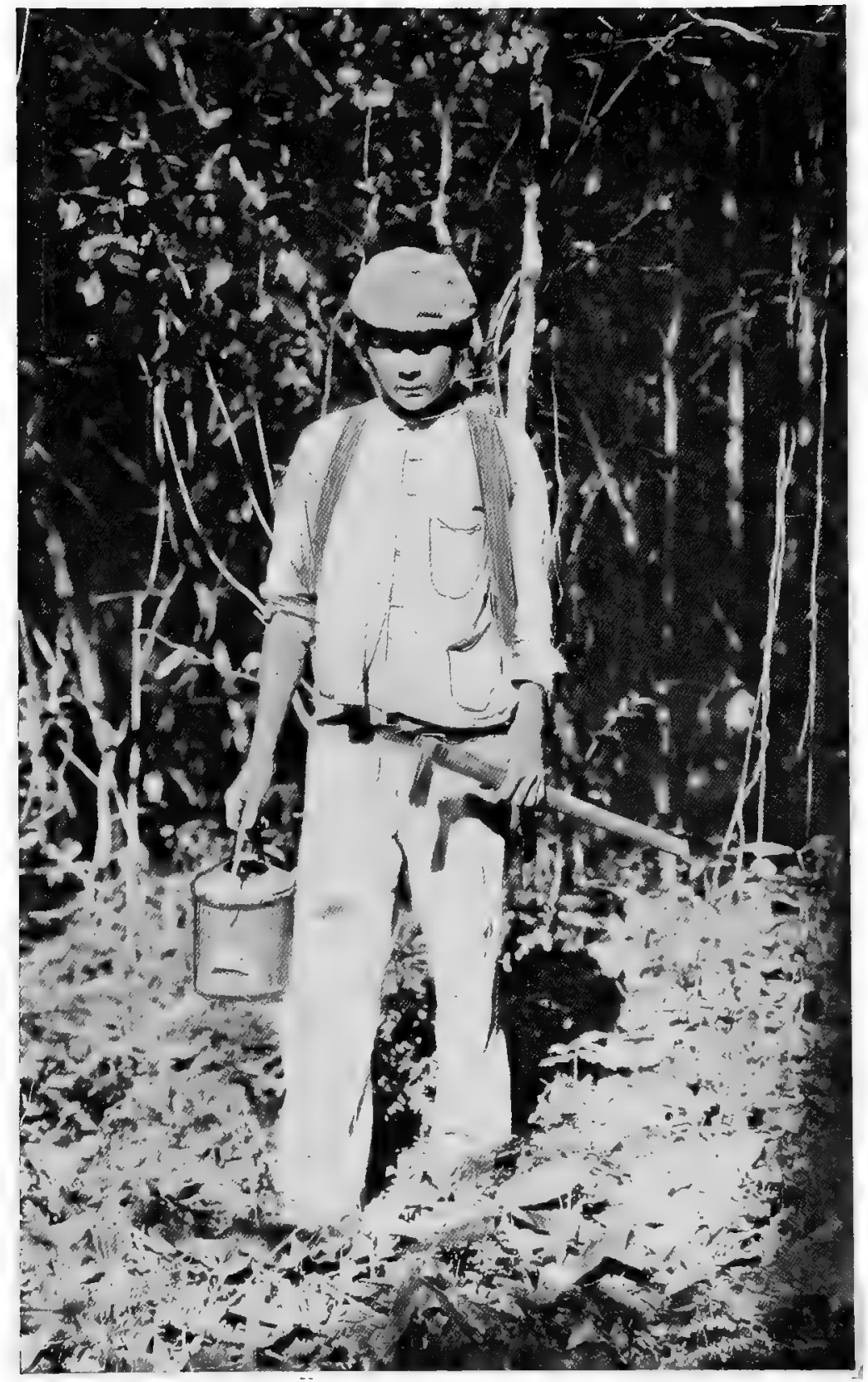

WALKING THROUGH THE FOREST ESTATE OF FIDEL BACA \& CO., JACY PARANA RIVER. 
ESTADO DE MATTO-GROSSO NA EXPOSICCÃO INTERNACIONAL DE BORRACُHA DE 1912 EM NEW-YORK

POR

\section{LEOPOLDO DE MATTOS}

NEW-YORK, 1912

DR. JOAQUIM AUGUSTO DA COSTA MARQUES PRESIDENTE DO ESTADO DE MATTO-GROSSO

1911-1915 


\section{O ESTADO DE MATTO-GROSSO NA EXPOSIÇÃO DE BORRACHA DE 1912 EM NEW-YORK}

Dos vinte Estados que compõem a Republica dos Estados Unidos do Brasil, Matto-Grosso está collocado em segundo plano, pela sua extensão territorial situado ao Sul dos Estados do Amazonas e Pará, tendo a Leste os Estados de Goyaz, S. Paulo e Paraná, ao Sul a Republica do Paraguay e a Oeste a Republica da Bolivia.

Abrange no mappa uma porção que vae approximadamente desde o $14^{\circ}$ grao ao Sul do Equador até o Tropico do Capricornio. Sua área immensa é de cerca de 50175 leguas quadradas, segundo Candido Mendes, ou melhor, tem uma superficie de 1379651 kilometros quadrados.

Sua população é actualmente de cerca de 350,000 habitantes, não incluindo consideravel numero de indios bravios, cuja cathechese se procede com afinco, dia a dia, com o concurso simultaneo dos Governos Federal e Estadoal.

Sem contar a Capital, as cidades principaes do Estado são Corumbá, S. Luiz de Caceres, Miranda, Nioac, Poconé, Sant' Anna de Paranahyba, Diamantina, Rosario, Livramento e o novo Municipio recentemente installado de Sto. Antonio do Rio Madeira.

Cuyabá, sua capital, está situada á margem esquerda do rio do mesmo nome, a 288 metros acima do nivel do mar, e deve as stuas origens aos Paulistas que formaram as legendarias bandeiras e que percorreram o Brasil Occidental no começo do seculo XVIII.

Em 1719 Paschoal Moreira Cabral subindo o Rio Coxipó Mirim, fundou á margem esquerda d'esta corrente uma povoação que denominou Forquilha, hoje a cidade de Cuyabá, onde naquelles tempos se descobriu uma rica mina de ouro.

Em outros tempos, conforme Elysée Reclus, a vastissima regiáo de Matto-Grosso era apenas, salvo uma estreita zona mediana, não mais que uma immensa solidão de limites indecisos e senão desconhecidos pelo menos ainda entregues aos indios e ás feras; a qual se ligava ao resto do Brasil por simples picadas de caçadores e pelos cursos dos rios que ali nascem. Realmente em outros tempos eram tamanhas as difficuldades de communicação do resto do paiz com Matto-Grosso, que ainda está na 


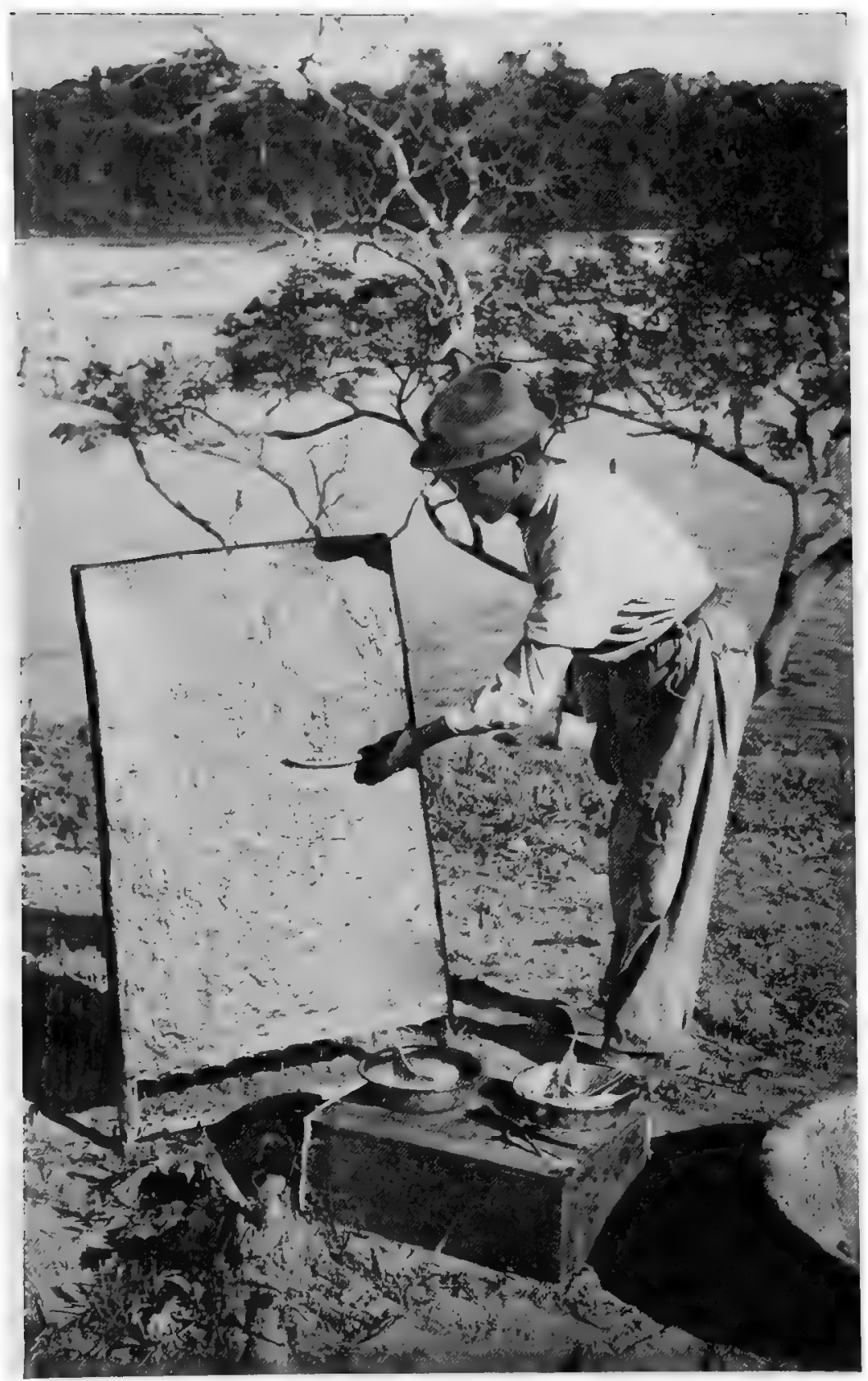

A RUBBER GATHERER MAKING A RUBBER SACK BY COVERING CANVAS WITH LIQUID RUBBER. 
memoria de muitos e no conhecimento dos que leem as paginas da Historia do Brasil, a impossibilidade que tiveram as tropas reunidas nas provincias do littoral para irem soccorrer directamente seus compatriotas de Matto-Grosso, quando a nação brazileira teve de responder á declaração de guerra do Paraguay.

Com os mil estorvos da travessia, o corpo de exercito composto de 3000 homens que partiu em Abril de 1865 do Rio de Janeiro e que só poude organisarse em Uberaba, na bacia superior do Paraná, estava reduzido apenas a 700 homens quando chegou a ponto inatacavel e seguro.

Vencida, porem, a guerra com o Paraguay, não ha nenhuma duvida que a a victoria do Brasil escancarou-lhe as portas de Matto-Grosso, pois que o declive natural do solo e o curso das aguas com a liberdade da navegação fluvial, garantida pelo triumpho, estabeleceu um serviço regular de paquetes do Rio de Janeiro a Corumbá e Cuyabá, pela via do Rio da Prata, passando por Montevideo, Buenos Ayres e Assumpção.

O caminho fluvial do Guaporé, Madeira e Amazonas foi muito utilisado no seculo XV111, depois da exploração feita por Manoel de Lima em 1742. A navegação pelo Rio Guaporé até o Rio Madeira, até enfim Sto. Antonio, que é o ponto inicial da navegação d'este ultimo rio, é longa e cheia de fadiga.

Comtudo Matto-Grosso vae gradualmente se approximando do litoral do Brasii por meio de estradas de ferro, taes como a Noroeste do Brasil que ligal-o-á dentro em breve ao Rio de Janeiro e a estrada de ferro já projectada que partindo de $\mathrm{S}$. Luiz de Caceres irá até a antiga cidade de Matto-Grosso, donde o rio Guaporé começa a ser navegavel até Guajará-Mirim, ponto terminal da grande via Madeira-Mamoré Railway.

Dentro de pouco tempo, como se vê, as estradas mixtas serão una realidade, comprehendendo rios navegaveis por vapores e os trechos de communicação entre estes rios. O Paranapanema e o Ivahy, nos Estados do Paraná e S. Paulo continuam para outro lado do rio Paraná subindo o Ivinhema e o Brilhante, até as visinhas montanhas de Miranda, na parte meridional de Matto-Grosso. As magnificas regiôes de Matto-Grosso promettem ser de futuro, e futuro já bem proximo, um grande centro de povoamento, e conseguintemente um futuro foco de civilisação, pela provavel fusão dos diversos elementos de immigração que para alli certamente concorrorem com o correr dos tempos e a facilidade que forem apresentando cada vez mais os meios de communicação. Algures se disse, que a colonisação far-se-ha sem duvida pelo Sul, pelo lado do Paraguay e da Argentina; mas nos dias que correm, com a presença da Madeira Mamoré Railway, indubitavelmente a colonisação darse-á tambem pelo Norte, facilitada a communicaçäo pelo Rio 
Amazonas, de que é um dos affluentes o Madeira, á margem direita do qual está Porto Velho, ponto inicial da mesma Madeira Mamoré Railway. E estes effeitos já se começam a produzir com a fundação de um novo Municipo e Comarca de Matto-Grosso, que é o Municipio de Sto. Antonio do rio Madeira, cortado pela referida via ferrea e a cuja região dedicaremos adiante um capitulo especial.

Já vae portanto sé enchendo de população a extremidade da vertente septentrional do territorio de Matto-Grosso, postoque a da vertente meridional é realmente a que contem maior numero de habitantes.

Matto-Grosso é uma das regiões de menor relevo do continente da America do Sul; alli não se encontram elevaçôes de terreno que constituam verdadeiras montanhas.

As terras elevadas do Brasil tem os seus pontos de culminancia nas cadeias orientaes da Mantiqueira, dos Aymorés e de Espinhaço e vão-se abaixando proporcionalmente d'este lado para o Oeste do Estado de Goyaz e do outro lado são as elevadas massas da cadeia dos Andes que se inclinam para Leste com os seus contrafortes. Diz Elysée Reclus, que separando os dois systemas orographicos, vae serpeando em forma de valle uma planicie intermediaria, que certamente foi outr'ora um estreito maritimo separando as duas ilhas-Brasil Oriental e Andes.

Hoje correm aguas fluviaes na depressão por onde passaram outr'ora as aguas marinhas e a planicie está cheia actualmente de suas alluviôes. O verdadeiro centro da America do Sul está entre as duas cidades de Cuyabá e Corumbá.

Para os que desconhecem a região, as vertentes são as vezes confundidas com as serras, e em cartas geographicas se desenha uma cadeia de montanhas mais ou menos continua, entre as bacias do Tapajóz e do Madeira, entre as nascentes do mesmo Tapajóz e do Paraguay em seguida, e finalmente entre ainda o Tapajóz e o Araguaya. Comtudo este relevo semicircular não existe senão fragmentado, pois que as elevações que dominam as planicies do alto Paraguay e seus affluentes são na realidade um alto chapadao de extractos horisontaes ou mui ligeiramente inclinados e carcomidos pelos rios que descem para o grande Amazonas.

São antes taboleiros que montanhas, ou ao menos estas não se elevam senão em alguns pontos do grande planalto, attingindo, aqui e alem, uns mil metros de altura, emquanto a elevação media do proprio paredão é de quinhentos metros.

Assim, o conjuncto orographico do Estado de Matto-Grosso chamado indifferentemente cordilheira dos Parecys, não apresenta aspecto montanhoso senão para o lado do Sul; n'esta face escarpada, a rocha é talhada a pique ou recortada em agulhas, mas do 
outro lado para o Tapajóz e Xingú, uma encosta longa se estende e vae morrer gradualmente nas planicies do Estado do Amazonas.

D'Orbigny reconheceu na eminencia da parte septentrional do Estado de Matto-Grosso a existencia de camadas pertencentes á edade carbonifera e correspondendo ás rochas da mesma natureza, que do lado opposto da região se apresenta nos contrafortes bolivianos de Santa Cruz de la Sierra. Depois d'este, Hart e Derby verificaram que as partes meridionaes do Araxá, que são as bordas elevadas do planalto, datam provavelmente das epochas paleozoicas, e que alli estão representadas as camadas carboniferas devonianas e siluricas. Leitos fossiliferos encontrados pelo geologo Smith abaixo das collinas da Chapada, 50 kilometros á Leste de Cuyabá, puzeram fora de duvida estes factos. Mais ao Norte, na zona de rochedos que em travessões cortam o Madeira, - Tapajóz, o Xingú, o Tocantins e seus affuentes, as paredes desnudadas pela erosão são todas de formação crystallina: granitos, gneis, porphiros e quartzitos.

As elevações que se desenvolvem na direcção do Sul entre as nascentes do Paraguay e as do Araguaya, em seguida entre o Paraguay e o Paraná, não apresentam as mesmas caracteristicas dos planaltos do Norte. As eminencias da parte Oriental do Estado de Matto-Grosso foram esbarancadas dos dois lados a Leste e Oeste e devastadas por estas excavações lateraes, tomam em certos pontos o aspecto de verdadeiras cadeias de montanhas, e assim é que desenham-se do Norte ao Sul as serras de S. Jeronymo, do Maracajú e Anhanbahy.

Rochas eruptivas, chamadas no paiz bassaltos, provavelmente porphyricas, romperam as camadas de grez que compõem as montanhas e parece que formaram pela sua desaggregação "tèrras roxas," analogas ás que dão aos fazendeiros.de S. Paulo tão copiosas colheitas de café.

$\mathrm{Na}$ especie de circo limitado pelo semi-circulo das elevações levantam se massiços isolados, rochas, cujos extractos, visiveis de longe, têm uma regularidade perfeita. Os proprios morros têm pela maior parte formas geometricas: dir-se-ia que se esboroaram vastos lanços, deixando paredões lisos, eguaes aos flancos de uma pyramide. Os cumes horizontaes como se as pontas tivessem sido decepadas por um instrumento cortante correspondem a outros cumes, e vê se que outr'ora faziam parte de um mesmo chapadao. Segundo Taunay, que percorreu o paiz, estes massiços de grez, de camadas horizontaes e regularmente superpostas, são formados de sedimentos lacustres coados pelo mar de agua doce que outr'ora cobriu a região.

As ruinas d'estes paredões e das escarpas contribuiram tambem para mudar a phisionomia da paysagem. Os escombros, apanhados e arrastados pelos rios, foram revestir de camadas 


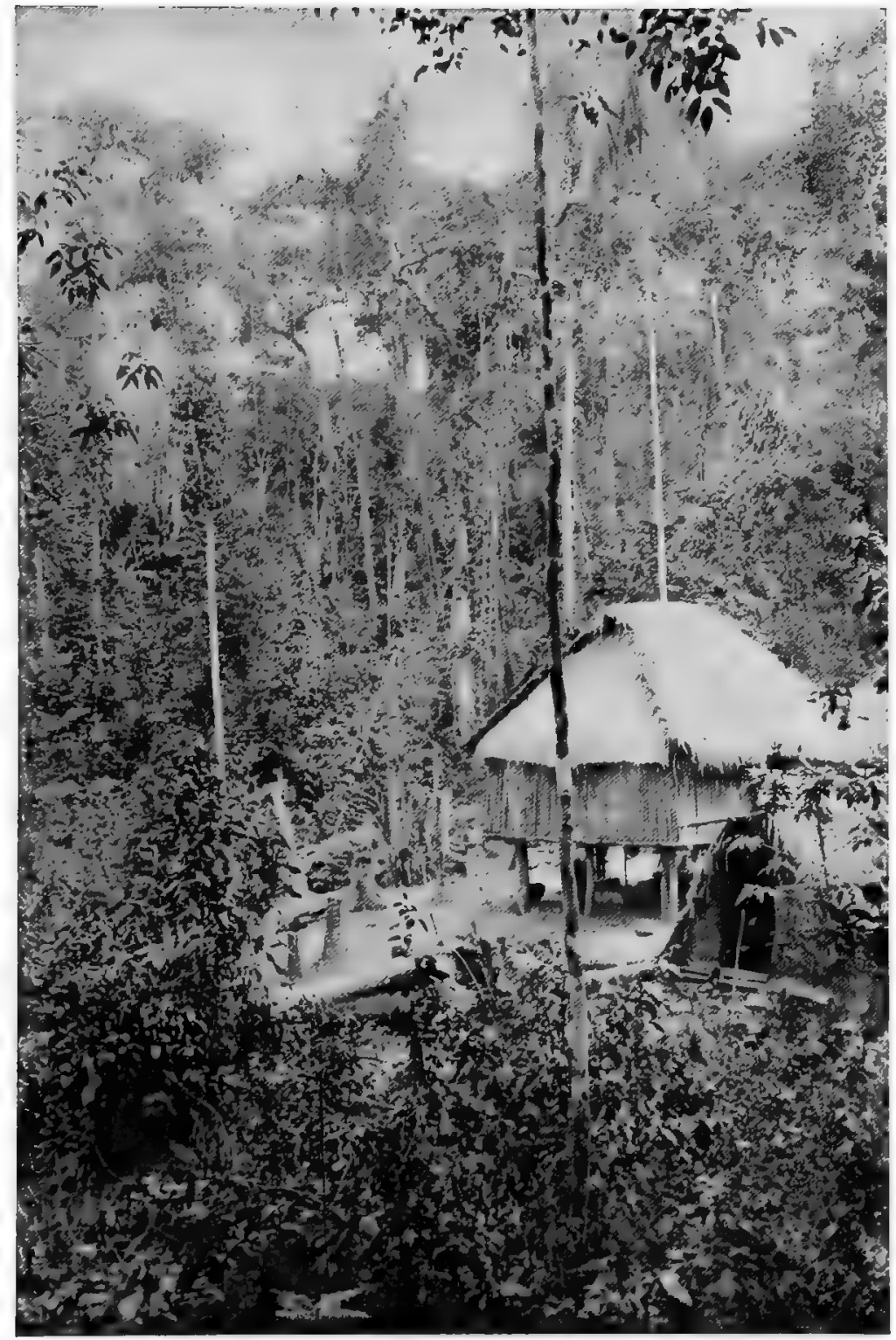

HUT OF RUBBER GATHERERS ON THE UPPER ACRE. 
novas o solo, e muitas saliencias de pedras desappareceram debaixo dos restos esmigalhados das montanhas e outras não mostram senão as pontas por cima doz terrenos de formação mais recente. Massiços que se prendiam aos planaltos e ás cadeias do interior estão agora separados d'ellas, porque suas bases se acham soterradas e elles emergem abruptamente do solo. Estes picos distinctos aos quaes se deu o nome de itambés, erigem seus cabeços por cima dum mar de arvores comparaveis a gigantescos edificios erguidos pela mão do homem. A Leste da parte meridional de Matto-Grosso, elles enfileiramse e agrupam-se em archipelagos, depois cada vez mais altos e menos numerosos, á proporção que se caminha para Oeste, ou completamente solitarios no circulo do horizonte, apparecem até nas margens do rio Paraguay e ainda do outro lado do mesmo.

O alto Guaporé, Itenez dos Bolivianos, posto que comprehendido na bacia do immenso Amazonas, como affluente do Madeira pelo Mamoré, pertence especialmente ao Estado de Matto-Grosso, pois que a cidade d'este nome foi fundada nas suas margens e quasi toda a população de Estado se accumulou na depressão, cuja metade occidental este rio percorre. Sua principal nascente, muito ferruginosa, desponta n'uma grota junto á borda do Araxá, e corre primeiro na direcção do Sul, parallellamente a outros rios que descem para o Paraguay; mas ao deixar as ultimas collinas o ribeirão curva-se para Oeste, depois para Noroeste e já engrossado por numerosos affluentes atravessa a planicie, em que está a cidade que se chamou na sua fundação Villa-Bella e hoje se denomina Matto-Grosso.

O Paraguay é um dos rios mais notaveis da Terra como via de navegação, segundo affirma Elysée Reclus; poucos têm um declive mais suave e fraco proporcionalmente a sua extensão. Affirma Castelnau que elle nasce na altitude de 305 metros; nos lugares onde as aguas tranquillas deslizam lentamente para o mar, a altitude dos campos é apenas de 200 metros, e a partir de um ponto situado a quatro mil kilometros do mar, o declive é apenas de cinco centimetros. D'este modo, vapores de pequeno calado podem subir livremente até os confins do Brasil, muito ao Norte das duas Republicas da Argentina e Paraguay e chegar á base do planalito pelo rio principal e pelos seus affuentes, Jaurú, Sepotuba, Cuyabá, S. Lourenço e Taquary. O Paraguay apresenta ainda $u$ m phenomeno notavel, que é o do cruzamento de suas nascentes com as dos affluentes do Rio Amazonas.

O Jaurú approxima-se tanto do Guaporé, que seria facil passar por um canal as aguas do rio Occidental para um affluente do Jaurú. Outro tributario do Paraguay, o Aguapehy, só está separado do rio Alegre, que desce para a antiga cidade de VillaBella, hoje Matto-Grosso, por um isthmo de pouca largura, de 
fraco relevo, que segundo Leverger, mede 2400 braças ou 5280 metros. No anno de $17 \% 2$, e depois, tentou-se cavar um canal em pontos diversos do isthmo, masas obras não chegaram a termo por falta de commercio na localidade. Certamente estradas de ferro, em mais ou menos dias, supprirão a ausencia do canal que ligaria Montevideo ao Pará, passando em grande parte do Estado de Matto-Grosso, e por uma via continental navegavel de 8300 kilometros, segundo refere Bartholomeu Bossi.

$\mathrm{O}$ rio Paraguay tem como affluentez principaes os rios $\mathrm{S}$. Lourenço, engrossado pelas aguas do Cuyabá, o Taquary, o Mondego e o Apa, limite este ultimo entre o Brasil e a Republica do Paraguay.

Por occasião das enchentes, seu nivel e o dos seus affluentes eleva-se de dez e onze metros e derrama-se á esquerda e á direita, formando um mar ephemero que se estende ao longe, a perder de vista e se prolonga em banhados. Os primeiros viajantes hespanhoes deram o nome de lago Xarayes á baixada onde se esparramam as aguas quasi dormentes dos braços principaes do rio. Este lago tem de extensão cerca de 600 kilometros de Sul a Norte, entre as boccas do Jaurú e as collinas do Fecho-dosMorros e em certos pontos chega a 250 de largura.

Elle não é permanente, como se pensava outr'ora, mas em qualquer epocha do anno ha trechos alagados que os indios denominam bahias e com razão, pois que são bahias de um antigo mar, que hoje está meio secco, e a maior parte de taes lagoas está em communicação constante com o rio Paraguay, ora por furos lateraes, ora por longos canaes, taes como os denominados lagos de Uberaba, Gaiaba, Mandioré, Caceres, etc. D'entre estes lagos, uns não contem senão agua doce trazida pela innundação fluvial, emquanto outros, que são antigas cavidades outr'ora occupadas por agua do mar, conservam no fundo de seus leitos camadas salinas, que dão ao liquido um sabor caracteristico. E' singular que este contraste da natureza das aguas doces ou salinas tambem se produza nos terrenos da vasta planicie, e assim é que campos extensos, cobertos de ricas alluviões, deram nascimento a mattas cerradas, e o agricultor pode muito bem alli obter colheitas maravilhosas. $\mathrm{E}^{\prime}$ certamente por este motivo que os campos de Matto-Grosso tanto se prestam á industria pastoril.

A horizontalidade do terreno, formada pelo centro da depressão do immenso valle, impede que o confluente se conserve em um leito regular, e as aguas escapando por ambos os lados ramificam-se n'um labirintho do rios e falsos rios. Os ramos lateraes seguem por entre as zonas dos banhados, até á confluencia do rio Taquary e do rio Miranda, que descem das montanhas de Leste, recebendo o primeiro d'estes, na região superior, um affluente, o Coxim, considerado pelos viajantes como um dos mais pitto- 


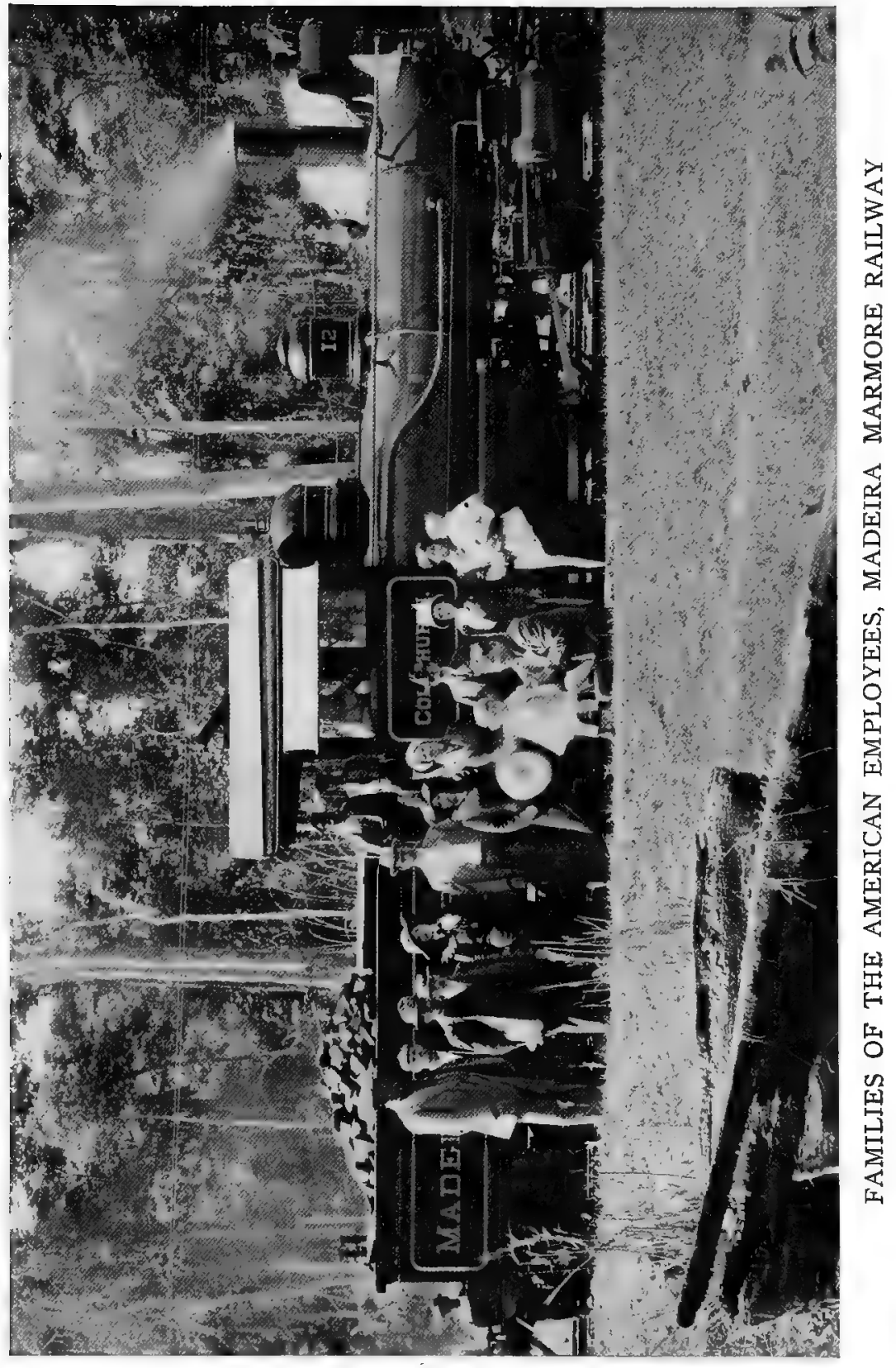


rescos rios do Brasil. E' curioso ver em alguns lugares o Coxim estreitara-se entre paredões a pique, de 50 metros de altura, e as pequenas embarcações correrem sobre elle como no fundo de um vallão que não tem mais de 10 ou 12 metros de largura.

O clima de Matto-Grosso é relativamente quente nas regióes baixas e alagadas pelas enchentes dos rios, taes como Paraguay; nas regióes dos planaltos o clima é salubre e frio. O movimento das columnas de ar é determinada pela forma de corredor aberto entre a cordilheira dos Andes e as terras altas do Brasil, bem no centro do continente Sul Americano, e por elle são arrastadas; aos ventos tepidos proveniente da região da Amazonia, succedem no inverno ventos que sopram do frio pampa. Nas alturas do circo de chapadões e montanhas que rodeiam a planicie do Estado de Matto-Grosso, o frio desce abaixo do ponto de congelação. As copiosas chuvas trazidas pelo rebojo dos ventos que contornam o planalto central do Brasil e vem esbarrar nos primeiros contrafortes dos Andes, cahem com muita regularidade no verão e são frequentemente acompanhadas de trovoadas.

Consoante alguns observadores, a queda da agua annual é de 3 metros, e em Cuyabá contam-se mais ou menos 135 dias de chuva por anno medio.

O Estado de Matto-Grosso, pela sua situação geographica no continente Sul Americano, collocado no ponto de separação das duas grandes bacias do Brasil, reune ao mesmo tempo as floras e as faunas da região da Amazonia e das regiões Platinas. Entretanto, a flora tropical predomina com sua infinita variedade de formas vegetaes em todas as regiões das florestas, isto é, á beira dos rios, e entre as especies famosas habitantes das margens do Rio Mar, poucas ha que não estejam representadas na região do alto Guaporé, ou das quaes se não encontrem congeneres.

Em nenhuma parte se desenvolye como alli as palmeiras Cipós, e em 1875 uma commissão de limites descobriu uma d'estas palmeiras Urumbamba (Calamus procumbeus) ou Desmoncus rudentum de Martius, com mais de 200 metros de comprimento e apenas com a grossura de um centimetro !O algodoeiro o tabacco, a ipeccacuanha, chamada alli poaya nascm espontaneamente nas planicies e nas florestas; esta ultima sobretudo colhem-na nas florestas do alto Jaurú e dos rios visinhos. O mate, a mais notavel das plantas da zona meridional e que faz a riqueza de algumas regiōes como do Estado do Paraná, cresce alli espontaneamente entre Miranda e o rio Apá, sem fallar propriamente da seringueira, que é encontrada em immensas e cerradas florestas n'uma ex- 


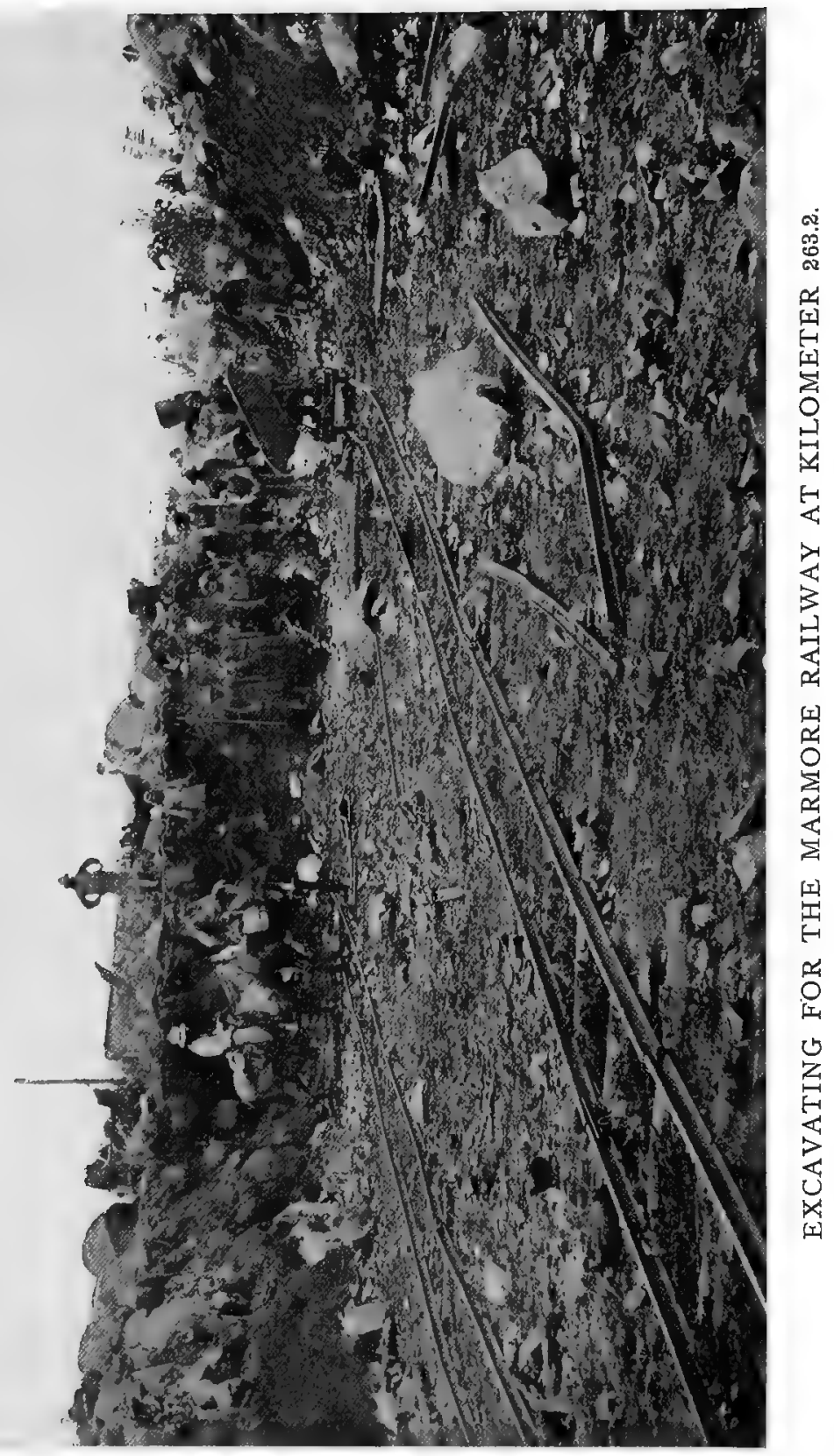




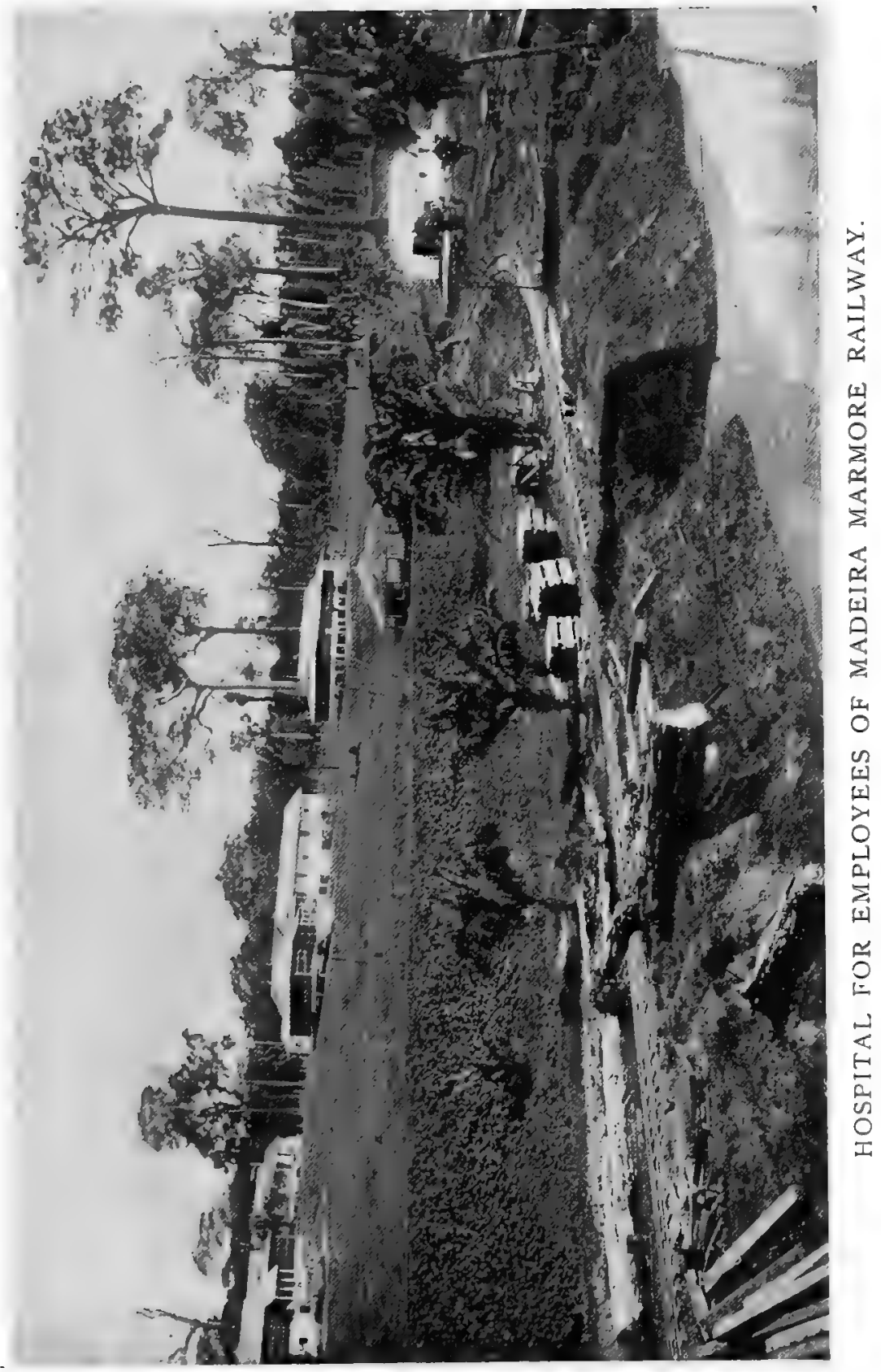


tensão comprehendida desde Cuyabá até o Madeira, e a qual fará o assumpto especial d'este ligeiro exposto.

As madeiras de construcção são abundantissimas e em grande variedade, podendo-se citar o pao-brasil, o jacarandá, a peroba, a canella, o cedro, o jequitibá, a massaranduba, o pao-d'arco, o paoferro, o pao-setim, o vinhatico, etc.

Entre os animaes, encontram-se os veados, as antas e as onças, alem de um grande numero de outros pequenos, proprios das regiões tropicaes. As aves e os passaros, aves ribeirinhas e passaros cantores das florestas, são pela sua variedade quasi innumeros. A avestruz vinda das regióes dos pampas chegou as planicies marginaes do alto Paraguay; os peixes abundam n'uma riquissima e magnifica variedade nos grandes e pequenos rios.

No reino mineral, o Estado de Matto-Grosso possúe minas numerosas de ouro, prata; platina, cobre, estanho, chumbo, mercurio, carvão de pedra, ferro, pedras, preciosas, diamantes, \&c., exístindo já quatro companhias inglezas na exploração de minas de ouro. Ha tambem granitos, crystal de rocha, malacacheta, pedra calcaria, sal-gemma, \&c. Finalmente nas regióes do Araxá, ha fontes de aguas mineraes sulphurosas.

O Estado de Matto-Grosse é a região do Brasil onde se encontram as maiores fazendas de gado, nã̃o só em extensão territorial, como em numero de cabeças de gado. vaccum e cavallar, havendo algumas que contam cem mil cabeças. Calcula-se o numero de cabeças de gado vaccum em Matto-Grosso em dois bilhões e quinhentas mil.

Nos dias que correm, ainda é um pouco difficil o transporte de gaclo de Matto-Grosso para o Rio de Janeiro, principalmente, e a exportação é feita pelo caminho de Oeste até Uberaba, onde a invernada se faz. em dois ou trez mezes, até que os animaes se refaçam e possam ser conduzidos em caminho de ferro até o littoral do Rio de Janeiro. Vê-se, entretanto que, com a terminação da via ferrea Noroeste do Brasil, o problema do transporte para o littoral será resolvido, assim como a Madeira Mamoré Railway, contando Matto-Grosso presentemente com rios navegaveis e dentro de bem pouco tempo com a via ferrea de que já fallamos, de S. Luiz de Caceres á antiga cidade de Matto-Grosso, donde começa a ser navegavel o rio Guaporé até Guarjara-Mirim, ponto terminal da Madeira Mamoré Railway, resolverá tambem o problema da exportação de gado para os Estados do Amazonas, Pará, \&c.

D'este leve exposto conclue-se que o territorio do Estado de Matto-Grosso é grandemente rico de gado e ouro, de diamante e café, de tabaco e mate, de borracha e ipecacuanha e de todos os productos dos tropicos e das zonas temperadas:-elle só bastaria 
para constituir um dos mais vastos e mais opulentos imperios do mundo!

Dotado de um clima, se bem que quente ao Norte, porem temperado e mesmo frio nas demais regiões, como a dos planaltos, apresentando um accumulo de riquezas raro e ainda pouco explorado como está, forçosamente para lá o homem das diversas partes da Terra, na sua constante actividade, na sua crescente lucta pela vida, immigrará e concorrerá com a intelligencia e com o esforço do trabalho, para fazer d'aquella parte do Brasil um grande emporio de industrias, commercio, navegação, caminhos de ferro e conseguintemente uma grande nascente de civilisação, donde, pela fusão das diversas raças, o mesmo homem surgirá sempre grande, sempre vencedor no immenso concerto e na elevada harmonia da Vida e da Terra!

A borracha que se vê n'esta Exposição é extrahida e vinda toda das vastas regiões cortadas pelos rios Machados, ou Dgy-Paraná, Jamary, Jacy-Paraná, Mutum-Paraná, Paca-Nova e Guaporé com seus affluentes, aquelles a seu turno affuentes do grande rio Madeira, em cuja margem direita está situado o novo Municipio e Comarca de Sto. Antonio do rio Madeira, installado em 2 de Julho do anno corrente.

$\mathrm{O}$ novo Municipio tem os seguintes limites: partindo da cachoeira de Sto. Antonio no rio Madeira, no parallelo de 8 48', o rio Madeira acima; o rio Mamoré acima até a foz do Guaporé no parallelo de 12 , este parallelo até a sua intersecção com o rio Camararé ; este rio abaixo até a sua confluencia no Juruema; este rio abaixo até o ponto em que se reune ao Arinos; o parallelo que n'este ponto passa até a sua intersecção com o rio S. Manuel; este rio abaixo até sua confluencia no Tapajóz; e d'este ponto até encontrar a cachoeira de Sto. Antonio no Rio Madeira a linha que extrema os territorios dos Estados de Matto-Grosso e do Amazonas.

Todo o immenso territorio do novo Municipio é cortado ao Norte pela Madeira Mamoré Railway, que conta 365 kilometros de via ferrea já construidos, partindo de Porto Velho no Estado do Amazonas, distante 7 kilometros da sede propriamente do Municipio, até Guajará-Mirim.

A via ferrea Madeira Mamoré, alem das estações já construidas, em Porto Velho, Candelaria, Sto. Antonio, Jacy-Paraná, Abunã, Villa Murtinho e Guajará-Mirim, tem 46 pontos de parada que correspondem ao numero dos seus acampamentos.

Entre as vias de communicação do novo Municipio de Sto. Antonio do rio Madeira com os visinhos Estados do Amazonas e Pará e tambem com a capital e outras cidades do Estado de MattoGrosso, comecemos por dizer algo da linha telegraphica ora ainda em construcção por conta do Governo Federal e da respectiva 


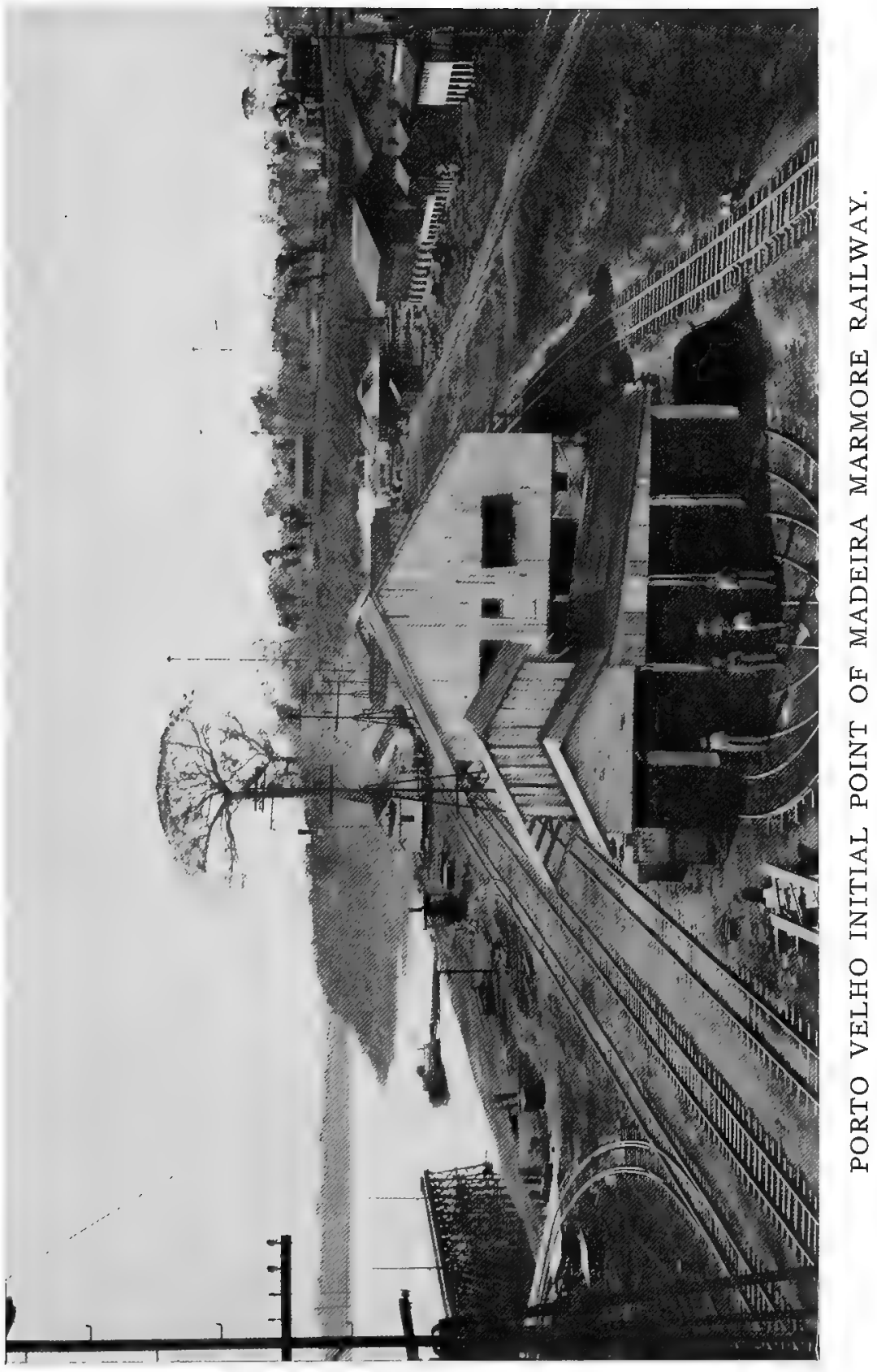


estrada de rodagem. São duas as turmas de engenheiros e operarios que constroem a linha telegraphica, uma partida do Norte-Sto. Antonio-e outra do Sul-Diamantina. Partindo de Sto. Antonio, a linha telegraphica segue o parallelo $848^{\prime}$ até encontrar o rio Jamary, n'uma extensão de cerca de sessenta kilometros; ahi chegando desvia se para o rumo das cabeceiras do rio Dgy-Paraná, no lugar denominado Urupá, onde se deve encontrar com a turma do Sul e onde a ligação será feita. A 3 de Junho de 1912 na mais alta cabeceira do rio Dgy-Paraná, já foi inaugurada a estação telegraphica de José Bonifacio, pela turma do Sul, emquanto a do Norte tambem já inaugurou em data anterior as estações de Sto. Antonio do rio Madeira e Jamary. Este emprehendimento notavel está sob a intelligencia e extraordinaria dedicação do snr. Coronel de Engenheiros do Exercito Brazileiro, Candido Rondon, que tem o record das construcções de linhas telegraphicas no Brasi] e quiçá na America do Sul.

Prompta dentro de um anno, mais ou menos, a linha telegraphica marginará uma estrada de rodagem de 40 metros de largura, de cerca de duzentas leguas de extensão a partir de Cuyabá até Sto. Antonio do rio Madeira. Esta immensa via de communicação cortando todo um vasto sertão sobretudo rico em borracha e ouro, terá de dez em dez leguas uma estação telegraphica.

Em Porto Velho, ponto inicial da Madeira Mamoré Railway, ha já por sua vez funccionando uma poderosa estação radiographica do systema Marconi e que se communica diariamente com Manaos e já se tem communicado mesmo com Iquitos e com os Departamentos Federaes do Acre, do Purús e do Juruá.

Quanto á navegação de Manaos até Sto. Antonio do rio Madeira, ella é feita em boas condições e em navios confortaveis. Nas aguas baixas, isto é, nos tempos da secca do grande rio Amazonas e seus affluentes, sobem de Manaos até aquelles pontos os navios de tonelagem até 500 , nos tempos de aguas altas, em que o valle do Amazonas todo se alaga, navios transantlaticos de 7 mil a nove mil toneladas sobem de Manaos até alli, em quatro dias de viagem, como já tem succedido no transporte de materiaes para construcção da Madeira Mamoré Railway, acostando facilmente em 2 caes feitos de madeira de lei, o primeiro construido em frente as officinas de Porto Velho e o segundo em Candelaria. Por sua vez o Governo da Republica está resolvido a construir um caes de pedra e cal entre Porto Velho e Sto. Antonio.

Os pequenos navios que navegam durante a secca dos rios, teem accomodações para passageiros de $1 .^{a}$ e $3 .^{a}$ classe, são illuminados á luz electrica, possuem fabricas de gelo e fazem bem a viagem de Manaos a Porto Velho e Sto. Antonio em cerca de 5 dias, com uma media de velocidade de 10 milhas por lora, fazendo escala por péquenos portos e cidades amazonenses, situadas nas margens 


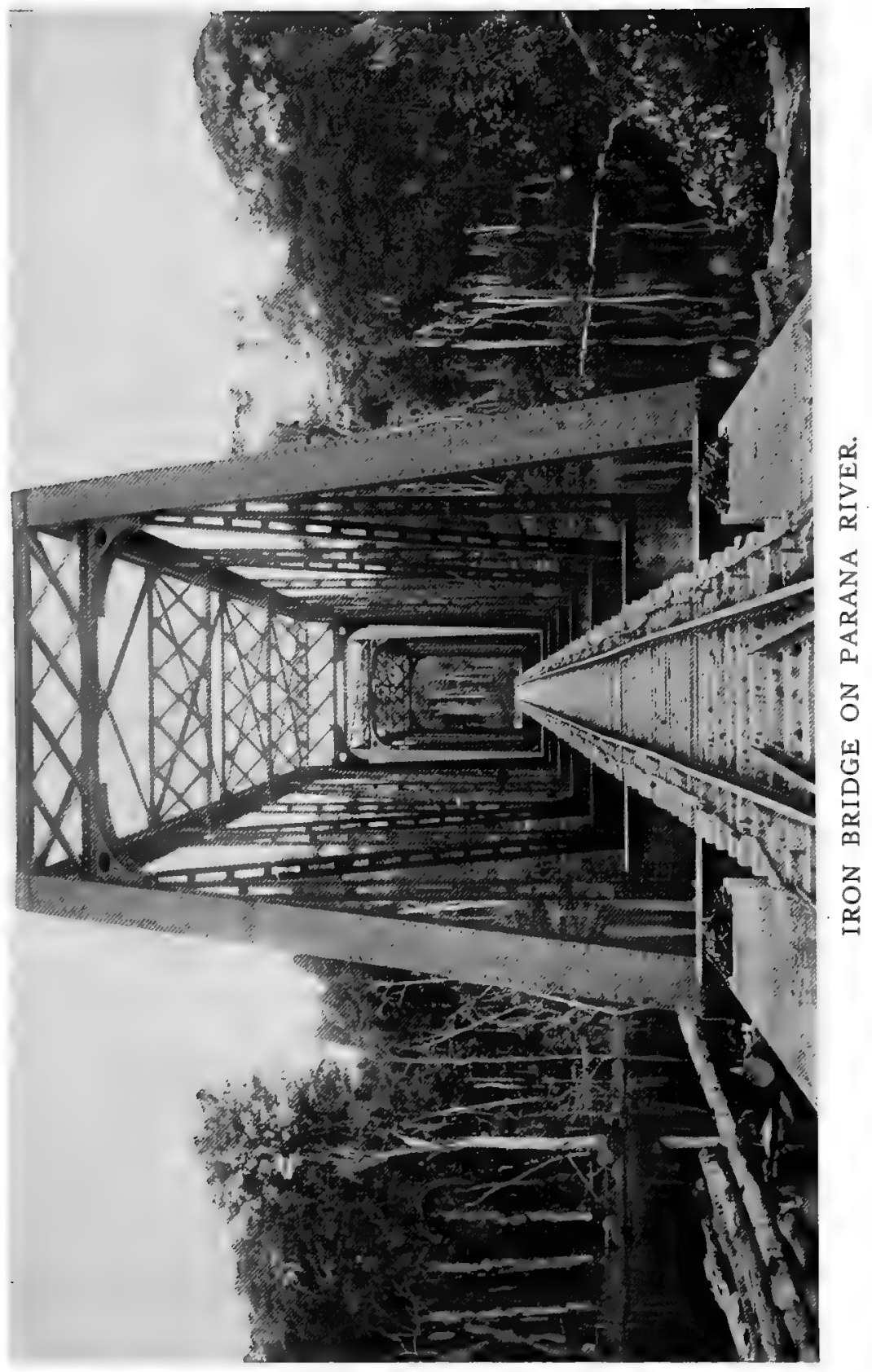


rio Madeira. Na descida tanto dos grandes transantlaticos como dos pequenos navios de 500 toneladas, a viagem se faz mais rapidamente, em 3 e 4 dias.

A borracha de Sto. Antonio do rio Madeira é da mesma natureza phisica e chimica de toda borracha do valle do Amazonas, e esta asserção salta á vista, quando nos lembramos que a parte do Estado de Matto-Grosso occupada pelo novo Municipio é justamente aquella limitrophe dos Estados do Amazonas e do Pará.

$\mathrm{Na}$ parça de Manaos, para onde vem o producto pela via do rio Madeira, e na de Belem do Pará onde é enviada pela via do rio Tapajóz, ella é sempre cotada pelos mesmos preços e nas mesmas condiçốes das produzidas propriamente nas regiões da Amazonia.

A sua producção, que vem num crescendo desde o anno de 1906 , é actualmente de cerca de 2 milhões de kilos annuaes, que augmentará certamente numa proporção-impossivel desde já de ser previstacom a presença e o desenvolvimento da Madeira Mamoré Railway, da estrada de rodagem da linha telegraphica e os progressos constantes da navegação.

No. 1ro. semestre do anno fluente a producção da borracha foi superior a de não importa qual seja o anno desde 190\%, conforme se verifica do quadro estatistico annexo.

N'aquellas regiões, comprehendidas desde Cuyabá até á sede do novo Municipio, existem seringaes capazes de produzir por si sós dentro do periodo de um anno, mais de quarenta milhões de kilos de borracha.

Para attingir a este ideal, bastaria que os capitaes concorressem para exploração de uma industria extractiva, cuja fonte brota espontaneamente da terra sem carencia de cultivo e para animar e estimular aquelles que desejam ali empregar os seus esforços e capitaes, ahi está a lei do Governo do Estado de Matto-Grosso, que offerece favores especiaes aos que, alem propriamente da exploração dos vastos seringaes já existentes, se quizerem dedicar ao plantio e cultivo da mesma syphonia elastica.

Tratando-se uma exposição de borracha em New-York, é justo chamarmos a attenção dos que nos queiram ler para o facto bem importante da concorrencia que já começa dos capitaes norteamericanos para a exploração d'aquella região.

O grande capitalista Percival Farquhar, americano do Norte, já incorporou duas companhias sob as razões sociaes de Julio Muller Rubber, e Guaporé Rubber; com o fim não só de explorar a industria extractiva de hevea brasiliensis, como tambem para os diversos ramos de agricultura attinentes ao fabrico do assucar, dos tecidos de algiodão \&c. \&c. 


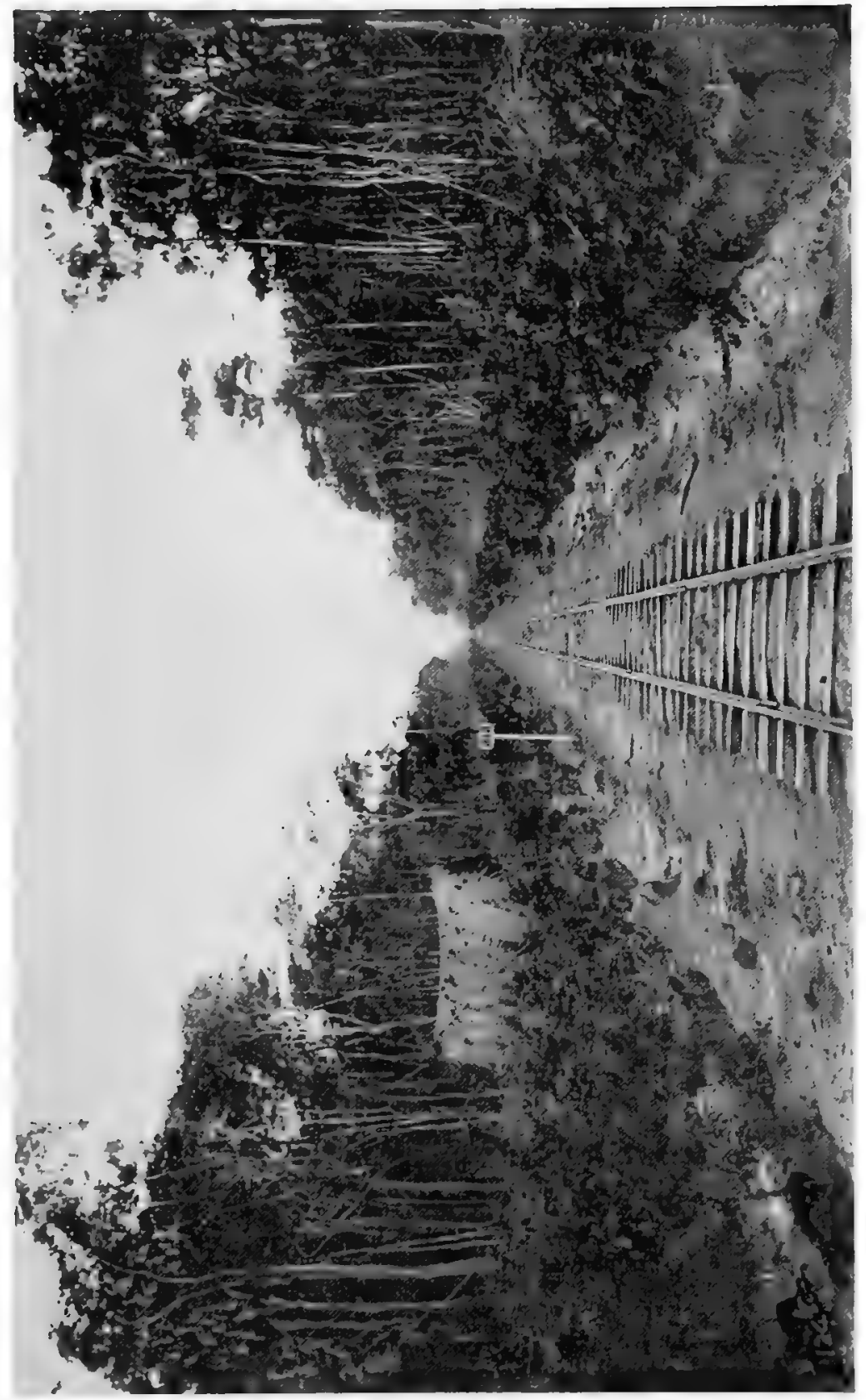

 
Actualmente a extracção da borracha nos vastos seringaes do Municipio de Sto. Antonio do rio Madeira occupa cerca de cinco mil trabalhadores, mas este numero augmentará cada vez mais, positivamente, á proporção que o referido Municipio se for tornando o ponto de convergencia para onde affluirão as correntes commerciaes, industriaes e agricolas dos centros de Matto-Grosso e da Republica da Bolivia.

Isto é facil de imaginar, quando vemos que a estrada de ferro Madeira Mamoré por seá em communicação para o Sul com S. Luiz de Caceres por meio do rio Guaporé e da estrada de ferro que de S. Luiz de Caceres irá até á antiga cidade de Matto-Grosso, ligando assim a bacia do Prata de intermedio o rio Paraguay-á bacia do rio Amazonas, e para Leste, a mesma Maderia Mamoré Railway levará os seus trilhos até Ribeira-Alta, ligando as vastas e riquissimas regiões da Republica Boliviana tambem á bacia do Amazonas, de intermedio o rio Maderia. Presentemente, parte para aquella região o Engenheiro chefe e Director da Maderia Mamoré Railway, Mr. H. Dose, que vai dar começo a construcção do referido ramal de Guajará Mirim-Matto-Grosso-á Ribeira Alta-Bolivia-, que ficará concluida dentro do praso de um anno e meio e terá cerca de cem kilometros de extensão.

Accrescendo a isto ainda a construcção prompta, dentro de um anno, da grande estrada de rodagem da linha telegraphica de Cuyabá até Sto. Antonio do rio Madeira, poderemos facilmente imaginar o que n'um futuro, que nada faz pensar será muito remoto, irá ser o novo Municipio de Sto. Antonio do rio Madeira, como um verdadeiro e incontestavel ponto de convergencia de tăo fortes e ricas correntes de desenvolvimento de progresso e de civilização.

Antes de terminar, não devemos esquecer que o territorio em questao não se presta somente á producção da gomma elastica, que aliás como em todo o valle do Amazonas é agreste e nasce á lei da natureza. Convem dizer que alli, alem do cacao e do algodão, que tambem são agrestes, podem ser plantados e cultivados a canna de assucar, o café, a baunilha, o milho, o feijão, o arroz, o tabaco, a batata, a castanha, \&c.

A propria Madeira Mamoré Railway Co., concessionaria de uma vasta faixa de terra á margem de sua linha ferrea, pensa em fazer o plantio do cacao, da canna de assucar, \&c., \&c., aproveitando os referidos terrenos.

De tudo o que fica exposto em linlias bem ligeiras e nas quaes procuramos nos approximar sempre da verdade, dando noticias sobre a região em questão, pode-se concluir facilmente que só o novo Municipio de Sto. Antonio do rio Madeira, que exporta 


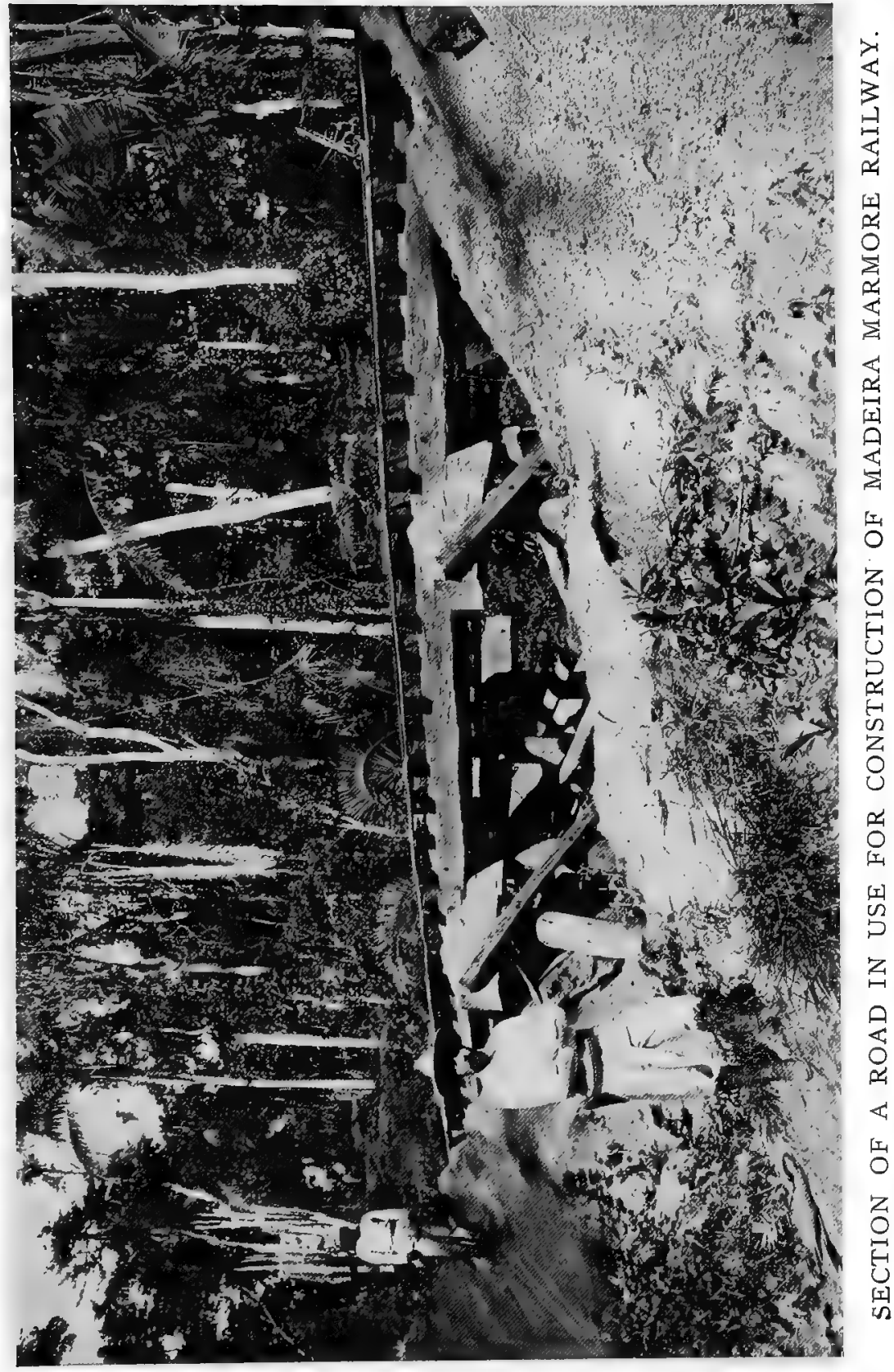


actualmente para o commercio mundial, via Pará e Manaos, cerca de 2 milhões de kilos de borracha, passará a exportar dentro de poucos annos, sobretudo com a immigração que todos os factores nos levam esperar, de 10 a 15 milhões.

O auctor d'este exposto pede indulgencia para as lacunas que nelle forem encontradas:-foi escripto nos raros momentos livres ao trabalho fatigante de organisar a exposição das amostras de borracha até o respectivo embarque em Manaos para New-York.

As amostras da borracha de Matto-Grosso que figuram no recinto da Exposição, são expostas por ordem do Governo, pela benemerita Associação Commercial do Amazonas.

\section{ESTADO DE MATTO GROSSO}

DELEGACIA FISCAL DO NORTE

QUADRO DEMONSTRATIVO DA PRODUCÇÂO DA BORRACHA DOS VALLES DO MADEIRA E ALTO TAPAJOZ NOS ANNOS de 1907 a 1912, EM COMPA RAÇÂO COM A MESMA PRODUCÇÂO NO PRIMEIRO SEMESTRE DE 1912.

\begin{tabular}{|c|c|c|c|c|c|c|}
\hline Procedencia & 1907 & 1908 & 1909 & 1910 & 1911 & $\begin{array}{c}1912 \\
\text { só o lo. } \\
\text { semestre }\end{array}$ \\
\hline $\begin{array}{l}\text { Machado e Jamary.... } \\
\text { Jacy Paraná Alto Ma- }\end{array}$ & 1.092454 & 1.252194 & 910982 & 1.295605 & 1.317917 & 1.315995 \\
\hline deira e Moré ....... & 98464 & 152713 & 150759 & 142458 & 201562 & 250612 \\
\hline Alto Tapajóz ........ & $\ldots \ldots$ & 156034 & 167841 & 107458 & 73688 & 113453 \\
\hline & 1.190918 & 1.560941 & 1.229582 & 1.545521 & 1.593167 & 1.689060 \\
\hline
\end{tabular}




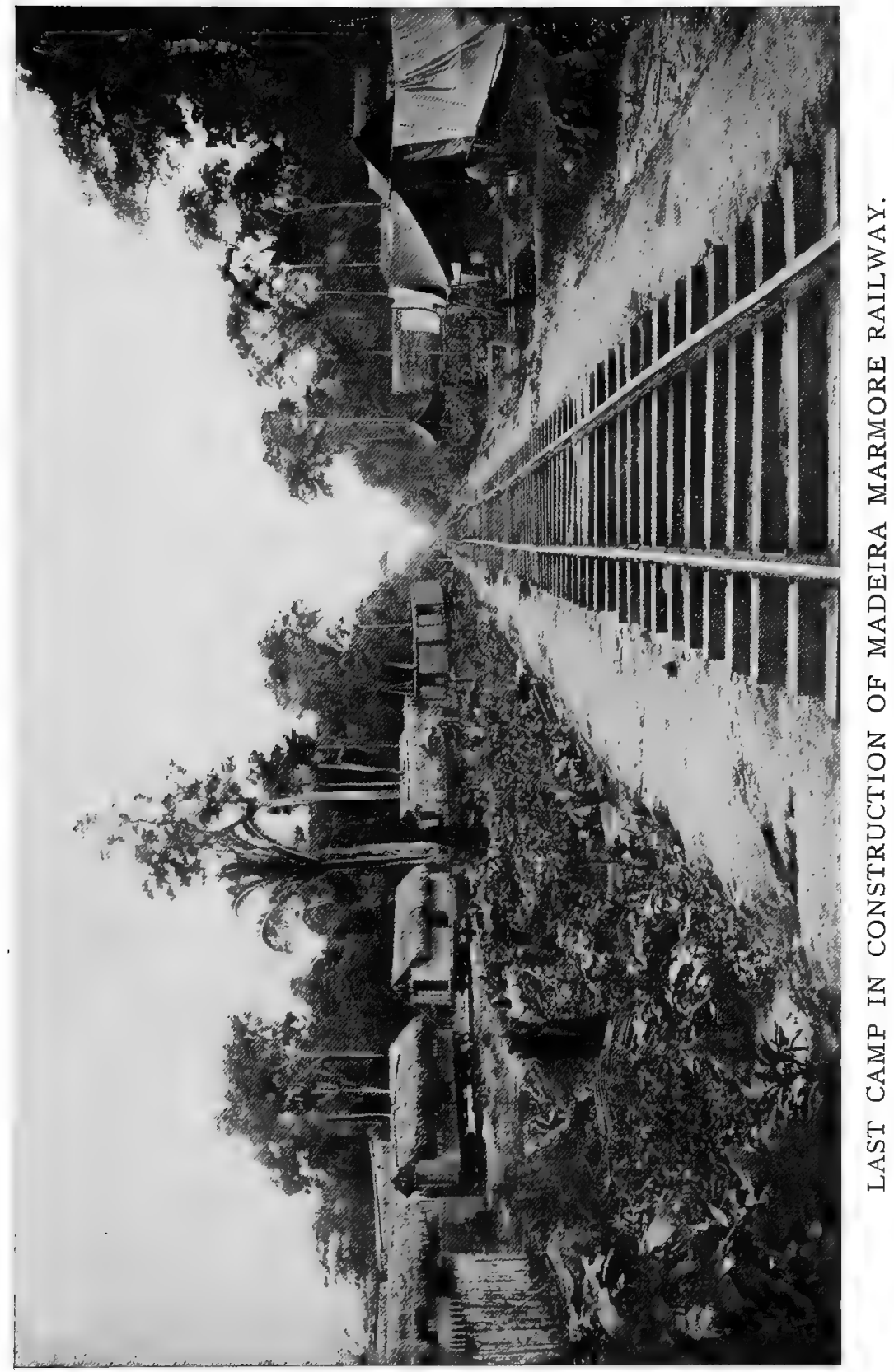




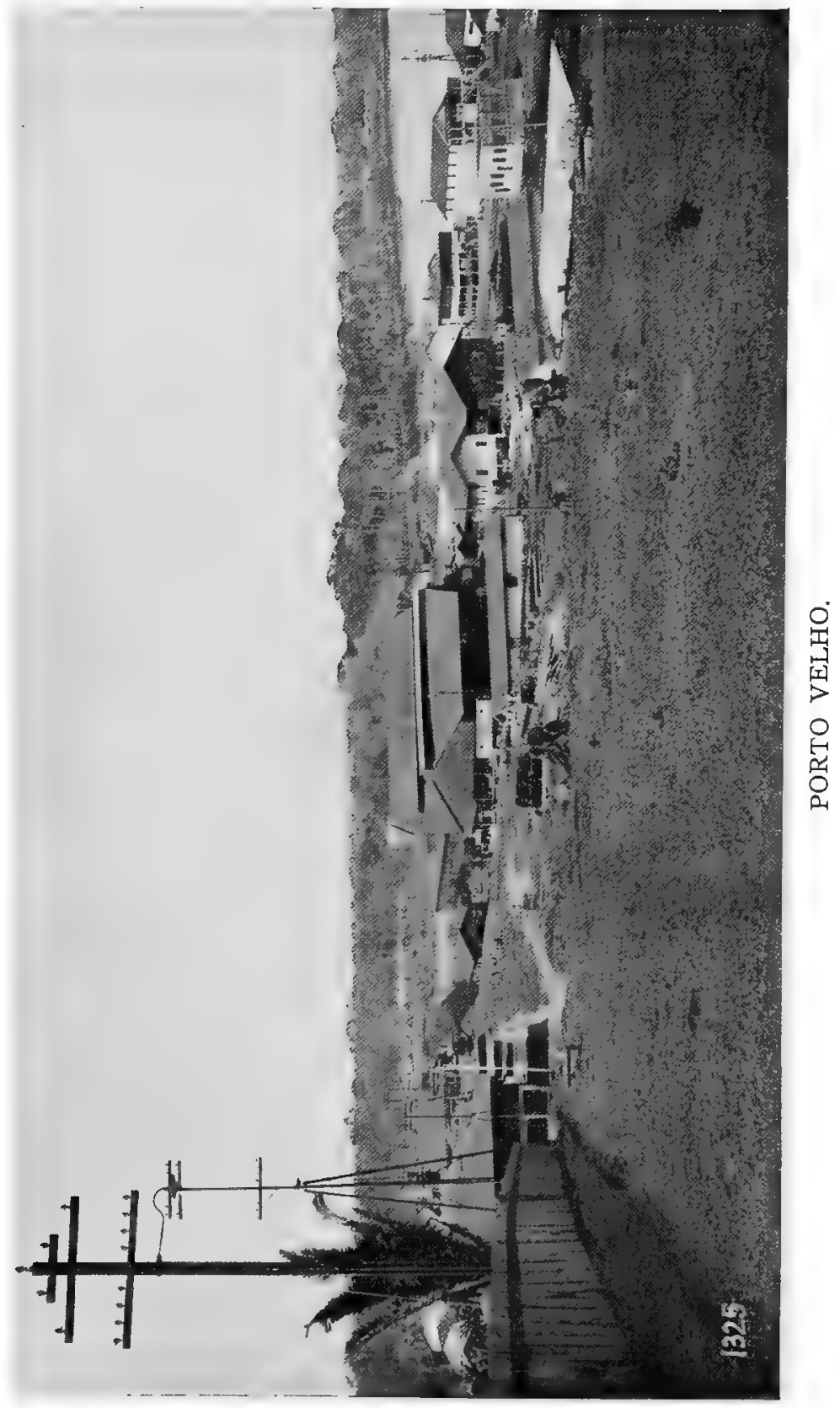


STATE OF BAHIA 


\section{EXHIBITS OF THE STATE OF BAHIA AT THE INTERNATIONAL RUBBER EXHIBITION IN NEW YORK, 1912}

\section{STATE OF BAHIA.}

1 bale of 100 kilos of superior maniçoba rubber.

1 bale of 100 kilos of first quality maniçoba rubber.

1 bale of 100 kilos of second quality maniçoba rubber.

1 bale of 50 kilos of superior mangabeira rubber.

1 bale of 50 kilos of first quality of mangabeira rubber.

1 package of 20 kilos of caucho rubber.

Various statistical tables, photographs, diagrams and a panoramic view of the City of Bahia.

Books and pamphlets concerning the natural resources of the state.

\section{BY S. HESS \& COMPANY.}

Samples of the various kinds of native rubber of Bahia.

Two sacks of the seed of the maniçoba rubber tree cultivated in Bahia.

Specimens of the maniçoba tree.

\section{BY F. STEVENSON \& COMPANY, LTD.}

1 bale of 100 kilos of superior maniçoba rubber from JEQUIE.

\section{BY M. ULMANN \& COMPANY.}

1 bale of 50 kilos of superior maniçoba rubber.

1 bale of 50 kilos of first quality maniçoba rubber.

1 bale of superior mangabeira rubber.

1 package of caucho rubber from the State of Bahia. 


\section{BY VON DER LINDE \& COMPANY.}

Specimens of the various kinds of rubber, from the State of Bahia, in a glass case.

\section{BY MORAES \& COMPANY.}

1 bale of 100 kilos of superior maniçoba rubber.

\section{By JOSE C. DA COSTA SANTOS.}

1 bale of superior maniçoba rubber.

1 bale of first quality maniçoba rubber.

1 bale of second quality maniçoba rubber.

Specimens of the various kinds of rubber of Bahia.

\section{STATE OF ALAGOAS.}

Specimens of various kinds of rubber.

Specimens of the rubber grown in JARAGUA.

These specimens were sent by $\mathrm{Mr}$. Americo Mello, representative of the Commercial Museum of Rio de Janeiro, in the State of Alagoas.

\section{STATE OF PERNAMBUCO.}

Two large packages of the various kinds of rubber grown in the State. These were sent by Dr. Antonio Valenca, representative of the Commercial Museum of Rio de Janeiro, in the State of Pernambuco. 
STATE OF

MINAS GERAES 


\section{STATE OF MINAS GERAES—PROVISIONAL NOTE}

\section{EXHIBITS}

1. Wild Manisoba (Manihot) Rubber in the raw and cleaned market condition.

2. Planted Manisoba Rubber, viz.: (a) Fine; (b) Seconds; (c) Scrao.

3. Photographs taken on the San Francisco River, the rubber region of the "Highlands of Brazil."

4. Photographs of Rubber Trees, viz.: (a) Manihot Glaziovii; (b) Manihot Heptaphylla; (c) Manihot Piauhyensis.

5. Photographs of Bello Horisonte, capital of the State of Minas Geraes, and of other localities of importance and general interest. Maps of the State and Climatological Charts. 
BRAZIL DAY
Saturday, September 28

222. 







